\title{
The role of cognitive tests and teachers in the transition from primary to secondary education
}

Citation for published version (APA):

Feron, E. (2018). The role of cognitive tests and teachers in the transition from primary to secondary education. [Doctoral Thesis, Maastricht University]. Datawyse / Universitaire Pers Maastricht. https://doi.org/10.26481/dis.20180629ef

Document status and date:

Published: 01/01/2018

DOI:

10.26481/dis.20180629ef

Document Version:

Publisher's PDF, also known as Version of record

\section{Please check the document version of this publication:}

- A submitted manuscript is the version of the article upon submission and before peer-review. There can be important differences between the submitted version and the official published version of record.

People interested in the research are advised to contact the author for the final version of the publication, or visit the DOI to the publisher's website.

- The final author version and the galley proof are versions of the publication after peer review.

- The final published version features the final layout of the paper including the volume, issue and page numbers.

Link to publication

\footnotetext{
General rights rights.

- You may freely distribute the URL identifying the publication in the public portal. please follow below link for the End User Agreement:

www.umlib.nl/taverne-license

Take down policy

If you believe that this document breaches copyright please contact us at:

repository@maastrichtuniversity.nl

providing details and we will investigate your claim.
}

Copyright and moral rights for the publications made accessible in the public portal are retained by the authors and/or other copyright owners and it is a condition of accessing publications that users recognise and abide by the legal requirements associated with these

- Users may download and print one copy of any publication from the public portal for the purpose of private study or research.

- You may not further distribute the material or use it for any profit-making activity or commercial gain

If the publication is distributed under the terms of Article $25 \mathrm{fa}$ of the Dutch Copyright Act, indicated by the "Taverne" license above, 
The role of cognitive tests and teachers in the transition from primary to secondary education 
Printing: Datawyse | Universitaire Pers Maastricht

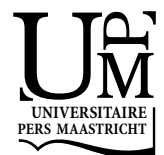

ISBN 9789462959743

\section{(C) 2018}

All rights reserved. No parts of this publication may be reproduced or transmitted in any form or by any means, electronic or mechanical, including photocopy, recording or otherwise, without prior written permission of the author. 


\title{
The role of cognitive tests and teachers in the transition from primary to secondary education
}

\author{
PROEFSCHRIFT \\ ter verkrijging van de graad van doctor aan de Universiteit Maastricht, \\ op gezag van de Rector Magnificus, Prof dr. Rianne M. Letschert \\ volgens het besluit van het College van Decanen, \\ in het openbaar te verdedigen \\ op vrijdag 29 juni 2018 om 12.00 uur \\ door \\ Eva Simone Michèlle Laure Feron
}




\section{Promotor}

Prof. dr. Bas ter Weel

\section{Co-promotor}

Dr. Trudie Schils

\section{Beoordelingscommissie}

Prof. dr. Rolf van der Velden (voorzitter)

Dr. Ron Diris

Prof. dr. Dinand Webbink (Erasmus Universiteit Rotterdam)

Dr. Karen van der Wiel (Centraal Planbureau)

Het onderzoek in hoofdstuk 6 kwam tot stand op basis van financiering vanuit het actieprogramma Onderwijs Bewijs van het ministerie van Onderwijs, Cultuur en Wetenschap. Het actieprogramma stimuleert de ontwikkeling van 'evidence-based' onderwijsinnovatie. Doel is om via wetenschappelijke experimenten kennis te verzamelen over wat werkt in het onderwijs, en over wat niet werkt. 


\section{Acknowledgements}

Upon the completion of this dissertation there are people to whom I would like to express my gratitude. First of all, prof. dr. Bas ter Weel, my supervisor. Thank you for your clear vision, your patience and your attention to detail. Dr. Trudie Schils, my daily supervisor. Thank you for your encouragement and support, you have a gift for motivating people. Your warm personality makes it easy and pleasant to cooperate and work together.

I would also like to thank prof. dr. Lex Borghans for his valuable comments and for our many discussions about education, economics and other important things in life. I am grateful to prof. dr. Flavio Cunha for giving me the opportunity to join the University of Pennsylvania as a visiting scholar and for taking the time to discuss my ideas and give feedback on my papers. Thank you prof. dr. Rolf van der Velden, prof. dr. Dinand Webbink, dr. Karen van der Wiel and dr. Ron Diris for assessing my dissertation and providing me with useful feedback.

I am especially thankful to my mother Joke and my sister Merel for their unconditional love and support. I am very lucky to have you as my family. Over the past years there were also other people, friends and colleagues, who have supported and encouraged me. You are very dear to me. 



\section{Contents}

Acknowledgements $\quad 5$

Chapter 1: Introduction 11

1.1 Motivation 13

1.2 Aim 15

1.3 Summary of the main findings 17

1.4 Implications $\quad 19$

References $\quad 21$

Chapter 2: Data description 23

2.1 The Dutch education system $\quad 25$

2.1.1 General information 25

2.1.2 Test 28

2.1.3 Teacher's assessment 30

2.2 The data 31

2.2.1 General information 31

2.2.2 Representativeness 31

2.3 Field experiment 32

2.4 Correlation vs. causal evidence 33

References $\quad 34$

Chapter 3: Does the teacher beat the test? The value of the teacher's assessment in predicting children's ability $\quad 35$

$\begin{array}{ll}3.1 \text { Introduction } & 37\end{array}$

3.2 Background and strategy $\quad 40$

3.2.1 Dutch education system 40

3.2.2 Background 41

3.2.3 Strategy 42

3.3 Data 44

3.3.1 Descriptive statistics $\quad 45$

3.3.2 Possible selection $\quad 49$

3.4 Track placement 50

3.4.1 Differences between objective and subjective assessment measures $\quad 50$

3.4.2 Determinants of track placement 52

3.5 Switching tracks $\quad 57$

3.5.1 Documenting switchers

3.5.2 Determinants of track switching 60 
3.6 Test scores in 9th grade

3.7 Conclusions 65

References 66

$\begin{array}{ll}\text { Appendix } & 67\end{array}$

Chapter 4: The impact of cognitive tests on teachers updating their assessments 89

4.1 Introduction 91

4.2 Background and strategy 95

4.2.1 Background $\quad 95$

$\begin{array}{ll}\text { 4.2.2 Strategy } & 95\end{array}$

4.3 Data 96

4.3.1 Descriptive statistics

4.3.2 Selection 100

$\begin{array}{ll}4.4 \text { Results } & 100\end{array}$

4.4.1 Differences between assessment measures 101

4.4.2 Updating 106

4.4.3 Heterogeneity in gender and education level of parents 108

4.4.4 Robustness checks 112

4.5 Policy perspective 113

$\begin{array}{ll}4.6 \text { Conclusions } & 114\end{array}$

References 115

$\begin{array}{ll}\text { Appendix } & 117\end{array}$

Chapter 5: The impact of changing incentives on achievement tests and assessment measures Evidence from a policy change in the Netherlands $\quad 145$

5.1 Introduction 147

$\begin{array}{ll}5.2 \text { Background and strategy } & 149\end{array}$

5.2.1 The policy change 149

5.2.2 Reasons for the policy change 151

5.2.3 Possible implications and strategy 151

5.3 Data 154

5.3.1 Descriptive statistics 155

5.3.2 Selection 159

5.4 Results 159

5.4.1 Before-after results 159

5.4.2 Heterogeneity in gender and education level of parents 165

5.4.3 Predictive power of the $5^{\text {th }}$ grade test score 170

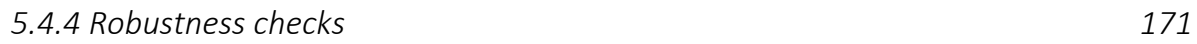

5.5 Policy perspective 172

5.6 Conclusion 174

References 176 
Chapter 6: Motivation and its effect on school performance: A randomized field experiment among underachievers $\quad 189$

6.1 Introduction 191

6.2 The intervention 194

6.2.1 Defining underachievement 194

6.2.2 Design of the intervention 196

6.2.3 Selection of schools and children 197

6.2.4 Sample of schools

6.2.5 Outcome measures and empirical strategy 199

6.3 Results

201

6.3.1 Descriptive statistics

201

6.3.2 Randomization

202

6.3.3 Compliance

205

6.3.4 Treatment effects

6.4 Conclusion

References

Appendix

Nederlandse samenvatting (Dutch summary)

Valorisation

Curriculum Vitae

271 

Chapter 1:

Introduction 



\subsection{Motivation}

A good transition between the different stages of education is necessary for an optimal investment in and an optimal development of children's human capital. Children themselves and society in general benefit when children optimize their investment in education, use their potential to the fullest and smoothly move through the education system. This reduces the number of children who have to repeat a grade, switch to a lower track or leave school early. It also contributes to a higher educated population. Delays and switches in children's educational career are inefficient and expensive. In general, the decisions made concerning children's transition from primary to secondary education are high stakes for all parties involved.

The transition from primary to secondary education, where children are placed into tracks based on their performance and expected ability, is an important educational decision. The Dutch education system relies on early tracking. Consequently, the track to which children are allocated has important consequences for their future schooling career (Hanushek and Woessmann, 2006; Inspectorate of Education, 2014; Timmermans et al., 2013). School tracks determine the type (more practical vs. more theoretical) and the level of education (vocational, general or academic). Children's track placement is an important determinant of their schooling career in secondary school as well as their schooling and labour market possibilities after secondary school.

To determine children's best suited track placement measures of children's ability level are needed. In the Dutch education system, two measures are used to determine children's ability level and track placement in secondary school. These measures are the teacher's assessment of children's ability level and a standardized test score. Both measures estimate children's ability level based on different sets of information. A teacher can base his assessment of children's ability, for example, on children's prior performance, classroom behaviour, background information, personality and other characteristics known to the teacher. The test score measures how well children perform on a cognitive test that assesses their skills in math and language. These measures contain noise which makes it difficult to place children in the educational tracks that are best suited to their true ability level.

Developments in the transition from primary to secondary education and tracking are part of the national and the international debate on education. Recently there have been several policy changes regarding the transition from primary to secondary education in the Netherlands. In these policy changes the teacher's assessment is assigned a more prominent role as a determinant of children's track placement. At the same time the role of the standardized test is de-emphasized as a determinant of children's track placement. These policy developments pose interesting questions for research.

When measured along the lines of the results in international tests, such as the Program of International Student Assessment (PISA) and the Survey of Adult Skills (PIAAC), the Dutch education system is generally considered as one of the best performing edu- 
cation systems among the OECD-countries. For example, the PISA 2012 results show that among the 65 countries that participated, the Netherlands ranked $10^{\text {th }}$ in mathematics, $15^{\text {th }}$ in reading and $14^{\text {th }}$ in science (OECD, 2016). Despite this relatively high rank in terms of average outcomes there is a growing concern among policymakers regarding inequality of opportunities and increased rigidity in track placement related to the system of extensive early tracking (OECD, 2012; OECD, 2016; Inspectorate of Education, 2016).

Both national and international policy advisors and regulators have expressed concerns regarding early tracking. For example, the Dutch Inspectorate of Education (2015) stated in its 2014-2015 annual review of the Dutch education system that differences in equality of opportunity are increasing and that the education level of children's parents is becoming a more important determinant of children's education level. Furthermore, according to the OECD (2016, p. 40.) "There is a tension between the central principle of tracking, that students of given cognitive skills are best suited to a particular type of educational programme, and school discretion, in which tracking decisions depend on teachers' advice and cognitive scores that are interpreted on a variable basis". There are no formal guidelines for establishing the teacher's assessment or track placement. Therefore, it is based on variable criteria, such as the differing use of test scores across schools for establishing the teacher's assessment. Furthermore, schools in the Netherlands can select students and are free to impose additional selection requirements (OECD, 2016; Korpershoek et al., 2016; Inspectorate of Education, 2013). The Dutch education council (2010 and 2014) and the OECD (2012) have argued that education systems that use extensive early tracking should ensure flexibility so that children are offered additional opportunities if changes in their performance occur. However, the impression is that these possibilities are diminishing as the possibilities for "bridge classes" where selection is delayed and "scaffolding diplomas" where students are allowed access to a higher level of education after graduating from their initial track, are becoming increasingly difficult.

Another challenge for the Dutch education system is the underperformance and lack of motivation of children a few years after they have been allocated to tracks in secondary education. According to the OECD (2016) and the Dutch education council (2007), motivation of Dutch children in secondary school is inadequate and there are too few top performers, given the overall high standards. Furthermore, in conversations with secondary schools it became apparent that various schools experience difficulties with children's performance as of approximately $9^{\text {th }}$ grade. These schools relate children's lower performance to a lack of motivation. They argue that these children should be able to perform better, based on their earlier performance in $6^{\text {th }}$ grade, if they were more motivated to work harder. When children underperform in school, human capital accumulation is not optimal and children could have learned more, possibly even graduate from a higher track and face better prospects if they performed up to their expected level. 
In an education system that uses extensive early tracking it is essential to understand the determinants of track placement and their relation to children's further school career. The Dutch education system with its extensive early tracking, offers an opportunity to investigate the relation between the teacher's assessment, the test score, track placement, track switching, and other measures of performance such as grades and motivation. The relationships that are investigated in this dissertation are based on data from the Netherlands, but questions regarding the relation between teacher's assessments, test scores and children's performance are of universal importance.

\subsection{Aim}

The four studies in this dissertation provide a better understanding of the importance of assessment measures of children's ability level in the transition from primary to secondary education. Figure 1 gives an overview of the outline of this dissertation. There are four topics that represent the core of this dissertation: tests, teacher's assessments, track placement and motivation. The first paper discusses the relation between tests, teacher's assessments and track placement in the transition from primary to secondary school. One of the conclusions from this paper is that tests and teacher's assessments are both strong determinants of children's track placement but that teacher's assessments have a stronger effect on track placement compared to tests. The second paper builds on this conclusion and addresses the question if, and how, teachers adjust their own initial teacher's assessment based on information from children's test score. One of the conclusions of this paper is that the adjustments teachers make to their assessment seem to be related to children's social-economic background. The third paper supposes that objective assessment measures e.g. tests, are generally more beneficial to children from lower social-economic backgrounds compared to children from higher social-economic backgrounds as subjective assessment measures such as teacher's assessments are more likely to be biased with regard to children's ethnicity or socialeconomic background. Therefore, the third paper investigates what happens to assessment measures of children's ability level when a policy change decreases the importance of test scores, and thereby increases the importance of teacher's assessments. The fourth paper observes children who are in $9^{\text {th }}$ grade and whose current performance in $9^{\text {th }}$ grade is below their expected performance in $6^{\text {th }}$ grade. This paper investigates the effect of an intervention targeted at children's non-cognitive skills on their motivation and school performance. 


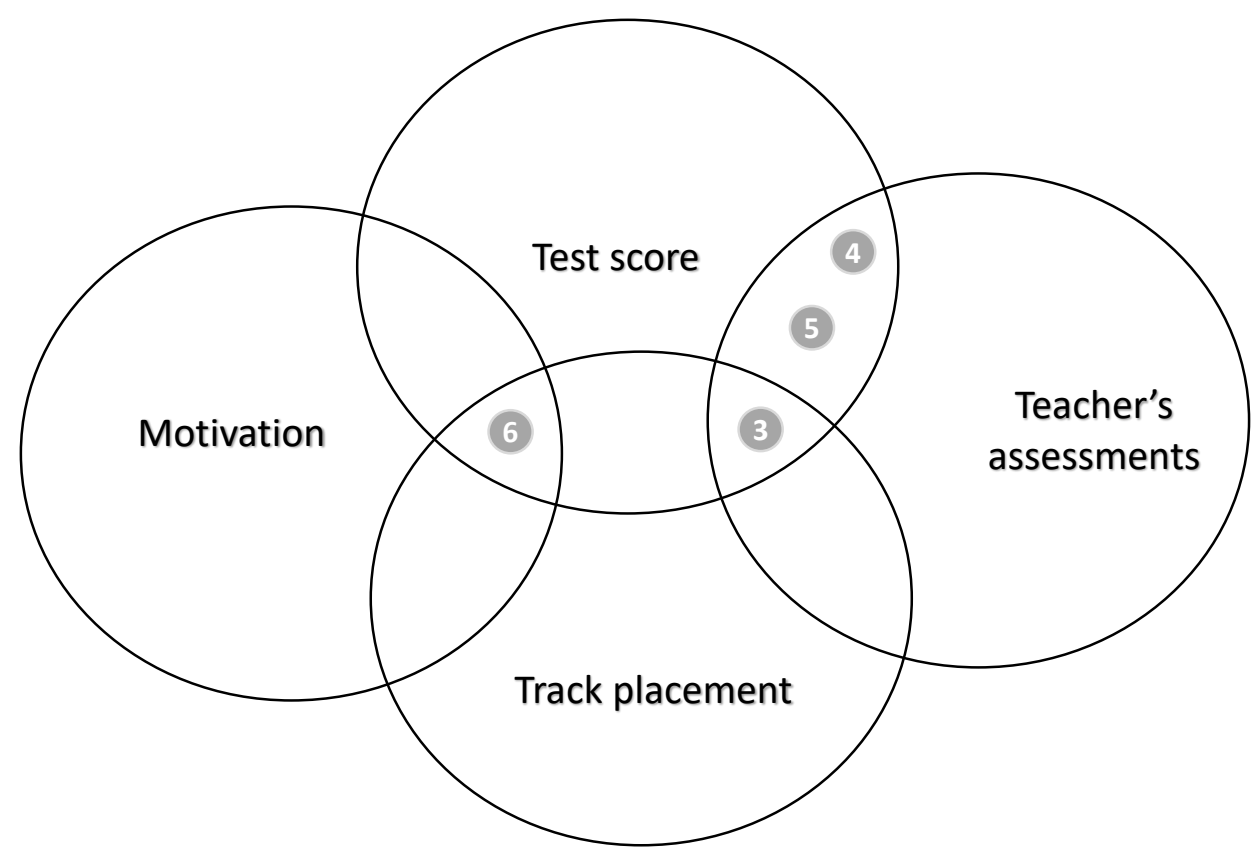

Figure 1: Outline of the dissertation

This dissertation answers four questions:

1. How are test scores (TS) and the final teacher's assessment (FTA) related to track placement (TP) and track switching in the first three years of secondary education? (Chapter 3)

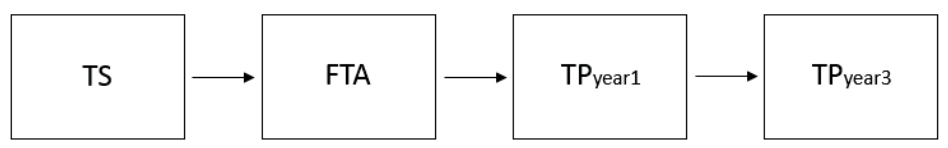

2. How do teachers adjust their own initial assessment of children's ability level (ITA) after receiving information from test scores? (Chapter 4)

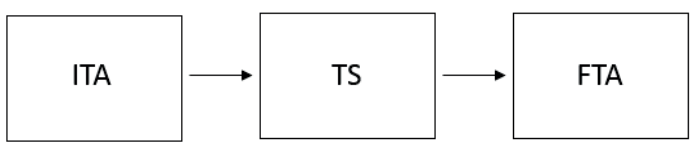

3. What happens to assessment measures of children's ability level when a policy change decreases the importance of test scores? (Chapter 5) 


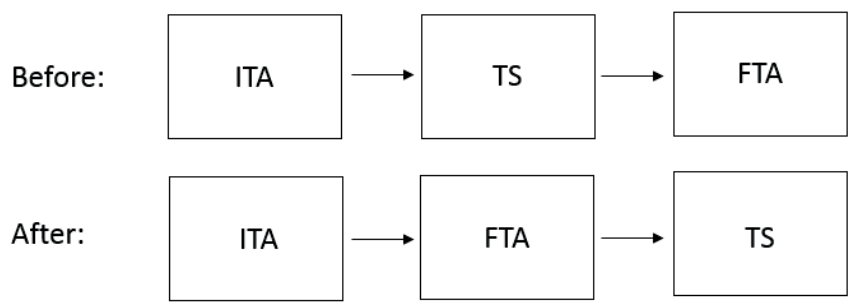

4. What is the effect of an intervention targeted at children's non-cognitive skills on children's motivation and school performance? (Chapter 6)

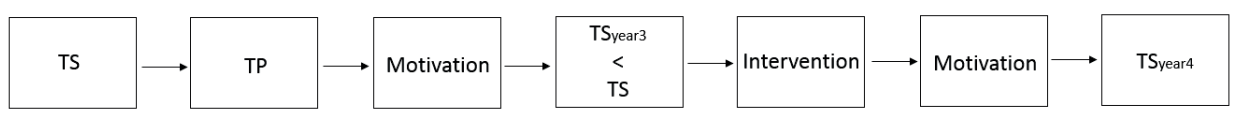

\subsection{Summary of the main findings}

In chapter 3 I investigate to what extent the teacher's assessment contains additional information, on top of the information provided by cognitive test scores, that is used in determining children's ability level in 6th and in $9^{\text {th }}$ grade and how this relates to track switching. The research strategy involves three steps. First, it is investigated if there are non-random differences between cognitive test scores and the teacher's assessment at the individual level. Second, a horse race is conducted to investigate if cognitive test scores or the teacher's assessment is more predictive of track placement in 7th grade and track allocation in 9th grade. Third, it is investigated whether track switchers (between 7th and 9th grade) have been allocated according to the teacher's assessment or cognitive test scores. The most important findings can be summarized as follows. First, for 19 percent of the sample a substantial difference between the assessment measures of ability in 6th grade is observed. Girls are more likely to receive a teacher's assessment that is higher than their test score compared to boys and children from families with lower socio-economic status are less likely to receive a teacher's assessment that is higher than the test score compared to children from higher level families. Second, the estimates suggest that the teacher's assessment is twice as powerful in explaining the gap between the lowest and the highest track placement compared to the test score, in both 7th and 9th grade. Third, the analysis suggests that children who are allocated according to the teacher's assessment are the least likely to switch tracks. Finally, the estimates suggest that the teacher's assessment positively correlates with the 9th grade test scores, whereas the cognitive test score in 6th grade does not. Switching tracks between 7th and 9th grade seems to have a negative effect on the test score in 9th grade, pointing towards costs of switching.

Chapter 4 builds on the analyses presented in chapter 3 by showing how teachers use the information they receive from children's test scores to adjust their own assess- 
ment of children's ability level, given at an earlier point in time. This study uses information on the initial teacher's assessment, the test score and the final teacher's assessment, in this order. The research methodology of this study consists of three steps. The first step is to determine what factors predict the final teacher's assessment. In the second step we investigate the effect size of having a different test score, compared to the initial teacher's assessment, on the final teacher's assessment. The third step is to investigate whether the adjustment the teacher makes is heterogeneous across gender and social-economic status of the children. Two main findings are obtained. First, the estimates suggest that teachers on average adjust their initial assessment of children's ability by 19 percent of a standard deviation after observing children's test score. Second, teachers seem to adjust their initial assessment heterogeneously across the gender and social-economic background of children. The adjustments are less favourable for girls and children from lower social-economic backgrounds. The estimates show that even though it is generally assumed that teachers incorporate a rich set of characteristics into their assessments, there is a significant dependency on the exit test in $6^{\text {th }}$ grade for determining children's ability level.

Chapter 5 investigates whether a change in the incentives changes the way teachers incorporate available information into their teacher's assessment. As of the schoolyear 2014-2015 children take the final test only after the teacher has made his assessment and the teacher's assessment is the relevant measure for children's track allocation decision in secondary school. The effect of this change is investigated in three steps. First, the initial teacher's assessment, the test score and the final teacher's assessment before and after the policy change are observed and it is investigated if changes occur. Second, the results are split by gender and the education level of the mother and the father and it is observed if there is heterogeneity across gender and the education level of the parents. Third, it is investigated if teachers start to use earlier test scores as inputs for their assessment now that they can no longer use the $6^{\text {th }}$ grade test score. It is investigated if there is an increase in the predictive power of the $5^{\text {th }}$ grade test score for the teacher's assessments. First, it is observed that on average there does not seem to be a change in the test score. However, the initial and final teacher's assessment seem to be more alike following the policy change, where the final teacher's assessment appears to be significantly lower on average. Second, following the policy change girls seem to score significantly higher on the test while boys seem to score significantly lower and children whose parents have completed a higher level of education seem to receive a higher initial and final teacher's assessment compared to children whose parents have only completed a lower level of education. Finally, it is observed that teachers seem to put more emphasis on children's $5^{\text {th }}$ grade test score for their teacher's assessments following the policy change.

In chapter 6 the effect of an intervention targeted at children's non-cognitive skills on children's motivation and school performance is investigated. Underachievement is at the centre of the educational debate in many countries as underachievement leads 
to suboptimal investments in human capital. A randomized field experiment is used, in which during several months, underachieving children receive monthly assignments that target: (a) their study skills by raising awareness in the field of self-discipline, critical thinking, decision making and problem solving; and (b) school motivation and future orientation by raising awareness of the usefulness of performance in school and obtaining a degree. The program confronts children with their study behaviour and school attitude. Outcomes of this study are continued participation with the treatment and children's gpa. Since the children in our target group are selected because they are currently underperforming, it is expected that these children have a higher probability of dropping out as their motivation to take up and complete the treatment is likely lower compared to other children. The estimates suggest that children with a lower gpa and children with a higher reported level of motivation more often continue with the treatment. The study finds no effect of the intervention on children's motivation or gpa.

\subsection{Implications}

The results of the first study indicate that the teacher's assessment is a better predictor of children's track placement in $7^{\text {th }}$ and $9^{\text {th }}$ grade than the test score. The teacher's assessment also seems beneficial as it generally allocates children to a higher track compared to the test score and allocating children based on the teacher's assessment does not seem to lead to more children switching tracks between $7^{\text {th }}$ and $9^{\text {th }}$ grade. Therefore, allocating children to tracks based on the teacher's assessment appears to lead to a higher investment in human capital, compared to allocation based on test scores.

However, the teacher's assessment also appears to be dependent on information received from the $6^{\text {th }}$ grade test score. This follows from two results. First, teachers significantly adjust their assessment of children's ability level after learning about these children's test score. Second, teachers revert to earlier test scores when the test score in $6^{\text {th }}$ grade is not available and use these measures of children's ability level as input for their own assessment.

Furthermore, results of the second and third study show that the teacher's assessment is sensitive to heterogeneity across gender and the social-economic background of children. First, it is observed that teachers adjust their assessment of children's ability level heterogeneously across the gender and the social-economic background of children. Second, the results indicate that when the test becomes a less important measure of children's track placement, changes in the teacher's assessments differ across gender and children's social-economic background, favouring children from higher socialeconomic backgrounds. These results suggest that even though allocating children into tracks based on the teacher's assessment could be more efficient, as it could lead to higher investments in human capital, there might be a trade-off concerning equity. 
These findings have implications for different parties. Children (and parents) benefit from the test as an assessment measure as it gives an objective assessment of their ability level independent from their other characteristics. This can provide additional information about their true ability level than only relying on the teacher's assessment. These studies also give an insight into the assessment process as done by teachers. These studies do not ascertain through which channel the heterogeneity in the teacher's assessment can be explained. The heterogeneity could be the result of new information or stereotyping. Nevertheless, teachers should be aware of this process and the potential consequences. Furthermore, schools and society in general gain insight into the selection and allocation process into tracks. Schools gain insight into the potential consequences of their own policies and choices made at the beginning of children's educational career. Society gains insight into the determinants that can result in a higher investment in human capital.

The fourth study shows how difficult it is to target specific groups of children with a school intervention. This study focused on children who in $9^{\text {th }}$ grade perform at a lower level compared to their expected performance in $6^{\text {th }}$ grade. These children could, arguably, benefit from interventions aimed at improving their motivation and performance. However, as they are not motivated to perform well in school they are also less likely to successfully participate in these kind of policy interventions. This study shows the importance of school support for this type of research. Without specifically targeting these children and without support from teachers and school staff it is difficult for outside researchers to successfully perform interventions. 


\section{References}

Dutch education council, (2007), Presteren naar vermogen, Technical report, Dutch education council.

Dutch education council, (2010), Vroeg of laat.

Dutch education council, (2014), Overgangen in het onderwijs.

Hanushek, E. A. and Woessmann, L., (2006), Does educational tracking affect performance and inequality?

Differences-in-differences evidence across countries. The Economic Journal. Vol. 116. pp. 63-76.

Inspectorate of Education, (2013), De Staat van het Onderwijs 2011/2012.

Inspectorate of Education, (2014), De kwaliteit van het basisschooladvies. Een onderzoek naar de totstandkoming van het basisschooladvies en de invloed van het basisschooladvies op de verdere schoolloopbaan

Inspectorate of Education, (2016), De Staat van het Onderwijs 2014/2015

Korpershoek, H., Beijer, C., Spithoff, M., Naaijer, H.M., Timmermans, A.C., van Rooijen, M., Vugteveen, J., and Opdenakker, M.-C., (2016), Overgangen en aansluitingen in het onderwijs. Deelrapportage 1: reviewstudie naar de po-vo en de vmbo-mbo overgang. Groningen: GION

OECD, (2012), Equity and Quality in Education: Supporting Disadvantaged Students and Schools, OECD Publishing.

OECD, (2016), Netherlands 2016: Foundations for the future, reviews of national policies for education, OECD Publishing, Paris

Timmermans, A., Kuyper, H. and van der Werf, G., (2013), Schooladviezen en onderwijsloopbanen. Voorkomen, risicofactoren en gevolgen van onder- en overadvisering. Groningen: GION. 

Chapter 2:

Data description 



\subsection{The Dutch education system}

\subsubsection{General information}

In the Netherlands primary education consists of eight years of which the first two are spent in kindergarten. As of the third year of elementary school (i.e., 1st grade), children formally learn how to read and write. Most children start kindergarten at the age of 4 , enter 1st grade at the age of 6 and finish elementary school at the age of 12 . As of secondary school children are allocated to tracks.

The Dutch secondary education system is hierarchically structured by ability and consists of three main tracks that differ in duration and qualification. Figure 1 gives an overview of the tracks in secondary education. The four-year track (VMBO or T1) qualifies children for vocational education (MBO). These vocational programmes are provided at regional training centres (ROCs), agrarian training centres (AOCs) and vocational schools (vakscholen). The five-year track (HAVO or T2) qualifies children for higher vocational education ( $\mathrm{HBO}$ ), which are practical oriented programmes, usually provided at universities of applied sciences including both professional bachelor and masters programmes. 


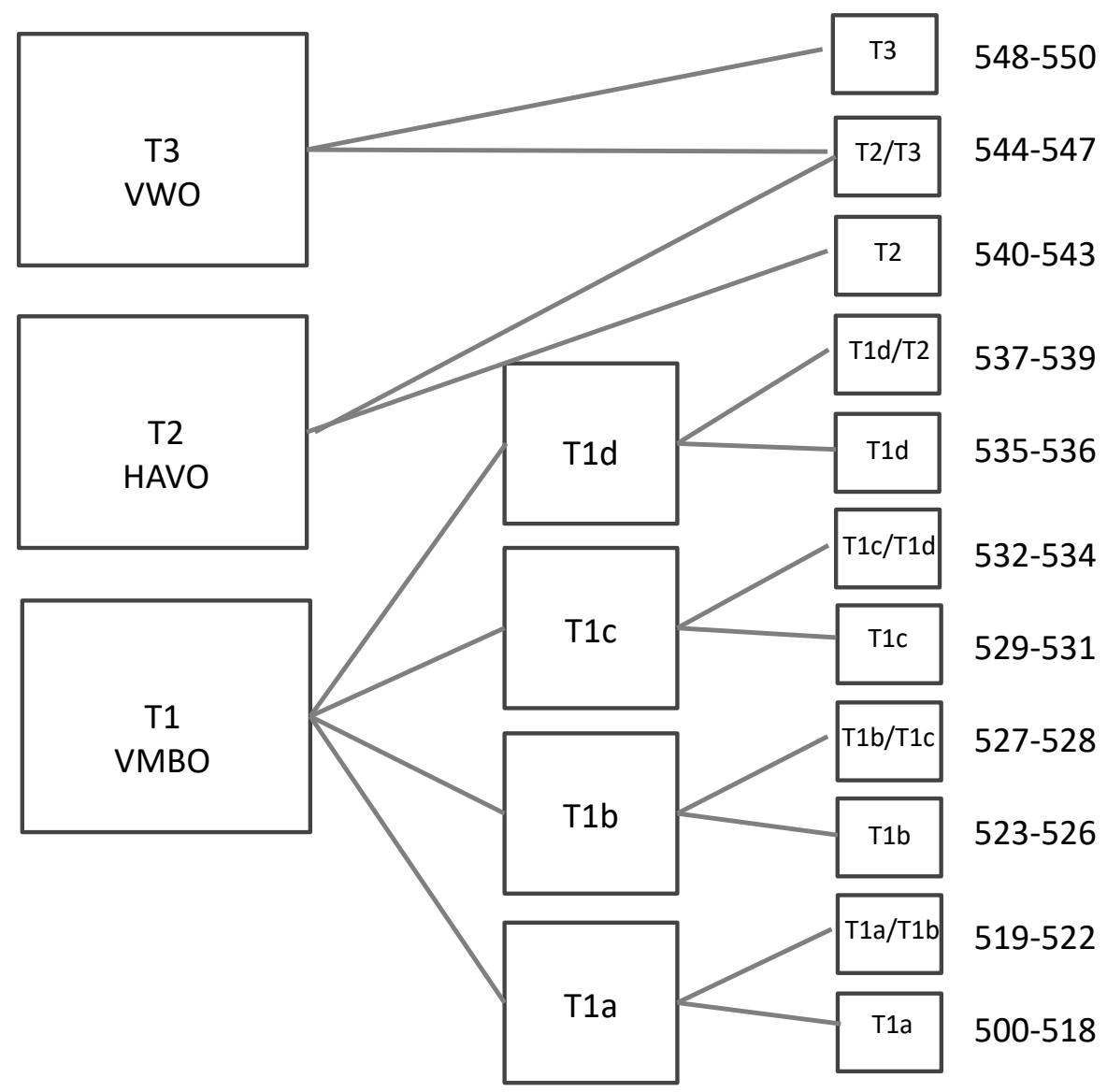

Figure 1: overview of educational tracks

The six-year track (VWO or T3) qualifies children for university education (WO) including bachelors and master programmes and the opportunity to move on to Ph.D programmes (OECD, 2016). The second column in Figure 1 shows four sub-tracks at prevocational education (T1a to T1d). The difference between these four sub-tracks is the importance of a practical versus a more theoretical focus of the curriculum. Time spent on more theoretically oriented courses increases with the tracks from T1a to T1d. ${ }^{1}$ The third column of Figure 1 shows all possible tracks, some of which are combinations of the three major tracks.

The track placement (TP) decision is made by the secondary school. In our data this decision is based on test scores (TS) and the elementary school's teacher's assessment (FTA). Figure 2 shows this sequence of events. To determine the optimal track place-

\footnotetext{
${ }^{1}$ The six-year track (T3) can also be divided into two sub-tracks of which one includes the option to take courses in Greek and Latin. Our data do not allow us to distinguish between these two sub-tracks, which means that we combine them in T3.
} 
ment for children, secondary schools receive an educational report for every child. This educational report provides an overview of the child's learning outcomes and progress, its behaviour, (social-emotional) development and possible special needs. The educational report also includes the teacher's assessment of the child's ability level and the child's test score on an exit test in $6^{\text {th }}$ grade (PO-raad and VO-raad, 2016). Secondary schools use this information to allocate children into tracks. There are no legal criteria set for the admittance to a track or school. Every secondary school can decide how and if children are admitted and to which track they are allocated. Occasionally, an interview or an entrance test takes place to assess a child's ability. In regions where there is a higher supply of children (or a higher demand for secondary schools), schools can follow a stricter admission procedure than regions where the supply of children is lower (Korpershoek et al., 2016). For example, a number of schools use lotteries to decide which children are admitted. In approximately 50 percent of the municipalities primary and secondary schools make joint agreements about a local procedure for the transition from primary to secondary education (ITS et al., 2013).

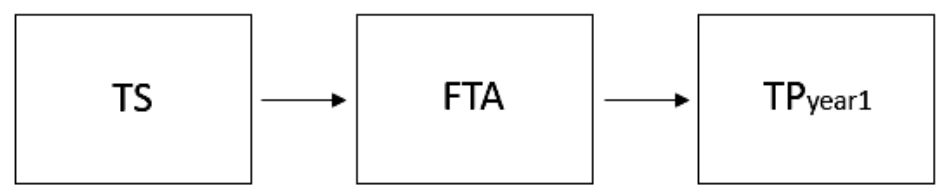

Figure 2: sequence of events for track placement

As of schoolyear 2014-2015 a policy change has taken effect that influences the transition from primary to secondary education. Two important changes are the introduction of a compulsory exit test in primary education and children's track placement in secondary education gives more weight to the teacher's assessment of children's ability level. The obligatory exit test promotes continuous learning in the transition from primary to secondary education by providing information about children's level of knowledge and skills (Ministerie van Onderwijs, Cultuur en Wetenschap, 2014). As of schoolyear 2014-2015 the final teacher's assessment is announced before the $1^{\text {st }}$ of March while the test takes place between the $15^{\text {th }}$ of April and the $15^{\text {th }}$ of May (Rijksoverheid, 2016; Rijksoverheid, 2016a). If children perform better on the test compared to their teacher's assessment the teacher is obligated to reconsider the initial assessment of children's ability level. In case the teacher's assessment deviates from the test score, the teacher needs to motivate this decision (Rijksoverheid, 2016b). Furthermore, secondary schools are not allowed to use any other information about children's ability level, such as IQ tests, earlier test scores or other information, for their admission and track placement (PO-raad and VO-raad, 2016). 


\subsubsection{Test}

In $6^{\text {th }}$ grade, the final year of primary education, children complete an exit test. This test consists of questions in the areas of math, reading, study skills and science. Schools have different tests that they can choose from. ${ }^{2}$ The test that is used in this dissertation is called the "Eindtoets Basisonderwijs" from Cito, which is the most commonly used objective assessment test in $6^{\text {th }}$ grade. Approximately 85 percent of all Dutch children complete this high-stakes test in 6th grade (Ministerie van Onderwijs, Cultuur en Wetenschap, 2015). An example of an official test form is shown in Figure 3 . The test is standardized, which implies that the test procedure is the same for all children who take part in the test. The degree of difficulty of the test is approximately the same across different years. Every year the test is calibrated to ensure that children's average scores on the test are comparable across years. Children's performance on this test is measured on a scale from 501 to 550 .

The aim of the $6^{\text {th }}$ grade test is to establish to what extent children master the reference levels of math and language skills and to provide an independent and appropriate perspective on children's expected performance and their best track placement in secondary education (Rijksoverheid, 2016a). The test is not meant to provide a signal of grades or performance on an intelligence test, which can lead to negative connotations. The test institute offers guidelines for children's track allocation by reporting brackets of scores and accompanying track placement suggestions.

\footnotetext{
${ }^{2}$ In 2016 schools can choose from three approved exit tests. https://www.rijksoverheid.nl/onderwerpen/toelating-middelbare-school/inhoud/keuzemogelijkhedenverplichte-eindtoets-basisschool
} 


\section{Centrale eindtoets PO $1^{\mathrm{e}}$ toetsdag dinsdag 21 april 2015}

Alleen met potlood invullen. Vergissingen goed uitgummen.
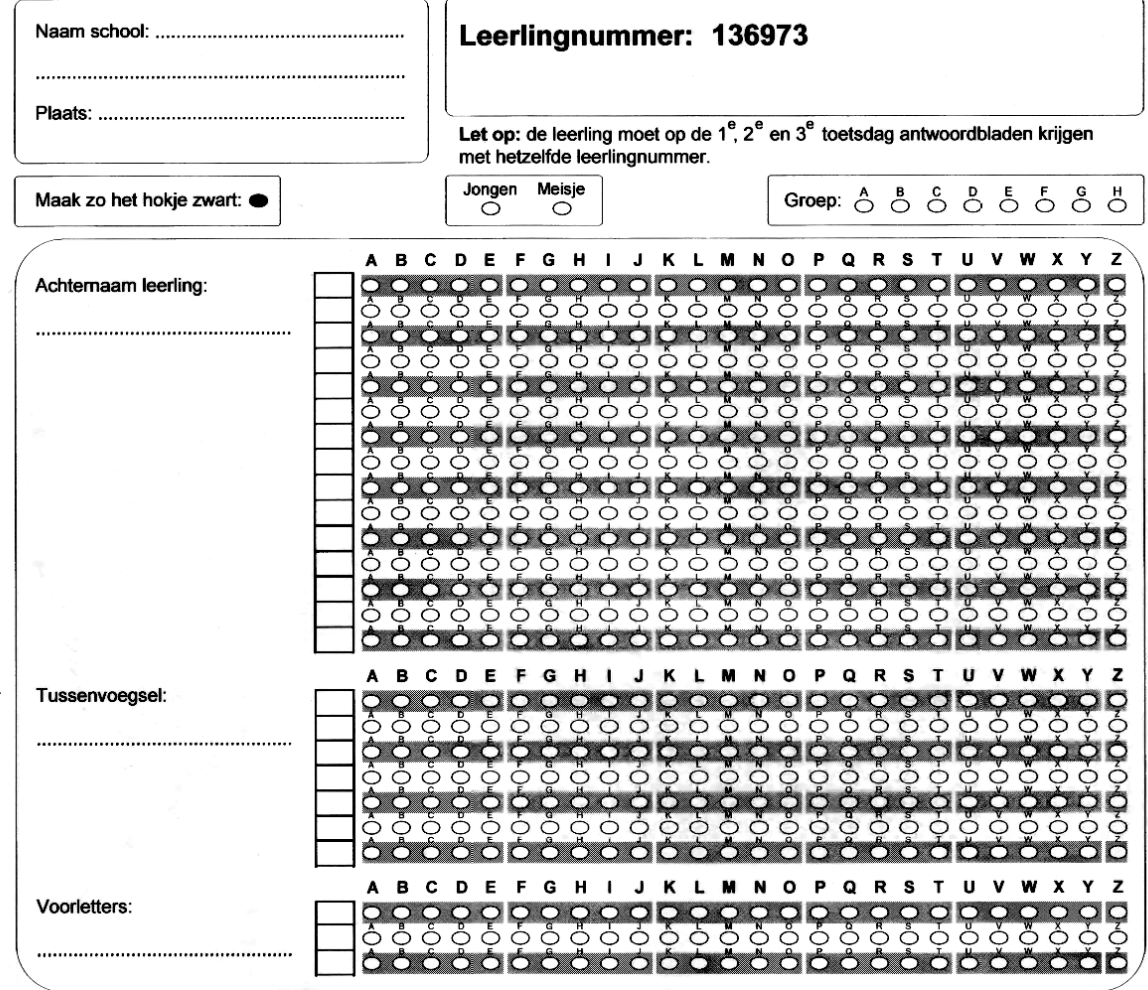

\section{Leerlingnummer: 136973}

Let op: de leerling moet op de $1^{\mathrm{e}}, 2^{\mathrm{e}}$ en $3^{\mathrm{e}}$ toetsdag antwoordbladen krijgen met hetzelfde leerlingnummer.

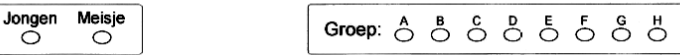

\begin{tabular}{|c|c|}
\hline \multicolumn{2}{|c|}{ Geboortedatum: } \\
\hline Dag: & 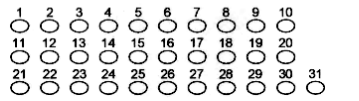 \\
\hline Maand: & 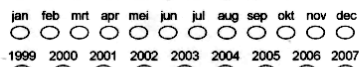 \\
\hline Jaar: & 0000 \\
\hline
\end{tabular}

Laatste vier cijfers van het BSN

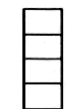
$\begin{array}{llllllllll}0 & 1 & 2 & 3 & 4 & 5 & 6 & 7 & 8 & 9 \\ 0 & 0 & 0 & 0 & 0 & 0 & 0 & 0 & 0 & 0 \\ 0 & 1 & 2 & 3 & 4 & 5 & 6 & 7 & 8 & 9 \\ 0 & 0 & 0 & 0 & 0 & 0 & 0 & 0 & 0 & 0 \\ 0 & 1 & 2 & 3 & 4 & 5 & 6 & 7 & 8 & 9 \\ 0 & 0 & 0 & 0 & 0 & 0 & 0 & 0 & 0 & 0 \\ 0 & 1 & 2 & 3 & 4 & 5 & 6 & 7 & 8 & 9 \\ 0 & 0 & 0 & 0 & 0 & 0 & 0 & 0 & 0 & 0\end{array}$
Advies leerkracht brugklastype:

$O$ basisberoepsgerichte leerweg

$O$ basis- en kaderberoepsgerichte leerweg

$\bigcirc$ kaderberoepsgerichte leerweg

$\bigcirc$ gemengde/theoretische leerweg

gemengde/theoretische leerweg en havo

havo

havo/wwo

wwo (inclusief gymnasium)

\begin{tabular}{l}
$\begin{array}{l}\text { Aangepaste versie: } \\
\bigcirc \mathrm{Ja} \\
\mathrm{Nee}\end{array}$ \\
\hline Ontheffing: $\quad$ Ja \\
\hline
\end{tabular}

Aangepaste versie:

Figure 3: Example of an official test form 
The test also serves other purposes. High scores on the standardized test are an important way in which elementary schools try to signal the quality and value-added of their educational efforts. Elementary schools seem to use their average scores on this test to attract new children. In addition, the Dutch Inspectorate of Education uses these results, controlled for individual characteristics, as one of the inputs for their overall evaluation of the school's quality and value-added. Furthermore, inputs for the Inspectorate of Education's evaluation of secondary schools' performance include the percentage of children who graduate every year as well as the percentage of children who switch tracks. Allocating children to tracks that are too high (too low) leads to switching downward (upward) and would induce negative (positive) evaluations on this part of the performance assessment (Tweede Kamer der Staten-Generaal, 2015). ${ }^{3}$ Nevertheless, secondary schools also benefit from having more children in the higher tracks as this is beneficial for signalling the quality of the schools' education, which potentially helps to attract more children.

\subsubsection{Teacher's assessment}

In addition to the objective test score, teachers make a personal assessment of each child's level of ability. The assessment can be based, among others, on the teacher's experience and interaction with the child, observable demographic and socio-economic factors and the child's performance throughout all grades in primary school. At the time teachers announce their assessment of the child's ability level they know how the child performed on the test. This subjective assessment is provided before children apply to secondary school.

Elementary school teachers do not have a strong incentive for strategic behaviour in such a way that their assessment overstates the child's ability level. The teacher's compensation scheme does not depend on the assessments made. Furthermore, the elementary school's population usually goes to the same set of secondary schools every year. This repeated interaction leads to more aligned incentives and a better understanding of ability signals between the elementary and the secondary schools. Additionally, each year children are assigned to a class in which they are generally taught by one elementary school teacher.

\footnotetext{
${ }^{3}$ As of June 2016 the Inspectorate of Education uses a new model to calculate learning outcomes that uses a different method for assessing schools' educational quality and no longer 'punishes' schools when children switch down tracks.
} 


\subsection{The data}

\subsubsection{General information}

The "Onderwijs Monitor Limburg" (OML) is a collaboration between Maastricht University, school boards (primary, secondary and tertiary) and government bodies in Limburg (a province in the South of the Netherlands). The OML aims to gain insight into the educational development of children in order to foster the further improvement of education and to acquire knowledge about the dynamics of educational processes in general. The OML is part of a larger program (Educatieve Agenda Limburg) that focuses on the monitoring of educational development and teacher quality. The starting point of the OML is information which is already collected within schools. Additional testing and surveying is done where needed (in close collaboration with the schools) (Educatieve Agenda Limburg, 2016).

This combination provides a unique dataset about the educational development of children in Limburg. Almost all schools in the region have participated in the data collection process. Approximately 95 percent of all primary schools and 90 percent of all secondary schools have participated in the data collection process. The unique feature of this data is that these children are followed over time as they progress from $6^{\text {th }}$ to $9^{\text {th }}$ grade. In both years the data collection includes administrative data from the school information systems, surveys among children and their parents, test results and teacher's assessments. The data covers children from all tracks with the exception of those who are in special needs education. Depending on the chapter, either longitudinal or panel data is used.

The most important variables for the analyses are obtained from the schools' information systems and from surveys. These variables include children's test score in $6^{\text {th }}$ grade, the teacher's assessment of children's ability level in $6^{\text {th }}$ grade, track placement in secondary school in $7^{\text {th }}$ grade and key demographic variables such as gender, age of the child and the education level of the father and the mother. The administrative data together with the survey data allow researchers to follow children over time and investigate longer-term impacts. Additionally, multiple sources of data give a more complete picture of children's environment and characteristics and it can confirm the validity of the measures. ${ }^{4}$

\subsubsection{Representativeness}

The data contains information on children who attend schools in Limburg. The province of Limburg is the most southern province of the Netherlands. This particular data is used since it offers unique opportunities to investigate questions in education economics

\footnotetext{
${ }^{4}$ The importance of using multiple sources of data has been proven successful by different authors such as Chetty et al. (2010), Dohmen et al. (2011) and Vischer et al. (2013).
} 
concerning the importance of the teacher's assessments and test scores and their impact on children's further school career. The data are not directly generalizable to the whole population of the Netherlands. Children and their environment in Limburg have certain characteristics that are particular to this province and that differ from other provinces. Table 1 gives a brief overview of the comparability of some regional characteristics. For example, compared to the average of the Netherlands, Limburg has a lower number of immigrants, faces a population decline, has relatively more lower and fewer higher educated people and its inhabitants have a lower average personal income.

Table 1: Characteristics of the Netherlands and Limburg

\begin{tabular}{lll}
\hline & \multicolumn{2}{l}{$\begin{array}{l}\text { The Netherlands (average } \\
\text { per province) }\end{array}$} \\
\hline Population & $1,408,393$ & $1,117,941$ \\
Immigrants & 305,443 & 233,569 \\
Population density per km2 & 502 & 520 \\
Average number of persons per household & 2.17 & 2.11 \\
Total population growth (in persons) & 5,953 & $-2,065$ \\
Working population (18-65 year in \%) & 71 & 67 \\
Highest attained education level (18+ years excluding students in \%)* & 39 \\
Lower & 34 & 41 \\
Middle & 41 & 20 \\
Higher & 25 & 28,400 \\
Average personal income (in euro) & 30,200 & 39 \\
\hline
\end{tabular}

Source: Centraal Bureau voor de Statistiek, 2015, Demografische kerncijfers per gemeente 2015; Centraal Bureau voor de Statistiek, 2014, Inkomen, arbeidsdeelname, opleidingsniveau, vermogen en sociale samenhang naar regio; Centraal Bureau voor de Statistiek, 2016, Gemiddeld inkomen van personen naar regio.

* Lower: SOI 10, 20, 31, 32 en 33, Middle: SOI 41, 42 en 43, Higher: SOI 51, 52, 53,60 en 70 http://www.cbs.nl/nl-NL/menu/methoden/classificaties/overzicht/soi/2006/default.htm

** Average gross income from labor and social services

\subsection{Field experiment}

The additional data for the fourth paper was collected by performing a field experiment at secondary schools in Limburg. For this study 18 schools were recruited to participate in the experiment. After the schools decided to participate in the experiment, children were selected per school to take part in the treatment or the control group. The children that participated in this experiment were also part of the schools that participate in the data collection process of the OML. Therefore, for these children information is available concerning the test score and the teacher's assessment in $6^{\text {th }}$ grade as well as demographic variables comparable to the data used in the other three papers. The selection of children was made based on test score data obtained from the OML. For this paper multiple sources of data were used to get a more detailed picture of the 
children in our sample and to validate our measures (Chetty et al. (2011); Dohmen et al, (2011); Vischer et al. (2013).

Data specifically collected for this paper are the children's grades, measured on a scale from 1-10. From the schools we obtained information on children's grades before the start of the experiment and after the experiment had ended. Other variables that are specific to this paper are the variables related to motivation, homework and selfconfidence. These variables are obtained from the surveys collected by the OML before the start of the experiment.

\subsection{Correlation vs. causal evidence}

To execute proper analyses and give substantiated policy implications research needs to give an extensive description of the situation and context of the research question. To describe the situation and context researchers need good data that allows them to observe people's characteristics and follow them over time. To find out what works and what does not work researchers should (preferably) use (quasi)experimental research methods. In topics related to education causal relationships are difficult to ascertain and the interpretation of findings needs to be adjusted accordingly. Causal relationships are difficult to identify as exogenous variation is scarce. For example, it is difficult to find a variable that is related to track placement but not related to the test score or the teacher's assessment. Variables that are available in the data can generally be linked to one of these ability measures. Other empirical methods such as (natural) experiments offer the possibility to show causal relationships but have other drawbacks such as the control that is needed to maintain the proper execution of a research design, they are generally small scale and usually expensive to set up. The first three empirical papers in this dissertation show relationships in the data by means of correlations. The fourth paper uses a randomized field experiment and shows causal relationships. Both research methods are essential in the area of education economics. 


\section{References}

Brunello G. and D. Checchi, (2007), Does school tracking affect equality of opportunity? New international evidence, Economic Policy, vol. 22, no. 52, pp. 781-861.

Chetty, R., Friedman, J. N., Hilger, N., Saez, E., Whitmore Schanzenbach, D., Yagan, D., (2011). How does your kindergarten classroom affect your earnings? Evidence from project STAR, Quarterly Journal of Economics, Vol. 126. No. 4. pp. 1593-1660.

Diris, R. (2012). The economics of the school curriculum, PhD thesis, Maastricht University.

Dohmen, T., Falk, A., Huffman, D., Sunde, U., Schupp, J. and Wagner, G.G., (2011). Individual Risk Attitudes: Measurement, Determinants and Behavioral Consequences, Journal of the European Economic Association, Vol. 9 No. 3. pp. 522-550.

Educatieve Agenda Limburg (EAL), (2016), de Onderwijs Monitor Limburg. http://www.educatieveagenda limburg.nl/onderwijsmonitor-p/english

van Elk, R., M. van der Steeg and D. Webbink (2009). The effect of early tracking on participation in higher education, CPB Document no. 182, http://www.cpb.nl/en/publication/effect-early-tracking-participationhigher-education.

Hanushek, E. A. and Woessmann, L., (2006), Does educational tracking affect performance and inequality? Differences-in-differences evidence across countries. The Economic Journal. Vol. 116. pp. 63-76.

ITS, Kohnstamm Instituut, Oberon, (2013), Selectiemechanismen in het onderwijs, Nijmegen, Amsterdam, Utrecht: ITS, Kohnstamm Instituut, Oberon.

Korpershoek, H., Beijer, C., Spithoff, M., Naaijer, H.M., Timmermans, A.C., van Rooijen, M., Vugteveen, J., and Opdenakker, M.-C., (2016), Overgangen en aansluitingen in het onderwijs. Deelrapportage 1: reviewstudie naar de po-vo en de vmbo-mbo overgang. Groningen: GION.

Ministerie van Onderwijs, Cultuur en Wetenschap, (2014), Beleidsreactie op het advies van de Onderwijsraad Overgangen in het onderwijs.

Ministerie van Onderwijs, Cultuur en Wetenschap, (2015), Eerste inzichten Wet Eindtoetsing PO.

OECD, (2016), Netherlands 2016: Foundations for the Future, OECD Publishing, Paris. DOI: http://dx.doi.org/10.1787/9789264257658-en

PO-raad \& VO-raad, (2016), Nieuwe regelgeving overgang po-vo, http://www.nieuweregelgevingovergangpovo.nl/schooladvies/

Rijksoverheid, (2016), Wet op het primair onderwijs. Artikel 9b, Centrale eindtoets taal en rekenen. http://wetten.overheid.nl/BWBR0003420/2016-08-

01\#Hoofdstukl_TiteldeellI_Afdeling1_Paragraaf1_Artikel10a;

Rijksoverheid, (2016a), Verplichte eindtoets basisonderwijs. https://www.rijksoverheid.nl/onderwerpen/ toelating-middelbare-school/inhoud/verplichte-eindtoets-basisonderwijs

Rijksoverheid, (2016b), Wet op het primair onderwijs. Artikel 42, Onderwijskundig rapport en schooladvies. http://wetten.overheid.nl/BWBR0003420/2016-08-

01\#Hoofdstukl_TiteldeellI_Afdeling1_Paragraaf1_Artikel10a

Tweede Kamer der Staten-Generaal, (2015), Brief van de staatssecretaris van onderwijs, cultuur en wetenschap, kamerstuk 31289-246.

Vischer, T., Dohmen, T., Falk, A., Huffman, D., Schupp, J., Sunde, U., Wagner, G.G., (2013). Validating an UltraShort Survey Measure of Patience, Economics Letters, Vol. 120 No. 2. pp. 142-145 


\section{Chapter 3:}

Does the teacher beat the test? ${ }^{5}$

The value of the teacher's assessment in predicting children's ability

\footnotetext{
${ }^{5}$ Published as: Feron, E., Schils, T. and Weel, B. t. (2016) Does the Teacher Beat the Test? The Value of the Teacher's Assessment in Predicting Student Ability, De Economist, Vol. 164. No. 4. pp. 391-418.
} 



\subsection{Introduction}

The weight of cognitive test scores in allocating children to different levels of education has increased over time (e.g., Kautz et al., 2014). The reason why cognitive test scores are widely used as assessment measures to sort children is that they are assumed to give objective measures of ability levels. Assessments made by teachers represent more subjective measures of ability and have been criticized for being biased; for example towards gender and against minorities (e.g., Dee, 2005; Burgess and Greaves, 2013; Fairlie et al., 2014). However, teacher's assessments could also be valuable complements to cognitive test scores. Teachers work with children on a daily basis, which allows them to also assess other determinants of ability such as motivation and classroom behavior (e.g., Segal, 2008).

This research investigates to what extent a teacher's assessment contains additional information that is useful in determining elementary school children's ability level on top of the information provided by cognitive test scores. We make use of a database that contains information about cognitive test scores and teacher's assessments in elementary school and about initial track placement and subsequent careers in secondary school of Dutch pupils. The Netherlands has an educational system that involves early tracking (i.e. at the age of 12). Our empirical analysis benefits from this system because we observe both high-stakes cognitive test scores and teacher's assessments at the end of 6th grade and the transition from elementary to secondary school during which children are allocated to different (hierarchical) education tracks.

The research strategy involves three steps. The first step is to document whether or not there are non-random differences between cognitive test scores and teacher's assessments at the individual level. In the second step we investigate whether or not cognitive test scores or teacher's assessments are more predictive of track placement in 7 th grade and track allocation in 9th grade. In a complementary analysis we document the determinants of math and language test scores in 9th grade by correlating them with both ability signals. In the third step we pay attention to track switchers (between 7th and 9th grade) to investigate whether these children have been allocated according to teacher's assessments or cognitive test scores. ${ }^{6}$ The application of the assessment measures by secondary schools to allocate children to different tracks (or the lack thereof) yields information about the usefulness of objective and subjective assessment measures in allocating children.

Our database for the empirical analysis includes 4,500 children. The database is constructed by making use of administrative data from school tracking systems and survey data of children in 6th and 9th grade in the period 2009-2012 (i.e., these children were in

\footnotetext{
${ }^{6}$ The benefits of an early tracking system are highest when children are allocated to tracks most suitable given their ability level and that they stay within this track throughout their secondary school careers. These seem to be the most important reasons for early tracking in for example Germany (e.g., Woessmann, 2004) and the Netherlands (e.g., Diris, 2012), two countries that track children the earliest among all OECD countries.
} 
6th grade in 2009 and were followed until 9th grade in 2012). We have access to a collection of data consisting of both objective and subjective assessment measures in 6th grade, track placement from 7th to 9th grade, test scores on an identical test across all different tracks in 9th grade and information about switching tracks in secondary school. The survey data include measures about demographic factors as well as socio-economic status. The objective assessment measure is a high-stakes standardized test score (socalled Cito Eindtoets) which children take in 6th grade. This objective test score provides a well-defined measure of levels of achievement and is annually taken by almost all 6th grade children in the Netherlands. ${ }^{7}$ The subjective assessment measure is the teacher's assessment of the child's ability level. This subjective assessment is made by teachers in 6 th grade after they have observed the test score from the objective assessment.

Our four most important findings can be summarized as follows. First, for 19 percent of our sample we observe a substantial difference between the objective and subjective assessment measure of ability in 6th grade. In three quarters of these cases the subjective teacher's assessment measure is higher than the test score. We find that there are systematic differences between the objective and subjective assessment measure. Our most important findings relate to gender and social-economic status. Girls are more likely to receive a teacher's assessment that is higher than their test score compared to boys and children from families with lower socio-economic status are less likely to receive a teacher's assessment that is higher than the test score compared to children from higher level families. ${ }^{8}$

Second, our estimates suggest that the teacher's assessment is twice as powerful to explain the gap between the lowest and the highest track placement compared to the test score, in both 7th and 9th grade. These results suggest that secondary schools put more emphasis on the subjective assessment measure relative to the objective assessment measure when allocating children to tracks in 7th grade. It also suggests that the teacher's assessment is not only more predictive of initial track placement but also of the longer term career in secondary school compared to the cognitive test score. In addition, secondary schools seem to allocate children in accordance with the highest assessment signal of ability. Finally, our estimates are conservative or lower-bound estimates as we only consider eight different educational tracks in secondary education for these analyses and are very strict in labelling signals as different. ${ }^{9}$

\footnotetext{
${ }^{7}$ Approximately 85 percent of all Dutch children who are in 6th grade participate in the Cito Eindtoets every year.

${ }^{8}$ These numbers are consistent with previous studies using data about the Dutch education system. For example, Timmermans et al. (2012) investigate the relationship between assessment measures and secondary school careers. They use a different dataset, which contains information about children from all regions in the Netherlands but no information on track placement and switching. Their descriptive statistics about assessment measures are similar to ours, which suggests that our analysis is likely to be representative for the Netherlands. Golsteyn and Schils (2014) show that boys and girls score differently on the $6^{\text {th }}$ grade tests according to differences in personality that might also be related to higher teacher assessments.

${ }^{9}$ We group the tracks in pre-vocational education which leads to eight educational tracks as the number of children allocated to each of these tracks is relatively low. This decreases the variation in the data compared to analyzing 11 educational tracks.
} 
Third, we observe that the teacher's assessment has non-random deviations from the test score. The question is whether these non-random deviations are efficient with respect to later outcomes, such as switching tracks. We observe that approximately 24 percent of our sample makes a switch between tracks between 7th and 9th grade. Our analysis suggests that children who are allocated according to the teacher's assessment are the least likely to switch tracks.

Finally, the estimates suggest that the teacher's assessment positively correlates with the 9th grade test scores, whereas the cognitive test score in 6th grade does not explain test scores in 9th grade (when controlling for the teacher's assessment). Furthermore, switching tracks between 7th and 9th grade seems to have a negative effect on the test score in 9th grade, pointing towards costs of switching.

This paper contributes to the literature about the consequences of using objective and subjective assessment measures for tracking and successive performance. Dee (2005), Lindahl (2007), Lavy (2008), Gibbons and Chevalier (2008), Cornwell et al (2012) and Burgess and Greaves (2013) all use objective and subjective assessment measures to study discrimination and uncertainty. It is shown that systematic differences exist between these two types of instruments in the assessment of children's performance, such as between boys and girls, or between blacks and whites. Bernardi et al. (2014) show that additional information from cognitive and non-cognitive tests is able to help children make a more efficient track allocation choice. Our contribution to this literature is that we analyze differences in both assessment measures for track allocation and switching, where we are able to observe children's later outcomes in 9th grade in the form of track allocation, track switches and their scores on a math and language test.

Other studies have shown that test scores in secondary school are predictive of labor-market outcomes (e.g., Murnane et al., 1995 and Currie and Thomas, 1999). We obtain a set of estimates suggesting that switching seems to lead to lower test scores in 9th grade. This seems to support arguments that switching tracks harms children's accumulation of human capital, which is documented in Van Elk et al. (2009) and Diris (2012) for the Netherlands.

Our work also contributes to the literature on early school tracking. The long-run effects of early tracking for human capital development and educational opportunities have been summarized by Hanushek and Woessmann (2006) and Brunello and Checchi (2007). According to the OECD, the early tracking regime in the Netherlands causes a severe constraint for the growth of higher education participation. It states that "In the end, postponement of the present early tracking regime seems inevitable; although this is a major change in the way Dutch society thinks of itself" (OECD, 2007, p.38). Consistent with this advice, other studies using Dutch data suggest that relatively low-ability children could improve their educational outcomes by about 30 percentage points when tracking is postponed by one year. At the same time, most children do not seem to be hurt by the presence of low-ability children in the first year of secondary school. Only children who are considered to have the highest ability seem to be hurt by the 
presence of lower ability peers (e.g., Van Elk et al., 2009 and Diris, 2012). We show that a substantial fraction of our population is not allocated to the right track, which seems akin to restraints on optimal human capital development.

We proceed as follows. First, we present background features of the Dutch education system and explore the research strategy. Section 3 documents the data description and statistics of our core variables. Sections 4-6 present the results on the differences between objective and subjective assessment measures, track switching and 9th grade test scores. Section 7 briefly addresses the policy perspective of our analysis with a focus on reducing switching. Section 8 concludes. We present additional results and detailed data descriptions in the Appendix to this paper.

\subsection{Background and strategy}

We observe five main outcomes for each child: the test score which serves as an objective assessment of ability at the end of elementary school (6th grade), the elementary school teacher's assessment which serves as a subjective assessment measure of ability (6th grade), track allocation in the first and third year of secondary education (7th and 9th grade), the results from a cognitive test in 9th grade, and track switching in the first three years of secondary education (7th-9th grade). We now present information on these measures and information about the Dutch education system.

\subsubsection{Dutch education system ${ }^{10}$}

Countries differ in the age at which they first track children into different types of schools. In the majority of OECD countries, tracking takes place between the ages of 14 to 16 . Some countries, including the Netherlands, undertake the first tracking at the age of 12 when children progress from elementary to secondary school (i.e., from 6th to 7th grade). ${ }^{11}$ We take advantage of this system by studying the allocation in secondary school, the transition from elementary to secondary school and performance in 9th grade.

Figure 1 shows all possible tracks, some of which are combinations of the three major tracks. Both the objective and subjective assessment measure are tailored toward

\footnotetext{
${ }^{10}$ More information about the Dutch education system can be found in chapter 2.

${ }^{11}$ Research has been conducted to investigate the effects of early tracking on differences in human capital formation and educational opportunities (e.g., Hanushek and Woessmann, 2006 and Brunello and Checchi, 2007 for comprehensive review studies). The overall conclusion of these investigations has been that the earlier the tracking, the greater the impact of socio-economic factors, such as parental education, on educational outcomes and opportunities. For the Netherlands, Van Elk et al. (2009) and Diris (2012) find that early tracking reduces participation in and completion of education for relatively low-ability children placed in lower tracks at the age of 12 , while there does not seem to be a positive effect on those placed in the higher tracks. One of the main reasons of implementing an educational system with early tracking is to provide children with a learning environment in which they benefit from classrooms with homogenous populations. Such populations would benefit from peer effects. In addition, it allows for a focused curriculum and appropriately paced instructions.
} 
allocating children into one of these 11 track combinations. The 6th grade test distinguishes brackets which are consistent with these 11 track combinations, shown in the fourth column of Figure 1. Teacher assessment is measured on the same 11-point scale.

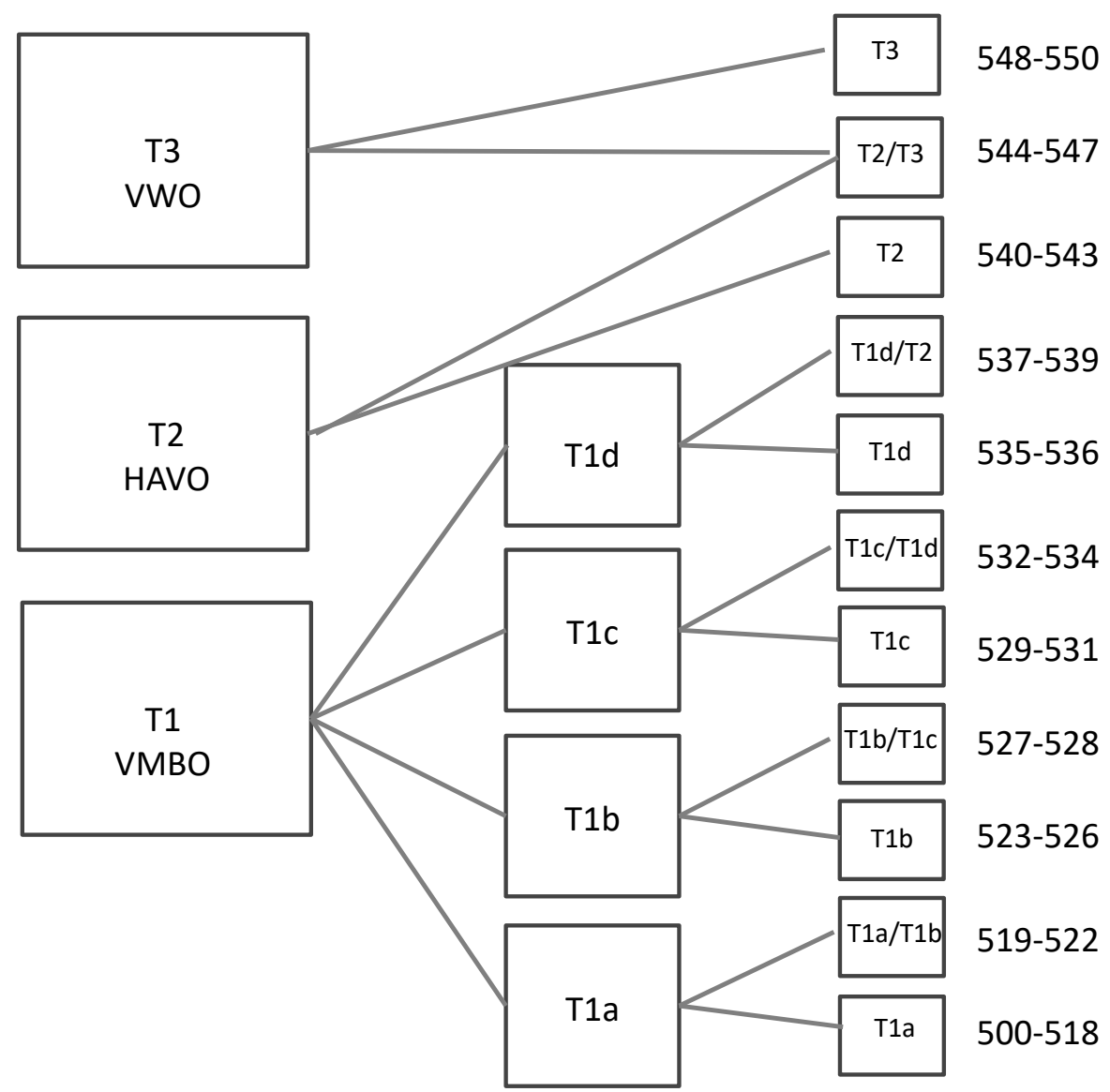

Figure 1:: Tracks in secondary education in The Netherlands

Note: The left-hand side shows the three major tracks from high (T3) to low (T1). The T1 track is subdivided into four sub-tracks. The right-hand side of the figure shows the 11 tracks to which children can be allocated in 7th grade and the objective assessment measure (test score) in the brackets that belongs to each of these tracks.

\subsubsection{Background}

The children in our data have completed this Cito Eindtoets in 2009, which is the most common objective assessment test in elementary schools in the Netherlands. The test was taken during three days at the beginning of February 2009. The test is standardized meaning that the test procedure is the same for all children. In the assessment children have to answer questions in the areas of math, reading, study skills and science. The 
degree of difficulty of the test is approximately equal across different years. The test is calibrated every year to ensure that children's average scores on the test are comparable across different years. The performance is measured on a scale between 501 and 550 .

The aim of the cognitive test score is to provide an independent and appropriate perspective on children's expected performance and their best track placement in secondary education. The test is not meant to provide a signal of grades or performance on an intelligence test, which can lead to negative connotations. The test institute offers guidelines for children's track allocation by reporting brackets of scores and accompanying track assessments. We followed these guidelines for constructing our objective ability measure variable. We use the brackets as the outcome measure of the objective assessment measure.

In addition to the objective test score, teachers make a personal assessment of each child's level of ability. The assessment is based on the teacher's experience and interaction with the child, observable demographic and socio-economic factors and the child's performance throughout all grades in elementary school. Teachers also know the test score from the objective assessment measure when they present their assessment of the child's ability. This subjective assessment is provided in the spring of 2009 before children apply to a secondary school. The teacher's assessment is provided in similar brackets as the objective assessment and fits with possible track allocations in secondary schools. Secondary schools obtain the information about the objective and subjective assessment measures and allocate children to tracks.

\subsubsection{Strategy}

Our analysis first focuses on the way in which both the objective and subjective assessment measures in 6th grade help to explain track placement in 7th grade. Both assessment measures aim to measure ability, but face the problem that the true underlying and unobserved level of ability is unknown. We define the objective assessment measure of child $i$ as his test score $\left(T S_{i}\right)$. This test score depends on $i$ 's true and unobserved ability $\left(A_{i}\right)$, a vector of observed characteristics $\left(X_{i}\right)$ and the elementary school he attends $\left(P_{i}\right)$. These ingredients lead to the following measurement of child $i$ 's test score:

$$
T S_{i}=f\left(A_{i}, X_{i}, \beta_{P_{i}}\right) .
$$

In an ideal world $T S_{i}=A_{i}$. In practice this is not true because $T S_{i}$ is measured with noise and observed characteristics $X_{i}$ are likely to influence the measurement of $A_{i}$ by $T S_{i}$. The reason for adding school fixed effects (or dummies in our cross-sectional specifications) is that characteristics of elementary schools can be related to test results of children in 6th grade, which can influence $T S_{i}$. Some of these school characteristics we cannot observe. Hence, we add school fixed effects to the model. 
We define the subjective assessment measure of child $i$ as the teacher's assessment of his ability $\left(T A_{i}\right)$. This measure includes the same ingredients as well as the observed test score:

$$
T A_{i}=g\left(A_{i}, X_{i}, T S_{i}, \beta_{P_{i}}\right) .
$$

The information about the child's test score influences the teacher's assessment of the child's ability. We abstract from differences in school fixed effects that may select teachers with certain attitudes because we do not observe individual teachers in the data. Because children are assigned to one teacher in the final year of primary education and most elementary schools have only one 6th grade class, potential teacher effects are captured by school fixed effects. This is also the reason for indexing all variables with child $i$ and for ignoring teacher $j$ effects.

Finally, we observe child $i$ 's initial track placement $\left(T P_{i}\right)$ in 7 th grade (at secondary school) and thereafter allocation in 9th grade. The decision about initial placement is made by the secondary school and includes the objective and subjective assessment measures. Adding secondary school fixed effects to the model would create additional endogeneity as not all schools offer the same track levels and secondary school fixed effects are related to $T S_{i}$ and $T A_{i}$.

$$
T P_{i}=h\left(A_{i}, X_{i}, T S_{i}, T A_{i}, \beta_{P_{i}}\right) .
$$

In the first part of the empirical analysis we analyze if there are any systematic differences between the test score, the teacher's assessment and track placement for various socio-economic background characteristics of children. Furthermore, we are primarily interested in explaining the track placement of child $i$. We estimate equation (3) with an ordered probit model to find the determinants of track placement in both 7th and 9th grade. Second, we do not observe $A_{i}$ but two signals $T S_{i}$ and $T A_{i}$. Third, in the empirical analysis we incorporate the possibility that secondary schools take into account both $T S_{i}$ and $T A_{i}$, although $T A_{i}$ includes information about $T S_{i}$. In this way we have the two signals competing with each other. A statistically significant coefficient of $T S_{i}$ would in all likelihood suggest that secondary schools put weight on both signals of ability. The equation we first estimate is:

$$
T P_{i}=C+a_{1} X_{i}+a_{2} T S_{i}+a_{3} T A_{i}+\beta_{P_{i}}+\varepsilon_{i}
$$

where $\varepsilon_{i}$ is the error term.

In the second part of the empirical analysis we estimate the determinants of track switching in the first three years of secondary school (i.e., in the period spanning 7th, 8th and 9th grade). To do so, we first estimate a set of probit models in which we show what type of children tend to switch tracks. Second, we estimate probit models in which we estimate the probability of switching tracks $\left(S W_{i}\right)$ for child $i$ :

$$
S W_{i}=C+a_{1} X_{i}+a_{2} T S_{i}+a_{3} T A_{i}+a_{4} T P_{i}+\gamma_{S_{i}}+\varepsilon_{i},
$$


where $\varepsilon_{i}$ is the error term. We estimate different versions of the model in which the dependent variable is switch, switch up or switch down. We only include secondary school fixed effects because switching takes place in secondary school. We show below that elementary school fixed effects have no impact on track placement, which makes us confident that including only secondary school fixed effects is sufficient to estimate the determinants of switching.

Finally, we estimate models to investigate to what extent test scores on an identical (low-stakes) test in 9th grade are correlated with the ability signals from the teacher and the test score in 6th grade. We also estimate to what extent switching is correlated with test scores in 9th grade.

The strength of the data at our disposal is that we are able to observe performance in both primary and secondary school. In addition, we have detailed information about elementary school teacher's assessments and initial track placement in secondary school. This is a unique feature in the literature. Nevertheless, the analysis is constrained by the fact that we are not able to identify a source of exogenous variation in our data. Ideally, one would want to conduct an experiment in which a random portion of the sample was placed according to the test scores' signal, another part according to the teacher's signal and a final slice of the population as it is currently done (i.e., decided by the secondary school). The alternative is to find instruments to deal with the "self-fulfilling prophecy" that creates endogeneity. The "self-fulfilling prophecy" is the idea that when a child is placed on a higher or lower track than he should be according to his true ability, the child is more likely to switch back to the track that matches his true ability. This is to be kept in mind when interpreting the results in the switching section. Furthermore, all tests, but also the teacher's assessment, contain measurement error and analyses concerning ability suffer from omitted variable bias. However, such instruments are not readily available. Our analyses focus on outcomes between 6th and 9th grade. In order to find exogenous variation we would need a set of instruments related to (one of) our assessment measures and at the same time unrelated to any unobservable variables that might influence our outcome variable. Since children's true ability is unobserved, this is problematic. We are aware of the endogeneity concerns with respect to omitted variable bias and also with the fact that potential measurement error is an important disclaimer when interpreting the estimated coefficients, but try to deal with this in the best way possible by using primary and secondary school fixed effects and a rich set of covariates, including track placement in 7th grade.

\subsection{Data}

Before we present our results, we first document the most salient features of our data to reveal information about the allocation of children and to present a number of key 
descriptive statistics. More information as well as additional regression analyses are presented in the Appendix.

\subsubsection{Descriptive statistics}

For the analyses we use a unique dataset on the educational development of children in a given region (Limburg) of the Netherlands. Table 1 documents the distribution of test scores $T S_{i}$ in 7th and 9th grade, teacher advice $T A_{i}$, and (initial) track placement $T P_{i}$, across the 11 different tracks. The numbers in each row add up to 100 percent. In addition, the table documents the number of switchers from the initial track to which they are allocated in 7th grade. The numbers represent the fraction of children who switch away from each of these tracks. The distribution of test scores and teacher's assessments seems to be broadly consistent but there are also important differences. Track placement and teacher's assessment at higher levels of secondary education is different from the test scores, with almost a quarter of the sample being placed in T3 in 7th grade. Teacher's assessments seem to be more favorable for the higher tracks compared to the test score. These differences are further explored in Section 4.

Table 1: The distribution of test scores, teacher assessment and track placement

\begin{tabular}{|c|c|c|c|c|c|c|c|c|c|c|c|}
\hline & \multicolumn{11}{|l|}{ Track } \\
\hline & $\mathrm{T} 1 \mathrm{a}$ & $\mathrm{T} 1 \mathrm{a} / \mathrm{b}$ & $\mathrm{T} 1 \mathrm{~b}$ & $\mathrm{~T} 1 \mathrm{~b} / \mathrm{c}$ & $\mathrm{T} 1 \mathrm{c}$ & $\mathrm{T} 1 \mathrm{c} / \mathrm{d}$ & $\mathrm{T} 1 \mathrm{~d}$ & $\mathrm{~T} 1 \mathrm{~d} / 2$ & $\mathrm{~T} 2$ & $\mathrm{~T} 2 / 3$ & T3 \\
\hline$T S_{i}$ & 2.00 & 2.62 & 3.87 & 2.76 & 6.33 & 9.07 & 7.11 & 13.98 & 20.49 & 18.96 & 12.82 \\
\hline$T A_{i}$ & 4.00 & 3.27 & 4.53 & 0.31 & 0.11 & 5.18 & 10.96 & 12.33 & 18.02 & 16.62 & 24.67 \\
\hline$T P_{i}$ & 2.69 & 3.11 & 7.27 & 0.00 & 1.53 & 1.84 & 10.73 & 10.84 & 11.07 & 25.93 & 24.98 \\
\hline$S W_{i}$ & 3.59 & 0.21 & 11.30 & 0.00 & 7.29 & 5.28 & 19.01 & 10.35 & 12.99 & 9.93 & 20.06 \\
\hline$T S_{i}$ 9th & 1.21 & 2.21 & 4.14 & 0.00 & 1.88 & 1.38 & 11.70 & 11.31 & 9.82 & 29.14 & 27.12 \\
\hline
\end{tabular}

Note: All rows add up to 100. $n=4,500$ except for $S W_{i}$ where $n=4,019$ and $T S_{i} 9^{\text {th }}$ where $n=1,812$. See Figure 1 for a schedule of the different educational tracks. $T S_{i}$ is the objective assessment measure based on the Cito Eindtoets (test score) in 6th grade. $T A_{i}$ is the subjective assessment measure based on the teacher advice in 6th grade. $T P_{i}$ is track placement in 7 th grade. $S W_{i}$ is a measure of switching. The numbers in this row show the fraction of children that switch away from this track after initial placement in 7 th grade. $T S_{i} 9$ th is the test score in 9th grade on math or language.

Furthermore, teachers seem to be reluctant to advise tracks in the middle tracks of vocational education (i.e., tracks in T1). As can be observed from Table 1, some T1 subtracks contain only few observations. These are combination tracks to which only a few children are allocated. ${ }^{12}$ We join the combination tracks and the regular tracks for $\mathrm{T} 1$ when analyzing differences between $T S_{i}$ and $T A_{i}$. This means that for the analysis of track allocation we combine tracks $\mathrm{T} 1 \mathrm{a}$ and $\mathrm{T} 1 \mathrm{a} / \mathrm{T} 1 \mathrm{~b}, \mathrm{~T} 1 \mathrm{~b}$ and $\mathrm{T} 1 \mathrm{~b} / \mathrm{T} 1 \mathrm{c}$ and $\mathrm{T} 1 \mathrm{c}$ and $\mathrm{T} 1 \mathrm{c} / \mathrm{T} 1 \mathrm{~d}$ into three categories. This results in a more conservative estimate of the determinants of allocation in Section 4. As the difference between $T S_{i}$ and $T A_{i}$ does not

\footnotetext{
${ }^{12}$ It is possible that this is related to the availability of this type of school track in the area.
} 
have a direct impact on the number of children who switch tracks, we use 11 tracks for the analyses of switching tracks. We define differences in $T S_{i}, T A_{i}$ and $T P_{i}$ when there is a difference of at least two tracks. Furthermore, we define a switch between tracks when children switch at least two tracks. For example, if children switch from track T2 to track T1d/T2 or track T2/T3 this is not defined as a switch. When children switch from track T2 to track T1d or track T3 this is defined as a switch.

Table 2 reports descriptive statistics. Our data include slightly more girls than boys. In 6th grade children are on average 12 years old. Most of the children (and their parents) were born in the region (Limburg) but there are also children (and their parents) who were born in another part of the Netherlands or abroad. The education level of the father and mother is measured as the highest completed level of education. The average education level of parents suggests that they have completed vocational education. Parental education levels are measured in four different categories: (1) lower education, (2) vocational education, (3) higher education and (4) university education. The labor-market position of the father and mother is also measured in four categories: (1) employed, (2) unemployed, (3) sick/unable to work and (4) not in the labor force. Almost all fathers are employed, while more mothers report to be unemployed. The number of workdays per week of the father and mother is a measure of the amount of time allocated to paid work. Most fathers work fulltime, while more mothers report to work part-time. In The Netherlands, part time employment is an important form of employment for women with young children (e.g., Bosch et al., 2010). Working time is defined in three categories: (1) part-time 1-2 days per week, (2) part-time 3-4 days per week and (3) fulltime. Almost 80 percent of the children in our sample live with both parents in 9th grade. ${ }^{13}$

The teacher's assessment, track placement and test score are all measured on a scale from 1-8. The original test score in 6th grade is measured on a scale from 501-550. Based on test score ranges provided by the institution that supplies the test in 6th grade, we rescaled the test score to a scale from 1-8. Average test score and average test score (short) correspond to a T1d/T2 track. The average teacher's assessment and average track placement correspond to a T2 track (see Figure 1). Almost 24 percent of children switch tracks between 7th and 9th grade.

\footnotetext{
${ }^{13}$ The corresponding survey question is: "Do you live at home with both parents?"
} 
Table 2: Descriptive statistics of the main variables in the empirical analysis

\begin{tabular}{|c|c|c|c|c|c|c|}
\hline & $\mathrm{N}$ & Mean & SD & Min & Median & Max \\
\hline Female & 4,422 & 0.51 & 0,50 & 0 & 1 & 1 \\
\hline Age (years) & 4,500 & 12.06 & 0.55 & 10 & 12 & 14.75 \\
\hline $\begin{array}{l}\text { Region of birth child } \\
\text { 1. Limburg } \\
\text { 2. The Netherlands } \\
\text { 3. Abroad }\end{array}$ & 3,943 & 1.15 & 0.46 & 1 & 1 & 3 \\
\hline Region of birth father & 3,923 & 1.36 & 0.67 & 1 & 1 & 3 \\
\hline Region of birth mother & 3,935 & 1.35 & 0.67 & 1 & 1 & 3 \\
\hline $\begin{array}{l}\text { Education father } \\
\text { 1. Lower education } \\
\text { 2. Vocational education } \\
\text { 3. Higher education } \\
\text { 4. University }\end{array}$ & 3,752 & 2.38 & 1.10 & 1 & 2 & 4 \\
\hline Education mother & 3,763 & 2.22 & 1.03 & 1 & 2 & 4 \\
\hline $\begin{array}{l}\text { Labor market position father } \\
\text { 1. Employed } \\
\text { 2. Unemployed } \\
\text { 3. Sick/unable to work } \\
\text { 4. Other }\end{array}$ & 3,858 & 1.12 & 0.51 & 1 & 1 & 4 \\
\hline Labor market position mother & 3,869 & 1.48 & 1.04 & 1 & 1 & 4 \\
\hline $\begin{array}{l}\text { Workdays per week father } \\
\text { 1. Part-time } 1-2 \text { days } \\
\text { 2. Part-time } 3-4 \text { days } \\
\text { 3. Fulltime }\end{array}$ & 3,249 & 2.91 & 0.29 & 1 & 3 & 3 \\
\hline Workdays per week mother & 2,848 & 2.31 & 0.62 & 1 & 2 & 3 \\
\hline Living with both parents & 3,608 & 0.79 & 0.41 & 0 & 1 & 1 \\
\hline Teacher's assessment & 4,500 & 5.60 & 2.15 & 1 & 6 & 8 \\
\hline Track placement & 4,500 & 5.75 & 2.16 & 1 & 7 & 8 \\
\hline Test score & 4,500 & 538.67 & 8.03 & 504 & 540 & 550 \\
\hline Test score (short) & 4,500 & 5.21 & 2.02 & 1 & 6 & 8 \\
\hline Switching & 4,019 & 0.24 & 0.42 & 0 & 0 & 1 \\
\hline
\end{tabular}

Note: The same description of region of birth of the child applies to the father and mother. Similarly, the same description of Education father, Labor market position father and Workdays per week father apply to the mother.

Figure 2 shows the distributions for the test score (Panel A), the teacher's assessment (B), and track placement (C) in the eight brackets we use for the first section of the empirical analyses. These eight categories are underlying our definitions of $T S_{i}, T A_{i}$ and $T P_{i}$. The vertical axis in each of the three panels shows the percentage of children in each category. These percentages add up to 100. As can also be observed from the numbers displayed in Tables 1 and 2, the differences in means and other moments of the distribution between the three measures are relatively small. 
A: Objective assessment measure (test score) in 6th grade

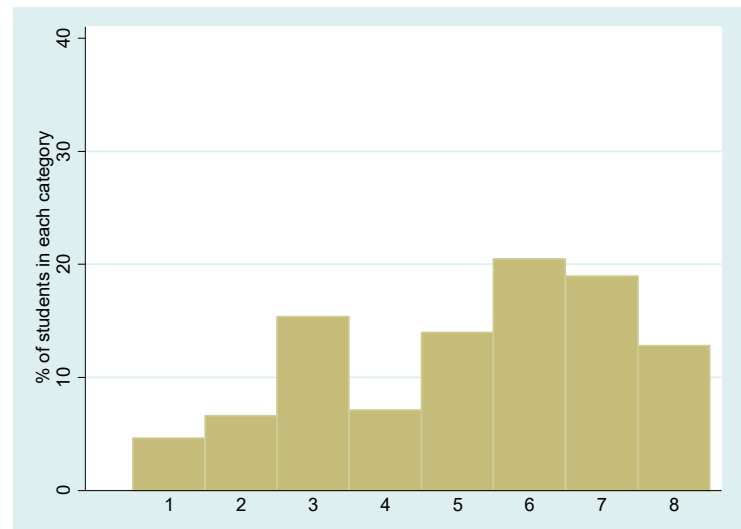

B: Subjective assessment measure (teacher assessment) in 6th grade

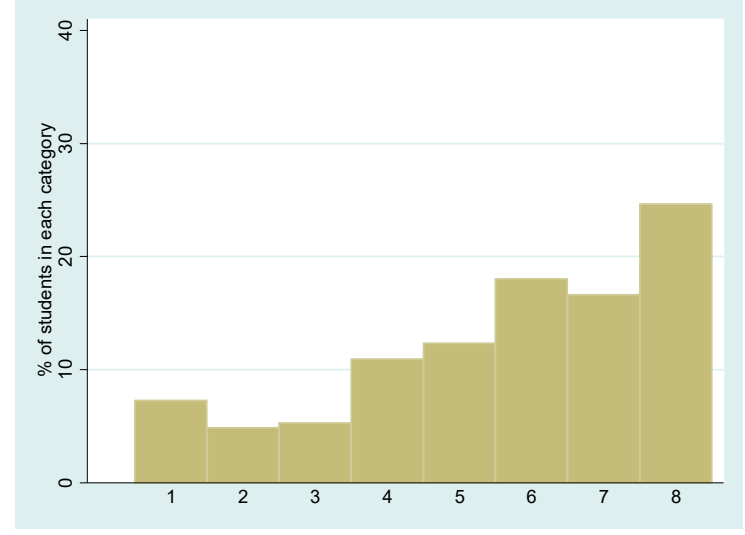

C: Track placement in 7th grade

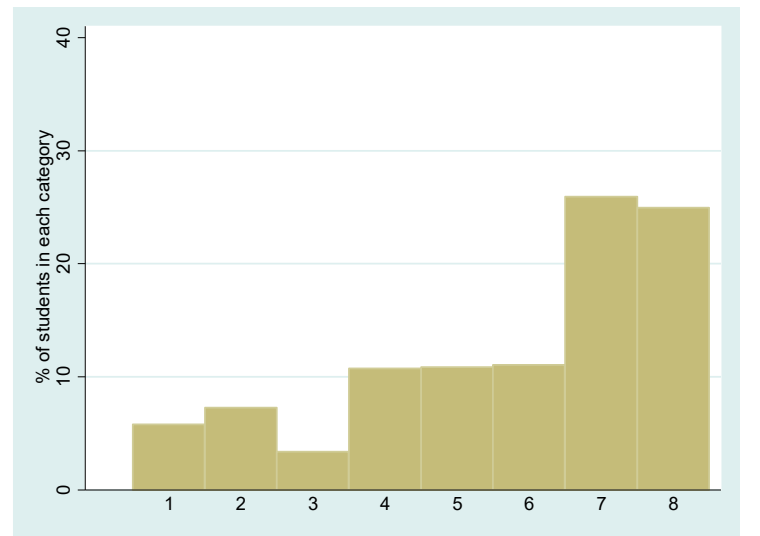

Figure 2: The distribution of objective and subjective assessment measures in 6th grade and track placement in 7 th grade in 8 brackets (from low to high) 
Table 3 shows the bivariate correlation coefficients and their statistical significance of the main variables in our empirical analyses. ${ }^{14}$ We observe that the correlations among the teacher's assessment, test scores and track placement are high and positive, which comes without surprise given the patterns displayed in Figure 2. What is also interesting to observe is that track placement shows a higher positive correlation with the teacher's assessment than with test scores. Furthermore, we observe that there is a negative correlation between switching tracks and the test score, the teacher's assessment and track placement. The majority of the switches happen in the pre-vocational track as can be observed from Table 1.

Finally, we use information about a math and language test that children in our sample have taken in 9th grade. This test was a low-stakes test and part of the research project conducted at the schools in our sample. It main purpose was to have a schoolindependent test score for children in 9th grade. The difficulty level of the test differs according to the children's track level. Since we want to compare the effect of switching tracks across tracks we only use the questions on math or language that are identical for all students. This leaves us with 11 questions on math and 8 questions on language. Since we do not have enough observations for all tracks, we only look at students in track T1c, $\mathrm{T} 1 \mathrm{~d}, \mathrm{~T} 2$ and T3 in relation to their score on the math or language test. The average percentage of questions answered correctly increases from 34 in track T1c to 49 in track T3. The standard deviation is around 20 percent in all tracks. The distribution of the test score in 9 th grade is presented in the last row of Table 1. The row adds up to 100 percent and shows the percentage of students per initial track placement in 7 th grade.

Table 3: Correlation coefficients

\begin{tabular}{lllll}
\hline & Teacher's assessment & Test score & Track placement & Switching \\
\hline Teacher's assessment & 1 & & & \\
Test score & $0.8495^{* * *}$ & 1 & & \\
Track placement & $0.8896^{* * *}$ & $0.8040^{* * *}$ & 1 & 1 \\
Switching & $-0.2247^{* * *}$ & $-0.1973 * * *$ & $-0.2309 * * *$ & 1 \\
\hline
\end{tabular}

Note: Bivariate correlation coefficients. ${ }^{* * *},{ }^{* *}$ represents significance at the 1 and 5 percent level respectively. Teacher Assessment, track placement and test score (short) are all measured on a scale from 1-8. All other variables are measured as described in table 2.

\subsubsection{Possible selection}

Data has been collected from 155 elementary schools (95 percent of all schools in the given region) and 30 secondary schools (90 percent of all schools in the given region). This results in a database of $n=4,500$ for the first section, $n=4,019$ for the second section and $n=1,812$ for the third section of the empirical analyses of this paper. In the first section of the empirical analyses we discuss non-random differences between the test score, the teacher's assessment and track placement in 7th and 9th grade. In the second section of

\footnotetext{
${ }^{14}$ Appendix A presents a correlation table of all variables of interest and a detailed description of the covariates.
} 
the empirical analyses we discuss track switching because mistakes in initial track placement or suboptimal allocation can be made undone in the first part of secondary education. In the third section we correlate both ability signals and switching with 9th grade test scores. Data has been collected for 9,092 children. For the analyses in the first section of the paper we only use those children for whom we observed the teacher's assessment and the test score in our data. For the analyses in the second section we also need to know children's track placement in 7th, 8th and 9th grade, which reduces the sample size to 4,019 . Finally, 9th grade test scores are available for 1,812 children.

Possible selection issues with regard to the sample we use for our analyses are addressed. It is investigated whether individual characteristics are able to predict whether children end up in our sample for analyses. We are mainly concerned about schools only reporting data for their well performing children and holding back information on their poorer performing children. However, after controlling for school fixed effects we find that individual characteristics are not significantly related to selection into our sample. We conclude that selection is not an issue (see the Appendix for a more elaborate analysis).

\subsection{Track placement}

This section presents our first set of estimation results. We first investigate to what extent there are non-random differences between the objective and subjective assessment measures. Second, we present a set of estimates about the determinants of track placement in 7th and 9th grade.

\subsubsection{Differences between objective and subjective assessment measures}

To compare differences between our objective and subjective assessment measures we have created three categories: $T A_{i}<T S_{i}, T A_{i}=T S_{i}$ and $T A_{i}>T S_{i}$. Figure 4 shows that 81 percent of the children in our sample are faced with objective and subjective assessment scores that are equal. If there is no systematic difference between the teacher's assessment and the test score, we would expect both assessments to be equal on average. Any deviations should be approximately symmetric. From Figure 4 we observe however that it is more likely that the subjective assessment measure is higher when there is a difference between the two measures. In 5.1 percent of the cases the subjective assessment is lower compared to the objective assessment, in 13.9 percent it is higher. Since the teacher's assessment makes use of the information revealed by the test score, the teacher has access to a child's educational history in elementary school and has knowledge about a child's background characteristics and earlier test scores, she has an information advantage. ${ }^{15}$

\footnotetext{
${ }^{15}$ If we use 11 different tracks instead of 8, 32.9 percent of all children is faced with different assessment measures. Of these children 83 percent receives a higher subjective assessment measure of ability.
} 


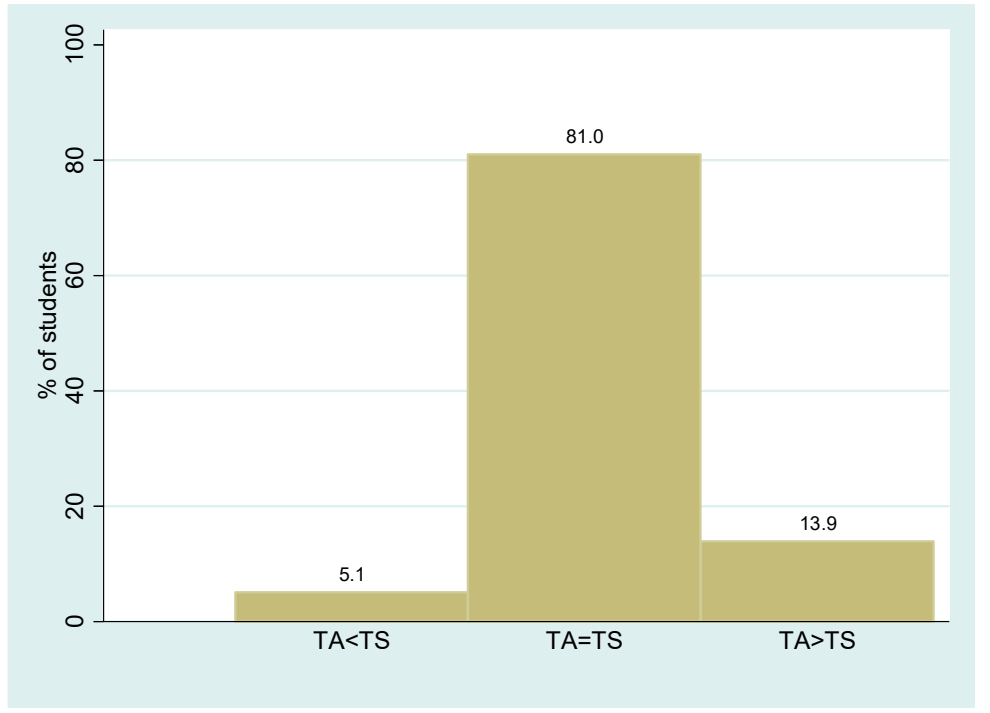

Figure 4: Similarities of and differences between objective and subjective assessment measures

Note: $n=4,500$. The three columns add up to 100 percent. Objective assessment measures are test scores in 6th grade $\left(T S_{i}\right)$; subjective assessment measures are teacher assessments in 6th grade $\left(T A_{i}\right)$.

When we look into the differences between the test score, the teacher's assessment and track placement in 7th grade, we find that most of the differences we observe are related to gender and social-economic status. Table C1 and C2 in the Appendix show descriptive statistics and estimated marginal effects from ordered probit models. From these analyses we observe the following main patterns. First, we observe that girls seem more likely to receive a teacher's assessment that is higher compared to the test score, while they seem less likely to receive a teacher's assessment that is lower compared to the test score. In addition, girls are more likely to receive a track placement equal to the subjective assessment measure and more likely to have a test score that is lower compared to their track placement. This suggests that girls not only get a more favorable assessment from the elementary school teacher, but also with regard to track placement in secondary school. Second, from the labor market position of the mother we observe that children who have mothers who are unemployed are less likely to receive a subjective assessment that is higher than the objective assessment. These children are also less likely to have a test score that is lower than their initial track placement and more likely to receive a track placement that is equal to their test score. Furthermore, children of mothers who are sick/unable to work are less likely to receive a subjective assessment that is higher than the objective assessment. These children are also less likely to receive a test score that is lower than their track placement and more likely to receive a track placement that is equal to or lower than their objective assessment. This indicates that secondary schools seem to allocate these students unfavorably. In our data over 70 per- 
cent of the mothers who are unemployed and over 85 percent of the mothers who are sick \unable to work completed only lower education or vocational education. Burgess and Greaves (2013) obtain similar results with respect to ethnic minorities, which they attribute to negative stereotyping of particular groups in society.

\subsubsection{Determinants of track placement}

Figure 5 shows how children are allocated to tracks according to the two assessment measures. The figure is divided into three panels. The first panel documents track placement of children who are faced with $T A_{i}<T S_{i}$. The second panel displays track placement of those with $T A_{i}=T S_{i}$ and the final panel shows placement of those with $T A_{i}>T S_{i}$. Track placement can be equal to either $T A_{i}$ or $T S_{i}$ in the upper and lower panel or $T A_{i}=T S_{i}$ in the middle panel of Figure 5. In addition, placement in the category labeled "else" represents those children who are placed in a track that was recommended by neither the subjective assessment nor the objective assessment measure. In almost all of these cases the subjective and objective assessment measures differ by more than three levels and track placement is in between these two measures. In some cases track placement is higher or lower than both assessment measures indicate. In the latter case our data suggest that it is more likely that track placement is higher than both assessment measures would merit.

The bars in Panel A of Figure 5 suggest that when $T A_{i}<T S_{i}$ children are more likely to be placed according to $T A_{i}$ than $T S_{i}$ (40.2 percent vs. 17.9 percent). At first sight, this suggests that secondary schools seem to act in a relatively conservative way by following the lower of the two signals. They seem to attach more value to the teacher's assessment of the child's ability relative to the test score. At the same time, the share of children placed in tracks that do not directly correspond with one of the assessment measures is relatively large (41.9 percent). The numbers in Panel $\mathrm{C}$ suggest that secondary schools are more likely to follow the teacher's assessment even when it is higher than the test score. More than two thirds of the population with $T A_{i}>T S_{i}$ is placed according to $T A_{i}$. Also the share of children placed in tracks that do not directly correspond with the assessment measures is relatively low compared to the case in which $T A_{i}<T S_{i}$. Combined with the information from Panel A, a picture emerges that secondary schools attach more value to the teacher's assessment of children's ability relative to test scores. Note that the teacher's assessment of a child's ability is on average higher than the test score would suggest. Finally, the statistics in Panel B of Figure 5 reveal that when both assessment measures give the same signal about children's ability almost all children are placed in the corresponding track. Nevertheless, 7.3 percent of the children are allocated to a different track. Upon closer inspection most of these children are allocated to higher tracks relative to what the teacher's assessment and the test score recommend. Overall, it seems to be the case that secondary schools have a preference to allocate children according to the teacher's assessment measure and/or according to the assessment that signals the highest ability. 
A: $T A_{i}<T S_{i}$

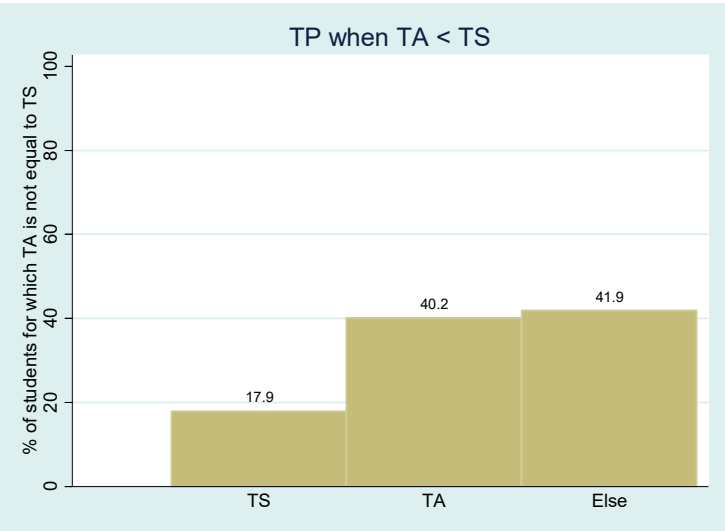

B: $T A_{i}=T S_{i}$

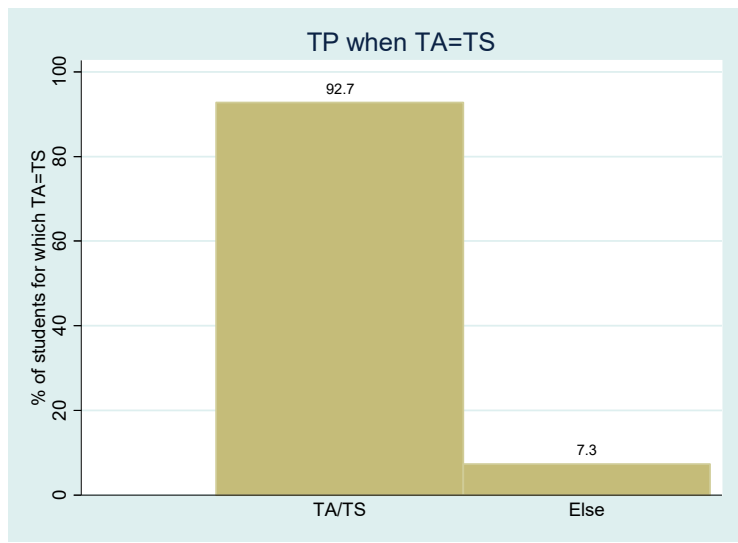

$\mathrm{C}: T A_{i}>T S_{i}$

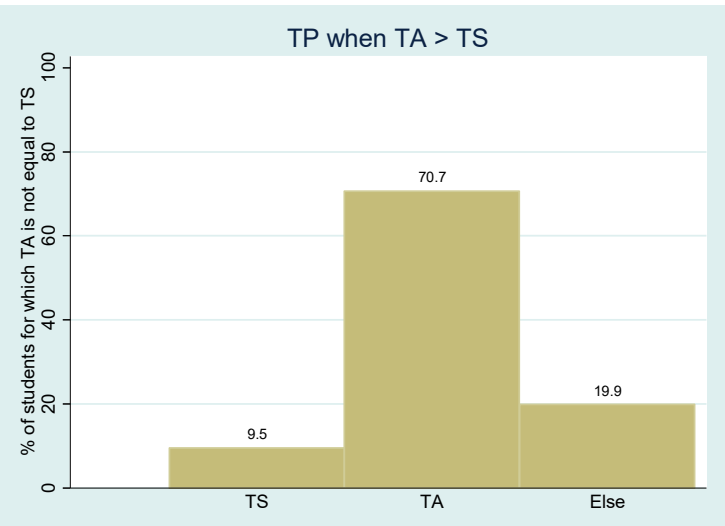

Figure 5: Track placement for different objective and subjective assessment measures 
We continue by estimating the determinants of track placement in 7th grade. Table 4 presents the estimation results of equation (4). The estimates are coefficients from ordered probit models where track placement (measured between 1 and 8) is the dependent variable. In the first two columns we either use the test score or the teacher's assessment to estimate the determinants of track placement. As expected, we observe a strong positive relation between both the test score and track placement and the teacher's assessment and track placement. When we rescale the test score and the teacher's assessment by the cut points in their respective regressions we observe that a one standard deviation increase in the test score (teacher's assessment) bridges 35.1 percent (35.2 percent) of the gap between the lowest and the highest track placement, without adding any other control variables. In column (3) we add both the test score and the teacher's assessment to the model. The test score and the teacher's assessment do not seem to be orthogonal. When the test score and the teacher's assessment are both added to the model we observe that a one standard deviation increase in the test score (teacher's assessment) bridges 11.7 percent (25.2 percent) of the gap between the lowest and the highest track placement, without adding any other control variables. The difference in coefficients between the test score and the teacher's assessment is significant. An important observation is that the teacher's assessment seems to be a better predictor of track placement than the test score. In columns (4)-(6) we add control variables, elementary school fixed effects and a measure of children's GPA on math and language tests in previous years, respectively. Our estimates remain approximately the same in these different specifications. Overall, both the teacher's assessment and the test score seem likely to be important determinants of track placement in 7th grade. From our final specification in column (6) we conclude that the teacher's assessment appears to play a more important role in determining track placement compared to the test score. The estimated coefficient is about twice as large. This finding seems to be consistent with the subjective assessment measure having more information about the child's ability than the objective assessment measure.

In columns (7)-(12) we investigate the determinants of track placement in 9th grade. Track placement in 9th grade consists of six categories as over time the combination tracks disappear and children get allocated to their final track. ${ }^{16}$ Columns (7)-(9) show the results for the sample of children who have not switched tracks between 7th and 9th grade. We obtain estimated coefficients that suggest that the teacher's assessment is still the best predictor of track placement for the children who have not switched tracks.

\footnotetext{
${ }^{16}$ Secondary schools use combination tracks in the first year(s) of secondary education due to the uncertainty around ability. By using combination tracks schools can observe performance and allocate children to the most appropriate track after learning more about the ability. The combination tracks disappear into the neighboring main tracks. For example, children placed in track T2/T3 in the first year are expected to be replaced in track T2 or T3 in year 2 or 3. Such a re-placement is not considered as switching tracks.
} 
Columns (10)-(12) show the results for the entire sample of children we observe in 9th grade. We obtain a set of coefficients that suggests that there is no statistically significant difference between the predictive power of the test score and the teacher's assessment. These results indicate that the teacher is the best predictor of children's' ability both in 7th grade and later on in the children's secondary school career. However, the results also show that the predictive power of the teacher compared to the predictive power of the test score falls over time. A possible explanation for this is that children who were initially assessed too favorable by the teacher have switched to a lower track in the first three years of secondary education.

To take into account the covariation between the teacher's assessment and the test score we also estimate the predictive power of the teacher's assessment on track placement in 7th and 9th grade after correcting for the predictive power of the test score. This seems a natural thing to do because the teacher knows the test score of the child when the assessment is made. We find that the teacher's assessment is still highly predictive of track placement in 7th and 9th grade after controlling for the covariation between the teacher's assessment and the test score. The estimated coefficients of these analyses can be found in Appendix E. 


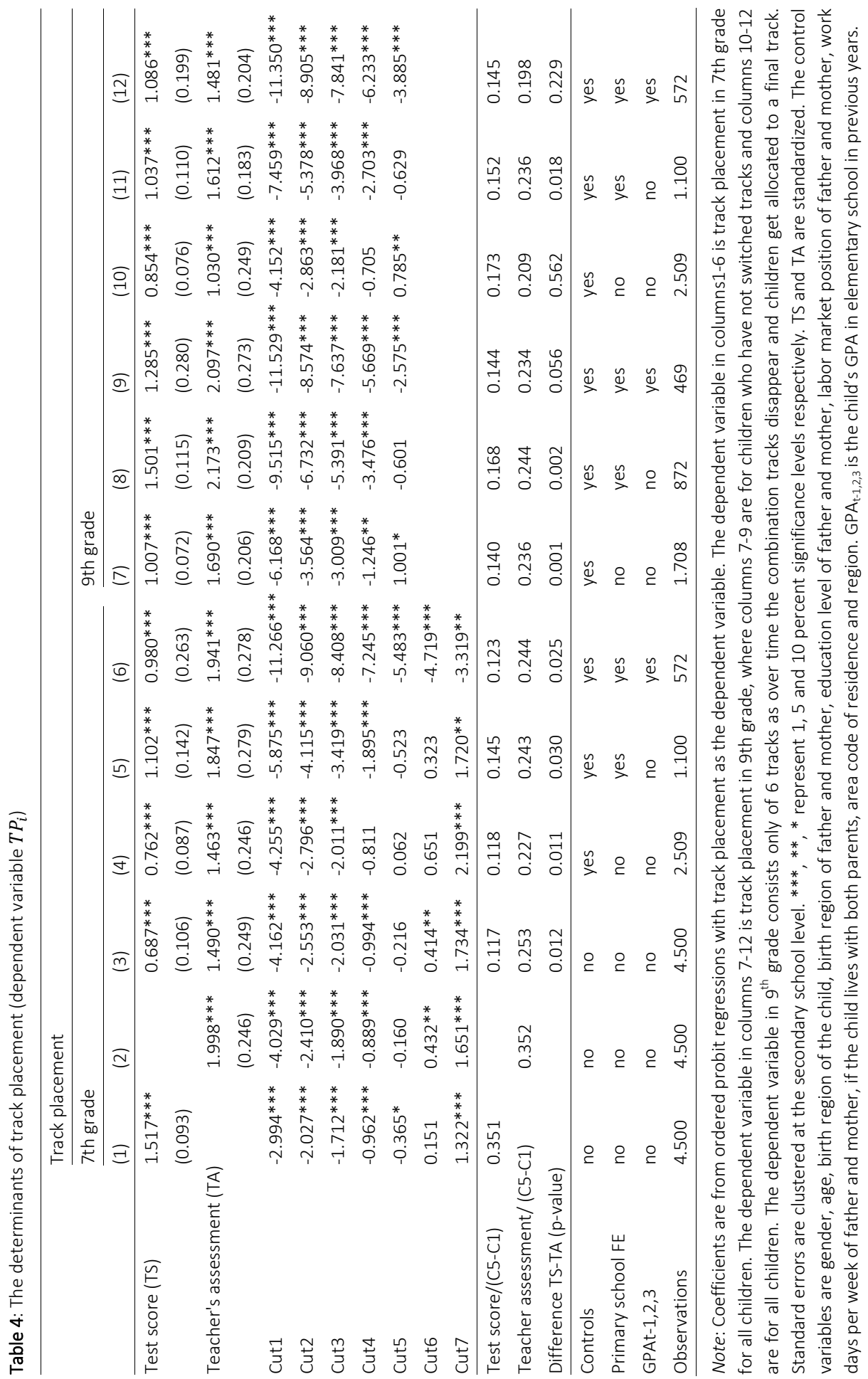




\subsection{Switching tracks}

Children could be allocated suboptimally across different levels of secondary education. Suboptimal allocation encourages switching, which comes with a cost of suboptimal human capital investments and adjustment cost. In addition, children could have to stay for an additional period in the secondary education system because transitions between tracks are not always smooth. Note that switching tracks is the most drastic measure that secondary schools can take when children are not performing up to expectations. For example, the first option for children who are not able to keep up with the required level is to let them repeat the same grade. In the event that the school believes that grade retention will be insufficient, children have to switch tracks. Furthermore, it is possible that the costs of switching tracks are different when children switch up tracks compared to when they switch down tracks. It is likely that the costs of switching tracks for children who switch down are more related to demotivation and that the cost of switching up tracks are more related to previous underinvestment of human capital.

\subsubsection{Documenting switchers}

Figure 3 shows that approximately 24 percent of our sample of children switches tracks between 7th and 9th grade. Most of the switches (55 percent) happen from 8th to 9th grade. Approximately 71 percent of all children who switch between tracks switch down and only about 29 percent of all children who switch between tracks switch up. ${ }^{17}$ In Figure 3 we observe that most children who switch tracks switch two tracks up or down measured on the track scale from 1-11 as described in Figure 1. Furthermore, correlations between the teacher's assessment, test score, track placement and switching are negative. This is due to the nature of our data. Since we observe track switches until 9th grade, we capture almost all of the switches in the T1 track but we capture less of the switches in the T2 and T3 tracks as these children still have the opportunity to switch tracks after 9th grade. This finding is confirmed by results from the Inspectorate of Education for all children in The Netherlands (Inspectorate of Education, 2007). Appendix $D$ documents the characteristics of switchers in detail and presents the coefficients of probit models.

\footnotetext{
${ }^{17}$ Our data includes 1,266 switchers. Of these switchers 43 children switch down/up multiple tracks and 65 children switch both up and down between 7th and 9th grade. We analyze overall switches which means that we refer to 1,158 switchers (i.e., 1,266 - $43-65=1,158$ ). Figure 3 includes all 1,266 switchers.
} 


\section{Total switches}

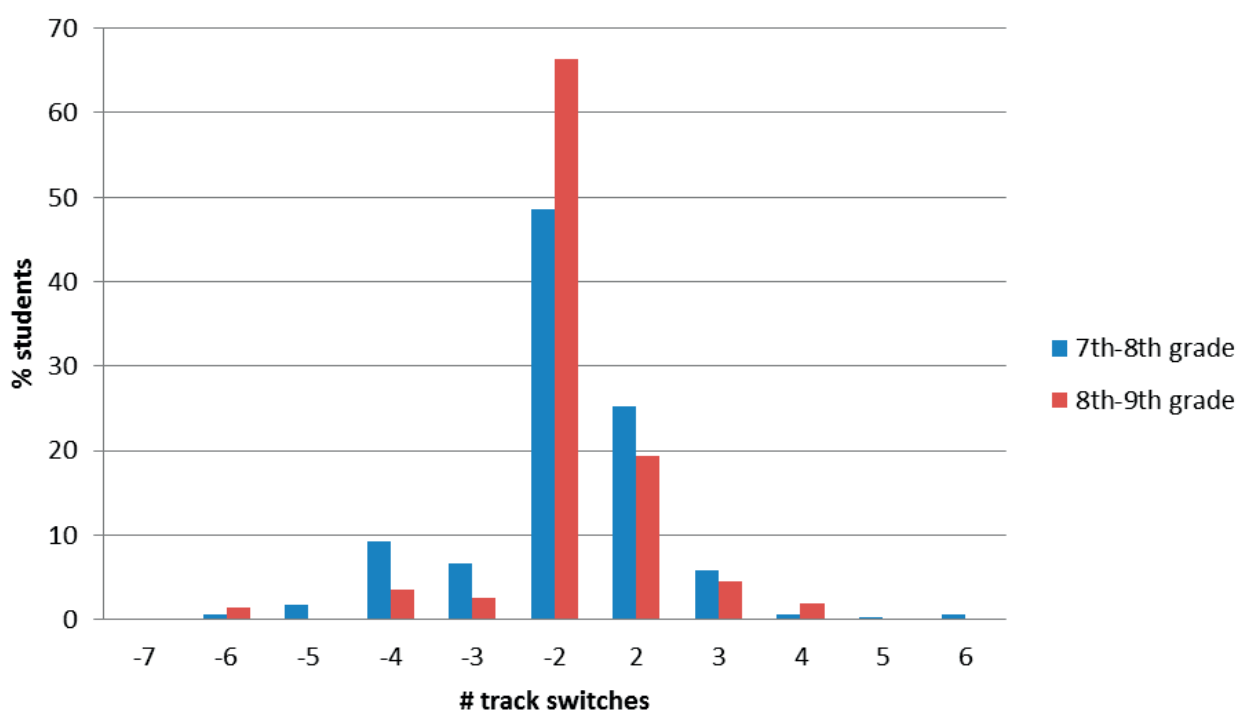

Figure 3: Track switching between initial track allocation in 7th grade and 9th grade

Note: The figure shows the total number of switchers. Negative numbers on the horizontal axis are defined as switches down and positive numbers as switches up. The blue and red bars add up to 100 percent individually.

Figure 6 shows track switching by differences in objective and subjective assessment measures. The figure is divided into three panels. The first panel documents the track switching of children who are faced with $T A_{i}<T S_{i}$. The second panel displays track switching of those with $T A_{i}=T S_{i}$ and the final panel shows switching of those with $T A_{i}>T S_{i}$. Similar to Figure 5, track placement is equal to either $T A_{i}, T S_{i}$ or "else". The category labeled "else" represents those children who are placed in different tracks than the measures advised. Note that the number of switchers is determined on the basis of all 11 possible tracks.

The bars in Panel A suggest that when $T A_{i}<T S_{i}$ fewer children switch between tracks when they have been placed according to $T A_{i}$ and more children switch when they are placed according to $T S_{i}$ or in another track than either measurement pointed at. Comparison of $T A_{i}$ and $T S_{i}$ in Panel A suggests that those who are placed according to $T S_{i}$ are more likely to switch up consistent with the argumentation that the teacher's assessment is generally more generous about the children's ability than the test score. 
A: $T A_{i}<T S_{i}$

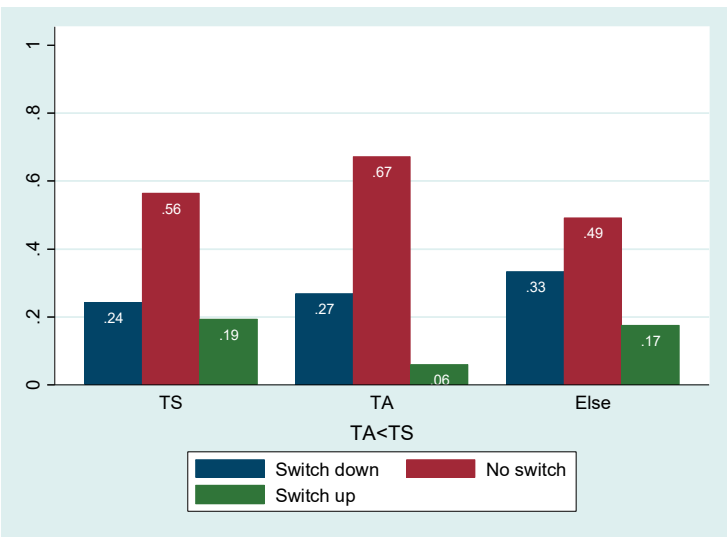

B: $T A_{i}=T S_{i}$

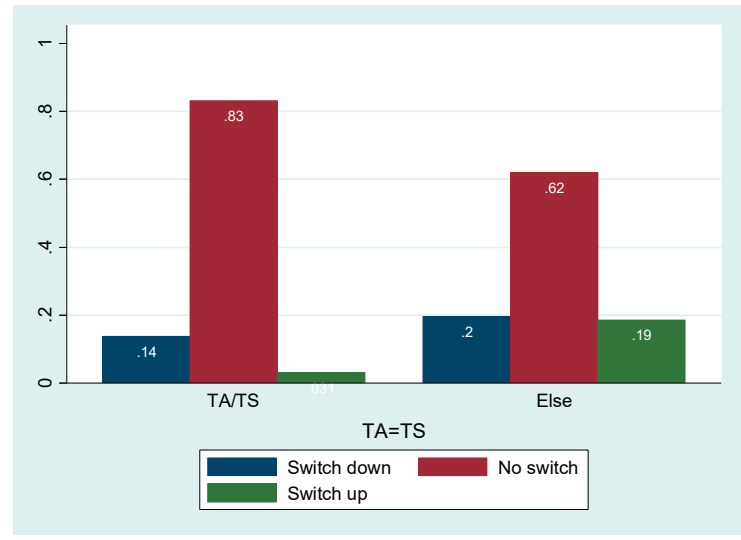

$\mathrm{C}: T A_{i}>T S_{i}$

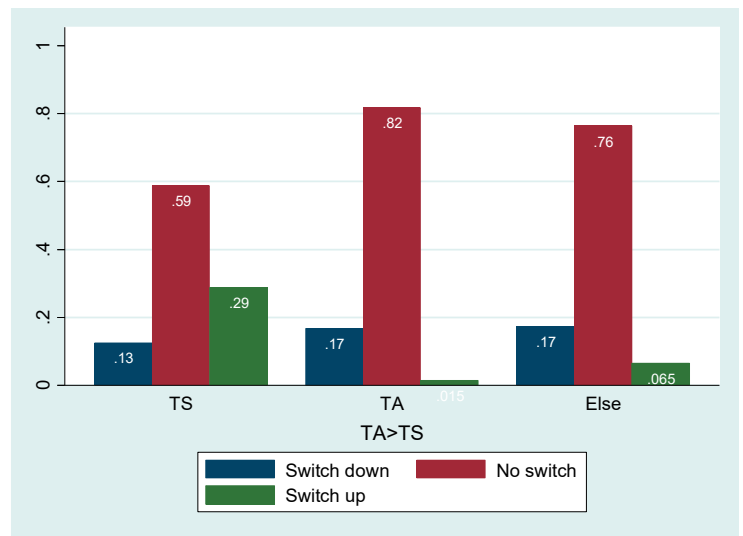

Figure 6: Track switching for different objective and subjective assessment measures 
The numbers in Panel $\mathrm{C}$ suggest that although secondary schools are more likely to follow the teacher's assessment, even when it is higher than the test score, the number of switchers is relatively low when children are allocated based on $T A_{i}$. In addition, if children are placed according to $T S_{i}$ more children switch up. Finally, the statistics in Panel B of Figure 6 reveal that children switch less often if $T P_{i}=T A_{i}=T S_{i}$. The overall picture that emerges from Figure 6 is that children placed according to $T A_{i}$ have a lower probability to switch tracks relative to children placed according to $T S_{i}$. This conclusion seems to hold regardless of the difference between $T A_{i}$ and $T S_{i}$. In addition, children allocated in accordance with the highest (lowest) of the two assessment measures seem to have a higher probability to switch down (up) a track, which is consistent with overassessment (underassessment) of a child's ability.

\subsubsection{Determinants of track switching}

We continue by presenting the results of analysing probit models in which we estimate the probability of switching. Columns (1)-(3) in Table 5 present marginal effects for overall switching, columns (4)-(6) present marginal effects for switching down and columns (7)-(9) present marginal effects for switching up. The third specification in all three models includes control variables and secondary school fixed effects. Furthermore, standard errors are clustered at the secondary school level.

The estimated coefficients in column (3) suggest that children who are placed in a track according to the teacher's assessment (and not according to the test score) are 9.8 percent more likely to switch tracks, children who are placed according to the test score (and not according to the teacher assessment) are 17.9 percent more likely to switch tracks and children who are placed not according to the teacher's assessment or the test score are 16.7 percent more likely to switch tracks compared to the base level. $^{18}$

The coefficients displayed in column (6) suggest that children placed in a track according to the teacher's assessment (and not according to their test score) are more likely to switch down, whereas children who are placed according to their test score (and not according to their teacher's assessment) or according to neither of the assessment measures are not more likely to switch down. Finally, from the estimated coefficients shown in column (9) we observe that children who are placed in a track according to their test score (and not according to their teacher's assessment) and children who are placed according to neither of the assessment measures are more likely to switch up, whereas children placed according to their teacher's assessment (and not according to their test score) are not more likely to switch down. Finally, children for whom $T P_{i}=T A_{i}=T S_{i}$ are least likely to switch tracks. For these children there is only little uncertainty about the most efficient track placement. These results

\footnotetext{
${ }^{18}$ The base level in all these analyses is when $T P_{i}=T A_{i}=T S_{i}$ or $T P_{i}=T A_{i} \& T P_{i}=T S_{i}$ but $T A_{i} \neq T S_{i}$. For example: $T A=T 3, T S=T 2$ and $P L=T 2 / T 3$.
} 
seem to suggest that children are less likely to switch when they are allocated to tracks based on the teacher's assessment. However, the teacher's assessment is generally more favourable than the test score about a child's ability. Therefore, children who are allocated according to the teacher's assessment are more likely to switch down and children allocated to the test score are more likely to switch up. ${ }^{19}$

Table 5: Switching between tracks

\begin{tabular}{|c|c|c|c|c|c|c|c|c|c|}
\hline & \multicolumn{3}{|l|}{ Switch } & \multicolumn{3}{|c|}{ Switch down } & \multicolumn{3}{|c|}{ Switch up } \\
\hline & $(1)$ & $(2)$ & (3) & $(4)$ & (5) & $(6)$ & (7) & (8) & (9) \\
\hline \multirow[t]{2}{*}{$\mathrm{PL}=\mathrm{TA} \neq \mathrm{TS}$} & $0.099 * * *$ & $* 0.093 * * *$ & * $0.098 * * *$ & * $0.103 * * *$ & $* 0.091 * * *$ & $* 0.085 * * *$ & ${ }^{k}-0.017$ & -0.010 & -0.000 \\
\hline & $(0.029)$ & $(0.030)$ & $(0.032)$ & $(0.026)$ & $(0.025)$ & $(0.027)$ & $(0.012)$ & $(0.010)$ & $(0.007)$ \\
\hline \multirow[t]{2}{*}{$P L=T S \neq T A$} & $0.319 * * *$ & $* 0.161 * * *$ & * $0.179 * *$ & $0.102 * * *$ & * 0.024 & 0.025 & $0.252 * *$ & $0.096 * * *$ & $* 0.084 * *$ \\
\hline & $(0.101)$ & $(0.049)$ & $(0.078)$ & $(0.038)$ & $(0.043)$ & $(0.038)$ & $(0.117)$ & $(0.036)$ & $(0.042)$ \\
\hline \multirow[t]{2}{*}{$\mathrm{PL} \neq \mathrm{TA} \neq \mathrm{TS}$} & $0.269 * * *$ & $* 0.197 * * *$ & $* 0.167 * *$ & $0.131^{* *}$ & 0.090 & 0.079 & $0.164^{*}$ & $0.105^{* * *}$ & $* 0.059 *$ \\
\hline & $(0.100)$ & $(0.065)$ & $(0.081)$ & $(0.060)$ & $(0.073)$ & $(0.062)$ & $(0.097)$ & (0.038) & $(0.035)$ \\
\hline Controls & no & no & yes & no & no & yes & no & no & yes \\
\hline Secondary school FE & no & yes & yes & no & yes & yes & no & yes & yes \\
\hline Observations & 4,019 & 3,836 & 2499 & 4,019 & 3,664 & 2281 & 4,019 & 3,031 & 1750 \\
\hline
\end{tabular}

Note: Probit regressions with marginal effects. Standard errors are clustered at the secondary school level. $* * *, * *, *$, at 1 percent, 5 percent and 10 percent significance levels respectively. The base level in these regressions is when $\mathrm{PL}=\mathrm{TA}=\mathrm{TS}$ and when $\mathrm{PL}=\mathrm{TA} \& \mathrm{PL}=\mathrm{TS}$ but $\mathrm{TA} \neq \mathrm{TS}$. This can happen for example when $T A=T 3, T S=T 2$ and $P L=T 2 / T 3$. In column 1, the base level represents 52,97 percent of the children. The three other categories shown in the table represent 30,28 percent, 5,8 percent and 10,95 percent respectively. We control for gender, age, birth region of the child, birth region of the father and mother, education level of the father and mother, labor market position of father and mother, if the child lives with both parents, area code of residence and region.

\subsection{Test scores in 9th grade}

For a subsample of children we have data about a math and language test score in 9th grade. Children were randomly assigned questions in either math, language or both. We use the answers to 11 math questions or 8 language questions that have been asked to children in all tracks. This results in test scores of $n=1,812$ children.

Table 6 documents the estimated coefficients of an analysis in which we investigate the effect of the teacher's assessment and test scores in 6th grade on the test score in 9 th grade. The coefficients shown are coefficients from OLS regressions in which the dependent variable is the child's score on the test in 9th grade. The test score and the teacher's assessment are standardized and standard errors are clustered at the second-

\footnotetext{
${ }^{19}$ In Appendix F we look at the type of school children attend. We see that most of the track switching takes place within the pre-vocational education tracks. This is consistent with findings from the Dutch Education Inspectorate. Furthermore, in the switching analyses we control for the type of school (level of comprehensiveness) children attend.
} 
ary school level. Columns (1) and (2) show that both the test score and the teacher's assessment in 6th grade are positively and statistically significant related to children's test score in 9th grade. Put together, the teacher's assessment seems to be able to predict the test score in 9th grade more accurately. This effect is robust to the inclusion of secondary school fixed effects, which suggests that this effect is not specific to certain (characteristics of) schools. ${ }^{20}$

We also estimate the predictive power of the teacher's assessment for children's test scores in 9th grade after controlling for the covariation between the teacher's assessment and the test score in 6th grade. This analysis results in an estimated coefficient of 0.0395 that is statistically significant at the 10 percent level. So, even after controlling for the covariation between the teacher's assessment and the test score, the assessment seems to be more predictive of later test scores compared to the 6th grade test score. It seems likely that the teacher's assessment also captures other skills, besides math and language, that are important determinants of children's school career.

Table 6: Determinants of scores on math or language tests in 9th grade

\begin{tabular}{lllll}
\hline & \multicolumn{4}{l}{ math or language test 9th grade } \\
\cline { 2 - 4 } & $(1)$ & $(2)$ & $(3)$ & $(4)$ \\
\hline Test score & $0.027^{*}$ & & 0.006 & 0.002 \\
Teacher's assessment & $(0.014)$ & & $(0.015)$ & $(0.016)$ \\
Controls & & $0.071^{* * *}$ & $0.067^{* * *}$ & $0.060^{* * *}$ \\
Secondary school FE & & $(0.016)$ & $(0.018)$ & $(0.018)$ \\
Observations & yes & yes & yes & yes \\
Adjusted R-squared & no & no & no & yes \\
\hline
\end{tabular}

Note: Estimates are coefficients from OLS regressions. The dependent variable is the children's score on a math or language test in 9th grade. Test score and teacher advice are standardized. Standard errors are clustered at the secondary school level. $* * *, * *, *$, at 1 percent, 5 percent and 10 percent significance levels respectively. We control for track placement in 7th grade, gender, age, region of birth of child, father and mother, education level of father and mother, labor market position of father and mother, days worked of father and mother, if the child lives with both parents, area code of residence and region.

\footnotetext{
${ }^{20}$ The test in 9th grade is limited (8 to 11 questions) and is a low-stakes test. The correlation between children's test score in 6th grade and their test score in 9th grade is 0.16 and statistically significant at the 1 percent level. For the analyses in Table 6 one could argue that the teacher's assessment is better at predicting children's test score in 9th grade as the teacher's assessment likely captures other elements next to children's ability that affect children's test score on a low-stakes test more compared to their test score on a high-stakes test. The test score in 6th grade could be a better predictor of children's test score on a high-stakes test but such information is unavailable.
} 
Table 7 shows the results of an analysis in which we explain the effects of switching on 9 th grade test scores. We compare children who have switched tracks to children who have not. The coefficients are from OLS regressions with the test score in 9th grade as the dependent variable. The standard errors are clustered at the secondary school level. Table 7 has three panels. The top panel presents estimates for overall switching, the middle panel presents estimates for switching down and the bottom panel presents estimates for switching up. In the top panel the coefficients for switching show that for children in the pre-vocational track (T1c in Figure 1), the pre-higher education track and the pre-university track there is a statistically significant negative effect of switching tracks on the 9th grade test score. Second, the coefficients displayed in the middle panel of the table suggest that children in the pre-vocational education track (GL) and children in the pre-higher education track experience a statistically significant negative effect of switching down tracks. Finally, in the bottom panel of Table 7 the displayed coefficients suggest that children in the pre-vocational education track (T1d) and children in the pre-university track experience a statistically significant negative effect of switching up tracks. Overall, it seems to be the case that children who have switched tracks experience a negative effect on their test score in 9th grade compared to children who have not switched tracks. ${ }^{21}$

\footnotetext{
${ }^{21}$ Here we assume that track switches are caused by poor performance and not related to unobservable characteristics, such as illness or behavioral problems.
} 


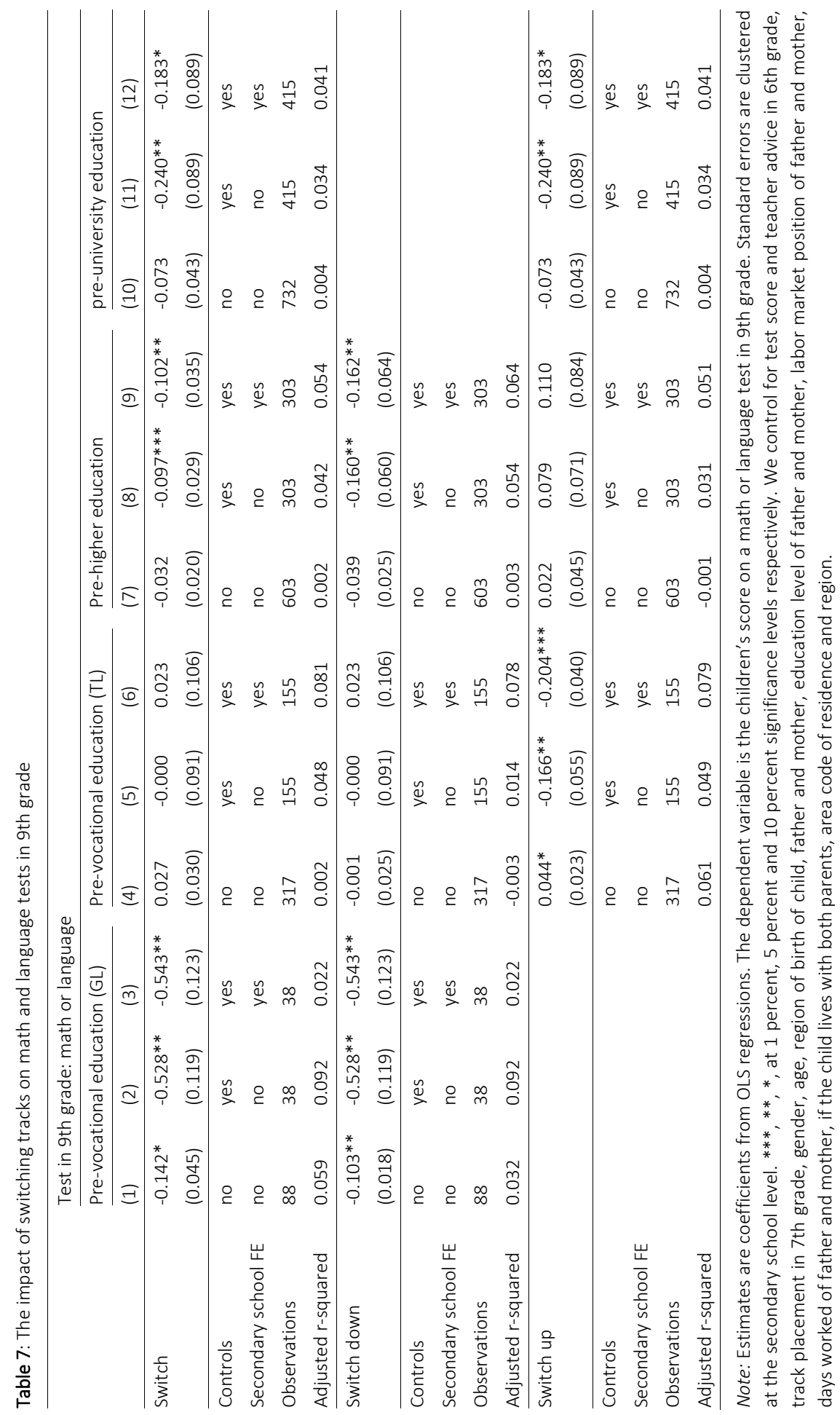




\subsection{Conclusions}

This paper documents and interprets the determinants of track placement in the transition from primary to secondary education and the first three years of secondary education. Our main findings suggest that both objective and subjective assessment measures of ability in 6th grade predict track placement in 7th grade. The subjective assessment measure of the teacher contains more information as the teacher has more knowledge about the child's socio-economic background, the objective test score in 6th grade, previous test scores and other characteristics of the child. Our estimates suggest that the teacher's assessment in elementary school is a better predictor of a child's track placement and subsequent performance in secondary school compared to the 6th grade test score. We also observe that approximately 24 percent of our population of children switches tracks between 7th and 9th grade. We obtain a set of estimates that suggests that children are the least likely to switch when they are allocated to a track based on the teacher's assessment. However, when we look at switching down and up separately our estimates suggest that children placed in tracks according to the teacher's assessment are more likely to switch down and children placed in tracks according to the test score and children allocated not according to any of these assessment measures are more likely to switch up. Finally, test scores in 9th grade seem to be better predicted by the teacher's assessment compared to 6th grade test scores. In addition, switchers obtain lower test scores on this 9th grade test relative to children who remain in their initial tracks.

This research uses a straightforward research design and explores a dataset which includes information on assessment measures, track placement and subsequent performance. Future work could extend our analysis by using for example more detailed information about different parts of the objective assessment measure. Test scores could be decomposed in a language and math component, which could benefit the analysis of allocation and performance in secondary school. In addition, the relationship with individual characteristics is interesting to explore further. We have used a limited number of covariates because of data limitations, but future data collection efforts also include measures of behavior and personality traits. This information could help in estimating more precise coefficients and possibly additional determinants of performance and allocation. Finally, the children in our database are followed throughout the rest of their educational careers. This opens avenues for future research about longer term effects of track allocation. 


\section{References}

Bernardi, M., M. Bratti and G. De Simone (2014). "I wish I knew..." - Misperceived ability, school track counselling services and performances in upper secondary education, IZA Discussion Paper no. 7940, http://ftp.iza.org/dp7940.pdf.

Bosch, N., A. Deelen and R. Euwals (2010). "Is part-time employment here to Stay? Working hours of Dutch women over successive generations, Labor, vol. 24, no. 1, pp. 35-54.

Brunello G. and D. Checchi (2007). Does school tracking affect equality of opportunity? New international evidence, Economic Policy, vol. 22, no. 52, pp. 781-861.

Burgess, S. and E. Greaves (2013). Test scores, subjective assessment, and stereotyping of ethnic minorities, Journal of Labor Economics, vol. 31, no. 3, pp. 535-576.

Cito (2012). Terugblik en resultaten 2012. Eindtoets Basisonderwijs Groep 8, Cito, Arnhem.

Cornwell, C., D.B. Mustard and J. van Parys (2012). Noncognitive skills and the gender disparities in test scores and teacher assessments: evidence from primary school, Journal of Human Resources, vol. 48, no. 1, pp. 236-264.

Currie, J. and D. Thomas (1999). Early test scores, socioeconomic status and future outcomes, NBER Working Paper no. 6943, http://www.nber.org/papers/w6943.

Dee, T.S. (2005). A teacher like me: does race, ethnicity or gender matter? American Economic Review, vol. 95, no. 2, pp. 158-165.

Diris, R. (2012). The economics of the school curriculum, PhD thesis, Maastricht University.

Education Inspectorate (2007). Transition from primary to secondary education. http://www.onderwijsinspectie.nl/binaries/content/assets/Actueel_publicaties/2007/Aansluiting+vo+bo + printversie.pdf

van Elk, R., M. van der Steeg and D. Webbink (2009). The effect of early tracking on participation in higher education, CPB Document no. 182, http://www.cpb.nl/en/publication/effect-early-tracking-participationhigher-education.

Fairlie, R.W., Hoffmann, F and Oreopoulos, P. (2014). A community college instructor like me: race and ethnicity interactions in the classroom. American Economic Review, vol. 104, no. 8, pp. 2567-2591.

Gibbons, S. and A. Chevalier (2008). Assessment and age 16+ education participation, Research Papers in Education, vol. 23, no. 2, pp. 113-123.

Golsteyn, B.H.H. and T. Schils (2014). Gender gaps in primary school achievement: A decomposition into endowment and returns to IQ and non-cognitive factors, Economics of Education Review, 41: 176-187

Hanushek, E. and L. Woessmann (2006). Does early tracking affect educational inequality and performance? Differences-in-differences evidence across countries, Economic Journal, vol. 116, no. 510, pp. c63-c76.

Kautz, T., J.J. Heckman, R. Diris, B. ter Weel and L. Borghans (2014). Fostering and measuring skills: Improving cognitive and non-cognitive skills to promote lifetime success, Working Paper, University of Chicago.

Lavy, V. (2008). Do gender stereotypes reduce girls' human capital outcomes? Evidence from a natural experiment, Journal of Public Economics, vol. 92, no. 10-11, pp. 2083-2105.

Lindahl, E. (2007). Comparing teachers' assessments and national test results - evidence from Sweden, IFAU Working Paper no. 2007:24.

Murnane, J., J.B. Willett and F. Levy (1995). The growing importance of cognitive skills in wage determination, Review of Economics and Statistics, vol. 77, no. 2, pp. 251-266.

OECD (2007). Thematic review of tertiary education - The Netherlands, Country Note, OECD, Paris.

Segal, C. (2008). Classroom behavior, Journal of Human Resources, vol. 43, no. 4, pp. 783-814.

Timmermans, A., H. Kuyper and G. van der Werf (2012). Schooladviezen en onderwijsloopbanen. Voorkomen, risicofactoren en gevolgen van onder- en overadvisering, Gronings Instituut voor Onderwijs van Onderwijs, Rijksuniversteit Groningen.

Woessmann, L. (2004). Institutional comparisons in educational production, Journal for Institutional Comparisons, vol. 2, no. 4, pp. 3-6. 


\section{Appendix}

This appendix presents supporting material. The data come from a unique dataset on the educational development of children in a given region (Limburg) of the Netherlands, collected by researchers from Maastricht University. These data are collected in a cooperative project with (primary and secondary) schools, school boards and municipalities to analyze school performance in order to foster educational improvement. After selecting children for whom we have information on their test score, teacher assessment and track placement we retain a working sample of $n=4,500$ children.

In Section A we discuss the bivariate correlation coefficients of all of our outcomes measures and covariates used in our analyses. In section B we investigate whether or not individual characteristics are able to predict whether children end up in our sample of analyses. Section C1 presents an initial overview of whether the differences between the test score, the teacher assessment and track placement are related to individual characteristics. Section C2 follows up on Section C1 and presents the marginal effects of the differences between the test score, the teacher assessment and track placement. In Section D1 we move to track switching where we first provide an overview of how switching is related to individual characteristics. We distinguish between switching up and down tracks. Afterwards in Section D2 we observe the marginal effects of probit models for switching. 


\section{A. Correlations}

Table A shows the bivariate correlation coefficients of our main variables of interest, $T S_{i}, T A_{i}$ and $T P_{i}$ as well as the covariates used in our analyses. We observe that girls seem to have a slightly lower test score compared to boys. Second, older children seem to have a lower teacher assessment, test score and track placement while they seem to switch tracks more. This could be due to repetition. Third, children who have a father or mother that was born further away from Limburg seem to have a lower teacher assessment, test score and track placement. Furthermore, children whose mother was born further away from Limburg seem to switch track more. Fourth, the education level of the father and mother is positively related to the teacher assessment, test score and track placement of the child and negatively related to switching tracks. Fifth, it seems that there is a negative relationship between the father and mother not doing paid work and teacher assessment, test score and track placement of the child. Sixth, it seems that there is a positive relationship between the child living with both parents and the teacher assessment, test score and track placement. Seventh, workdays per week seems to be negatively correlated with teacher assessment, test score and track placement. The group of children that receives the highest teacher assessment, test score and track placement is largest when the father and/or mother work 3-4 days per week. Correlations among teacher assessment, test score and track placement are high and positive. 
Does the teacher beat the test?

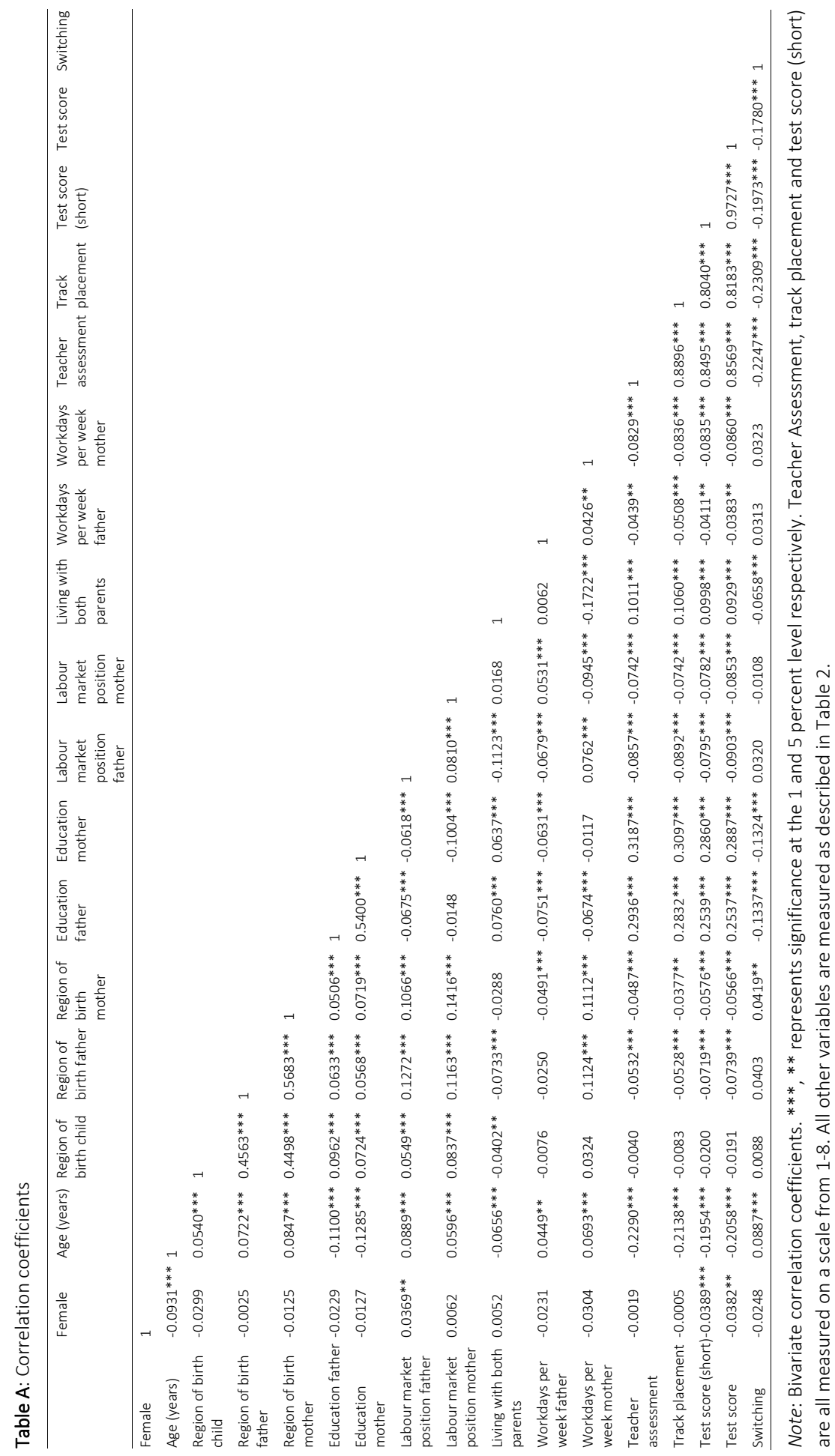




\section{B. Selection into the sample}

We address selection issues with regard to the sample we use for our analyses in Table B. Table B shows OLS estimates of whether characteristics of children are able to predict whether the child ends up in our sample for analyses or has missing data. The dependent variable is whether the child ends up in our sample (1) or has missing data (0). Children who end up in our sample for analyses are children for whom we have data on teacher assessment, test score and track placement in 7th grade.

Table B shows that after controlling for primary and secondary school fixed effects and clustering the standard errors at the secondary school level there are almost no individual characteristics that predict whether children end up in our sample for analysis or not. We use primary and secondary school fixed effects since we are concerned mainly about selection within schools, where schools only provide us with data about their best performing children and might leave out data about lower performing children. We expect that such selection would show up on children's SES data, such as education levels of parents. We cluster standard errors at the secondary school level since observations of children are not independent within the secondary school they attend. We do not find evidence at a five percent significance level that any of the characteristics of children is able to predict whether the child ends up in our sample for analyses. Since we do not find any observable characteristics of children that predict whether the child ends up in our sample, we assume that there are also no unobservable characteristics that distinguish the children in our sample from the children who are not in our sample. Note that there are missing observations in our analyses. This is due to the fact that we do not have information on all covariates for all children. Since we are specifically interested in whether any of these covariates predict selection into our sample of analyses we lose observations when data on covariates is missing. Furthermore, we only have elementary school fixed effects for children in the south of the region we obtained the data from. 
Table B: Selection into the sample

\begin{tabular}{|c|c|c|c|c|c|}
\hline & \multicolumn{5}{|c|}{ Selection into sample } \\
\hline & (1) & (2) & (3) & (4) & (5) \\
\hline \multirow[t]{2}{*}{ Female } & -0.005 & -0.009 & 0.002 & -0.006 & -0.006 \\
\hline & $(0.013)$ & $(0.017)$ & $(0.008)$ & (0.009) & (0.008) \\
\hline \multirow[t]{2}{*}{ Age 2nd quarter } & -0.002 & 0.022 & 0.003 & 0.021 & $0.021^{*}$ \\
\hline & $(0.019)$ & $(0.024)$ & $(0.011)$ & $(0.013)$ & $(0.011)$ \\
\hline \multirow[t]{2}{*}{ Age 3rd quarter } & $-0.032 *$ & -0.002 & $-0.029 * * *$ & $0.020^{*}$ & $0.020^{*}$ \\
\hline & $(0.018)$ & $(0.024)$ & $(0.011)$ & $(0.012)$ & $(0.011)$ \\
\hline \multirow[t]{2}{*}{ Age 4th quarter } & $0.033^{*}$ & -0.003 & 0.005 & 0.014 & 0.014 \\
\hline & (0.019) & $(0.025)$ & $(0.011)$ & $(0.013)$ & $(0.011)$ \\
\hline \multirow[t]{2}{*}{ Student born in other region NL } & $-0.055^{*}$ & -0.007 & -0.028 & -0.020 & -0.020 \\
\hline & $(0.029)$ & $(0.045)$ & $(0.018)$ & $(0.023)$ & $(0.023)$ \\
\hline \multirow[t]{2}{*}{ Student born abroad } & -0.015 & -0.037 & $-0.087 * * *$ & -0.025 & -0.025 \\
\hline & $(0.044)$ & $(0.060)$ & $(0.027)$ & $(0.031)$ & (0.029) \\
\hline \multirow[t]{2}{*}{ Father born in other region $\mathrm{NL}$} & -0.026 & 0.034 & -0.020 & $0.029 *$ & $0.029 *$ \\
\hline & $(0.022)$ & $(0.032)$ & $(0.013)$ & $(0.017)$ & $(0.016)$ \\
\hline \multirow[t]{2}{*}{ Father born abroad } & -0.037 & 0.012 & $-0.032 *$ & 0.007 & 0.007 \\
\hline & $(0.029)$ & $(0.036)$ & $(0.018)$ & (0.019) & $(0.015)$ \\
\hline \multirow[t]{2}{*}{ Mother born in other region NL } & 0.013 & -0.014 & -0.005 & -0.022 & -0.022 \\
\hline & $(0.022)$ & $(0.032)$ & $(0.013)$ & $(0.017)$ & $(0.021)$ \\
\hline \multirow[t]{2}{*}{ Mother born abroad } & $0.050 *$ & 0.014 & 0.015 & -0.010 & -0.010 \\
\hline & $(0.030)$ & $(0.037)$ & $(0.018)$ & (0.019) & $(0.017)$ \\
\hline \multirow[t]{2}{*}{ Father has vocational education } & $0.040 * *$ & 0.020 & $0.019 *$ & -0.011 & -0.011 \\
\hline & $(0.017)$ & $(0.023)$ & $(0.011)$ & $(0.012)$ & $(0.013)$ \\
\hline \multirow[t]{2}{*}{ Father has higher education } & $0.071^{* * *}$ & $0.079 * * *$ & 0.016 & -0.002 & -0.002 \\
\hline & $(0.022)$ & $(0.029)$ & $(0.013)$ & $(0.015)$ & $(0.013)$ \\
\hline \multirow[t]{2}{*}{ Father has university education } & $0.080 * * *$ & $0.105 * * *$ & $0.031^{* *}$ & 0.006 & 0.006 \\
\hline & $(0.023)$ & $(0.030)$ & $(0.014)$ & $(0.016)$ & $(0.014)$ \\
\hline \multirow[t]{2}{*}{ Mother has vocational education } & $0.034^{* *}$ & $0.079 * * *$ & $0.019 *$ & $0.025^{* *}$ & $0.025^{*}$ \\
\hline & $(0.017)$ & $(0.023)$ & $(0.010)$ & $(0.012)$ & $(0.014)$ \\
\hline \multirow[t]{2}{*}{ Mother has higher education } & $0.071^{* * *}$ & $0.096 * * *$ & 0.012 & 0.016 & 0.016 \\
\hline & $(0.023)$ & $(0.030)$ & $(0.014)$ & $(0.016)$ & $(0.016)$ \\
\hline \multirow[t]{2}{*}{ Mother has university education } & $0.092 * * *$ & $0.095 * * *$ & 0.004 & 0.020 & 0.020 \\
\hline & $(0.025)$ & $(0.033)$ & $(0.015)$ & $(0.017)$ & $(0.018)$ \\
\hline \multirow[t]{2}{*}{ Father is unemployed } & $-0.224 * *$ & $-0.352 * *$ & -0.035 & $-0.191 * *$ & -0.191 \\
\hline & $(0.111)$ & $(0.168)$ & $(0.068)$ & $(0.088)$ & $(0.137)$ \\
\hline \multirow[t]{2}{*}{ Father is sick/unable to work } & 0.081 & -0.116 & 0.008 & -0.030 & -0.030 \\
\hline & $(0.111)$ & $(0.152)$ & $(0.067)$ & $(0.080)$ & $(0.027)$ \\
\hline \multirow[t]{2}{*}{ Father other labour market position } & -0.201 & -0.086 & -0.098 & 0.003 & 0.003 \\
\hline & $(0.127)$ & $(0.148)$ & $(0.077)$ & $(0.078)$ & $(0.040)$ \\
\hline \multirow[t]{2}{*}{ Mother is unemployed } & -0.014 & 0.089 & 0.006 & -0.119 & -0.119 \\
\hline & $(0.100)$ & (0.169) & $(0.061)$ & (0.089) & $(0.086)$ \\
\hline
\end{tabular}


Chapter 3

\begin{tabular}{|c|c|c|c|c|c|}
\hline \multirow[t]{2}{*}{ Mother is sick/unable to work } & 0.066 & -0.013 & 0.033 & -0.065 & -0.065 \\
\hline & $(0.126)$ & $(0.152)$ & $(0.077)$ & (0.079) & (0.049) \\
\hline \multirow[t]{2}{*}{ Mother other labour market position } & $0.108 * *$ & -0.059 & 0.053 & -0.035 & -0.035 \\
\hline & $(0.054)$ & $(0.069)$ & $(0.033)$ & $(0.036)$ & $(0.035)$ \\
\hline \multirow[t]{2}{*}{ Student lives with both parents } & 0.027 & $0.037^{*}$ & 0.006 & 0.010 & 0.010 \\
\hline & $(0.017)$ & $(0.021)$ & $(0.010)$ & $(0.011)$ & $(0.010)$ \\
\hline \multirow{2}{*}{$\begin{array}{l}\text { Father works parttime } 3 / 4 \text { days per } \\
\text { week }\end{array}$} & 0.138 & 0.193 & 0.115 & $0.186^{*}$ & 0.186 \\
\hline & $(0.120)$ & $(0.211)$ & $(0.073)$ & $(0.110)$ & $(0.183)$ \\
\hline \multirow[t]{2}{*}{ Father works fulltime } & 0.124 & 0.181 & $0.130^{*}$ & $0.198^{*}$ & 0.198 \\
\hline & $(0.118)$ & (0.209) & $(0.071)$ & (0.109) & $(0.182)$ \\
\hline \multirow{2}{*}{$\begin{array}{l}\text { Mother works parrtime } 3 / 4 \text { days per } \\
\text { week }\end{array}$} & -0.014 & -0.011 & 0.002 & 0.004 & 0.004 \\
\hline & $(0.024)$ & $(0.034)$ & $(0.015)$ & $(0.018)$ & $(0.016)$ \\
\hline \multirow[t]{2}{*}{ Mother works fulltime } & $-0.056 * *$ & -0.049 & -0.018 & 0.002 & 0.002 \\
\hline & $(0.025)$ & $(0.035)$ & $(0.015)$ & $(0.018)$ & $(0.019)$ \\
\hline \multirow{2}{*}{$\begin{array}{l}\text { Student has repeated a grade in } \\
\text { secondary school }\end{array}$} & $0.258^{* * *}$ & 0.087 & $0.044 * *$ & 0.013 & 0.013 \\
\hline & $(0.028)$ & $(0.120)$ & $(0.018)$ & $(0.064)$ & $(0.019)$ \\
\hline \multirow[t]{2}{*}{ Constant } & -0.162 & 0.533 & $-0.554^{*}$ & $0.893 * * *$ & $0.893 * * *$ \\
\hline & $(0.474)$ & $(0.337)$ & $(0.291)$ & $(0.204)$ & $(0.236)$ \\
\hline Primary school FE & no & yes & no & yes & yes \\
\hline Secondary school FE & no & no & yes & yes & yes \\
\hline SEs clustered at the SS & no & no & no & no & yes \\
\hline Observations & 4,861 & 1,872 & 4,861 & 1,872 & 1,872 \\
\hline R-squared & 0.186 & 0.561 & 0.707 & 0.884 & 0.884 \\
\hline
\end{tabular}

Note: Coefficients are from OLS regressions. The dependent variable has value 1 when the child is included in the analyses sample and value 0 when the child has missing data on teacher assessment or test score in 6 th grade or track placement in 7 th grade. 


\section{C1. Similarities of and differences between assessment measures and allocation}

Table C1 shows a number of statistics. The left-hand panel shows the relation between different individual characteristics and the objective and subjective assessment measure, the middle panel shows the relation between individual characteristics and the subjective assessment measure and track placement, the right-hand panel shows the relation between individual characteristics and the objective assessment measure and track placement. ${ }^{22}$

We observe that girls more often seem to receive a teacher assessment that is higher compared to the test score, while they less often seem to receive a teacher assessment that is lower compared to the test score. In addition, girls more often receive a track placement equal to the subjective assessment measure and more often have a test score that is lower compared to their track placement. Second, the education level of the child's mother and father has a similar relation to the assessment measures and track placement. We observe that when a child's parents have a higher education level the child more often receives a subjective assessment that is higher than the objective assessment and less often receives a subjective assessment that is lower than the objective assessment compared to when the child's parents have a lower level of education. The middle and right-hand panel show that children of parents who have a higher education level less often receive a subjective and objective assessment that is higher than track placement. This suggests that girls and children from parents who are highly educated not only get a more favorable assessment, compared to boys and children from parents who are lower educated, from the elementary school teacher but also from the secondary school with regard to track placement. Third, from the labor market position of the mother we observe that children who have mothers that are unemployed more often receive a subjective assessment that is lower than the objective assessment and less often receive a subjective assessment that is higher than the objective assessment. Furthermore, children of mothers who are sick/unable to work less often receive a subjective assessment that is lower than track placement and more often receive an objective and subjective assessment that is higher than track placement. In our data over 70 percent of the mothers who are unemployed and over 85 percent of the mothers who are sick\unable to work completed only lower education or vocational education. Fourth, we observe a pattern related to the region of birth of the children and their parents. Children or parents born in another part of the Netherlands outside of Limburg or born abroad more often receive a subjective assessment higher than the objective assessment and more often receive a subjective and objective assessment that is not equal to track placement. In most of the cases when the assessment measures are not equal to track placement these children receive assessment

\footnotetext{
${ }^{22}$ In Table 4 we disregard the labor market position of the father and the workdays per week of the father. Almost all fathers are employed and work fulltime. There are too little observations in the other categories to make any statements about this information.
} 


\section{Chapter 3}

measures that are lower than track placement. This is especially the case for children or parents born abroad. Finally, we observe a pattern in children's birth quarters. There is an unofficial cut-off date for children's birthdays where children born after 1 October often have to wait another year to start primary education. Therefore, the oldest children are born in the fourth quarter. We observe that younger children more often receive a subjective assessment that is higher than the objective assessment. These children also more often receive a subjective assessment that is higher than their track placement and an objective assessment that is lower than their track placement. When we look at the 6th grade test scores of these children we see that test scores rise with children's age. Workdays per week mother and whether the child lives with both parents does not show any pattern. 
Table C1: Similarities of and differences between assessment measures and allocation

\begin{tabular}{|c|c|c|c|c|c|c|c|c|c|c|}
\hline & & \multicolumn{3}{|c|}{$\begin{array}{l}\text { Objective and } \\
\text { subjective assesment } \\
\text { measures }\end{array}$} & \multicolumn{3}{|c|}{$\begin{array}{l}\text { Subjective } \\
\text { assessment measures } \\
\text { and track placement }\end{array}$} & \multicolumn{3}{|c|}{$\begin{array}{l}\text { Objective assessment } \\
\text { measures and track } \\
\text { placement }\end{array}$} \\
\hline & & $\begin{array}{l}\mathrm{TAi}< \\
\mathrm{TSi}\end{array}$ & $\begin{array}{l}\mathrm{TAi}= \\
\mathrm{TSi}\end{array}$ & $\begin{array}{l}\text { TAi > } \\
\text { TSi }\end{array}$ & $\begin{array}{l}\mathrm{TAi}< \\
\mathrm{TPi}\end{array}$ & $\begin{array}{l}\mathrm{TAi}= \\
\mathrm{TPi}\end{array}$ & $\begin{array}{l}\mathrm{TAi}> \\
\mathrm{TPi}\end{array}$ & $\begin{array}{l}\mathrm{TSi}< \\
\mathrm{TPi}\end{array}$ & $\begin{array}{l}\mathrm{TPi}= \\
\mathrm{TSi}\end{array}$ & $\begin{array}{l}\text { TSi }> \\
\text { TPi }\end{array}$ \\
\hline \multirow[t]{2}{*}{ Female } & Boys & 6.19 & 81.70 & 12.11 & 7.81 & 87.34 & 4.85 & 18.48 & 75.60 & 5.91 \\
\hline & Girls & 4.21 & 80.34 & 15.46 & 7.17 & 89.33 & 3.50 & 21.21 & 74.84 & 3.94 \\
\hline \multirow[t]{4}{*}{ Education father } & Lower education & 8.14 & 79.04 & 12.82 & 9.66 & 85.96 & 4.37 & 19.13 & 73.96 & 6.92 \\
\hline & Vocational & 5.32 & 81.31 & 13.37 & 7.89 & 87.62 & 4.49 & 20.43 & 73.92 & 5.65 \\
\hline & Higher education & 3.95 & 81.21 & 14.83 & 5.93 & 91.38 & 2.68 & 19.77 & 76.69 & 3.53 \\
\hline & University & 3.15 & 82.61 & 14.24 & 6.18 & 90.20 & 3.62 & 20.77 & 76.66 & 2.57 \\
\hline \multirow{4}{*}{$\begin{array}{l}\text { Education } \\
\text { mother }\end{array}$} & Lower education & 7.93 & 78.63 & 13.44 & 8.12 & 86.94 & 4.93 & 19.83 & 73.21 & 6.96 \\
\hline & Vocational & 5.44 & 81.06 & 13.50 & 8.26 & 87.84 & 3.90 & 19.88 & 75.22 & 4.90 \\
\hline & Higher educ & 3.72 & 83.66 & 12.62 & 5.66 & 91.26 & 3.07 & 17.96 & 77.83 & 4.21 \\
\hline & University & 2.57 & 82.48 & 14.95 & 6.59 & 90.84 & 2.57 & 22.35 & 75.08 & 2.57 \\
\hline \multirow{4}{*}{$\begin{array}{l}\text { Labour market } \\
\text { position father }\end{array}$} & Employed & 5.42 & 81.07 & 13.52 & 7.57 & 88.50 & 3.92 & 19.73 & 75.46 & 4.81 \\
\hline & Unemployed & 1.32 & 85.53 & 13.16 & 7.89 & 86.84 & 5.26 & 27.63 & 60.53 & 11.84 \\
\hline & Sick/unable to work & 5.15 & 81.44 & 13.40 & 6.19 & 90.72 & 3.09 & 18.56 & 78.35 & 3.09 \\
\hline & Other & 5.97 & 79.10 & 14.93 & 5.97 & 85.07 & 8.96 & 16.42 & 77.61 & 5.97 \\
\hline \multirow{4}{*}{$\begin{array}{l}\text { Labour market } \\
\text { position mother }\end{array}$} & Employed & 5.49 & 81.02 & 13.49 & 7.81 & 88.33 & 3.86 & 19.68 & 75.25 & 5.07 \\
\hline & Unemployed & 7.06 & 84.71 & 8.24 & 7.06 & 89.41 & 3.53 & 16.47 & 77.65 & 5.88 \\
\hline & Sick/unable to work & 4.38 & 80.63 & 15.00 & 3.75 & 89.38 & 6.88 & 16.88 & 75.00 & 8.13 \\
\hline & Other & 4.70 & 81.39 & 13.91 & 6.95 & 89.37 & 3.68 & 22.29 & 74.44 & 3.27 \\
\hline \multirow{3}{*}{$\begin{array}{l}\text { Workdays per } \\
\text { week father }\end{array}$} & Fulltime & 5.78 & 80.80 & 13.42 & 7.60 & 88.43 & 3.97 & 19.70 & 75.22 & 5.08 \\
\hline & Parttime 3-4 days & 2.99 & 82.09 & 14.93 & 7.84 & 89.93 & 2.24 & 20.15 & 77.99 & 1.87 \\
\hline & ne $1-2$ days & & & & & & & & & \\
\hline \multirow{3}{*}{$\begin{array}{l}\text { Workdays per } \\
\text { week mother }\end{array}$} & Fulltime & 6.00 & 79.75 & 14.25 & 8.42 & 86.65 & 4.93 & 19.35 & 75.27 & 5.38 \\
\hline & Parttime 3-4 days & 5.16 & 81.98 & 12.86 & 7.64 & 89.42 & 2.95 & 19.69 & 75.22 & 5.09 \\
\hline & Parttime 1 -2 days & 5.44 & 81.17 & 13.39 & 8.37 & 87.87 & 3.77 & 18.83 & 77.82 & 3.35 \\
\hline \multirow{2}{*}{$\begin{array}{l}\text { Living with both } \\
\text { parents }\end{array}$} & No & 5.35 & 80.81 & 13.84 & 6.92 & 88.38 & 4.70 & 19.06 & 75.07 & 5.87 \\
\hline & Yes & 5.52 & 81.18 & 13.30 & 7.60 & 88.60 & 3.80 & 19.99 & 75.05 & 4.96 \\
\hline \multirow{3}{*}{$\begin{array}{l}\text { Region of birth } \\
\text { child }\end{array}$} & Limburg & 5.41 & 81.87 & 12.72 & 7.31 & 89.07 & 3.61 & 19.52 & 75.44 & 5.04 \\
\hline & Netherlands & 5.68 & 75.38 & 18.94 & 8.33 & 84.09 & 7.58 & 18.94 & 75.38 & 5.68 \\
\hline & Abroad & 5.45 & 75.15 & 19.39 & 10.30 & 82.42 & 7.27 & 24.85 & 69.70 & 5.45 \\
\hline \multirow{3}{*}{$\begin{array}{l}\text { Region of birth } \\
\text { father }\end{array}$} & Limburg & 5.60 & 81.59 & 12.81 & 7.74 & 88.72 & 3.53 & 19.74 & 75.10 & 5.16 \\
\hline & Netherlands & 4.21 & 81.50 & 14.29 & 4.95 & 90.11 & 4.95 & 16.48 & 78.75 & 4.76 \\
\hline & Abroad & 5.54 & 77.83 & 16.63 & 9.24 & 84.53 & 6.24 & 23.79 & 71.36 & 4.85 \\
\hline \multirow{3}{*}{$\begin{array}{l}\text { Region of birth } \\
\text { mother }\end{array}$} & Limburg & 5.32 & 81.90 & 12.78 & 7.23 & 89.13 & 3.65 & 19.04 & 75.88 & 5.09 \\
\hline & Netherlands & 4.83 & 80.69 & 14.48 & 7.14 & 87.45 & 5.41 & 19.69 & 75.10 & 5.21 \\
\hline & Abroad & 6.54 & 76.87 & 16.59 & 9.81 & 85.05 & 5.14 & 24.30 & 70.79 & 4.91 \\
\hline \multirow{4}{*}{$\begin{array}{l}\text { Birth quarter } \\
\text { child }\end{array}$} & $1 s t$ & 5.02 & 68.13 & 26.85 & 9.86 & 84.93 & 5.21 & 33.70 & 60.91 & 5.39 \\
\hline & 2nd & 5.81 & 67.08 & 27.10 & 9.66 & 83.63 & 6.71 & 32.47 & 60.82 & 6.71 \\
\hline & $3 r d$ & 5.21 & 64.75 & 30.04 & 8.83 & 83.48 & 7.69 & 35.60 & 56.98 & 7.42 \\
\hline & 4th & 6.23 & 68.57 & 25.19 & 10.22 & 85.11 & 4.68 & 33.25 & 60.43 & 6.32 \\
\hline
\end{tabular}

Note: $n=4,500$ in total but some children have missing data on some of the covariates. The numbers in the rows in each section of columns add up to 100 percent. $T S_{i}$ is the objective assessment measure based on the Cito Eindtoets (test score) in 6th grade. $T A_{i}$ is the subjective assessment measure based on teacher advice. $T P_{i}$ is track placement in 7th grade. All are measured in 8 brackets. The last row for 'work days per week father' is missing. There are too little fathers that work 1-2 days per week to draw any conclusions based on this information. 


\section{C2. Marginal effects of similarities of and differences between assessment and allocation}

Table C2 presents marginal effects of differences between the objective and subjective assessment measures and track placement. The left-hand panel shows the relation between different individual characteristics and the objective and subjective assessment measure, the middle panel shows the relation between individual characteristics and the subjective assessment measure and track placement, the right-hand panel shows the relation between individual characteristics and the objective assessment measure and track placement. We include elementary school fixed effects as we want to observe within school differences. ${ }^{23}$ In addition, all analyses in this paper include clustered standard errors either at the elementary school or secondary school level since we believe that the observations are not independent within schools. The marginal effects result from an ordered probit model in which we predict the probability that individual characteristics affect differences between assessment measures of differences between an assessment measure and track placement. ${ }^{24}$

First, we observe that girls are less likely to receive a subjective assessment that is lower than or equal to the objective assessment and more likely to receive a subjective assessment that is higher than the objective assessment compared to boys. Furthermore, girls are more likely to receive an objective assessment that is lower than track placement and less likely to receive an objective assessment that is equal or higher than track placement compared to boys. This suggests that elementary schools tend to give a higher assessment to girls compared to boys and that secondary schools tend to place girls in higher tracks compared to boys. Second, children born abroad or fathers born in another part of The Netherlands outside Limburg are less likely to receive an objective assessment that is lower than track placement and more likely to receive an objective assessment that is equal to track placement. In addition, children who have fathers who were born abroad are more likely to receive a subjective assessment that is equal to the objective assessment and less likely to receive a subjective assessment that is higher than the objective assessment. While children who have mothers that were born abroad are more likely to have a subjective assessment that is lower than track placement and less likely to have a subjective assessment that is higher than track placement. Third, children whose mother is unemployed or sick/unable to work are less likely to receive a subjective assessment that is higher than the objective assessment. Furthermore, these children are also less likely to receive an objective assessment that is lower than track placement. This suggests that primary and secondary schools seem to

\footnotetext{
${ }^{23}$ Specifications without elementary school fixed effects show estimates of similar size and statistical significance. This also suggests that different schools do not systematically over or under assess children or children with different characteristics.

${ }^{24}$ In Table 4 we disregard the labor market position of the father and the workdays per week of the father. Almost all fathers are employed and work fulltime. There are too little observations in the other categories to make any statements about this information.
} 
value when a child's mother is employed. In our sample mothers who are unemployed or sick/unable to work on average have a lower level of education. Fourth, secondary schools seem to value when mothers work fulltime as their children are more likely to receive a subjective assessment that is lower than track placement and less likely to receive a subjective assessment that is equal to or higher than track placement. 
Table C2: Marginal effects of similarities of and differences between assessment and allocation

\begin{tabular}{|c|c|c|c|c|c|c|c|c|c|}
\hline \multicolumn{10}{|l|}{ Marginal effects } \\
\hline & (1) & $(2)$ & (3) & (4) & (5) & (6) & (7) & (8) & (9) \\
\hline & $\mathrm{TA}<\mathrm{TS}$ & $\mathrm{TA}=\mathrm{TS}$ & $T A>T S$ & $\mathrm{TA}<\mathrm{PL}$ & $\mathrm{TA}=\mathrm{PL}$ & $\mathrm{TA}>\mathrm{PL}$ & $\mathrm{TS}<\mathrm{PL}$ & $\mathrm{TS}=\mathrm{PL}$ & $\mathrm{TS}>\mathrm{PL}$ \\
\hline \multirow[t]{2}{*}{ Female } & $-0.015^{* *}$ & $-0.043 * * *$ & ${ }^{*} 0.058^{* * *}$ & 0.008 & -0.006 & -0.002 & $0.068 * * *$ & $-0.062 * * *$ & ${ }^{*}-0.006^{* *}$ \\
\hline & $(0.006)$ & $(0.014)$ & $(0.020)$ & $(0.011)$ & $(0.009)$ & $(0.002)$ & $(0.026)$ & $(0.023)$ & $(0.003)$ \\
\hline \multirow[t]{2}{*}{ Age 2nd quarter } & 0.012 & $0.026 * *$ & $-0.038 *$ & 0.014 & -0.012 & -0.003 & 0.012 & -0.011 & -0.001 \\
\hline & $(0.008)$ & $(0.013)$ & $(0.020)$ & (0.019) & $(0.016)$ & $(0.004)$ & $(0.037)$ & $(0.034)$ & $(0.003)$ \\
\hline \multirow[t]{2}{*}{ Age 3rd quarter } & 0.001 & 0.004 & -0.006 & -0.000 & 0.000 & 0.000 & 0.035 & -0.032 & -0.003 \\
\hline & $(0.006)$ & $(0.017)$ & $(0.024)$ & $(0.015)$ & $(0.012)$ & $(0.003)$ & $(0.037)$ & $(0.034)$ & $(0.003)$ \\
\hline \multirow[t]{2}{*}{ Age 4th quarter } & 0.006 & 0.014 & -0.020 & 0.031 & -0.027 & -0.005 & 0.033 & -0.030 & -0.003 \\
\hline & $(0.008)$ & $(0.016)$ & $(0.023)$ & $(0.024)$ & $(0.021)$ & $(0.004)$ & $(0.040)$ & $(0.037)$ & $(0.003)$ \\
\hline \multirow[t]{2}{*}{ Student born in NL } & 0.008 & 0.016 & -0.024 & 0.068 & -0.062 & -0.006 & -0.025 & 0.022 & 0.003 \\
\hline & $(0.014)$ & $(0.019)$ & $(0.033)$ & $(0.047)$ & $(0.044)$ & $(0.004)$ & $(0.043)$ & $(0.037)$ & $(0.005)$ \\
\hline \multirow[t]{2}{*}{ Student born abroad } & 0.003 & 0.008 & -0.012 & -0.007 & 0.005 & 0.002 & $-0.095 * *$ & $0.077 * * *$ & 0.017 \\
\hline & $(0.018)$ & $(0.037)$ & $(0.054)$ & $(0.024)$ & $(0.017)$ & $(0.007)$ & $(0.041)$ & $(0.026)$ & $(0.015)$ \\
\hline \multirow[t]{2}{*}{ Father born in NL } & 0.012 & $0.022^{*}$ & -0.033 & -0.009 & 0.007 & 0.002 & $-0.063^{*}$ & $0.055^{*}$ & 0.008 \\
\hline & $(0.012)$ & $(0.013)$ & $(0.025)$ & $(0.016)$ & $(0.011)$ & $(0.005)$ & $(0.035)$ & (0.029) & $(0.006)$ \\
\hline \multirow[t]{2}{*}{ Father born abroad } & 0.014 & $0.024 * * *$ & $-0.038^{*}-$ & -0.006 & 0.005 & 0.001 & -0.038 & 0.034 & 0.004 \\
\hline & $(0.0$ & $(0.009)$ & $(0.020)$ & 10.0 & $(0.014)$ & $(0.005)$ & $(0.046)$ & $10 . C$ & (0. \\
\hline \multirow[t]{2}{*}{ Mother born in NL } & -0.001 & -0.002 & 0.002 & 0.003 & -0.002 & -0.001 & 0.009 & -0.009 & -0.001 \\
\hline & $(0.007)$ & $(0.024)$ & $(0.031)$ & $(0.023)$ & $(0.019)$ & $(0.004)$ & $(0.050)$ & $(0.046)$ & $(0.004)$ \\
\hline \multirow[t]{2}{*}{ Mother born abroad } & 0.005 & 0.012 & -0.017 & $0.046^{*}$ & $-0.041^{*}$ & $-0.005^{* *}$ & ${ }^{*} 0.065$ & -0.061 & -0.004 \\
\hline & $(0.013)$ & $(0.025)$ & $(0.038)$ & $(0.026)$ & $(0.025)$ & $(0.003)$ & $(0.064)$ & $(0.061)$ & $(0.003)$ \\
\hline \multirow{4}{*}{$\begin{array}{l}\text { Father has vocatio } \\
\text { education } \\
\text { Father has higher } \\
\text { education }\end{array}$} & 10.005 & 0.013 & -0.018 & $-0.024^{*}$ & 0.018* & 0.006 & -0.035 & 0.031 & 0.003 \\
\hline & $(0.007)$ & $(0.016)$ & $(0.022)$ & $(0.014)$ & $(0.009)$ & $(0.005)$ & $(0.035)$ & $(0.032)$ & $(0.004)$ \\
\hline & -0.000 & -0.001 & 0.001 & -0.004 & 0.003 & 0.001 & 0.036 & -0.033 & -0.003 \\
\hline & $(0.007)$ & $(0.022)$ & $(0.029)$ & $(0.017)$ & $(0.013)$ & $(0.004)$ & $(0.050)$ & $(0.047)$ & $(0.003)$ \\
\hline \multirow{2}{*}{$\begin{array}{l}\text { Father has university } \\
\text { education }\end{array}$} & -0.004 & -0.012 & 0.016 & -0.018 & 0.013 & 0.005 & 0.036 & -0.033 & -0.003 \\
\hline & $(0.006)$ & $(0.024)$ & $(0.030)$ & $(0.015)$ & $(0.010)$ & $(0.005)$ & $(0.048)$ & $(0.044)$ & $(0.003)$ \\
\hline \multirow{2}{*}{$\begin{array}{l}\text { Mother has } \\
\text { vocational education }\end{array}$} & 0.001 & 0.003 & -0.004 & 0.015 & -0.012 & -0.003 & 0.006 & -0.005 & -0.001 \\
\hline & $(0.006)$ & (0.019) & $(0.025)$ & (0.019) & $(0.016)$ & $(0.004)$ & $(0.039)$ & $(0.036)$ & $(0.003)$ \\
\hline \multirow{2}{*}{$\begin{array}{l}\text { Mother has higher } \\
\text { education }\end{array}$} & -0.002 & -0.005 & 0.007 & -0.023 & $0.016^{*}$ & 0.007 & -0.052 & 0.047 & 0.006 \\
\hline & $(0.007)$ & $(0.023)$ & $(0.030)$ & $(0.017)$ & (0.009) & $(0.007)$ & $(0.040)$ & $(0.035)$ & $(0.006)$ \\
\hline \multirow{2}{*}{$\begin{array}{l}\text { Mother has } \\
\text { university education }\end{array}$} & -0.005 & -0.017 & 0.022 & -0.012 & 0.009 & 0.003 & -0.006 & 0.005 & 0.001 \\
\hline & $(0.006)$ & $(0.027)$ & $(0.033)$ & $(0.017)$ & $(0.012)$ & $(0.005)$ & $(0.048)$ & $(0.043)$ & $(0.004)$ \\
\hline \multirow{2}{*}{$\begin{array}{l}\text { Father is sick/unable } \\
\text { to work }\end{array}$} & $-0.016^{* *}$ & *-0.344* & $0.360 * *$ & 0.009 & -0.007 & -0.002 & $0.419 * *$ & $-0.411^{* *}$ & $-0.008^{* *}$ \\
\hline & $(0.004)$ & $(0.179)$ & $(0.180)$ & $(0.032)$ & $(0.027)$ & $(0.005)$ & (0.179) & $(0.179)$ & $(0.003)$ \\
\hline \multirow{2}{*}{$\begin{array}{l}\text { Father has other } \\
\text { labour market } \\
\text { position }\end{array}$} & -0.004 & -0.016 & 0.021 & $-0.046 * *$ & *-0.269 & 0.316 & -0.089 & 0.073 & 0.016 \\
\hline & $(0.027)$ & $(0.135)$ & $(0.162)$ & $(0.010)$ & $(0.224)$ & $(0.222)$ & $(0.122)$ & $(0.079)$ & $(0.043)$ \\
\hline \multirow{2}{*}{$\begin{array}{l}\text { Mother is } \\
\text { unemployed }\end{array}$} & 0.431 & -0.342 & $90 * * *$ & 0 & -0.391 & $-0.007^{*}$ & $-0.146 * *$ & ${ }^{*} 0.084 * * *$ & 0.062 \\
\hline & $(0.316)$ & $(0.314)$ & (0.008) & $(0.317)$ & $(0.317)$ & $(0.004)$ & $(0.032)$ & $(0.025)$ & $(0.057)$ \\
\hline
\end{tabular}




\begin{tabular}{lllllllllll}
\hline $\begin{array}{l}\text { Mother is } \\
\text { sick/unable to work }\end{array}$ & 0.588 & -0.498 & $-0.090 * * * 0.033$ & -0.029 & -0.004 & $-0.138 * * 0.088^{* * *}$ & $0.050^{*}$ \\
Mother has other & 0.000 & $(0.371)$ & $(0.008)$ & $(0.059)$ & $(0.055)$ & $(0.004)$ & $(0.022)$ & $(0.008)$ & $(0.029)$ \\
$\begin{array}{l}\text { labour market } \\
\text { position }\end{array}$ & $(0.010)$ & $(0.029)$ & $(0.040)$ & $(0.072)$ & $(0.069)$ & $(0.004)$ & $(0.128)$ & $(0.126)$ & $(0.003)$ \\
$\begin{array}{l}\text { Father works } \\
\text { parttime 3/4 days }\end{array}$ & 0.001 & 0.003 & -0.004 & 0.024 & -0.021 & -0.004 & 0.018 & -0.017 & -0.001 \\
per week & $(0.008)$ & $(0.022)$ & $(0.031)$ & $(0.024)$ & $(0.022)$ & $(0.003)$ & $(0.046)$ & $(0.043)$ & $(0.003)$ \\
$\begin{array}{l}\text { Mother works } \\
\text { parttime 3/4 days }\end{array}$ & -0.009 & -0.026 & 0.035 & 0.041 & $-0.032 *$ & -0.009 & 0.012 & -0.011 & -0.001 \\
per week & $(0.008)$ & $(0.021)$ & $(0.029)$ & $(0.026)$ & $(0.019)$ & $(0.008)$ & $(0.044)$ & $(0.040)$ & $(0.004)$ \\
$\begin{array}{l}\text { Mother works } \\
\text { fulltime }\end{array}$ & -0.009 & -0.029 & 0.038 & $0.077 * *$ & $-0.065 * *-0.013 *$ & 0.039 & -0.036 & -0.003 \\
$\begin{array}{l}\text { Student lives with } \\
\text { both parents }\end{array}$ & 0.004 & 0.015 & -0.019 & 0.005 & -0.004 & -0.001 & 0.003 & -0.003 & -0.000 \\
\hline Observations & $(0.005)$ & $(0.019)$ & $(0.024)$ & $(0.014)$ & $(0.011)$ & $(0.003)$ & $(0.033)$ & $(0.030)$ & $(0.003)$ \\
\hline
\end{tabular}

Note: Ordered probit regressions with marginal effects. Every three columns represent one ordered probit regression of three levels. Standard errors are clustered at the elementary school level. All estimates include elementary school fixed effects and control variables for area code of residence and region. $T S_{i}$ is the objective assessment measure based on the Cito Eindtoets (test score) in 6th grade. $T A_{i}$ is the subjective assessment measure based on teacher advice. $T P_{i}$ is track placement in 7 th grade. All are measured in 8 brackets. $* * *, * *, *$ represents significance at the 1,5 and 10 percent level respectively. 


\section{D1. Similarities of and switching between tracks}

Table D1 shows the percentages of children who switch tracks between 7th and 9th grade. ${ }^{25}$ We observe that girls overall switch less than boys, however, there are more girls that switch up and more boys that switch down. Second, the higher the education level of the parents the fewer children switch between tracks. Children who have parents who have obtained lower education or vocational education are more likely to switch between tracks. As mentioned before this might be an artifact of our data since children's track placement is correlated with their parents' education level. Third, we observe that children whose mother is unemployed switch more. Switching both up and down tracks is more common compared to children whose mother is employed. Fourth, we observe that children whose mother works fulltime switch more compared to children whose mother works part-time. Especially switches down appear more often. Fifth, children who do not live with both parents switch more often, both switches up and down are more common. The last three effects are likely related to parents' education level. In at least two thirds of the cases when the child does not live with both parents the parents have either obtained lower education or vocational education. These findings are consistent with children of higher educated parents more often receiving a subjective assessment compared to the objective assessment. Finally, when the children's parents were born abroad the child more often switches down tracks. This is consistent with the finding that children's whose parents were born abroad more often receive a subjective assessment that is higher compared to the objective assessment. We do not observe a pattern in children's quarter of birth.

\footnotetext{
${ }^{25}$ In Table 5 we disregard the labor market position of the father and the workdays per week of the father. Almost all fathers are employed and work fulltime. There are too little observations in the other categories to make any statements about this information.
} 
Table D1: Similarities of and differences between switching tracks

\begin{tabular}{|c|c|c|c|c|c|c|c|}
\hline & & \multicolumn{2}{|l|}{ Switch } & \multicolumn{2}{|c|}{ Switch up } & \multicolumn{2}{|c|}{ Switch down } \\
\hline & & No & Yes & No & Yes & No & Yes \\
\hline \multirow[t]{2}{*}{ Female } & Boys & 76.03 & 23.97 & 93.34 & 6.66 & 81.46 & 18.54 \\
\hline & Girls & 77.63 & 22.37 & 92.57 & 7.43 & 83.62 & 16.38 \\
\hline \multirow[t]{4}{*}{ Education father } & Lower education & 71.94 & 28.06 & 90.93 & 9.07 & 78.52 & 21.48 \\
\hline & Vocational & 76.98 & 23.02 & 92.33 & 7.67 & 84.10 & 15.90 \\
\hline & Higher education & 81.40 & 18.60 & 94.15 & 5.85 & 86.35 & 13.65 \\
\hline & University & 85.54 & 14.46 & 95.54 & 4.46 & 89.46 & 10.54 \\
\hline \multirow[t]{4}{*}{ Education mother } & Lower education & 71.00 & 29.00 & 89.86 & 10.14 & 78.65 & 21.35 \\
\hline & Vocational & 77.41 & 22.59 & 92.85 & 7.15 & 83.85 & 16.15 \\
\hline & Higher education & 85.39 & 14.61 & 96.23 & 3.77 & 88.86 & 11.14 \\
\hline & University & 84.80 & 15.20 & 95.08 & 4.92 & 89.00 & 11.00 \\
\hline \multirow{4}{*}{$\begin{array}{l}\text { Labour market position } \\
\text { father }\end{array}$} & Employed & 78.05 & 21.95 & 93.01 & 6.99 & 83.86 & 16.14 \\
\hline & Unemployed & 80.90 & 19.10 & 92.13 & 7.87 & 87.64 & 12.36 \\
\hline & Sick/unable to work & 75.83 & 24.17 & 90.83 & 9.17 & 84.17 & 15.83 \\
\hline & Other & 67.57 & 32.43 & 94.59 & 5.41 & 71.62 & 28.38 \\
\hline \multirow{4}{*}{$\begin{array}{l}\text { Labour market position } \\
\text { mother }\end{array}$} & Employed & 78.02 & 21.98 & 93.08 & 6.92 & 83.79 & 16.21 \\
\hline & Unemployed & 71.84 & 28.16 & 88.35 & 11.65 & 82.52 & 17.48 \\
\hline & Sick/unable to work & 79.03 & 20.97 & 91.94 & 8.06 & 85.48 & 14.52 \\
\hline & Other & 78.24 & 21.76 & 93.70 & 6.30 & 83.40 & 16.60 \\
\hline \multirow{3}{*}{$\begin{array}{l}\text { Workdays per week } \\
\text { father }\end{array}$} & Fulltime & 77.76 & 22.24 & 92.90 & 7.10 & 83.60 & 16.40 \\
\hline & Parttime 3-4 days & 81.97 & 18.03 & 94.90 & 5.10 & 86.39 & 13.61 \\
\hline & Parttime $1-2$ days & & & & & & \\
\hline \multirow{3}{*}{$\begin{array}{l}\text { Workdays per week } \\
\text { mother }\end{array}$} & Fulltime & 76.50 & 23.50 & 92.50 & 7.50 & 82.67 & 17.33 \\
\hline & Parttime 3-4 days & 80.05 & 19.95 & 94.42 & 5.58 & 84.71 & 15.29 \\
\hline & Parttime $1-2$ days & 78.33 & 21.67 & 91.67 & 8.33 & 85.83 & 14.17 \\
\hline \multirow[t]{2}{*}{ Living with both parents } & No & 72.69 & 27.31 & 92.71 & 7.29 & 78.59 & 21.41 \\
\hline & Yes & 79.27 & 20.73 & 93.07 & 6.93 & 85.01 & 14.99 \\
\hline \multirow[t]{3}{*}{ Region of birth child } & Limburg & 77.75 & 22.25 & 93.19 & 6.81 & 83.53 & 16.47 \\
\hline & Netherlands & 77.51 & 22.49 & 89.36 & 10.64 & 84.50 & 15.50 \\
\hline & Abroad & 78.97 & 21.03 & 94.36 & 5.64 & 84.62 & 15.38 \\
\hline \multirow[t]{3}{*}{ Region of birth father } & Limburg & 78.34 & 21.66 & 93.37 & 6.63 & 84.12 & 15.88 \\
\hline & Netherlands & 78.81 & 21.19 & 91.52 & 8.48 & 84.77 & 15.23 \\
\hline & Abroad & 73.84 & 26.16 & 92.05 & 7.95 & 80.43 & 19.57 \\
\hline \multirow[t]{3}{*}{ Region of birth mother } & Limburg & 78.62 & 21.38 & 93.41 & 6.59 & 84.41 & 15.59 \\
\hline & Netherlands & 77.65 & 22.35 & 91.68 & 8.32 & 82.87 & 17.13 \\
\hline & Abroad & 73.63 & 26.37 & 91.89 & 8.11 & 80.73 & 19.27 \\
\hline \multirow[t]{4}{*}{ Birth quarter child } & $1 s t$ & 77.74 & 22.26 & 93.77 & 6.23 & 82.56 & 17.44 \\
\hline & 2nd & 76.35 & 23.65 & 92.20 & 7.80 & 82.78 & 17.22 \\
\hline & $3 r d$ & 76.46 & 23.54 & 92.42 & 7.58 & 82.54 & 17.46 \\
\hline & 4th & 75.65 & 24.35 & 93.38 & 6.62 & 81.29 & 18.71 \\
\hline
\end{tabular}

Note: $n=4,937$. For the analysis of switching we use all children for whom we have information on track placement from $7^{\text {th }}-9^{\text {th }}$ grade to keep sample size as large as possible. For 4,019 of these children we have information on their teacher advice $\left(T A_{i}\right)$ and test score $\left(T S_{i}\right)$ in 6 th grade. The numbers in each row section add up to 100 percent. The last row for 'work days per week father' is missing. There are too little fathers that work 1-2 days per week to draw any conclusions based on this information. 


\section{D2. Marginal effects of similarities of and differences between track switching}

Table D2 reports marginal effects of similarities of and differences between switching. The first column presents estimates from overall switching, while the second and third column specify switching up or switching down. ${ }^{26}$ We include secondary school fixed effects as we want to observe within school differences. In addition, standard errors are clustered at the secondary school level as the individual observations are not independent within schools. The marginal effects result from probit models in which we predict the probability that individual characteristics affect switching, switching up and switching down. ${ }^{27}$

From Table D2 we observe that girls are less likely to switch and especially less likely to switch down tracks compared to boys. This indicates that elementary schools are correct to more often award girls with a higher subjective assessment than their objective assessment compared to boys and that secondary schools are correct to more often place girls in a higher track than their objective assessment recommended. Second, children born in the Netherlands but outside Limburg are less likely to switch and especially less likely to switch down tracks compared to children born in Limburg. This indicates that the elementary school was correct in more often giving these children a subjective assessment that was higher than the objective assessment. Third, we observe that children whose fathers a higher educated are increasingly less likely to switch between tracks and especially to switch down tracks. This indicates that elementary schools were correct to less often give these children a subjective assessment that is lower than their objective assessment. Furthermore, secondary schools also seem to have been correct when they less often place children of higher educated parents in a track that is lower than the subjective or objective assessment. Finally, children who live with both parents are less likely to switch and especially less likely to switch down tracks. This effect is likely related to the education level of the children's parents. We do not find a pattern for the other covariates in the model.

\footnotetext{
${ }^{26}$ The estimated coefficients of switch up and switch down do not exactly add up to the estimated coefficient of overall switching. This is due to the fact that there are 65 children that switch both up and down between 7th and 9th grade. These children are captured twice in the switch up/down but only once with regard to overall switching. We keep these children in our analyses as we want to document all switches.

${ }^{27}$ In Table 5 we disregard the labor market position of the father and the workdays per week of the father. Almost all fathers are employed and work fulltime. There are too little observations in the other categories to make any statements about this information.
} 
Table D2: Marginal effects of similarities of and differences between switching

\begin{tabular}{|c|c|c|c|}
\hline & (1) & $(2)$ & (3) \\
\hline & Switch & Switch up & Switch down \\
\hline \multirow[t]{2}{*}{ Female } & $-0.035^{*}$ & 0.005 & $-0.051 * * *$ \\
\hline & $(0.020)$ & $(0.006)$ & $(0.016)$ \\
\hline \multirow[t]{2}{*}{ Age 2nd quarter } & -0.007 & 0.001 & -0.026 \\
\hline & $(0.024)$ & $(0.006)$ & $(0.023)$ \\
\hline \multirow[t]{2}{*}{ Age 3rd quarter } & 0.009 & -0.001 & -0.005 \\
\hline & $(0.031)$ & $(0.007)$ & $(0.031)$ \\
\hline \multirow[t]{2}{*}{ Age 4th quarter } & 0.017 & -0.001 & 0.011 \\
\hline & $(0.028)$ & $(0.007)$ & $(0.028)$ \\
\hline \multirow[t]{2}{*}{ Student born in other region NL } & $-0.066^{* *}$ & 0.005 & $-0.053^{*}$ \\
\hline & $(0.029)$ & $(0.007)$ & $(0.029)$ \\
\hline \multirow[t]{2}{*}{ Student born abroad } & -0.015 & -0.006 & -0.030 \\
\hline & $(0.047)$ & $(0.009)$ & $(0.024)$ \\
\hline \multirow[t]{2}{*}{ Father born in other region NL } & 0.025 & 0.005 & -0.012 \\
\hline & $(0.035)$ & $(0.011)$ & $(0.026)$ \\
\hline \multirow[t]{2}{*}{ Father born abroad } & 0.017 & 0.005 & 0.015 \\
\hline & $(0.035)$ & $(0.015)$ & $(0.029)$ \\
\hline \multirow[t]{2}{*}{ Mother born in other region NL } & 0.017 & 0.002 & 0.019 \\
\hline & $(0.033)$ & $(0.007)$ & $(0.032)$ \\
\hline \multirow[t]{2}{*}{ Mother born abroad } & 0.011 & -0.006 & 0.018 \\
\hline & $(0.037)$ & $(0.008)$ & $(0.036)$ \\
\hline \multirow[t]{2}{*}{ Father has vocational education } & -0.032 & 0.001 & $-0.042 * *$ \\
\hline & $(0.022)$ & $(0.003)$ & (0.019) \\
\hline \multirow[t]{2}{*}{ Father has higher education } & $-0.042 * *$ & 0.003 & $-0.043 * * *$ \\
\hline & $(0.021)$ & $(0.004)$ & $(0.014)$ \\
\hline \multirow[t]{2}{*}{ Father has university education } & $-0.065 * * *$ & -0.001 & $-0.063 * * *$ \\
\hline & $(0.017)$ & $(0.006)$ & $(0.019)$ \\
\hline \multirow[t]{2}{*}{ Mother has vocational education } & -0.009 & -0.004 & -0.003 \\
\hline & $(0.018)$ & $(0.008)$ & $(0.023)$ \\
\hline \multirow[t]{2}{*}{ Mother has higher education } & -0.041 & -0.004 & -0.036 \\
\hline & $(0.027)$ & $(0.008)$ & $(0.026)$ \\
\hline \multirow[t]{2}{*}{ Mother has university education } & -0.017 & 0.000 & -0.026 \\
\hline & $(0.028)$ & $(0.008)$ & $(0.029)$ \\
\hline \multirow[t]{2}{*}{ Father is sick/unable to work } & 0.155 & & 0.144 \\
\hline & $(0.277)$ & & $(0.293)$ \\
\hline \multirow[t]{2}{*}{ Father other labour market position } & -0.017 & 0.054 & -0.058 \\
\hline & $(0.097)$ & $(0.090)$ & $(0.068)$ \\
\hline \multirow[t]{2}{*}{ Mother is unemployed } & 0.064 & & 0.052 \\
\hline & $(0.148)$ & & $(0.131)$ \\
\hline \multirow[t]{2}{*}{ Mother is sick/unable to work } & -0.091 & & -0.042 \\
\hline & $(0.063)$ & & $(0.080)$ \\
\hline
\end{tabular}


Chapter 3

\begin{tabular}{llll}
\hline Mother other labour market position & -0.021 & -0.009 & -0.029 \\
Student lives with both parents & $(0.060)$ & $(0.010)$ & $(0.051)$ \\
& $-0.055^{* *}$ & 0.006 & $-0.061^{* * *}$ \\
Father works parttime 3/4 days per week & $(0.023)$ & $(0.008)$ & $(0.024)$ \\
Father works fulltime & $0.931^{* * *}$ & $0.996^{* * *}$ & $0.930^{* * *}$ \\
& $(0.008)$ & $(0.005)$ & $(0.011)$ \\
Mother works parrtime 3/4 days per week & $0.266^{* * *}$ & 0.028 & $0.205^{* * *}$ \\
Mother works fulltime & $(0.020)$ & $(0.031)$ & $(0.010)$ \\
& -0.025 & -0.013 & -0.002 \\
Student has repeated a grade in secondary school & -0.055 & $(0.012)$ & $(0.041)$ \\
& $(0.041)$ & -0.009 & 0.001 \\
Secondary school FE & -0.006 & $(0.009)$ & $(0.039)$ \\
\hline Observations & $(0.039)$ & -0.011 & -0.029 \\
\hline
\end{tabular}

Note: Probit regressions with marginal effects. Standard errors are clustered at the secondary school level. All estimates include control variables for the test score and teacher advice in $6^{\text {th }}$ grade, track placement in $7^{\text {th }}$ grade, area code of residence and region. $T S_{i}$ is the objective assessment measure based on the Cito Eindtoets (test score) in 6th grad. $T A_{i}$ is the subjective assessment measure based on teacher advice. $T P_{i}$ is track placement in 7th grade. All are measured in 8 brackets. ${ }^{* * *}, * *, *$ represents significance at the 1,5 and 10 percent level respectively. 


\section{E. Robustness check: taking into account the covariation between the teacher assessment (TA) and the test score (TS).}

Table E1 reports a robustness check to show that the teacher's assessment $(T A)$ has added value in predicting children's track placement in 7th and 9th grade on top of what is already explained by the test score (TS). The table shows estimated coefficients of the predictive value of the teacher's assessment for ordered probit models after correcting for the predictive power of the test score. In the first step, we regress track placement on the test score. In the second step, we fix the parameter for the test score that we estimated in the first step. Afterwards, we regress track placement on the teacher's assessment, all control and dummy variables and the fixed parameter for the test score. This provides us with the predictive power of the teacher's assessment after correcting for the covariation between the teacher's assessment and the test score. Columns 1 and 3 show the estimated parameter for the test score that we keep fixed in columns 2 and 4 . In columns 2 and 4 we observe that after correcting for the covariance between the teacher's assessment and the test score the teacher's assessment still has a statistically significant positive coefficient. This indicates that the teacher's assessment has added value for track placement in both 7th and 9th grade on top of the predictive power of the test score. Analysis with OLS provide similar results.

Table E1: Robustness check

\begin{tabular}{|c|c|c|c|c|}
\hline & \multicolumn{4}{|c|}{ Track placement } \\
\hline & \multicolumn{2}{|l|}{7 th grade } & \multicolumn{2}{|l|}{ 9th grade } \\
\hline & (1) & (2) & (3) & (4) \\
\hline \multirow[t]{2}{*}{ Test score (TS) } & $2.104^{* * *}$ & 2.104 & $1.960 * * *$ & 1.960 \\
\hline & $(0.137)$ & $(0.000)$ & $(0.111)$ & $(0.000)$ \\
\hline \multirow[t]{2}{*}{ Teacher assessment (TA) } & & $1.237 * * *$ & & $1.028^{* * *}$ \\
\hline & & $(0.257)$ & & (0.169) \\
\hline cut1 & -2.275 & $-4.637 * * *$ & $-5.276 * * *$ & $-8.269 * * *$ \\
\hline cut2 & -0.994 & $-2.830 *$ & $-3.876 * * *$ & $-6.133 * * *$ \\
\hline cut3 & -0.579 & -2.143 & $-2.858 * *$ & $-4.649 * * *$ \\
\hline cut4 & 0.469 & -0.500 & -1.855 & $-3.288 * * *$ \\
\hline cut5 & 1.545 & 1.017 & -0.003 & -0.955 \\
\hline cut6 & 2.262 & 1.942 & & \\
\hline cut7 & $3.504 * *$ & $3.523^{* *}$ & & \\
\hline Controls & yes & yes & yes & yes \\
\hline Primary school FE & yes & yes & yes & yes \\
\hline Observations & 1,100 & 1,100 & 1,100 & 1,100 \\
\hline
\end{tabular}


F. Robustness check: is switching related to the availability of school types in the region?

Tables F1 and F2 report descriptive statistics about the percentage of children that switch tracks and the level of comprehensiveness of schools. It is possible that it is easier for children to switch tracks when they go to a school that offers all tracks, a comprehensive school. First, the tables show that the most switching happens in schools that only offer pre-vocational tracks and that the least switching happens in schools that offer pre-higher and pre-university education. This can be a mechanical effect from our data since we observe children until $9^{\text {th }}$ grade which means that it is likely that we capture almost all of the switching in the pre-vocational tracks but not all of the switching in the pre-higher education and pre-university tracks. Students in the pre-higher education and pre-university tracks can still switch in later grades. Second, table F2 shows that more children switch in a comprehensive school (both in absolute as well as in relative terms) compared to children in non-comprehensive schools. It is likely that this effect is driven by track switches in pre-vocational education. 
Table F1: robustness check, is switching related to the availability of school types in the region? (column totals)

\begin{tabular}{lccccc}
\hline & Switch & & & \\
\cline { 2 - 6 } & $\begin{array}{l}\text { pre-vocational } \\
\text { tracks }\end{array}$ & $\begin{array}{l}\text { pre-higher/ } \\
\text { pre-uni }\end{array}$ & $\begin{array}{l}\text { theoretical pre- } \\
\text { vocational/pre- } \\
\text { higher/pre-uni }\end{array}$ & comprehensive & Total \\
\hline No & 481 & 1,575 & 952 & 771 & 3,779 \\
& 58.16 & 90.62 & 77.84 & 67.10 & 76.54 \\
Yes & 346 & 163 & 271 & 378 & 1,158 \\
& 41.84 & 9.38 & 22.16 & 32.90 & 23.46 \\
\hline Total & 827 & 1,738 & 1,223 & 1,149 & 4,937 \\
& 100.00 & 100.00 & 100.00 & 100.00 & 100.00 \\
\hline
\end{tabular}

Table F2: robustness check, is switching related to the availability of school types in the region? (row totals)

\begin{tabular}{|c|c|c|c|c|c|}
\hline & \multicolumn{5}{|l|}{ Switch } \\
\hline & $\begin{array}{l}\text { pre-vocational } \\
\text { tracks }\end{array}$ & pre-higher/pre-uni & $\begin{array}{l}\text { theoretical pre- } \\
\text { vocational/pre- } \\
\text { higher/pre-uni }\end{array}$ & comprehensive & Total \\
\hline \multirow[t]{2}{*}{ No } & 481 & 1,575 & 952 & 771 & 3,779 \\
\hline & 12.73 & 41.68 & 25.19 & 20.40 & 100.00 \\
\hline \multirow[t]{2}{*}{ Yes } & 346 & 163 & 271 & 378 & 1,158 \\
\hline & 29.88 & 14.08 & 23.40 & 32.64 & 100.00 \\
\hline \multirow[t]{2}{*}{ Total } & 827 & 1,738 & 1,223 & 1,149 & 4,937 \\
\hline & 16.75 & 35.20 & 24.77 & 23.27 & 100.00 \\
\hline
\end{tabular}



Chapter 4:

The impact of cognitive tests on teachers updating their assessments 



\subsection{Introduction}

Across countries different methods are used to assess children's ability levels and to select children into tracks. A teacher's assessment and a cognitive test are frequently used measures in this process. Tests are frequently used to measure children's cognitive ability as they are assumed to provide objective assessments of ability levels, whereas teacher's assessments are more likely to be subjective and biased (e.g., Dee, 2005; Burgess and Greaves, 2013; Fairlie et al., 2014). It is often assumed that teachers take into consideration all available information when assessing a child's ability level, or at least that teachers make an accurate selection of the available information. However, it is not clear how teachers weight the information that becomes available after children participate in a cognitive test. Both the teacher and the test attempt to measure the same unobserved variable, the child's ability level.

This study investigates to what extent and for which children teachers adjust their initial assessment of children's ability after observing these children's score on a highstakes math and language test at the end of $6^{\text {th }}$ grade. Previous research in chapter 3 of this dissertation and Timmermans et al. (2013) shows that the teacher's assessment and the test score are the two most important determinants of children's track allocation and schooling outcomes in secondary education. However, up to now it remains unclear to what extent an independent teacher's assessment is equally accurate or significantly better (or worse) at predicting children's ability levels without the added benefit of a test score to guide the teacher's assessment process. We use a unique dataset that allows us to distinguish the initial teacher's assessment, the test score and the final teacher's assessment. This allows us to show how teachers use the test score to adjust their own initial assessment of children's ability level and it highlights that certain groups are more affected by this adjustment process than others. Furthermore, this gives us insights into the accuracy and confidence with which teachers measure children's ability levels.

The research methodology of this study consists of three steps. The first step is to determine what factors predict the final teacher's assessment. We investigate the predictive power of the initial teacher's assessment and the cognitive test score in determining the final assessment. In the second step we investigate the effect size of having a different test score, compared to the initial teacher's assessment, on the final teacher's assessment. The third step is to investigate whether the adjustment the teacher makes is heterogeneous across gender and social-economic status.

This study takes advantage of a dataset that has information on the teacher's assessment before and after the test score is known. ${ }^{28}$ The children for which we have information in our dataset took the test in February 2009. On the official test form the

\footnotetext{
${ }^{28}$ This test is a high-stakes standardized test called the 'Eindtoets Basisonderwijs' which is taken by approximately 85 percent of all $6^{\text {th }}$ grade children in the Netherlands every year. The other 15 percent of children attend schools that use another standardized test of which we do not have data.
} 
teacher has been asked to indicate, by ticking a box, what his assessment of the child would be at that moment. The teacher has to indicate this in terms of eight different levels, which are shown in Figure 1. After the child has completed the test, the form is sent back to the test agency for scoring and the teacher's assessment is recorded. ${ }^{29}$ During the first week of March the schools receive the children's test scores and teachers announce their final assessment of the children's ability levels. The final teacher's assessment and the test score are determinants of children's track placement in secondary schools. These events occur in a period of approximately four weeks. This short period makes it unlikely that children are able to significantly improve their ability in this period. The data for the empirical analysis include 2,661 children. The data are constructed from administrative data from primary and secondary school tracking systems as well as questionnaire data when these children were in $6^{\text {th }}$ grade in 2009 . The questionnaire data include measures about demographics and social-economic status.

The most important findings from this study are as follows. First, both the initial teacher's assessment and the test score are significant predictors of the final teacher's assessment. It seems that these measures capture different information relating to children's ability levels. This is consistent with the findings reported in chapter three of this dissertation. Second, having a higher (lower) test score compared to the initial teacher's assessment has a significant positive (negative) effect on children's final teacher's assessment. This finding suggests that, on average, teachers adjust their initial assessment upwards by 0.443 track and downwards by 0.424 track, after observing the children's test score. The size of these effects suggests that teachers adjust their assessment by approximately 19 percent of a standard deviation. It thereby highlights the importance of test scores in the assessment process. Finally, we observe that teachers heterogeneously adjust their assessment across the gender and social-economic status of children. The adjustments are on average less favourable for girls compared to boys and more favourable for children from a higher social-economic background compared to children from a lower social-economic background. The downwards adjustment for girls is approximately 1.4 times as large as for boys and the downwards adjustment for children of low educated parents is approximately 1.5 to 2.0 times as large as for children of high educated parents.

The content of this paper relates to the economic literature on human capital formation. Human capital theory relates investments in education to later life productivity, health, and several labour-market outcomes such as wages and the probability of unemployment. Human capital can be broadly defined to include skills and knowledge but also includes non-cognitive skills. A part of the stock of human capital is accumulated from a level of innate ability that is growing in schooling and non-schooling investments (e.g., Carneiro and Heckman, 2003; Cunha and Heckman, 2007). When teachers assess children's ability levels and recommend a track allocation for children in secondary

\footnotetext{
${ }^{29}$ See Figure 1 for a copy of the official test form.
} 
education, teachers to a large extent influence the type and amount of investments children will be able to make in terms of human capital accumulation. Children who receive a low teacher's assessment will likely conduct different human capital investments compared to children who receive a high assessment. In order for children to receive the best suited track allocation we need information on their ability level. In the Dutch education system this information is provided by teacher's assessments and test scores which attempt to measure children's true ability level.

This paper also contributes to the literature on the relation between objective and subjective assessment measures for successive performance in school. Research has shown that systematic differences exist between teacher's assessments and test scores. These systematic differences are correlated with observable characteristics of different groups in society. For example, studies by Burgess and Greaves (2013), Dee (2005; 2007), Fairlie et al. (2014), Ferguson (2003), Lavy (2008), Lindahl (2007) and Plewis (1997) show that interactions between teachers' and children's behaviour or teachers' expectations, are related to differences between test results and teacher's assessments across gender and ethnic minorities. Girls are on average awarded more generous teacher's assessments compared to their test scores, while the evidence for ethnic minorities is mixed and depends on the specific ethnic minority. Furthermore, Cornwell et al. (2012) show that teacher's assessments and test scores differ systematically between children, where boys are generally graded less favourably by their teachers compared to their test scores.

Finally, this paper also contributes to the literature on statistical discrimination or stereotyping. If teachers adjust their assessments heterogeneously across groups, based on some form of bias or prejudice and not because the new information obtained from the test score provides them with more accurate information compared to a previous assessment, this is consistent with statistical discrimination or stereotyping where teachers systematically over-assess high-achieving groups and under-assess lowachieving groups. The adjustments could be made because teachers base their assessments on the level they expect children to perform at. This could lead to assessments based on group characteristics rather than on the children's individual ability level (e.g., Phelps, 1972; Akerlof and Kranton, 2002; Jussim and Harber, 2005; Lavy and Sand, 2005).

This paper proceeds as follows. Section 2 gives background information regarding the educational system and the strategy of this paper. Section 3 describes the data and presents statistics of the main variables used in the analyses. Section 4 presents the results. Section 5 addresses the policy perspective of the main findings and section 6 concludes. 


\section{Centrale eindtoets PO $1^{\mathrm{e}}$ toetsdag dinsdag 21 april 2015}

Alleen met potlood invullen. Vergissingen goed uitgummen.
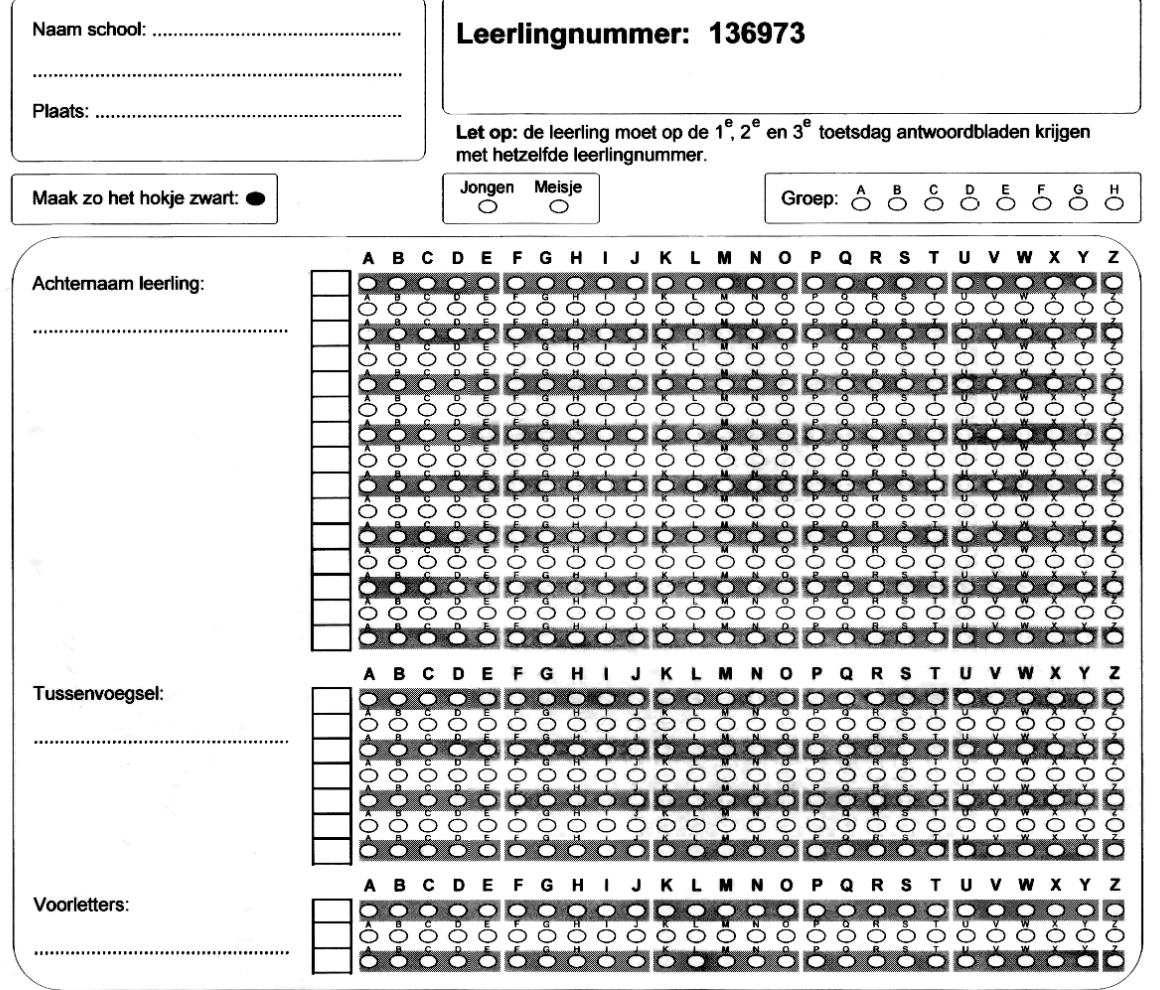

\section{Leerlingnummer: 136973}

Let op: de leerling moet op de $1^{\mathrm{e}}, 2^{\mathrm{e}}$ en $3^{\mathrm{e}}$ toetsdag antwoordbladen krijgen Let op: de leerling moet op de
met hetzelfde leerlingnummer.

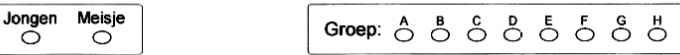

\begin{tabular}{|c|c|}
\hline \multicolumn{2}{|c|}{ Geboortedatum: } \\
\hline Dag: & 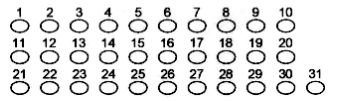 \\
\hline Maand: & 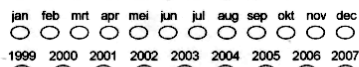 \\
\hline Jaar: & 0000 \\
\hline
\end{tabular}

Laatste vier cijfers van het BSN

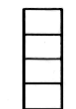
$\begin{array}{llllllllll}0 & 1 & 2 & 3 & 4 & 5 & 6 & 7 & 8 & 9 \\ 0 & 0 & 0 & 0 & 0 & 0 & 0 & 0 & 0 & 0 \\ 0 & 1 & 2 & 3 & 4 & 5 & 6 & 7 & 8 & 9 \\ 0 & 0 & 0 & 0 & 0 & 0 & 0 & 0 & 0 & 9 \\ 0 & 1 & 2 & 3 & 4 & 5 & 6 & 7 & 8 & 9 \\ 0 & 0 & 0 & 0 & 0 & 0 & 6 & 0 & 8 & 9 \\ 0 & 1 & 2 & 3 & 4 & 5 & 6 & 7 & 8 & 9 \\ 0 & 0 & 0 & 0 & 0 & 0 & 0 & 0 & 0 & 0\end{array}$
Advies leerkracht brugklastype:

basisberoepsgerichte leerweg

$O$ basis- en kaderberoepsgerichte leerweg

$\bigcirc$ kaderberoepsgerichte leerweg

$\bigcirc$ gemengde/theoretische leerweg

gemengde/theoretische leerweg en havo

havo

havo/wwo

wwo (inclusief gymnasium)

\begin{tabular}{l}
\hline $\begin{array}{l}\text { Aangepaste versie: } \\
\bigcirc \mathrm{Ja} \\
\mathrm{N} \text { Nee }\end{array}$ \\
\hline Ontheffing: $\quad$ Ja $\quad$ Nee \\
\hline
\end{tabular}

Aangepaste versie

Figure 1: Official test form 


\subsection{Background and strategy}

The main strength of the research strategy of this paper is that we observe the timeline of events in the data. Within a time span of approximately three weeks we observe the initial teacher's assessment, the test score and the final teacher's assessment, respectively. We use this timing of events to identify the adjustment teachers make in assessing children's ability.

\subsubsection{Background}

The test was made during three days on the $3^{\text {rd }}, 4^{\text {th }}$ and $5^{\text {th }}$ of February in 2009. The completed test forms were sent back to the test agency by regular mail on the last day of the test. During the first week of March 2009 schools received the children's test scores and teachers made their final assessment. This final assessment was communicated to children and parents. Due to the short time span between the different teacher's assessments we assume that it is unlikely that children have significantly changed their math and language skills. Furthermore, we assume that the factors that affect the initial teacher's assessment affect the final teacher's assessment to the same extent. The only difference is that in the final teacher's assessment the teacher is able to weigh in the children's test score. Furthermore, we assume that there is no reason to expect strategic behaviour on the side of the children. The teacher notes the initial teacher's assessment on the front page of the test form along with other information about the child, as indicated by the test agency. In 2009 parents and children are not informed about this initial teacher's assessment that is noted on the test form. ${ }^{30}$ Therefore, we do not expect that children's motivation depends on the initial teacher's assessment.

\subsubsection{Strategy}

The analysis first focuses on the determinants of the final teacher's assessment. We estimate equation (1) to observe whether the test score or the initial teacher's assessment shows a stronger correlation with the final teacher's assessment. Second, we estimate equation (2) to observe the relation, between children who have a higher or lower test score compared to the initial teacher's assessment, on children's final teacher's assessment. This analysis looks at whether teachers adjust their initial assessment after observing the children's test scores. Third, the analysis looks at whether the effect is heterogeneous across groups. An example of these analyses for gender is estimated by equation (3). Similar equations are estimated for the parental education level. Finally, we investigate whether or not there is a difference between the language and math components of the test in determining the final assessment and we investigate in more

\footnotetext{
${ }^{30}$ Parents are not informed of this particular initial teacher's assessment since this form directly goes to the test agency for examination. It is possible that the teacher informs children's parents separately of his initial teacher's assessment.
} 
detail the estimates of gender and the parental education levels. In all estimations, $X_{i}$ refers to a set of control variables, $P_{i}$ refers to primary school dummy variables, $t_{i}$ refers to classroom dummy variables and $\varepsilon_{i}$ represents the error term.

$$
\begin{aligned}
& F T A_{i}=C_{1}+a_{1} X_{i}+a_{2} I T A_{i}+a_{3} T S_{i}+\beta_{P_{i}}+\gamma_{t_{i}}+\varepsilon_{i} \\
& F T A_{i}=C_{1}+a_{1} X_{i}+a_{2} I T A_{i}+a_{3} T S_{i}>I T A_{i}+a_{4} T S_{i}<I T A_{i}+\beta_{P_{i}}+\gamma_{t_{i}}+\varepsilon_{i}, \\
& F T A_{i}=C_{1}+a_{1} X_{i}+a_{2} I T A_{i}+a_{3} T S_{i}>I T A_{i} * \text { gender }+a_{4} T S<I T A_{i}+\beta_{P_{i}}+\gamma_{t_{i}}+ \\
& \varepsilon_{i}
\end{aligned}
$$

In all analyses standard errors are clustered at the primary school level. Furthermore, primary school dummy variables and classroom dummy variables are used to capture school effects, such as certain school policies and other things that all children present in a particular school in our dataset have in common. Classroom dummies serve as a dummy variable for teachers. Since every classroom (usually) has a different fulltime teacher, we try to capture the teacher effect with these dummy variables. We interpret the coefficients as within primary school and within classrooms effects. The dummy variables capture the between effects.

The test scores and the teacher's assessment are both measures of children's ability that contain measurement error. The test is a snapshot of a child's performance on math and language, where measurement error can occur due to the timing of the test, test circumstances, physical and mental fitness of the child on the particular point in time and the inherent measurement error related to measuring ability. The teacher's assessment, however, should incorporate the performance of children in class and on tests on multiple occasions. Furthermore, the teacher's assessment incorporates children's classroom behaviour, personality and background characteristics, which are important determinants of future success (e.g., Segal, 2008; Segal, 2013; Bertrand and Pan, 2013). Measurement error due to the timing of the test or the test circumstances is assumed to be less severe for the teacher's assessment. However, a possible concern with the assessment made by teachers is the possibility of (unintended) prejudice that teachers could have due to a child's social-economic background or gender.

\subsection{Data}

The dataset contains children who attended $6^{\text {th }}$ grade in 2009. It includes information from school tracking systems, questionnaires among children and their parents as well as test scores. ${ }^{31}$ The goal of both the teacher's assessment and the test score is to pro-

\footnotetext{
${ }^{31}$ Scores on the test in $6^{\text {th }}$ grade can be distinguished in brackets that are consistent with these 9 track combinations.
} 
vide an advice of the most appropriate level of education for a child in secondary school.

\subsubsection{Descriptive statistics}

Table 1 shows the distribution of the main variables of interest, the initial teacher's assessment, the test score and the final teacher's assessment, across the different tracks. ${ }^{32}$ A description of the Dutch education system and the different tracks in secondary education can be found in Chapter 2. The numbers in each row add up to 100 percent. Approximately 50 percent of all children receive an initial teacher's assessment, test score and final teacher's assessment to attend pre-vocational education in secondary school. The other 50 percent is divided between pre-higher vocational education and pre-university education. ${ }^{33}$ At first sight, the distributions of the teacher's assessments and the test scores seem to be generally consistent. However, there are some differences. The largest difference between the initial teacher's assessment and the final teacher's assessment seems to occur for children who are on the margin between pre-vocational education (T1c/d) and pre-higher vocational education ( $T 1 d / 2)$. Furthermore, there seems to be a jump in the number of children who receive a teacher's assessment to attend pre-university education (T3) between the initial teacher's assessment and the final teacher's assessment. It is likely that this leads to a higher track placement in secondary school. Figure 2 shows the same pattern. Since track placement is strongly related to later life outcomes, these changes are likely to offer children a different education and labour-market perspective after secondary school (Onderwijsraad, 2014).

Table 1: the distributions of the teacher assessments and the test score

\begin{tabular}{llllllllll}
\hline & $\mathrm{T} 1 \mathrm{a}$ & $\mathrm{T} 1 \mathrm{a} / \mathrm{b}$ & $\mathrm{T} 1 \mathrm{~b}$ & $\mathrm{~T} 1 \mathrm{~b} / \mathrm{c}$ & $\mathrm{T} 1 \mathrm{c} / \mathrm{d}$ & $\mathrm{T} 1 \mathrm{~d} / 2$ & $\mathrm{~T} 2$ & $\mathrm{~T} 2 / 3$ & $\mathrm{T3}$ \\
\hline Initial teacher assessment & 4.74 & 3.76 & 8.23 & 0.71 & 18.19 & 15.3 & 18.23 & 15.75 & 15.11 \\
Test score & 3.38 & 3.34 & 6.28 & 3.8 & 17.55 & 19.5 & 18.68 & 16.5 & 10.97 \\
Final teacher assessment & 5.52 & 2.33 & 8.23 & 0.41 & 6.09 & 24.01 & 17.02 & 14.05 & 22.32 \\
\hline
\end{tabular}

Note: All rows add up to 100 percent. $\mathrm{N}=2661$. See figure 1 for a schedule of the different educational tracks.

\footnotetext{
${ }^{32}$ Note that the initial teacher assessment and the final teacher assessment are never measured on a continuous scale.

33 There are more sub-tracks in pre-vocational education compared to pre-higher vocational and preuniversity education. This is also reflected in the lower amount of children per track in pre-vocational education. We distinguish nine educational tracks based on the initial teacher's assessment. The final teacher's assessment and the test score are recoded so that all variables are comparable on the same scale. The result is that for the final teacher's assessment and the test we combine track T1c with T1c/d and track T1d with $\mathrm{T} 1 \mathrm{~d} / 2$. In this paper we define a difference between any of the three main variables as a difference of one track. We consider a difference of one track as appropriate as the teacher is the only decision maker regarding the initial and final teacher's assessments and there is (almost) no time delay between the different measures of ability.
} 


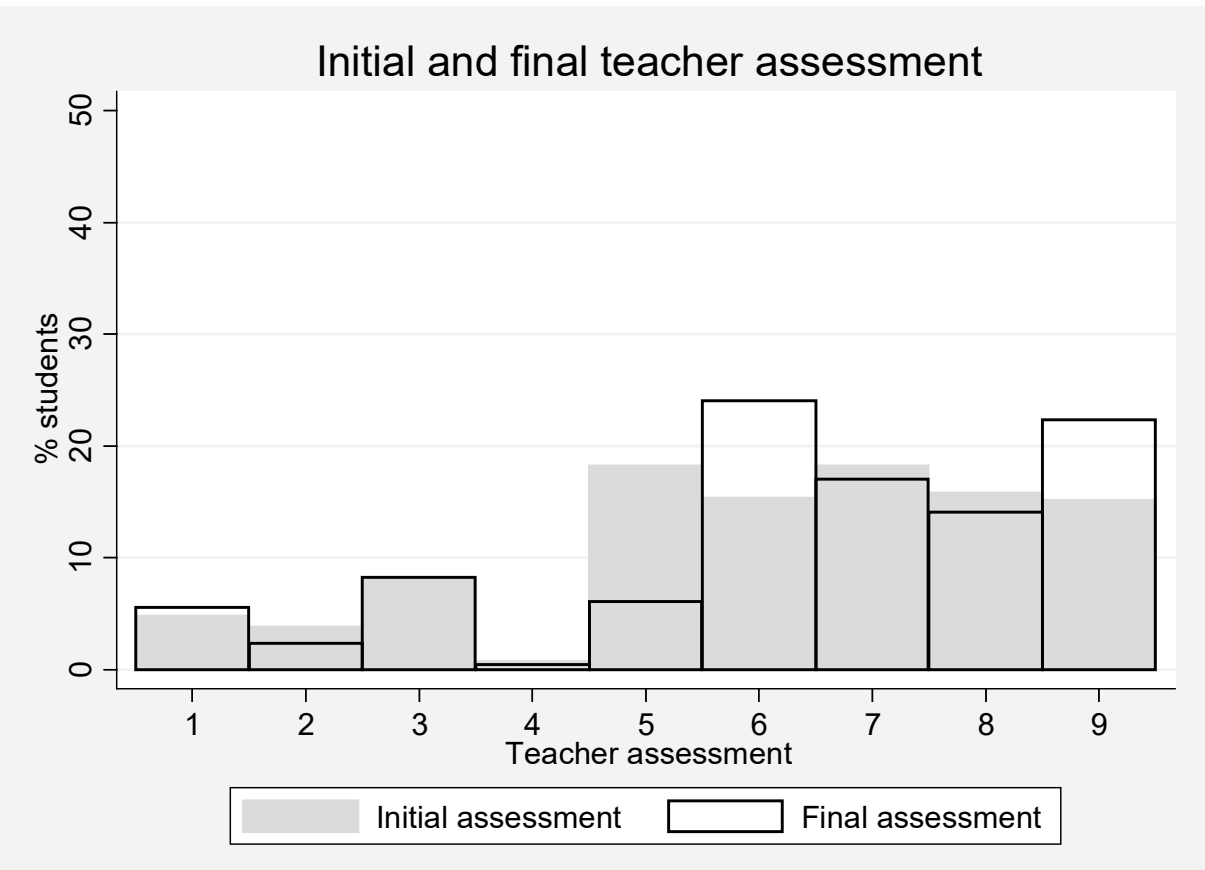

Figure 2: Difference between initial and final teacher assessment

Table 2 reports descriptive statistics. In our sample we have approximately the same percentage of boys and girls, who are on average 12 years old. Most children were born in Limburg but there are also children who were born in other regions of the Netherlands and children who were born abroad. The same description applies to the birth region of both the father and the mother of the child. The average parental education level suggests that they have completed vocational education. On average, fathers seem to be slightly higher educated than mothers. Most parents, both the father and the mother, report to be employed. Almost all fathers are employed whereas mothers are more frequently (compared to fathers) unemployed or do not participate in the labour market. Approximately 76 percent of the children lives with both parents. ${ }^{34}$ The initial teacher's assessment is measured on a scale from 1-9 where the average corresponds to the track T1d/2. The final teacher's assessment has an average track recommendation that is higher and slightly closer to the T2 track. Finally, the original test score is measured on a scale from 501-550. Based on information provided by the institution that supplies the test in $6^{\text {th }}$ grade, the test score is rescaled to be comparable to the scale of the teacher's assessments. The differences in the mean and the standard deviations for the three main variables of interest are relatively small.

\footnotetext{
${ }^{34}$ We do not have information on whether the parents are married. The corresponding questionnaire question is: "Do you live at home with both parents?"
} 
Table 3 shows the bivariate correlation coefficients and their statistical significance for the main variables of interest. ${ }^{35}$ The correlation coefficients between the initial teacher's assessment, the test score and the final teacher's assessment are all high and positive. They are also statistically significant. Given the information in Table 1 and the fact that these variables measure the same latent variable this is not surprising. An interesting observation is that the correlation coefficient between the test score and the final teacher's assessment is higher than the correlation coefficient between the test score and the initial teacher's assessment. A likely explanation for this finding is that teachers adjust their initial assessment after observing the children's test score, which provides us with a first indication that teachers on average update their assessment after observing the test score.

Table 2: descriptive statistics

\begin{tabular}{|c|c|c|c|c|c|c|}
\hline & $\mathrm{N}$ & Mean & SD & Min & Median & Max \\
\hline Female & 2660 & 0.50 & 0.50 & 0 & 1 & 1 \\
\hline Age (in months) & 2661 & 147.32 & 6.63 & 125 & 147 & 179 \\
\hline Region of birth child & 2283 & 1.13 & 0.44 & 1 & 1 & 3 \\
\hline 1. Limburg & & $91.40 \%$ & & & & \\
\hline 2. The Netherlands outside Limburg & & $4.60 \%$ & & & & \\
\hline 3. Abroad & & $4.00 \%$ & & & & \\
\hline Region of birth father & 2267 & 1.34 & 0.68 & 1 & 1 & 3 \\
\hline Region of birth mother & 2276 & 1.33 & 0.67 & 1 & 1 & 3 \\
\hline Education father & 2167 & 2.32 & 1.10 & 1 & 2 & 4 \\
\hline 1. Lower education & & $28.60 \%$ & & & & \\
\hline 2. Vocational education & & $32.00 \%$ & & & & \\
\hline 3. Higher education & & $18.40 \%$ & & & & \\
\hline 4. University education & & $21.00 \%$ & & & & \\
\hline Education mother & 2176 & 2.14 & 1.02 & 1 & 2 & 4 \\
\hline Labor market position father & 2220 & 1.15 & 0.57 & 1 & 1 & 4 \\
\hline 1. Employed & & $92.70 \%$ & & & & \\
\hline 2. Unemployed & & $2.20 \%$ & & & & \\
\hline 3. Sick/unable to work & & $2.80 \%$ & & & & \\
\hline 4. Other & & $2.30 \%$ & & & & \\
\hline Labor market position mother & 2230 & 1.54 & 1.09 & 1 & 1 & 4 \\
\hline Child lives with both parents & 2082 & 0.76 & 0.43 & 0 & 1 & 1 \\
\hline Initial teacher assessment & 2661 & 6.12 & 2.21 & 1 & 6 & 9 \\
\hline Test score & 2661 & 6.10 & 2.02 & 1 & 6 & 9 \\
\hline Final teacher assessment & 2661 & 6.44 & 2.26 & 1 & 7 & 9 \\
\hline
\end{tabular}

Note: The same description of region of birth of the child applies to the father and the mother. Similarly, the same description of education father and labor market position father apply to the mother.

\footnotetext{
${ }^{35}$ Appendix A shows the correlation coefficients of the other variables in our analysis.
} 
Table 3: correlation coefficients

\begin{tabular}{|c|c|c|c|}
\hline & Initial teacher assessment & Test score & Final teacher assessment \\
\hline Initital teacher assessment & 1 & & \\
\hline Test score & $0.8320 * * *$ & 1 & \\
\hline Final teacher assessment & $0.8967 * * *$ & $0.8680 * * *$ & 1 \\
\hline
\end{tabular}

Note: Bivariate correlation coefficients. ${ }^{* * *}$ represents significance at the 1 percent level. These variables are all measured on a scale from 1-9.

\subsubsection{Selection}

For 2,661 children we have information about the main variables of interest: the initial teacher's assessment, the test score and the final teacher's assessment. These data have been collected from 127 primary schools and 35 secondary schools. This is a subset of the original dataset that covers 3,303 children in primary education. Possible selection issues with regard to the analysis are addressed. It is investigated whether or not individual characteristics of children explain if they end up in our sample for analysis. The main concern regarding a possible selection bias is that schools only report data on their well-performing children and fail to report data on their poorer performing children. Children who are older turn out to be slightly less likely to be included in the sample used for analysis, whereas children who live with both parents are slightly more likely to be included in the sample. Furthermore, there seems to be a small effect of father's parental education: children whose father has finished vocational education or higher vocational education are slightly more likely to be included in the sample compared to children whose father has finished lower education only. This effect is not present for fathers with university education, which is our highest level of education measured. Additionally, there seems to be no difference between the determinants of selection into the sample for children for whom we have and for whom we do not have information on the test score. Finally, there seems to be no selection at the school level. There are no schools for which a large number of children drop out of our sample for analysis. $^{36}$

\subsection{Results}

This section reports the estimation results. It starts with a number of a basic statistics about the differences in test scores and first and final assessment. The section continues with presenting the estimated coefficients of updating by teachers and heterogeneity across different groups. It concludes with a number of robustness checks. The most salient results are shown in the main text and an elaborate appendix reports the results from using different interaction terms, estimation techniques, a decomposition of the

\footnotetext{
${ }^{36}$ See Appendix B for the analysis of selection into the sample.
} 
difference between the math and language component of the cognitive test score and performance in secondary school.

\subsubsection{Differences between assessment measures}

Table 4 and 5 display the differences between the initial teacher's assessment, the test score and the final teacher's assessment. Table 4 shows that differences between the initial teacher's assessment, the test score and the final teacher's assessment occur in every track. Each column shows the differences for each track. The first three rows of the first column show that 42.1 percent of the children received the same track recommendation from the test score as initially judged by the teacher (TS=ITA). In 57.9 percent of the cases the test score recommended a higher track than the initial teacher's assessment. The picture that emerges from the top three rows suggests that the higher (lower) the track, the more often the test score is lower (higher) than the initial teacher's assessment. The difference is mainly present between the lower levels of the pre-vocational education tracks and all higher tracks.

Second, the middle part of Table 4 shows the difference between the final teacher's assessment and the test score. The final teacher's assessment is often lower than the test score in the lower tracks, whereas the final teacher's assessment is often higher than the test score in the higher tracks. A possible explanation for this finding might be that teachers give some children a higher assessment based on other characteristics than their test score, for example non-cognitive skills or social-economic background (e.g., Cornwell et al. 2011).

Third, the last part of Table 4 shows the difference between the final teacher's assessment and the initial teacher's assessment. A downward adjustment of the teacher's assessment seems to be more likely to occur for those children whose teacher's assessment is at the level of pre-vocational education. An upward adjustment is more likely for children with assessments at the level of one of the middle tracks. Overall, the most consensus between the different measures occurs in the outer (lowest and highest) recommended tracks. In these tracks the uncertainty about children's ability is likely lower than for children who are recommended to the middle tracks. Some of these findings might be driven by a floor and/or ceiling effect as children in the highest recommended track cannot go further up and children in the lowest recommended track cannot go further down. 
Table 4: differences in TS, ITA and FTA

\begin{tabular}{|c|c|c|c|c|c|c|c|c|c|}
\hline & \multicolumn{9}{|c|}{ Tracks (ITA) } \\
\hline & $\mathrm{T} 1 \mathrm{a}$ & $\mathrm{T} 1 \mathrm{a} / \mathrm{b}$ & $\mathrm{T} 1 \mathrm{~b}$ & $\mathrm{~T} 1 \mathrm{~b} / \mathrm{c}$ & $\mathrm{T} 1 \mathrm{c} / \mathrm{d}$ & $\mathrm{T} 1 \mathrm{~d} / 2$ & $\mathrm{~T} 2$ & $\mathrm{~T} 2 / 3$ & T3 \\
\hline \multicolumn{10}{|l|}{ TS - ITA } \\
\hline $\mathrm{TS}<\mathrm{ITA}$ & 0.0 & 17.0 & 21.5 & 21.1 & 21.3 & 29.5 & 40.2 & 43.9 & 48.0 \\
\hline $\mathrm{TS}=\mathrm{ITA}$ & 42.1 & 24.0 & 21.5 & 10.5 & 40.1 & 38.8 & 34.6 & 40.6 & 52.0 \\
\hline $\mathrm{TS}>\mathrm{ITA}$ & 57.9 & 59.0 & 57.0 & 68.4 & 38.6 & 31.7 & 25.2 & 15.5 & 0.0 \\
\hline \multicolumn{10}{|l|}{ FTA - TS } \\
\hline $\mathrm{FTA}<\mathrm{TS}$ & 45.2 & 43.0 & 38.8 & 21.1 & 19.4 & 13.5 & 9.9 & 8.6 & 0.7 \\
\hline $\mathrm{FTA}=\mathrm{TS}$ & 44.4 & 45.0 & 28.8 & 42.1 & 36.2 & 42.3 & 39.1 & 35.3 & 55.5 \\
\hline $\mathrm{FTA}>\mathrm{TS}$ & 10.3 & 11.0 & 32.4 & 36.8 & 44.4 & 44.2 & 50.9 & 59.9 & 43.8 \\
\hline \multicolumn{10}{|l|}{ FTA - ITA } \\
\hline $\mathrm{FTA}<\mathrm{ITA}$ & 0.0 & 30.0 & 17.8 & 21.1 & 13.0 & 7.1 & 15.9 & 15.0 & 8.0 \\
\hline $\mathrm{FTA}=\mathrm{ITA}$ & 71.4 & 19.0 & 47.5 & 0.0 & 19.4 & 55.0 & 50.9 & 44.2 & 92.0 \\
\hline $\mathrm{FTA}>\mathrm{ITA}$ & 28.6 & 51.0 & 34.7 & 78.9 & 67.6 & 37.8 & 33.2 & 40.8 & 0.0 \\
\hline
\end{tabular}

TS = Test score, ITA = Initial teacher assessment, FTA = Final teacher assessment. Percentages of students per variable TS - ITA, FTA -TS and FTA-ITA by ITA. All columns add up to 100 percent.

Table 5 shows that there are differences between these three variables across gender and parental education levels. The first row in the first column shows that 32.4 percent of the children have a lower test score than their initial teacher's assessment. In 38.5 percent of the cases the test score and the initial teacher's assessment recommend the same track and in 29.1 percent of the cases the test score was higher than the initial teacher's assessment.

Overall, the first column suggests that the test score is generally slightly lower than the teacher's assessments and the final teacher's assessment seems to increase compared to the initial teacher's assessment, as can also be seen from Table 2. The last final part of the table (FTA-ITA) shows updating between the initial teacher's assessment and the final teacher's assessment for approximately 50 percent of all children, where 12.7 percent is adjusted downwards and 37.3 percent is adjusted upwards.

Columns 3 and 4 of Table 5 show the differences by gender. Girls less often than boys have a test score that is higher than the initial teacher's assessment and girls more often than boys have a final teacher's assessment that is higher than the test score. This suggests that teachers give girls more favourable assessments conditional on their test score, compared to boys. We find no apparent difference between girls and boys regarding updating between the initial and the final teacher's assessment.

Columns 5-8 of Table 5 display the difference for mother's education level and columns 9-12 show the differences for father's education level. The higher the mother's education level, the more often the test score seems to be lower than or equal to the initial teacher's assessment and the less often the test score seems to be higher than the initial teacher's assessment. This could suggest that teachers give more favourable initial assessments to children from higher educated parents. Furthermore, the higher 
the mother's education level, the less often the final teacher's assessment is lower than the test score and the more often the final teacher's assessment is higher than the test score. Finally, the higher the mother's education level, the less often the final teacher's assessment is lower than the initial teacher's assessment and the more often the final teacher's assessment is equal to the initial teacher's assessment.

These results are similar for the father's education level (in columns 9-12 of Table 5). It seems that the higher the parental education level the more often children's initial and final teacher's assessments are equal and the less often the final teacher's assessment is lower than the initial teacher's assessment. However, for children of higher educated parents the final teacher's assessment is less often higher than the initial teacher's assessment, compared to children of lower educated parents. An explanation for this finding could be the ceiling effect that might occur for children of higher educated parents. If we assume that children of higher educated parents already have a very high initial teacher's assessment there is less room for more upwards adjustment. The same reasoning applies for children of lower educated parents, there is less room for downwards adjustment.

Table 6 shows the determinants of the final teacher's assessment. The estimated coefficients are based on OLS models, and Appendix E shows similar results using ordered probit models. The initial teacher's assessment and the test score are both positively correlated with the final teacher's assessment and statistically significant. Columns 1-4 show that the estimates of the initial teacher's assessment and the test score are almost not affected when the other characteristics of children are added to the model. As of column 5 both the initial teacher's assessment and the test score are jointly added to the model. In columns 5-7 we observe that the initial teacher's assessment seems to be a slightly better predictor of the final teacher's assessment than the test score. The estimates only slightly change from column 5 to column 6 which seems to indicate that these estimates are representative for all schools, the estimates are almost equal when the dummy variable for the different schools are added to the model. Finally, from column 6 to column 7 we see a slight drop in the coefficients of the initial teacher's assessment and the test score. This is due to the inclusion of the classroom dummy variables. In column 7 the estimate for the initial teacher's assessment is not significantly different from the estimate of the test score. Furthermore, conditional on the initial teacher's assessment and the test score there are almost no other characteristics that are significantly related to the final teacher's assessment. Including both of the ability measures seems to soak up a lot of the variation in the children's characteristics, leaving them insignificant. ${ }^{37}$

\footnotetext{
${ }^{37}$ It is possible that the differences between the tracks are not linear. Therefore, the results of an ordered probit regression can be found in appendix $\mathrm{E}$. These coefficients show similar results for the relation between the initial teacher assessment, the test score and the final teacher assessment.
} 


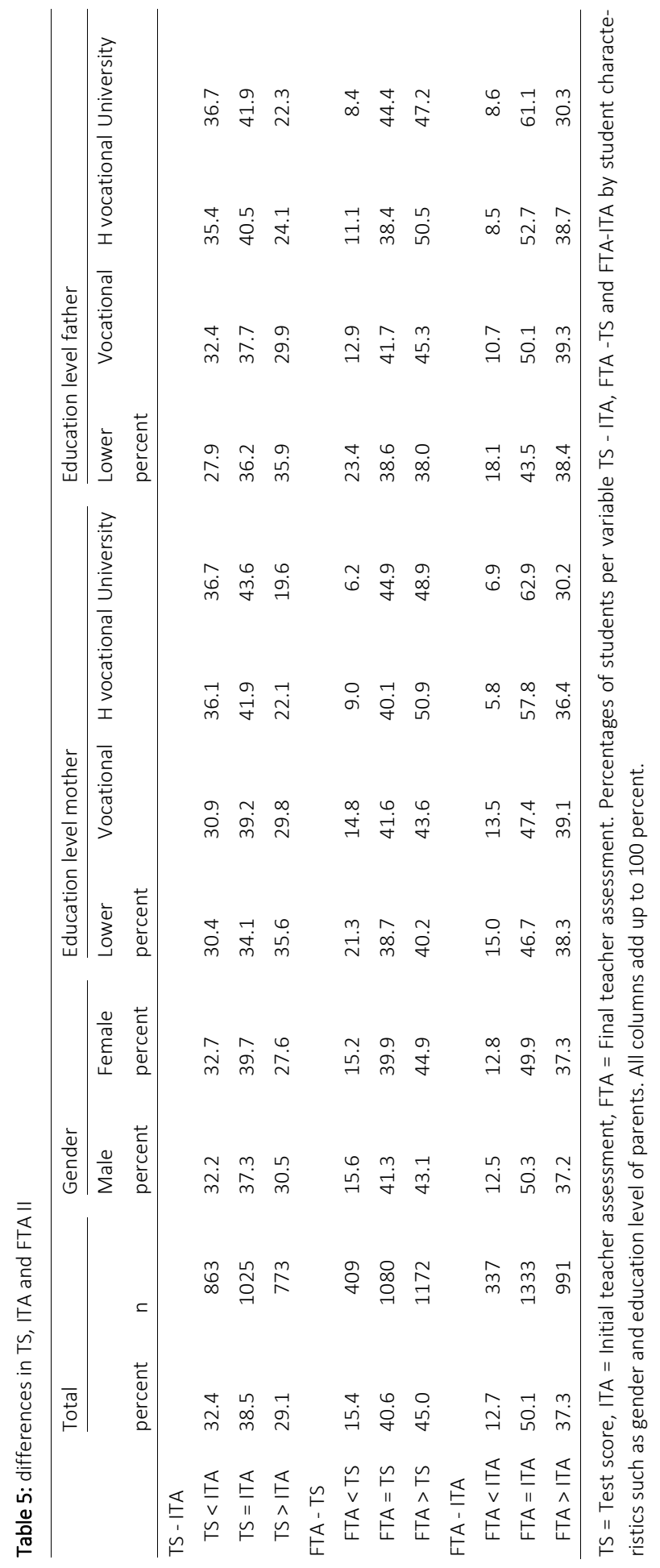


Table 6: determinants of the final teacher assessment

\begin{tabular}{|c|c|c|c|c|c|c|c|}
\hline & \multicolumn{7}{|c|}{ Final teacher assessment } \\
\hline & $(1)$ & $(2)$ & (3) & $(4)$ & $(5)$ & $(6)$ & (7) \\
\hline \multirow[t]{2}{*}{ Initial teacher assessment } & $0.917 * * *$ & $0.863 * * *$ & & & $0.596 * * *$ & $0.545^{* * *}$ & $0.407 * * *$ \\
\hline & $(0.016)$ & $(0.020)$ & & & $(0.024)$ & $(0.033)$ & $(0.030)$ \\
\hline \multirow[t]{2}{*}{ Test score } & & & $0.969 * * *$ & $0.894 * * *$ & $0.425 * * *$ & $0.426 * * *$ & $0.334 * * *$ \\
\hline & & & (0.019) & $(0.027)$ & $(0.027)$ & $(0.038)$ & $(0.040)$ \\
\hline \multirow[t]{2}{*}{ Female } & & -0.049 & & 0.027 & & -0.004 & -0.082 \\
\hline & & $(0.065)$ & & $(0.065)$ & & $(0.056)$ & $(0.052)$ \\
\hline \multirow[t]{2}{*}{ Age (in months) } & & $-0.012 * *$ & & $-0.022 * * *$ & & $-0.009 * *$ & -0.005 \\
\hline & & $(0.005)$ & & $(0.006)$ & & $(0.004)$ & $(0.004)$ \\
\hline \multirow[t]{2}{*}{ Child born in other region NL } & & -0.120 & & 0.079 & & -0.036 & 0.026 \\
\hline & & $(0.146)$ & & $(0.180)$ & & $(0.147)$ & $(0.110)$ \\
\hline \multirow[t]{2}{*}{ Child born abroad } & & 0.231 & & 0.291 & & 0.217 & -0.021 \\
\hline & & $(0.161)$ & & $(0.198)$ & & $(0.141)$ & $(0.156)$ \\
\hline \multirow[t]{2}{*}{ Father born in other region $\mathrm{NL}$} & & 0.142 & & -0.025 & & 0.078 & $0.140 *$ \\
\hline & & $(0.112)$ & & $(0.135)$ & & $(0.105)$ & $(0.083)$ \\
\hline \multirow[t]{2}{*}{ Father born abroad } & & 0.008 & & 0.074 & & 0.064 & -0.022 \\
\hline & & $(0.126)$ & & $(0.137)$ & & $(0.114)$ & $(0.107)$ \\
\hline \multirow[t]{2}{*}{ Mother born in other region NL } & & 0.071 & & 0.006 & & 0.028 & 0.001 \\
\hline & & $(0.100)$ & & $(0.103)$ & & $(0.082)$ & $(0.072)$ \\
\hline \multirow[t]{2}{*}{ Mother born abroad } & & -0.058 & & -0.123 & & -0.089 & -0.086 \\
\hline & & $(0.123)$ & & $(0.127)$ & & $(0.104)$ & $(0.103)$ \\
\hline \multirow[t]{2}{*}{ Father has vocational education } & & $0.142 *$ & & $0.213^{* *}$ & & $0.141 * *$ & 0.121 \\
\hline & & $(0.079)$ & & (0.089) & & $(0.066)$ & $(0.074)$ \\
\hline \multirow[t]{2}{*}{ Father has higher education } & & $0.192 *$ & & $0.303^{* * *}$ & & $0.179 * *$ & $0.181^{*}$ \\
\hline & & $(0.102)$ & & $(0.097)$ & & $(0.085)$ & $(0.093)$ \\
\hline \multirow[t]{2}{*}{ Father has university education } & & 0.148 & & $0.340 * * *$ & & $0.172 * *$ & 0.123 \\
\hline & & $(0.091)$ & & $(0.080)$ & & $(0.074)$ & $(0.082)$ \\
\hline \multirow[t]{2}{*}{ Mother has vocational education } & & $0.146^{*}$ & & $0.167^{*}$ & & 0.115 & 0.022 \\
\hline & & $(0.086)$ & & $(0.088)$ & & $(0.075)$ & $(0.082)$ \\
\hline \multirow[t]{2}{*}{ Mother has higher education } & & $0.326 * * *$ & & $0.302 * * *$ & & $0.208^{* *}$ & 0.081 \\
\hline & & $(0.099)$ & & $(0.102)$ & & $(0.086)$ & $(0.091)$ \\
\hline \multirow[t]{2}{*}{ Mother has university education } & & $0.255^{* *}$ & & $0.240^{*}$ & & 0.128 & 0.069 \\
\hline & & (0.109) & & $(0.132)$ & & $(0.105)$ & $(0.101)$ \\
\hline \multirow[t]{2}{*}{ Father is unemployed } & & -0.244 & & -0.138 & & -0.201 & -0.281 \\
\hline & & $(0.224)$ & & $(0.242)$ & & $(0.200)$ & $(0.182)$ \\
\hline \multirow[t]{2}{*}{ Father is sick/unable to work } & & -0.287 & & 0.022 & & -0.171 & -0.270 \\
\hline & & $(0.242)$ & & $(0.203)$ & & $(0.184)$ & $(0.179)$ \\
\hline \multirow{2}{*}{$\begin{array}{l}\text { Father has other labour market } \\
\text { position }\end{array}$} & & -0.092 & & $-0.509 * * *$ & & -0.182 & 0.027 \\
\hline & & $(0.194)$ & & $(0.179)$ & & $(0.148)$ & $(0.161)$ \\
\hline \multirow[t]{2}{*}{ Mother is unemployed } & & -0.046 & & 0.040 & & 0.011 & 0.226 \\
\hline & & $(0.166)$ & & $(0.192)$ & & $(0.142)$ & $(0.143)$ \\
\hline
\end{tabular}




\begin{tabular}{|c|c|c|c|c|c|c|c|}
\hline & \multicolumn{7}{|c|}{ Final teacher assessment } \\
\hline & $(1)$ & $(2)$ & (3) & $(4)$ & $(5)$ & $(6)$ & (7) \\
\hline \multirow[t]{2}{*}{ Mother is sick/unable to work } & & 0.039 & & 0.176 & & 0.104 & 0.097 \\
\hline & & $(0.131)$ & & $(0.164)$ & & $(0.126)$ & $(0.170)$ \\
\hline \multirow{2}{*}{$\begin{array}{l}\text { Mother has other labour market } \\
\text { position }\end{array}$} & & -0.114 & & -0.127 & & -0.098 & -0.113 \\
\hline & & $(0.105)$ & & $(0.097)$ & & $(0.089)$ & $(0.084)$ \\
\hline \multirow[t]{2}{*}{ Child lives with both parents } & & 0.012 & & -0.047 & & -0.030 & $-0.120 *$ \\
\hline & & $(0.073)$ & & $(0.072)$ & & $(0.062)$ & $(0.061)$ \\
\hline \multirow[t]{2}{*}{ Constant } & $0.823^{* * *}$ & $-2.718^{* * *}$ & * $0.549 * * *$ & $-2.091^{*}$ & $0.210^{* *}$ & $-4.102 * * *$ & $-2.943 * * *$ \\
\hline & $(0.120)$ & $(0.866)$ & $(0.151)$ & $(1.245)$ & $(0.106)$ & $(0.835)$ & $(0.760)$ \\
\hline School FE & no & yes & no & yes & no & yes & yes \\
\hline Classroom FE & no & no & no & no & no & no & yes \\
\hline Clustered SE & yes & yes & yes & yes & yes & yes & yes \\
\hline Observations & 1,986 & 1,404 & 1,986 & 1,404 & 1,986 & 1,404 & 1,404 \\
\hline R-squared & 0.808 & 0.845 & 0.747 & 0.815 & 0.853 & 0.880 & 0.923 \\
\hline
\end{tabular}

Note: Coefficients are from ordinary least squared regressions with the final teacher assessment as the dependent variable measured on a scale from 1-9. Standard errors are clustered at the primary school level. $* * *, * *, *$ represent 1,5 and 10 percent significance levels respectively. Other control variables in all the regressions are area code of residence and region.

\subsubsection{Updating}

A key question in this paper is whether differences between the initial teacher's assessment and the test score change the final teacher's assessment. Table 7 reports the estimated coefficients of several OLS models where the dependent variable is the final teacher's assessment and the two most important independent variables are 'test score $>$ initial teacher's assessment' and 'test score < initial teacher's assessment'. The variable 'test score > initial teacher's assessment' equals one if the test score is higher than the initial teacher's assessment and zero otherwise. The variable 'test score < initial teacher's assessment' equals one if the test score is lower than the initial teacher's assessment and zero otherwise. Adding both dummy variables to the model creates 'test score = initial teacher's assessment' as the baseline for the estimates. Columns 1 and 2 show that having a test score that is higher than the initial teacher's assessment is positively related to having a higher final teacher's assessment. Columns 3 and 4 show the opposite: having a test score that is lower than the initial teacher's assessment is negatively related to having a higher final teacher's assessment. Column 5 shows the estimates of both variables when they are jointly added to the model. In columns 6 and 7 school dummy variables and classroom dummy variables are added, respectively. The estimates are robust to the inclusion of control variables, school dummies and classroom dummies. Standard errors are clustered at the school level to take into account the correlation between children at the same school. Children who obtain a test score that is higher than the initial teacher's assessment, are adjusted upwards in the final teacher's assessment. The average upward adjustment is 0.443 track. When the test 
score is lower than the initial teacher's assessment, the final teacher's assessment is on average adjusted downwards by 0.424 track. ${ }^{38}$ On a scale from 1-9 these are considerable adjustments. This translates into an average adjustment of approximately 19 percent of the standard deviation of the final teacher's assessment. These results are consistent with expectations that teachers adjust their assessments of children's ability based on information provided by the test score. Table 7 shows that teachers adjust or update their assessments of children's ability based on information that is provided by the test score. When the test score is higher (lower) than the initial teacher's assessment this has a positive (negative) effect on the final teacher's assessment.

Table 7: determinants of the final teacher assessment II

\begin{tabular}{|c|c|c|c|c|c|c|c|}
\hline & \multicolumn{7}{|c|}{ Final teacher assessment } \\
\hline & (1) & (2) & (3) & (4) & (5) & (6) & (7) \\
\hline \multirow{2}{*}{$\begin{array}{l}\text { Test score > Initial teacher } \\
\text { assessment }\end{array}$} & $0.924 * * *$ & $0.798 * * *$ & & & $0.700 * * *$ & $0.594 * * *$ & $0.443 * * *$ \\
\hline & $(0.061)$ & $(0.068)$ & & & $(0.060)$ & $(0.065)$ & $(0.080)$ \\
\hline \multirow{2}{*}{$\begin{array}{l}\text { Test score }<\text { Initial teacher } \\
\text { assessment }\end{array}$} & & & $-0.764 * * *$ & $-0.755^{* * *}$ & $-0.525 * * *$ & $-0.581 * * *$ & $-0.424 * * *$ \\
\hline & & & $(0.056)$ & $(0.075)$ & $(0.053)$ & $(0.070)$ & $(0.074)$ \\
\hline \multirow[t]{2}{*}{ Initial teacher assessment } & $0.991 * * *$ & $0.929 * * *$ & $0.958 * * *$ & $0.906^{* * *}$ & $1.002 * * *$ & $0.945^{* * *}$ & $0.691^{* * *}$ \\
\hline & $(0.015)$ & $(0.021)$ & $(0.015)$ & $(0.020)$ & $(0.014)$ & $(0.021)$ & $(0.035)$ \\
\hline \multirow[t]{2}{*}{ Female } & & -0.019 & & -0.017 & & -0.002 & -0.077 \\
\hline & & $(0.061)$ & & $(0.060)$ & & (0.059) & $(0.055)$ \\
\hline \multirow[t]{2}{*}{ Age (in months) } & & $-0.012 * * *$ & & $-0.010 * *$ & & $-0.011 * *$ & -0.004 \\
\hline & & $(0.004)$ & & $(0.005)$ & & $(0.004)$ & $(0.004)$ \\
\hline \multirow[t]{2}{*}{ Child born in other region NL } & & -0.098 & & -0.080 & & -0.072 & 0.002 \\
\hline & & $(0.147)$ & & $(0.142)$ & & $(0.142)$ & $(0.111)$ \\
\hline \multirow[t]{2}{*}{ Child born abroad } & & 0.218 & & 0.190 & & 0.189 & -0.028 \\
\hline & & $(0.155)$ & & $(0.145)$ & & $(0.144)$ & $(0.154)$ \\
\hline \multirow[t]{2}{*}{ Father born in other region $\mathrm{NL}$} & & 0.082 & & 0.125 & & 0.084 & 0.145 \\
\hline & & $(0.105)$ & & $(0.115)$ & & $(0.111)$ & $(0.090)$ \\
\hline \multirow[t]{2}{*}{ Father born abroad } & & -0.001 & & 0.072 & & 0.051 & -0.041 \\
\hline & & $(0.125)$ & & $(0.119)$ & & $(0.122)$ & $(0.112)$ \\
\hline \multirow{2}{*}{$\begin{array}{l}\text { Mother born in other region } \\
\text { NL }\end{array}$} & & 0.107 & & 0.093 & & 0.115 & 0.065 \\
\hline & & $(0.092)$ & & $(0.097)$ & & $(0.091)$ & $(0.083)$ \\
\hline \multirow[t]{2}{*}{ Mother born abroad } & & -0.022 & & -0.038 & & -0.016 & -0.042 \\
\hline & & $(0.116)$ & & $(0.117)$ & & $(0.113)$ & $(0.107)$ \\
\hline \multirow{2}{*}{$\begin{array}{l}\text { Father has vocational } \\
\text { education }\end{array}$} & & $0.147^{* *}$ & & $0.156^{* *}$ & & $0.157^{* *}$ & $0.128^{*}$ \\
\hline & & (0.069) & & $(0.076)$ & & $(0.070)$ & $(0.076)$ \\
\hline
\end{tabular}

${ }^{38}$ It is possible that the differences between the tracks are not linear. Therefore, the results of an ordered probit regression can be found in appendix F. These coefficients show similar results. When the test score is higher than the initial teacher assessment this has a significant positive effect on the final teacher assessment and when the test score is lower compared to the initial teacher assessment this has a significant negative effect on the final teacher assessment. 


\begin{tabular}{|c|c|c|c|c|c|c|c|}
\hline \multicolumn{2}{|l|}{ Father has higher education } & \multicolumn{2}{|l|}{$\begin{array}{l}0.186 * * \\
(0.093)\end{array}$} & \multicolumn{2}{|l|}{$\begin{array}{l}0.232 * * \\
(0.096)\end{array}$} & $\begin{array}{l}0.218 * * \\
(0.091)\end{array}$ & $\begin{array}{l}0.198 * * \\
(0.095)\end{array}$ \\
\hline \multicolumn{2}{|l|}{$\begin{array}{l}\text { Father has university } \\
\text { education }\end{array}$} & \multicolumn{2}{|l|}{$\begin{array}{l}0.167 * * \\
(0.080)\end{array}$} & \multicolumn{2}{|l|}{$\begin{array}{l}0.176 * * \\
(0.086)\end{array}$} & $\begin{array}{l}0.183^{* *} \\
(0.078)\end{array}$ & $\begin{array}{l}0.126 \\
(0.084)\end{array}$ \\
\hline \multicolumn{2}{|l|}{$\begin{array}{l}\text { Mother has vocational } \\
\text { educatio }\end{array}$} & \multicolumn{2}{|l|}{$\begin{array}{l}0.123 \\
(0.080)\end{array}$} & \multicolumn{2}{|l|}{$\begin{array}{l}0.086 \\
(0.080)\end{array}$} & $\begin{array}{l}0.083 \\
(0.078)\end{array}$ & $\begin{array}{l}-0.011 \\
(0.084)\end{array}$ \\
\hline \multicolumn{2}{|l|}{ Mother has higher education } & \multicolumn{2}{|l|}{$0.286^{* * *}$} & $0.223^{* *}$ & & $\begin{array}{l}0.217 * * \\
(0.088)\end{array}$ & $\begin{array}{l}0.067 \\
(0.092)\end{array}$ \\
\hline \multicolumn{2}{|l|}{$\begin{array}{l}\text { Mother has university } \\
\text { education }\end{array}$} & \multicolumn{2}{|l|}{$0.202^{*}$} & \multicolumn{2}{|l|}{0.125} & $\begin{array}{l}0.115 \\
(0.104)\end{array}$ & $\begin{array}{l}0.034 \\
(0.101)\end{array}$ \\
\hline \multicolumn{2}{|l|}{ Father is unemployed } & \multicolumn{2}{|l|}{-0.254} & \multicolumn{2}{|l|}{-0.180} & $\begin{array}{l}-0.203 \\
(0.216)\end{array}$ & $\begin{array}{l}-0.259 \\
(0.198)\end{array}$ \\
\hline \multicolumn{2}{|l|}{ Father is sick/unable to work } & \multicolumn{2}{|l|}{$\begin{array}{l}-0.260 \\
(0.209)\end{array}$} & \multicolumn{2}{|l|}{$\begin{array}{l}-0.216 \\
(0.218)\end{array}$} & $\begin{array}{l}-0.213 \\
(0.199)\end{array}$ & $\begin{array}{l}-0.304 \\
(0.190)\end{array}$ \\
\hline \multicolumn{2}{|l|}{$\begin{array}{l}\text { Father has other labour } \\
\text { market position }\end{array}$} & \multicolumn{2}{|l|}{$\begin{array}{l}-0.101 \\
(0.179)\end{array}$} & \multicolumn{2}{|l|}{$\begin{array}{l}-0.158 \\
(0.179)\end{array}$} & $\begin{array}{l}-0.150 \\
(0.168)\end{array}$ & $\begin{array}{l}0.080 \\
(0.170)\end{array}$ \\
\hline \multicolumn{2}{|l|}{ Mother is unemployed } & 0.040 & & $\begin{array}{l}-0.054 \\
(0.155)\end{array}$ & & $\begin{array}{l}0.012 \\
(0.144)\end{array}$ & $\begin{array}{l}0.247^{*} \\
(0.148)\end{array}$ \\
\hline \multicolumn{2}{|l|}{ Mother is sick/unable to work } & \multicolumn{2}{|l|}{$\begin{array}{l}0.087 \\
(0.131)\end{array}$} & $\begin{array}{l}0.059 \\
(0.126)\end{array}$ & & $\begin{array}{l}0.090 \\
(0.126)\end{array}$ & $\begin{array}{l}0.079 \\
(0.172)\end{array}$ \\
\hline \multicolumn{2}{|l|}{$\begin{array}{l}\text { Mother has other labour } \\
\text { market position }\end{array}$} & \multicolumn{2}{|l|}{$\begin{array}{l}-0.049 \\
(0.100)\end{array}$} & \multicolumn{2}{|l|}{$\begin{array}{l}-0.114 \\
(0.098)\end{array}$} & $\begin{array}{l}-0.066 \\
(0.095)\end{array}$ & $\begin{array}{l}-0.090 \\
(0.086)\end{array}$ \\
\hline \multicolumn{2}{|l|}{ Child lives with both parents } & $\begin{array}{l}-0.013 \\
(0.069)\end{array}$ & & $\begin{array}{l}-0.015 \\
(0.066)\end{array}$ & & $\begin{array}{l}-0.027 \\
(0.064)\end{array}$ & $\begin{array}{l}-0.117^{*} \\
(0.064)\end{array}$ \\
\hline Constant & $\begin{array}{l}0.110 \\
(0.113)\end{array}$ & $\begin{array}{l}-3.189 * * * \\
(0.782)\end{array}$ & $\begin{array}{l}0.828^{* * *} \\
(0.113)\end{array}$ & $\begin{array}{l}-3.678 * * * \\
(0.829)\end{array}$ & $\begin{array}{l}0.286^{* * *} \\
(0.109)\end{array}$ & $\begin{array}{l}-3.806 * * * \\
(0.781)\end{array}$ & $\begin{array}{l}-2.742 * * * \\
(0.756)\end{array}$ \\
\hline School FE & no & yes & no & yes & no & yes & yes \\
\hline Classroom FE & no & no & no & no & no & no & yes \\
\hline Clustered SE & yes & yes & yes & yes & yes & yes & yes \\
\hline Observations & 1,986 & 1,404 & 1,986 & 1,404 & 1,986 & 1,404 & 1,404 \\
\hline R-squared & 0.836 & 0.862 & 0.832 & 0.864 & 0.845 & 0.872 & 0.920 \\
\hline
\end{tabular}

Note: Coefficients are from ordinary least squared regressions with the final teacher assessment as the dependent variable. Standard errors are clustered at the primary school level. ***, **, * represent 1, 5 and 10 percent significance levels respectively. Other control variables include area code of residence and region.

\subsubsection{Heterogeneity in gender and education level of parents}

It is also interesting to investigate whether or not teachers differ in these adjustments or in the magnitude of these adjustments for different groups of children. Heterogeneity in teacher adjustments across groups indicates that children's characteristics are related to how teachers assess their ability level. The primary goal is to investigate whether or not there are such effects present in the dataset. At this stage it is not possible to estimate what the consequences of these differences in treatment are for chil- 
dren's later outcomes nor is it possible to determine whether or not the teacher is right or wrong in making these adjustments.

Table 8 reports the estimated coefficients from OLS models where characteristics of children are interacted with a dummy for the positive or negative difference between the test score and the initial teacher's assessment. Table 8 reports estimates for the gender of the child and parental education levels. Columns 1 and 2 report the effects related to gender. The estimated coefficients do not suggest the presence of significant differences between boys and girls when the test score is higher than the initial teacher's assessment. However, when the test score is lower than the initial teacher's assessment teachers seem to adjust boys' final assessment downwards by 0.366 tracks on average, while teachers seem to adjust girls' final assessment downwards by 0.515 tracks on average. This difference is statistically significant at 5 percent. A possible explanation for this finding is that teachers more often give girls the benefit of the doubt by giving them a slightly higher initial teacher's assessment conditional on their test score. Likewise, it is also possible that teachers underestimate boys in their initial assessment. Possibly this is due to better classroom behaviour of girls at this age (e.g. Bertrand and Pan, 2011; Entwisle, Alexander \& Olsen, 2007; Segal, 2008 and Segal, 2013). As a result, teachers could be more disappointed with the performance of girls (compared to boys) when their test score is lower than the initial teacher's assessment.

The results for the parental education levels in Table 8 suggest a trend in the magnitude of the estimated coefficients for the relation of the difference between the test score and the initial teacher's assessment to the final teacher's assessment. ${ }^{39}$ The effect of having a test score that is higher than the initial teacher's assessment is on average positive across all parental education levels, while the effect of having a test score that is lower than the initial teacher's assessment is on average negative for the final teacher's assessment across all parental education levels. The interesting aspect is that having a higher educated parent is much more beneficial when the test score deviates from the initial teacher's assessment compared to having a lower educated parent. When the test score is higher than the initial teacher's assessment, the magnitude of the relation increases for children with higher educated parents. The positive effect of having a mother with a university education is 1.3 times as large compared to the effect of having a mother with a low level of education. For fathers the estimated effect is slightly larger (1.4) but not significantly so.

\footnotetext{
${ }^{39}$ The baseline for the regression coefficients of gender and the education level of parents is when the test score is equal to the initial teacher assessment. The baseline for the interaction coefficients in the first column of table 8 is when the test is lower or equal to the initial teacher assessment and the gender is boys (gender=0). Compared to these baseline estimates all reported coefficients in column 1 are significantly different. However, in column 1 the reported interaction coefficients for boys and girls are not significantly different from each other. The baseline for the effects of the education level of mothers in column 3 in table 8 is when the test score is lower or equal to the initial teacher assessment and the education level of the mother/father is lower education (education level=1). Compared to these baseline estimates all reported coefficients in column 3 are significantly different.
} 
When the test score is lower than the initial teacher's assessment the magnitude of the relation steadily decreases for children with higher educated parents. The positive effect of having a mother with a university education is 1.5 times as large compared to the effect of having a mother with lower education. For fathers the effect is even 2.0 times as large. The effect sizes of different education levels for mothers are not significantly different from the lower education level, however, the effect sizes of different education levels of fathers are significantly different from the lower education level.

There might be several explanations for these findings. First, it is possible that children from higher educated parents have more developed non-cognitive skills that influence their performance in school (e.g. Blanden et al., 2007; Garcia et al., 2017). These non-cognitive skills are unobserved in our model. Second, teachers might be aware that higher educated parents likely have higher income and more resources available to supports their children's educational needs, and are more able to make investments such as tutoring or other aids (e.g. Ben-Porath, 1967; Heckman et al., 2005). Third, there could be intergenerational mobility where higher educated parents are better able to support their children in school as these parents have followed a similar or higher track in school themselves (e.g. Black and Devereux, 2010). Fourth, teachers are aware that higher educated parents make more investments in their children by stimulating their children more to perform well in school compared to lower educated parents. Higher educated parents might also better understand the importance of education compared to lower educated parents (e.g. Guryan et al., 2008). Schools indicate that they incorporate children's behavioural characteristics, whether children have a stable home situation, the involvement of parents in their children's education and the opportunities that parents have to support their children, into teacher's assessments (Inspectorate of Education, 2014). Overall, we conclude that gender and parental education levels seem to be related to how teachers adjust their assessment of children's ability after observing the test score. 


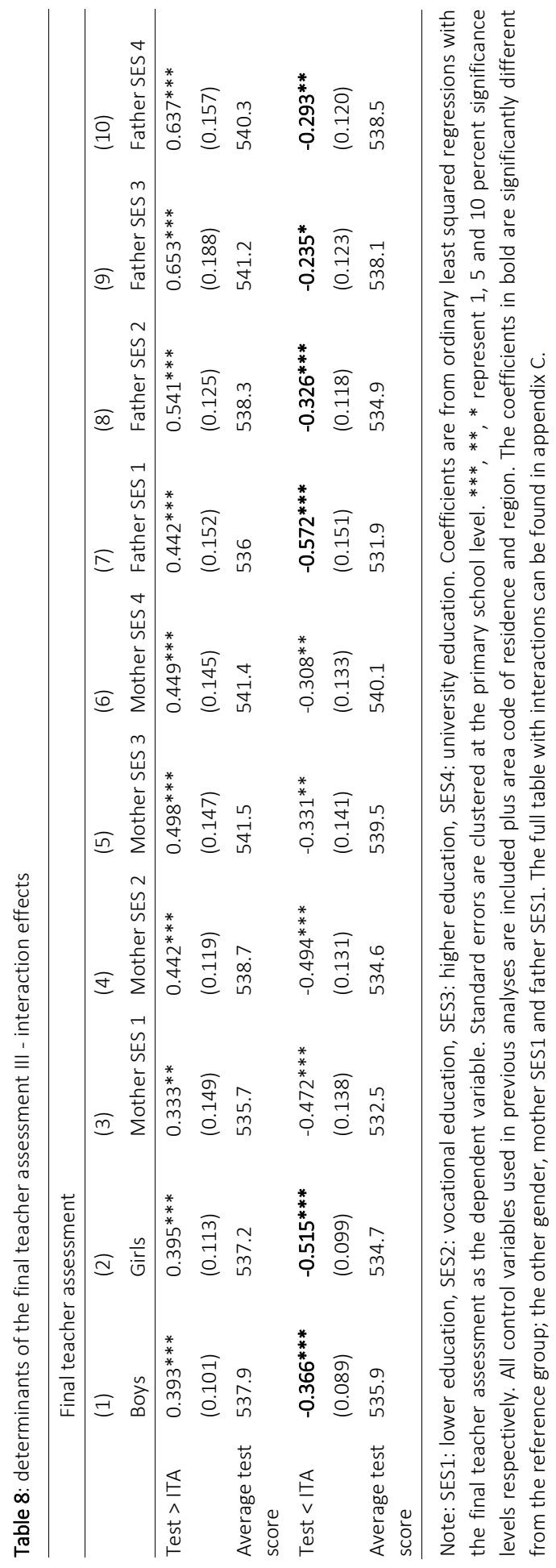




\subsubsection{Robustness checks}

To look further into the heterogeneity across groups we investigated three-way interactions between gender, parental education levels and the difference between the test score and the initial teacher's assessment on the final teacher's assessment. There seem to be no statistically significant differences between gender and parental education levels when the test score is higher than the initial teacher's assessment. However, when the test score is lower than the initial teacher assessment, we obtain estimated coefficients that suggest that there could be differences between gender and parental education. These results are documented in Appendix $D$ and are consistent with the results from Table 8 .

Several other papers have noted that there exists a difference in math and language scores between boys and girls (e.g., Goldin, Katz and Kuziemko, 2006; Dee, 2007; Fryer \& Levitt, 2010; Niederle \& Vesterlund, 2010). We investigate whether gender is related to the test score on the math and language component of the test and whether the final teacher's assessment is more dependent on the math or the language component of the test. The estimated coefficients in Appendix $G$ suggest that on average girls have a lower overall test score than boys. Girls have a significantly higher score on the language component and a significantly lower score on the math component of the test compared to boys. However, we do not find a significant difference in the relation between the language score and the final teacher's assessment and the math score and the final teacher's assessment when we standardize the language score and the math score. ${ }^{40}$ Both measures seem to have a similar relation to the final teacher's assessment.

When we finally investigate the interaction between gender and having a below/above average language or math score, we find that compared to the reference level; lower than average language score and boys, being a girl with a below average score on language has a significantly negative relation to the final teacher's assessment. The estimated coefficients are shown in Appendix $\mathrm{H}$. It seems that girls are more negatively affected by having a below average language score compared to boys. For both boys and girls having an above average language score is significantly positively related to the final teacher's assessment. However, the adjustment effect for boys on the final teacher's assessment is significantly higher than the adjustment effect for girls. A possible explanation for this finding is that this result is more expected from girls than from boys and therefore the teacher is more surprised by boys' performance. The estimated coefficients suggest that there is no difference between boys and girls who have a below or an above average math score on the final assessment.

\footnotetext{
${ }^{40}$ This analysis is not in the table.
} 


\subsection{Policy perspective}

The results in this research suggest that teachers adjust their initial assessment of children's ability level based on the additional information they obtain from the test score. Teachers adjust their assessment heterogeneously across gender and parental education levels. It is likely that the estimated coefficients that we obtain represent a lower bound of the adjustment effect based on the test score. This is likely the case because teachers have knowledge about children's previous test scores and they are likely correlated with their test score in $6^{\text {th }}$ grade. If teachers would not have this information about previous test scores, the adjustment effect based on the test score would in all likelihood be larger.

The policy implications of these findings depend on whether teachers are biased against certain groups or if teachers recognize that they made an incorrect initial assessment and correctly adjust their assessment based on the test score. In the first case, the teacher is biased against certain groups and the heterogeneous adjustment across groups is a reflection of this bias that is likely already present in the initial teacher's assessment. Even in this case the teachers' adjustment can be efficient depending on the reasons for the adjustment. For example, teachers might believe that children from highly educated parents are more likely to successfully complete a higher level of secondary education because their parents have more resources available for additional schooling or that children from highly educated parents are endowed with a different set of non-cognitive skills that are more beneficial for the successful completion of secondary education compared to children from lower educated parents. This might violate the idea of equal opportunities for all children regardless of their gender and socialeconomic background, but it might be efficient if the teacher is correct in his judgement that these children are more successful in completing secondary education. In the second case, the teacher is not biased against certain groups but he recognizes that he made an incorrect initial assessment. Now the adjustment is a reflection of additional information that has become available in terms of the test score.

To assess the value of a separate measure of children's ability levels we can compare how well the initial teacher's assessment and the final teacher's assessment predict children's performance in the form of children's track allocation in secondary education in $9^{\text {th }}$ grade. This question relates to the topic and the analysis in Chapter 3 , which is about track switching between $7^{\text {th }}$ and $9^{\text {th }}$ grade. The results in Appendix I seem to suggest that on average the final teacher's assessment is more accurate in predicting children's track allocation in $9^{\text {th }}$ grade compared to the initial teacher's assessment. Regardless of whether teachers adjust their initial assessment due to a bias against certain groups or due to the availability of new information, the test score seems to be a valuable addition. In the first case, the test score can be used as an objective measure of children's ability that can (partly) compensate for teachers' bias. The test score can indicate that children have the skills/knowledge to attend a certain level of secondary 
education. In this setting, the test ensures the (more) equal opportunities of children across groups. In the second case, the test score provides additional information to teachers that was previously not known. This additional information helps to reduce the measurement error in determining children's ability level and increases the probability of allocating children to their most appropriate track in secondary education.

\subsection{Conclusions}

Up to the schoolyear 2014-2015 two measures of children's ability level are used to allocate children to tracks in secondary school, the test score and the final teacher's assessment. One of the most attractive features of test scores is that they are assumed to reflect an objective assessment of children's ability level, whereas the teacher's assessment is subjective and could be (unintentionally) biased by prejudice. The advantage of the teacher's assessment is that it is able to incorporate more information than the test score.

This paper addresses the question to what extent and for whom teachers adjust their initial assessment of children's ability level after observing the children's test score. If teachers have all information necessary to make an accurate assessment of children's ability levels than adjustments based on the test score should not be necessary. However, the estimates in this paper show that teachers significantly adjust their initial assessments based on the test score. Apparently, the test score provides information that is not previously known to the teacher or information that was not yet incorporated into the teacher's assessment. The estimates show that teachers adjust their initial assessment heterogeneously across gender and parental education levels. We observe that girls and children whose parents obtained a low level of education receive a disadvantageous adjustment compared to boys and children whose parents obtained a higher level of education.

Whether the adjustment to the initial teacher's assessment is due to teachers' bias against certain groups or due to the availability of new information cannot be causally determined by the dataset that is used in this paper. Policy implications depend on which of these two channels drives the obtained results. Nevertheless, this paper shows that regardless of which of these two options is correct, the information that is provided by the test score in $6^{\text {th }}$ grade provides valuable additional information to teachers about children's ability levels. 


\section{References}

Akerlof, G. A. and Kranton, R. E., (2002) Identity and schooling: some lessons for the economics of education, Journal of Economic Literature, Vol. XL. pp. 1167-1201.

Ben-Porath, Y. (1967) The production of human capital and the life-cycle of earnings, The Journal of Political Economy, Vol. 75. No. 4. Part 1, pp. 352-365.

Bertrand, M and Pan, J., (2013) The trouble with boys: social influences and the gender gap in disruptive behavior, American Economic Journal: Applied Economics, Vol. 5. No. 1. pp. 32-64.

Black, S.E. and Devereux, P.J. (2010) Recent developments in intergenerational mobility. NBER working paper no. 15889.

Blanden, J., Gregg, P. and Macmillan, L. (2007) Accounting for intergenerational income persistence: noncognitive skills, ability and education. The Economic Journal, Vol. 117, No. 519, pp. 43-60.

Burgess, S. and Greaves, E., (2013), Test scores, subjective assessment, and stereotyping of ethnic minorities, Journal of Labor Economics, Vol. 31. No. 3. pp. 535-576.

Carneiro, P. M. and Heckman J., (2003), Human Capital Policy, IZA discussion paper no. 821.

Cito, 2015, 'Het verhaal van Cito', Retrieved from the World Wide Web on April $1^{\text {st }} 2015$ : http://www.cito.nl/over\%20cito/dit_is_cito/het_verhaal_van_cito

Cornwell, C., Mustard, D.B. and Jessica van Parys, (2012) Noncognitive skills and the gender disparities in test scores and teacher assessments, The Journal of Human Resources, Vol. 28. No. 1. pp. 236-264.

Cunha, F. and Heckman, J., (2007) The Technology of Skill Formation, American Economic Review, Vol. 97 No. 2. pp. 31-47.

Dee, T.S., (2005) A teacher like me: does race, ethnicity or gender matter?, The American Economic Review, Vol. 95, No. 2. pp. 158-165.

Dee, T.S., (2007) Teachers and the gender gaps in student achievement. Journal of Human Resources. Vol. 42 No. 3 pp. 528-554.

Entwisle, D.R., Alexander, K.L and Olson, L.S., (2007) Early schooling: the handicap of being poor and male, Sociology of Education, Vol. 80. No. 2. pp. 114-138.

Fairlie, R.W., Hoffmann, F and Oreopoulos, P., (2011) A community college instructor like me: race and ethnicity interactions in the classroom. Forthcoming in the American Economic Review.

Ferguson, R.D., (2003), Teachers' perceptions and expectations and the black-white test score gap, Urban Education, Vol. 38. No. 4. pp. 460-507.

Feron, E., Schils, T. and Weel, B. t. (2016) Does the Teacher Beat the Test? The Value of the Teacher's Assessment in Predicting Student Ability, De Economist, Vol. 164. No. 4. pp. 391-418.

Fryer, R. and Levitt, S., (2010), An empirical analysis of the gender gap in mathematics, American Economic Journal: Applied Economics, Vol. 2. No. 2.

Garcia, J.L., Heckman, J.J., Leaf, D. E. and Prados, M.J. (2017) Quantifying the Life-cycle Benefits of a Prototypical Early Childhood Program. Draft version may 26 ${ }^{\text {th }}$ 2017. https://heckmanequation.org/assets/ 2017/12/abc_comprehensivecba_JPE-SUBMISSION_2017-05-26a_sjs_sjs.pdf

Goldin, C., Katz, LF and Kuziemko, I., (2006), The homecoming of American college women: the reversal of the college gender gap, Journal of Economic Perspectives, Vol. 20. No. 4. pp. 133-156.

Guryan, J., Hurst, E. and Schettini Kearney, M. (2008) Parental Education and Parental Time with Children. Journal of Economic Perspectives, Vol. 22, No. 3., pp. 23-46.

Heckman, J.J., Lochner, L.J. and Todd, P. (2005) Earnings functions, rates of return and treatment effects: the Mincer equation and beyond. IZA Discussion papers no. 1700.

Inspectie van het Onderwijs, (2014), De kwaliteit van het basisschooladvies; een onderzoek naar de totstandkoming van het basisschooladvies en de invloed van het basisschooladvies op de verdere schoolloopbaan.

Jussim, L and Harber, K.D., (2005), Teacher expectations and self-fulfilling prophecies: knowns and unknowns, resolved and unresolved controversies, Personality and Social Psychology Review, Vol. 9 No. 2 pp. 131155. 
Kautz, T., Heckman, J.J., Diris, R. ter Weel, B and Borghans, L. (2014) Fostering and measuring skills: improving cognitive and non-cognitive skills to promote lifetime success, Working paper, University of Chicago.

Lavy, V., (2008) Do gender stereotypes reduce girls' or boys' human capital outcomes? Evidence from a natural experiment, Journal of Public Economics, Vol. 92. pp. 2083-2105.

Lavy, $V$ and Sand, E., (2015), On the origins of gender human capital gaps: short and long term consequences of teachers' stereotypical biases, NBER Working Paper No. 20909.

Lindahl, E. (2007) Comparing teachers' assessments and national test results - evidence from Sweden, IFAU working paper 2007:24.

Niederle, M. and Vesterlund, L, (2010), Expaining the gender gap in math test score: the role of competition. Journal of Economic Perspectives, Vol. 24 No. 2. pp. 129-144.

Onderwijsraad, (2014), Overgangen in het onderwijs, Den Haag: Onderwijsraad.

Plewis, I., (1997) Inferences about teacher expectations from national assessment at key stage one, British Journal of Educational Psychology, Vol. 67. pp. 235-247.

Phelps, E., (1972) A statistical theory of racism and sexism, The American Economic Review, Vol. 62. No. 4. pp. 659-661.

Rijksoverheid_a, 2015, 'Nieuwe landelijke eindtoets basisscholen later in het schooljaar' Retrieved from the World Wide Web on April $1^{\text {st }}$ : http://www.rijksoverheid.nl/nieuws/2011/03/01/nieuwe-landelijkeeindtoets-basisscholen-later-in-het-schooljaar.html

Rijksoverheid_b, 2015, 'Verplichte eindtoets basisonderwijs' Retrieved from the World Wide Web on April $1^{\text {st }}$ 2015: http://www.rijksoverheid.nl/onderwerpen/toelating-middelbare-school/verplichte-eindtoetsbasisonderwijs

Segal, C. (2008) Classroom behavior, Journal of Human Resources, Vol. 43. No. 4. pp. 783-814.

Segal, C. (2013) Misbehavior, education and labor market outcomes, Journal of the European Economic Association, Vol. 11. No. 4. pp. 743-779.

Timmermans, A., Kuyper, H and van der Werf, G., (2013) Schooladviezen en onderwijsloopbanen. Voorkomen, risicofactoren en gevolgen van onder- en overadvisering, Rijksuniversiteit Groningen; Gronings Instituut voor onderzoek van Onderwijs (GION). 


\section{Appendix}

This appendix presents supporting material. In Section A we discuss the bivariate correlation coefficients of all of our outcome measures and covariates used in our analyses. In section B we investigate whether or not individual characteristics are able to predict whether children end up in our sample for analyses. Section $C$ presents the interaction table of the determinants of the final teacher's assessment. Section D follows up on section $C$ and presents the three way interaction table of the determinants of the final teacher's assessment. Section E presents the results of an ordered probit regression corresponding to table 6 . Section $\mathrm{F}$ presents the results of an ordered probit regression corresponding to table 7 . Section $\mathrm{G}$ and section $\mathrm{H}$ present differences between math and language scores. Section I presents how the initial teacher's assessment and the final teacher's assessment predict children's track allocation in $9^{\text {th }}$ grade. 


\section{A. Correlations}

Table A shows the bivariate correlation coefficients of our main variables of interest, the initial teacher's assessment, the test score and the final teacher's assessment as well as the covariates used in the analysis. First of all, we observe that the correlation coefficients between our main variables of interest are all high and significant. The correlation coefficient between the test score and the final teacher's assessment is higher than the correlation coefficient between the test score and the initial teacher's assessment. This might be the first indication that teachers adjust their assessment after observing children's test score. Seconds, girls seem to have a lower test score compared to boys, but they do not seem to have lower teacher's assessments. Third, children who are older seem to have a lower test score and lower teacher's assessments. Fourth, the region of birth of the child and the mother does not seem to be related to the test score or to the teacher's assessments. However, when fathers are born further away from Limburg there seems to be a negative relationship with the children's test score and the teacher's assessments. Fifth, the education level of both the mother and the father is significantly positively related to the children's test score and the teacher's assessments. Sixth, fathers and mothers who are not employed show a negative relation to the children's test score and the teacher's assessments. Finally, children who report to live with both their mother and father seem to have a higher test score and teacher's assessments compared to children who do not live with both parents. Overall, the covariates used in the analysis do not show any surprising relationships with the children's test score and the teacher's assessments. 
The impact of cognitive tests on teachers updating their assessments

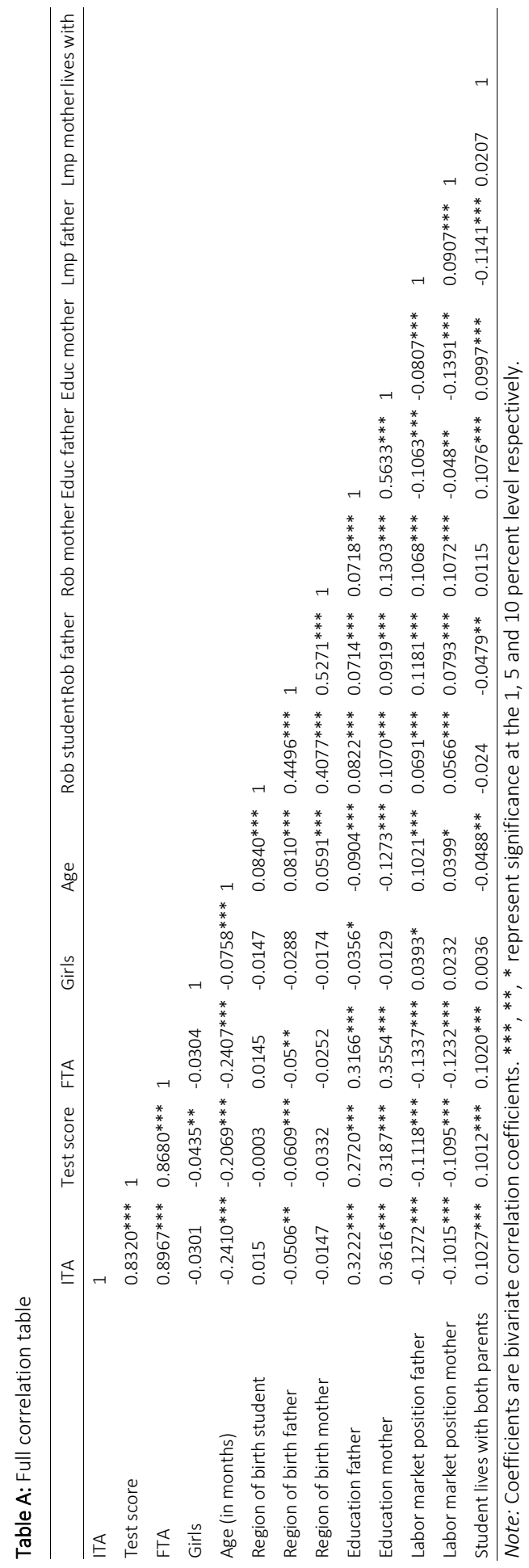




\section{B. Selection into the sample}

We address selection issues with regard to the sample we use for our analyses in Table B. Table B shows probit and OLS estimates of whether characteristics of children are able to predict whether the child ends up in our sample for analyses. The dependent variable is whether the child ends up in our sample (1) or has missing data (0). Children who end up in our sample for analyses are children for whom we have data on the initial teacher's assessment, the test score and the final teacher's assessment.

Table B shows that after controlling for primary school fixed effects and clustering the standard errors at the primary school level there are almost no individual characteristics that predict whether children end up in our sample for analysis or not. We use primary school fixed effects since we are concerned mainly about selection within schools, where schools only provide us with data about their best performing children and might leave out data about lower performing children. We expect that such selection would show up on children's SES data, such as the education levels of their parents. We cluster standard errors at the primary school level since observations of children are likely not independent within the primary school they attend. The results show that children who are older are less likely to be represented in our sample for analyses. When parents have vocational or higher education or the child lives with both parents, the child is approximately 4 percentage points more likely to end up in our sample compared to when the parents have lower education or the child does not live with both parents, however, we do not see this result for children whose parents have completed university education. In column 2 and column 5 we only use those children for whom we have information on their test score. There are only a few children for whom we have information on teacher's assessments but not on their test score. There does not seem to be a difference between the characteristics of children for whom we have a test score and for whom we do not have a test score. We find minor evidence that there are observable characteristics of children that are able to predict whether the child ends up in the sample. Since we do not find strong evidence that observable characteristics of children predict whether the child ends up in our sample, we assume that there are also no unobservable characteristics that distinguish the children in our sample from the children who are not in our sample. Note that there are missing observations in our analyses. This is due to the fact that we do not have information on all covariates for all children. Since we are specifically interested in whether any of these covariates predict selection into our sample for analyses we lose observations when data on covariates is missing. Furthermore, we only have primary school fixed effects for children in the south of the region where we obtained the data from. 
Table B: Selection into the sample

\begin{tabular}{|c|c|c|c|c|c|c|}
\hline & \multicolumn{6}{|c|}{ Selection into sample } \\
\hline & $(1)$ & $(2)$ & (3) & (4) & (5) & $(6)$ \\
\hline \multirow[t]{2}{*}{ Female } & 0.059 & 0.056 & -0.031 & 0.004 & 0.004 & -0.012 \\
\hline & $(0.101)$ & $(0.102)$ & $(0.050)$ & $(0.011)$ & $(0.011)$ & $(0.019)$ \\
\hline \multirow[t]{2}{*}{ Age (in months) } & $-0.027 * *$ & $-0.023 * *$ & $-0.012 * *$ & $-0.003 * *$ & $-0.003^{*}$ & $-0.005 * *$ \\
\hline & $(0.011)$ & $(0.011)$ & $(0.006)$ & $(0.001)$ & $(0.001)$ & $(0.002)$ \\
\hline \multirow[t]{2}{*}{ Child born in other region NL } & 0.188 & 0.240 & -0.011 & 0.027 & 0.032 & -0.003 \\
\hline & $(0.282)$ & $(0.246)$ & $(0.141)$ & $(0.030)$ & $(0.024)$ & $(0.053)$ \\
\hline \multirow[t]{2}{*}{ Child born abroad } & 0.319 & 0.219 & $-0.258^{*}$ & 0.020 & 0.014 & -0.095 \\
\hline & $(0.276)$ & $(0.273)$ & $(0.151)$ & $(0.027)$ & $(0.028)$ & $(0.058)$ \\
\hline \multirow[t]{2}{*}{ Father born in other region $\mathrm{NL}$} & -0.017 & 0.043 & -0.028 & -0.005 & 0.000 & -0.011 \\
\hline & $(0.221)$ & $(0.229)$ & (0.109) & $(0.024)$ & $(0.025)$ & $(0.041)$ \\
\hline \multirow[t]{2}{*}{ Father born abroad } & 0.143 & 0.167 & 0.044 & 0.019 & 0.020 & 0.014 \\
\hline & $(0.212)$ & $(0.215)$ & (0.108) & $(0.021)$ & $(0.021)$ & $(0.040)$ \\
\hline \multirow[t]{2}{*}{ Mother born in other region NL } & -0.185 & -0.201 & 0.005 & -0.016 & -0.016 & 0.002 \\
\hline & $(0.182)$ & $(0.192)$ & $(0.111)$ & $(0.018)$ & $(0.019)$ & $(0.042)$ \\
\hline \multirow[t]{2}{*}{ Mother born abroad } & -0.132 & -0.148 & $0.197^{*}$ & -0.013 & -0.013 & $0.073^{*}$ \\
\hline & $(0.178)$ & $(0.178)$ & $(0.110)$ & $(0.021)$ & $(0.021)$ & $(0.041)$ \\
\hline \multirow[t]{2}{*}{ Father has vocational education } & $0.376^{* * *}$ & $0.403^{* * *}$ & -0.010 & $0.042 * *$ & $0.042^{* *}$ & -0.003 \\
\hline & (0.139) & $(0.145)$ & $(0.068)$ & $(0.017)$ & $(0.017)$ & $(0.025)$ \\
\hline \multirow[t]{2}{*}{ Father has higher education } & $0.468^{* * *}$ & $0.479 * * *$ & 0.091 & $0.048^{* * *}$ & $0.047^{* * *}$ & 0.033 \\
\hline & $(0.167)$ & $(0.169)$ & $(0.089)$ & $(0.017)$ & $(0.017)$ & $(0.033)$ \\
\hline \multirow[t]{2}{*}{ Father has university education } & 0.184 & 0.168 & -0.020 & 0.021 & 0.018 & -0.007 \\
\hline & $(0.156)$ & $(0.156)$ & $(0.082)$ & $(0.018)$ & $(0.018)$ & $(0.031)$ \\
\hline \multirow[t]{2}{*}{ Mother has vocational education } & -0.036 & -0.129 & -0.026 & -0.000 & -0.010 & -0.010 \\
\hline & $(0.135)$ & $(0.135)$ & $(0.067)$ & $(0.015)$ & $(0.014)$ & $(0.025)$ \\
\hline \multirow[t]{2}{*}{ Mother has higher education } & 0.266 & 0.194 & 0.105 & 0.032 & 0.024 & 0.038 \\
\hline & $(0.205)$ & $(0.204)$ & $(0.088)$ & $(0.021)$ & $(0.020)$ & $(0.032)$ \\
\hline \multirow[t]{2}{*}{ Mother has university education } & 0.317 & 0.256 & -0.116 & 0.031 & 0.024 & -0.045 \\
\hline & $(0.197)$ & $(0.195)$ & $(0.118)$ & $(0.019)$ & $(0.019)$ & $(0.045)$ \\
\hline \multirow[t]{2}{*}{ Father is unemployed } & 0.201 & 0.151 & 0.007 & 0.013 & 0.010 & 0.003 \\
\hline & $(0.386)$ & $(0.388)$ & $(0.160)$ & $(0.038)$ & (0.039) & $(0.060)$ \\
\hline \multirow[t]{2}{*}{ Father is sick/unable to work } & -0.062 & 0.159 & 0.038 & -0.003 & 0.024 & 0.017 \\
\hline & (0.329) & $(0.343)$ & $(0.198)$ & $(0.042)$ & $(0.035)$ & $(0.074)$ \\
\hline \multirow{2}{*}{$\begin{array}{l}\text { Father has other labour market } \\
\text { position }\end{array}$} & 0.550 & 0.528 & 0.194 & 0.070 & 0.066 & 0.071 \\
\hline & $(0.335)$ & $(0.341)$ & (0.219) & $(0.047)$ & $(0.048)$ & $(0.079)$ \\
\hline \multirow[t]{2}{*}{ Mother is unemployed } & -0.344 & -0.317 & 0.106 & -0.004 & 0.001 & 0.041 \\
\hline & $(0.403)$ & $(0.436)$ & $(0.191)$ & $(0.042)$ & $(0.041)$ & $(0.068)$ \\
\hline \multirow[t]{2}{*}{ Mother is sick/unable to work } & 0.132 & 0.228 & -0.123 & 0.025 & 0.034 & -0.045 \\
\hline & $(0.243)$ & $(0.248)$ & $(0.128)$ & $(0.026)$ & $(0.024)$ & $(0.049)$ \\
\hline \multirow{2}{*}{$\begin{array}{l}\text { Mother has other labour market } \\
\text { position }\end{array}$} & 0.160 & 0.171 & 0.146 & 0.021 & 0.023 & 0.053 \\
\hline & $(0.165)$ & (0.170) & (0.089) & (0.017) & $(0.017)$ & (0.033) \\
\hline
\end{tabular}




\begin{tabular}{lllllll}
\hline \multicolumn{7}{l}{ Selection into sample } \\
& $(1)$ & $(2)$ & $(3)$ & $(4)$ & $(5)$ & $(6)$ \\
\hline Child lives with both parents & $0.326^{* *}$ & $0.288^{* *}$ & 0.051 & $0.038^{* *}$ & $0.033^{*}$ & 0.019 \\
& $(0.134)$ & $(0.137)$ & $(0.067)$ & $(0.017)$ & $(0.017)$ & $(0.025)$ \\
Constant & $5.358^{* *}$ & $5.333^{* *}$ & 0.342 & $1.491^{* * *}$ & $1.421^{* * *}$ & $0.849^{* *}$ \\
& $(2.170)$ & $(2.168)$ & $(1.175)$ & $(0.254)$ & $(0.253)$ & $(0.400)$ \\
\hline Model & Probit & Probit & Probit & OLS & OLS & OLS \\
School FE & yes & yes & no & yes & yes & no \\
Clustered SE & yes & yes & yes & yes & yes & yes \\
Observations & 1,091 & 1,041 & 2,363 & 2,363 & 2,304 & 2,363 \\
\hline
\end{tabular}

Note: The coefficients are from probit regressions and ordinary least squares regressions with a dummy variable for selection into the sample as the dependent variable. Selected into the sample equals 1 , all other observations equal 0 . In column 2 and 5 only children for whom we have information on the test score are included. Standard errors are clustered at the primary school level. ***,**, * represent 1, 5 and 10 percent significance levels respectively. Other control variables in all the regressions are areas code of residence and region. 


\section{Determinants of the final teacher's assessment - interaction table}

Table $\mathrm{C}$ reports the interaction table of the estimates from ordinary least squares regressions where characteristics of children are interacted with a dummy for the positive or negative difference between the test score and the initial teacher's assessment. These results have also been discussed in table 8 in the main section of this paper. The table reports estimates for the gender of the child and the education level of the father and the mother. Column 1 and 2 report the effects related to the gender of the child. The estimates for gender show no significant difference between boys and girls when the test score is higher than the initial teacher's assessment. However, when the test score is lower than the initial teacher's assessment teachers adjust boys' final assessment downwards with 0.366 tracks on average while teachers adjust girls' final assessment downwards with 0.515 tracks on average. This difference is statistically significant at 5 percent.

The results for the education level of the mother and the father show that there is a clear trend in the magnitude of the coefficients regarding the difference between the test score and the initial teacher's assessment to the final teacher's assessment. ${ }^{41}$ The effect of having a test score that is higher than the initial teacher's assessment is on average positive across all education levels of mothers and fathers while the effect of having a test score that is lower than the initial teacher's assessment is on average negative for the final teacher's assessment across all education levels of mothers and fathers. The interesting aspect is that having a highly educated parent is much more beneficial when the test score deviates from the initial teacher's assessment than is having a lower educated parent. When the test score is higher than the initial teacher's assessment the magnitude of the relation increases for children with higher educated parents. However, even though a clear trend is visible the differences between the effect sizes of different education levels for mothers and fathers are not significantly different from the effect of the lower education level. When the test score is lower than the initial teacher's assessment the magnitude of the relation steadily decreases for children with higher educated parents. The effect sizes of different education levels for mothers are not significantly different from the lower education level, however, the effect sizes of different education levels of fathers are significantly different from the lower education level.

\footnotetext{
${ }^{41}$ The baseline for the regression coefficients of gender and the education level of parents is when the test score is equal to the initial teacher's assessment. The baseline for the interaction coefficients in the first column of table 8 is when the test is lower or equal to the initial teacher's assessment and the gender is boys (gender=0). Compared to these baseline estimates all reported coefficients in column 1 are significantly different. However, in column 1 the reported interaction coefficients for boys and girls are not significantly different from each other. The baseline for the effects of the education level of mothers in column 3 in table 8 is when the test score is lower or equal to the initial teacher's assessment and the education level of the mother/father is lower education (education level=1). Compared to these baseline estimates all reported coefficients in column 3 are significantly different.
} 
Table C: Determinants of the final teacher's assessment - interaction table

\begin{tabular}{|c|c|c|c|c|c|c|}
\hline & \multicolumn{6}{|c|}{ Final teacher assessment } \\
\hline & (1) & $(2)$ & (3) & $(4)$ & $(5)$ & (6) \\
\hline \multirow[t]{2}{*}{ Test $>$ ITA \& boys } & $0.393 * * *$ & & & & & \\
\hline & $(0.101)$ & & & & & \\
\hline \multirow[t]{2}{*}{ Test $>$ ITA \& girls } & $0.395 * * *$ & & & & & \\
\hline & $(0.113)$ & & & & & \\
\hline \multirow[t]{2}{*}{ Test $<$ ITA \& boys } & & $-0.366 * * *$ & & & & \\
\hline & & $(0.089)$ & & & & \\
\hline \multirow[t]{2}{*}{ Test $<$ ITA \& girls } & & $-0.515 * * *$ & & & & \\
\hline & & (0.099) & & & & \\
\hline \multirow[t]{2}{*}{ Test $>$ ITA \& lower educ mother } & & & $0.333 * *$ & & & \\
\hline & & & $(0.149)$ & & & \\
\hline \multirow[t]{2}{*}{ Test > ITA \& vocational educ mother } & & & $0.442 * * *$ & & & \\
\hline & & & (0.119) & & & \\
\hline \multirow[t]{2}{*}{ Test $>$ ITA \& higher educ mother } & & & $0.498 * * *$ & & & \\
\hline & & & $(0.147)$ & & & \\
\hline \multirow[t]{2}{*}{ Test > ITA \& university educ mother } & & & $0.449 * * *$ & & & \\
\hline & & & $(0.145)$ & & & \\
\hline \multirow[t]{2}{*}{ Test > ITA \& lower educ father } & & & & $0.442 * * *$ & & \\
\hline & & & & $(0.152)$ & & \\
\hline \multirow[t]{2}{*}{ Test > ITA \& vocational educ father } & & & & $0.541 * * *$ & & \\
\hline & & & & $(0.125)$ & & \\
\hline \multirow[t]{2}{*}{ Test $>$ ITA \& higher educ father } & & & & $0.653^{* * *}$ & & \\
\hline & & & & $(0.188)$ & & \\
\hline \multirow[t]{2}{*}{ Test > ITA \& university educ father } & & & & $0.637^{* * *}$ & & \\
\hline & & & & $(0.157)$ & & \\
\hline \multirow[t]{2}{*}{ Test $<$ ITA \& lower educ mother } & & & & & $-0.472 * * *$ & \\
\hline & & & & & $(0.138)$ & \\
\hline \multirow[t]{2}{*}{ Test $<$ ITA \& vocational educ mother } & & & & & $-0.494 * * *$ & \\
\hline & & & & & $(0.131)$ & \\
\hline \multirow[t]{2}{*}{ Test $<$ ITA \& higher educ mother } & & & & & $-0.331^{* *}$ & \\
\hline & & & & & $(0.141)$ & \\
\hline \multirow[t]{2}{*}{ Test < ITA \& university educ mother } & & & & & $-0.308 * *$ & \\
\hline & & & & & $(0.133)$ & \\
\hline \multirow[t]{2}{*}{ Test $<$ ITA \& lower educ father } & & & & & & $-0.572 * * *$ \\
\hline & & & & & & $(0.151)$ \\
\hline \multirow[t]{2}{*}{ Test $<$ ITA \& vocational educ father } & & & & & & $-0.326 * * *$ \\
\hline & & & & & & $(0.118)$ \\
\hline \multirow[t]{2}{*}{ Test $<$ ITA \& higher educ father } & & & & & & $-0.235^{*}$ \\
\hline & & & & & & $(0.123)$ \\
\hline \multirow[t]{2}{*}{ Test $<$ ITA \& university educ father } & & & & & & $-0.293 * *$ \\
\hline & & & & & & $(0.120)$ \\
\hline \multirow[t]{2}{*}{ Constant } & $-2.555 * * *$ & $-2.642 * * *$ & $-2.522 * * *$ & $-2.559 * * *$ & $-2.619 * * *$ & $-2.532 * * *$ \\
\hline & $(0.897)$ & $(0.905)$ & $(0.903)$ & $(0.902)$ & $(0.898)$ & $(0.913)$ \\
\hline
\end{tabular}




\begin{tabular}{lllllll}
\hline \multicolumn{7}{l}{ Final teacher assessment } \\
& $(1)$ & $(2)$ & $(3)$ & $(4)$ & $(5)$ & $(6)$ \\
\hline School FE & yes & yes & yes & yes & yes & yes \\
Classroom FE & yes & yes & yes & yes & yes & yes \\
Clustered SE & yes & yes & yes & yes & yes & yes \\
Observations & 1,404 & 1,404 & 1,404 & 1,404 & 1,404 & 1,404 \\
R-squared & 0.920 & 0.920 & 0.920 & 0.920 & 0.920 & 0.920 \\
\hline
\end{tabular}

Note: Coefficients are from ordinary least squared regressions with the final teacher assessment as the dependent variable. Standard errors are clustered at the primary school level. ***, **, * represent 1, 5 and 10 percent significance levels respectively. All control variables used in previous analyses are included plus area code of residence and region. 


\section{Determinants of the final teacher's assessment - three-way interaction table}

Table D reports the interaction table of the estimates from ordinary least squares regressions where characteristics of children are interacted with a dummy for the positive or negative difference between the test score and the initial teacher's assessment.

The table reports estimates for the interactions between the test being higher/lower than the initial teacher's assessment, gender of the child and the education level of the father or the mother. There are no significant differences found between gender and parents' education level when the test score is higher than the initial teacher's assessment. This is in line with the results from table $8 .{ }^{42}$

However, when the test score is lower than the initial teacher's assessment we find that there is a significant difference between the gender of a child and the relation to the final teacher's assessment when the mother has vocational education. Girls' average teacher's assessment is adjusted significantly more downwards in this case. This same result occurs with fathers' education level. Furthermore, we find differences between fathers' education level when the test score is lower than the initial teacher's assessment. First, there is a significant difference for boys when the father has lower education compared to when the father has higher education. The negative effect of having a test score that is lower than the initial teacher's assessment is much lower for boys whose father has completed higher education. Second, there are significant differences between girls' adjustment when the father has lower education compared to when the father has higher or university education. In these cases the children whose father has lower education receive a significantly greater adjustment downwards in their final teacher's assessment.

\footnotetext{
${ }^{42}$ The baseline for the regression coefficients is when the test score is equal to the initial teacher's assessment. The baseline for the interaction coefficients in the first column of table $D$ is when the test is lower or equal to the initial teacher's assessment and the gender is boys (gender $=0$ ) and the education level of the mother is lower education (education=1). Compared to this baseline estimate some of the reported coefficients in column 1 are significantly different. However, in column 1 the reported interaction coefficients are not significantly different from each other.
} 
Table D: Determinants of the final teacher's assessment - three-way interaction table

\begin{tabular}{|c|c|c|c|c|}
\hline & \multicolumn{4}{|c|}{ Final teacher assessment } \\
\hline & $(1)$ & $(2)$ & (3) & (4) \\
\hline \multirow[t]{2}{*}{ Test $>$ ITA \& boys \& lower educ mother } & 0.255 & & & \\
\hline & $(0.185)$ & & & \\
\hline \multirow[t]{2}{*}{ Test > ITA \& boys \& vocational educ mother } & $0.264^{*}$ & & & \\
\hline & $(0.159)$ & & & \\
\hline \multirow[t]{2}{*}{ Test > ITA \& boys \& higher educ mother } & $0.489 * * *$ & & & \\
\hline & $(0.179)$ & & & \\
\hline \multirow[t]{2}{*}{ Test > ITA \& boys \& university educ mother } & $0.296^{*}$ & & & \\
\hline & $(0.172)$ & & & \\
\hline \multirow[t]{2}{*}{ Test > ITA \& girls \& lower educ mother } & 0.142 & & & \\
\hline & $(0.224)$ & & & \\
\hline \multirow[t]{2}{*}{ Test > ITA \& girls \& vocational educ mother } & $0.371^{* *}$ & & & \\
\hline & $(0.160)$ & & & \\
\hline \multirow[t]{2}{*}{ Test $>$ ITA \& girls \& higher educ mother } & 0.139 & & & \\
\hline & $(0.227)$ & & & \\
\hline \multirow[t]{2}{*}{ Test > ITA \& girls \& university educ mother } & 0.333 & & & \\
\hline & $(0.239)$ & & & \\
\hline \multirow[t]{2}{*}{ Test $>$ ITA \& boys \& lower educ father } & & $0.397^{*}$ & & \\
\hline & & $(0.230)$ & & \\
\hline \multirow[t]{2}{*}{ Test > ITA \& boys \& vocational educ father } & & $0.436 * * *$ & & \\
\hline & & $(0.149)$ & & \\
\hline \multirow[t]{2}{*}{ Test > ITA \& boys \& higher educ father } & & $0.737 * * *$ & & \\
\hline & & $(0.247)$ & & \\
\hline \multirow[t]{2}{*}{ Test $>$ ITA \& boys \& university educ father } & & $0.492 * * *$ & & \\
\hline & & $(0.164)$ & & \\
\hline \multirow[t]{2}{*}{ Test > ITA \& girls \& lower educ father } & & 0.343 & & \\
\hline & & $(0.216)$ & & \\
\hline \multirow[t]{2}{*}{ Test > ITA \& girls \& vocational educ father } & & $0.520 * * *$ & & \\
\hline & & $(0.182)$ & & \\
\hline \multirow[t]{2}{*}{ Test $>$ ITA \& girls \& higher educ father } & & $0.381^{*}$ & & \\
\hline & & $(0.228)$ & & \\
\hline \multirow[t]{2}{*}{ Test $>$ ITA \& girls \& university educ father } & & $0.645^{* *}$ & & \\
\hline & & $(0.269)$ & & \\
\hline \multirow[t]{2}{*}{ Test $<$ ITA \& boys \& lower educ mother } & & & $-0.429 * *$ & \\
\hline & & & $(0.185)$ & \\
\hline \multirow[t]{2}{*}{ Test < ITA \& boys \& vocational educ mother } & & & $-0.435^{* *}$ & \\
\hline & & & $(0.171)$ & \\
\hline \multirow[t]{2}{*}{ Test $<$ ITA \& boys \& higher educ mother } & & & $-0.319 *$ & \\
\hline & & & $(0.168)$ & \\
\hline \multirow[t]{2}{*}{ Test $<$ ITA \& boys \& university educ mother } & & & -0.208 & \\
\hline & & & $(0.164)$ & \\
\hline
\end{tabular}




\begin{tabular}{|c|c|c|c|c|}
\hline & \multicolumn{4}{|c|}{ Final teacher assessment } \\
\hline & (1) & $(2)$ & (3) & (4) \\
\hline \multirow[t]{2}{*}{ Test $<$ ITA \& girls \& lower educ mother } & & & $-0.621 * * *$ & \\
\hline & & & $(0.202)$ & \\
\hline \multirow[t]{2}{*}{ Test $<$ ITA \& girls \& vocational educ mother } & & & $-0.639 * * *$ & \\
\hline & & & $(0.156)$ & \\
\hline \multirow[t]{2}{*}{ Test $<$ ITA \& girls \& higher educ mother } & & & $-0.388 * *$ & \\
\hline & & & $(0.182)$ & \\
\hline \multirow[t]{2}{*}{ Test $<$ ITA \& girls \& university educ mother } & & & $-0.426 * *$ & \\
\hline & & & $(0.173)$ & \\
\hline \multirow[t]{2}{*}{ Test $<$ ITA \& boys \& lower educ father } & & & & $-0.478 * *$ \\
\hline & & & & $(0.215)$ \\
\hline \multirow[t]{2}{*}{ Test $<$ ITA \& boys \& vocational educ father } & & & & -0.177 \\
\hline & & & & $(0.162)$ \\
\hline \multirow[t]{2}{*}{ Test $<$ ITA \& boys \& higher educ father } & & & & -0.153 \\
\hline & & & & $(0.170)$ \\
\hline \multirow[t]{2}{*}{ Test $<$ ITA \& boys $\&$ university educ father } & & & & -0.166 \\
\hline & & & & $(0.150)$ \\
\hline \multirow[t]{2}{*}{ Test $<$ ITA \& girls \& lower educ father } & & & & $-0.652 * * *$ \\
\hline & & & & $(0.219)$ \\
\hline \multirow[t]{2}{*}{ Test $<$ ITA \& girls \& vocational educ father } & & & & $-0.410^{* *}$ \\
\hline & & & & $(0.173)$ \\
\hline \multirow[t]{2}{*}{ Test $<$ ITA \& girls \& higher educ father } & & & & -0.217 \\
\hline & & & & $(0.173)$ \\
\hline \multirow[t]{2}{*}{ Test < ITA \& girls \& university educ father } & & & & $-0.333^{*}$ \\
\hline & & & & $(0.178)$ \\
\hline \multirow[t]{2}{*}{ Constant } & $-2.377 * * *$ & $-2.448 * * *$ & $-2.585^{* * *}$ & $-2.558 * * *$ \\
\hline & $(0.782)$ & $(0.788)$ & (0.790) & $(0.806)$ \\
\hline School FE & yes & yes & yes & yes \\
\hline Classroom FE & yes & yes & yes & yes \\
\hline Clustered SE & yes & yes & yes & yes \\
\hline Observations & 1,404 & 1,404 & 1,404 & 1,404 \\
\hline R-squared & 0.915 & 0.915 & 0.915 & 0.915 \\
\hline
\end{tabular}

Note: Coefficients are from ordinary least squared regressions with the final teacher assessment as the dependent variable. Standard errors are clustered at the primary school level. ***, **, * represent 1, 5 and 10 percent significance levels respectively. All control variables used in previous analyses are included plus area code of residence and region. 


\section{E: Determinants of the final teacher's assessment - ordered probit regression for table 6 .}

In table 6 we presented OLS regression coefficients of the determinants of the final teacher's assessment. However, it is possible that the differences between the tracks are not linear. Therefore, we estimate the same equation with an ordered probit model. The coefficients of this model can be found in table $E$.

The first two rows in table $\mathrm{E}$ show the coefficients of the relation between the initial teacher's assessment, the test score and the final teacher's assessment. The table reports ordered probit coefficients and not marginal effects since we are interested in the difference between the two independent variables and not the exact size of the effects. In the first column we observe that the initial teacher's assessment is able to explain a larger part of the distance between the lowest and the highest final teacher's assessment than the test score, 0.067 versus 0.058 . The coefficients for the initial teacher's assessment and the test score do not seem to have a significantly different relation with the final teacher's assessment, $p$-value of 0.262 . This result is in line with the results obtained from the ordinary least squares regressions in table 6. 
Table E: Ordered probit regression for table 6

\begin{tabular}{|c|c|c|c|}
\hline & \multicolumn{3}{|c|}{ Final teacher assessment } \\
\hline & (1) & $(2)$ & (3) \\
\hline \multirow[t]{2}{*}{ Initial teacher assessment } & $0.786 * * *$ & $0.778 * * *$ & $0.724 * * *$ \\
\hline & $(0.054)$ & $(0.051)$ & $(0.043)$ \\
\hline \multirow[t]{2}{*}{ Test score } & $0.684^{* * *}$ & $0.659 * * *$ & $0.552 * * *$ \\
\hline & $(0.066)$ & $(0.049)$ & $(0.041)$ \\
\hline \multirow[t]{2}{*}{ Female } & $-0.232 * *$ & -0.021 & -0.059 \\
\hline & $(0.092)$ & $(0.074)$ & -0.065 \\
\hline \multirow[t]{2}{*}{ Age (in months) } & -0.008 & $-0.012 *$ & $-0.013 * * *$ \\
\hline & $(0.008)$ & $(0.006)$ & -0.005 \\
\hline \multirow[t]{2}{*}{ Child born in other region NL } & 0.093 & -0.084 & -0.097 \\
\hline & $(0.213)$ & $(0.205)$ & $(0.170)$ \\
\hline \multirow[t]{2}{*}{ Child born abroad } & -0.025 & 0.263 & 0.291 \\
\hline & $(0.270)$ & (0.199) & (0.199) \\
\hline \multirow[t]{2}{*}{ Father born in other region NL } & $0.448 * * *$ & 0.191 & 0.163 \\
\hline & $(0.163)$ & $(0.168)$ & $(0.142)$ \\
\hline \multirow[t]{2}{*}{ Father born abroad } & -0.134 & -0.054 & -0.031 \\
\hline & $(0.193)$ & $(0.158)$ & $(0.123)$ \\
\hline \multirow[t]{2}{*}{ Mother born in other region NL } & -0.121 & -0.030 & -0.069 \\
\hline & $(0.168)$ & $(0.139)$ & $(0.121)$ \\
\hline \multirow[t]{2}{*}{ Mother born abroad } & -0.102 & -0.069 & -0.082 \\
\hline & $(0.208)$ & $(0.158)$ & $(0.136)$ \\
\hline \multirow[t]{2}{*}{ Father has vocational education } & $0.276^{* *}$ & $0.186 * *$ & $0.170 * *$ \\
\hline & $(0.124)$ & $(0.090)$ & $(0.081)$ \\
\hline \multirow[t]{2}{*}{ Father has higher education } & $0.372^{* *}$ & $0.258^{*}$ & $0.230^{*}$ \\
\hline & $(0.173)$ & $(0.143)$ & $(0.126)$ \\
\hline \multirow[t]{2}{*}{ Father has university education } & 0.108 & $0.212^{*}$ & $0.218^{* *}$ \\
\hline & $(0.136)$ & $(0.112)$ & $(0.100)$ \\
\hline \multirow[t]{2}{*}{ Mother has vocational education } & 0.091 & 0.149 & 0.084 \\
\hline & $(0.137)$ & $(0.112)$ & $(0.100)$ \\
\hline \multirow[t]{2}{*}{ Mother has higher education } & 0.237 & $0.417 * * *$ & $0.346 * * *$ \\
\hline & $(0.151)$ & $(0.117)$ & $(0.099)$ \\
\hline \multirow[t]{2}{*}{ Mother has university education } & $0.370 * *$ & $0.477 * * *$ & $0.404 * * *$ \\
\hline & $(0.187)$ & $(0.159)$ & $(0.138)$ \\
\hline \multirow[t]{2}{*}{ Father is unemployed } & $-0.632 * *$ & -0.331 & $-0.371^{*}$ \\
\hline & $(0.271)$ & $(0.255)$ & $(0.210)$ \\
\hline \multirow[t]{2}{*}{ Father is sick/unable to work } & -0.190 & -0.049 & -0.160 \\
\hline & $(0.287)$ & $(0.253)$ & $(0.221)$ \\
\hline \multirow[t]{2}{*}{ Father has other labour market position } & 0.376 & -0.168 & -0.127 \\
\hline & $(0.273)$ & $(0.214)$ & $(0.205)$ \\
\hline \multirow[t]{2}{*}{ Mother is unemployed } & $0.506^{*}$ & 0.081 & -0.087 \\
\hline & $(0.267)$ & $(0.238)$ & $(0.195)$ \\
\hline
\end{tabular}




\begin{tabular}{|c|c|c|c|}
\hline & \multicolumn{3}{|c|}{ Final teacher assessment } \\
\hline & (1) & $(2)$ & (3) \\
\hline \multirow[t]{2}{*}{ Mother is sick/unable to work } & 0.070 & 0.117 & 0.033 \\
\hline & $(0.239)$ & $(0.169)$ & $(0.164)$ \\
\hline \multirow[t]{2}{*}{ Mother has other labour market position } & $-0.266^{*}$ & -0.099 & -0.130 \\
\hline & $(0.142)$ & $(0.126)$ & $(0.112)$ \\
\hline \multirow[t]{2}{*}{ Child lives with both parents } & $-0.254 * *$ & -0.061 & -0.033 \\
\hline & $(0.113)$ & $(0.092)$ & $(0.078)$ \\
\hline \multirow[t]{2}{*}{ Constant cut1 } & $8.200 * * *$ & $8.755^{* * *}$ & $6.716 * * *$ \\
\hline & $(1.468)$ & $(1.131)$ & $(0.843)$ \\
\hline \multirow[t]{2}{*}{ Constant cut2 } & $9.453 * * *$ & $9.750 * * *$ & $7.627 * * *$ \\
\hline & $(1.476)$ & $(1.146)$ & $(0.868)$ \\
\hline \multirow[t]{2}{*}{ Constant cut3 } & $11.282 * * *$ & $11.396 * * *$ & $9.126 * * *$ \\
\hline & $(1.531)$ & $(1.173)$ & $(0.902)$ \\
\hline \multirow[t]{2}{*}{ Constant cut4 } & $11.398 * * *$ & $11.491 * * *$ & $9.211 * * *$ \\
\hline & $(1.538)$ & $(1.171)$ & $(0.901)$ \\
\hline \multirow[t]{2}{*}{ Constant cut5 } & $12.504 * * *$ & $12.336 * * *$ & $9.941 * * *$ \\
\hline & $(1.564)$ & $(1.192)$ & $(0.924)$ \\
\hline \multirow[t]{2}{*}{ Constant cut6 } & $16.022^{* * *}$ & $14.698 * * *$ & $12.029 * * *$ \\
\hline & $(1.659)$ & $(1.204)$ & $(0.938)$ \\
\hline \multirow[t]{2}{*}{ Constant cut7 } & $18.082 * * *$ & $16.170 * * *$ & $13.353^{* * *}$ \\
\hline & $(1.697)$ & $(1.230)$ & $(0.968)$ \\
\hline \multirow[t]{2}{*}{ Constant cut8 } & $19.908^{* * *}$ & $17.541^{* * *}$ & $14.582^{* * *}$ \\
\hline & $(1.716)$ & $(1.239)$ & $(0.972)$ \\
\hline Initial teacher assessment / (C8-C1) & 0.067 & 0.089 & 0.092 \\
\hline Test score / (C8-C1) & 0.058 & 0.075 & 0.070 \\
\hline Difference ITA - TS (p-values) & 0.262 & 0.153 & 0.012 \\
\hline School FE & yes & yes & no \\
\hline Classroom FE & yes & no & no \\
\hline Clustered SEs & yes & yes & yes \\
\hline Observations & 1,404 & 1,404 & 1,404 \\
\hline
\end{tabular}

Note: Coefficients are from ordered probit regressions with the final teacher assessment as the dependent variable measured on a scale from 1-9. Standard errors are clustered at the primary school level. ***, **, * represent 1,5 and 10 percent significance levels respectively. Other control variables in all regressions are area code of residence and region. 


\section{F: Determinants of the final teacher's assessment - ordered probit regression for table 7}

In table 7 we presented OLS regression coefficients of the determinants of the final teacher's assessment. However, it is possible that the differences between the tracks are not linear. Therefore, we estimate the same equation with an ordered probit model. The coefficients of this model can be found in table $F$.

The first two rows in table $\mathrm{F}$ show the coefficients of the relation between the 'test score > initial teacher's assessment' and the 'test score < initial teacher's assessment' and the final teacher's assessment. The table reports ordered probit coefficients and not marginal effects since we are only interested in the sign and significance of these two estimates. In all three columns we observe that there is a significantly positive relationship between the 'test score > initial teacher's assessment' and the final teacher's assessment and a significantly negative relationship between the 'test score < initial teacher's assessment' and the final teacher's assessment. This result is in line with the results obtained from the ordinary least squares regressions in table 7. 
Table F: Ordered probit regression for table 7

\begin{tabular}{|c|c|c|c|}
\hline & \multicolumn{3}{|c|}{ Final teacher assessment } \\
\hline & $(1)$ & $(2)$ & (3) \\
\hline \multirow[t]{2}{*}{ Test score > Initial teacher assessment } & $0.786 * * *$ & $0.742 * * *$ & $0.710 * * *$ \\
\hline & $(0.123)$ & $(0.095)$ & $(0.084)$ \\
\hline \multirow[t]{2}{*}{ Test score $<$ Initial teacher assessment } & $-0.965 * * *$ & $-0.972 * * *$ & $-0.804 * * *$ \\
\hline & $(0.136)$ & $(0.094)$ & $(0.078)$ \\
\hline \multirow[t]{2}{*}{ Initial teacher assessment } & $1.322 * * *$ & $1.327^{* * *}$ & $1.193 * * *$ \\
\hline & $(0.073)$ & $(0.055)$ & (0.049) \\
\hline \multirow[t]{2}{*}{ Female } & $-0.214^{* *}$ & -0.020 & -0.063 \\
\hline & $(0.092)$ & $(0.075)$ & $(0.066)$ \\
\hline \multirow[t]{2}{*}{ Age (in months) } & -0.006 & $-0.013 * *$ & $-0.015 * * *$ \\
\hline & $(0.008)$ & $(0.006)$ & $(0.005)$ \\
\hline \multirow[t]{2}{*}{ Child born in other region NL } & 0.046 & -0.143 & -0.141 \\
\hline & $(0.212)$ & $(0.187)$ & $(0.164)$ \\
\hline \multirow[t]{2}{*}{ Child born abroad } & 0.015 & 0.222 & 0.282 \\
\hline & $(0.258)$ & (0.197) & $(0.207)$ \\
\hline \multirow[t]{2}{*}{ Father born in other region NL } & $0.506^{* * *}$ & 0.221 & 0.171 \\
\hline & $(0.172)$ & $(0.172)$ & $(0.143)$ \\
\hline \multirow[t]{2}{*}{ Father born abroad } & -0.188 & -0.066 & -0.046 \\
\hline & $(0.194)$ & $(0.159)$ & $(0.128)$ \\
\hline \multirow[t]{2}{*}{ Mother born in other region NL } & 0.032 & 0.118 & 0.058 \\
\hline & $(0.184)$ & $(0.144)$ & $(0.129)$ \\
\hline \multirow[t]{2}{*}{ Mother born abroad } & -0.026 & 0.042 & 0.023 \\
\hline & $(0.211)$ & $(0.167)$ & $(0.149)$ \\
\hline \multirow[t]{2}{*}{ Father has vocational education } & $0.281^{* *}$ & $0.195 * *$ & $0.186^{* *}$ \\
\hline & $(0.124)$ & (0.093) & $(0.081)$ \\
\hline \multirow[t]{2}{*}{ Father has higher education } & $0.405^{* *}$ & $0.313^{* *}$ & $0.262 * *$ \\
\hline & $(0.170)$ & (0.139) & $(0.124)$ \\
\hline \multirow[t]{2}{*}{ Father has university education } & 0.105 & $0.223^{*}$ & $0.222^{* *}$ \\
\hline & $(0.140)$ & $(0.114)$ & $(0.101)$ \\
\hline \multirow[t]{2}{*}{ Mother has vocational education } & -0.004 & 0.086 & 0.040 \\
\hline & $(0.137)$ & $(0.110)$ & $(0.097)$ \\
\hline \multirow[t]{2}{*}{ Mother has higher education } & 0.188 & $0.405^{* * *}$ & $0.347^{* * *}$ \\
\hline & $(0.151)$ & $(0.116)$ & $(0.096)$ \\
\hline \multirow[t]{2}{*}{ Mother has university education } & 0.268 & $0.407^{* * *}$ & $0.360 * * *$ \\
\hline & $(0.177)$ & $(0.150)$ & $(0.133)$ \\
\hline \multirow[t]{2}{*}{ Father is unemployed } & $-0.575 * *$ & -0.308 & -0.333 \\
\hline & $(0.291)$ & $(0.259)$ & $(0.212)$ \\
\hline \multirow[t]{2}{*}{ Father is sick/unable to work } & -0.280 & -0.105 & -0.212 \\
\hline & $(0.295)$ & $(0.258)$ & $(0.223)$ \\
\hline \multirow[t]{2}{*}{ Father has other labour market position } & 0.448 & -0.106 & -0.071 \\
\hline & $(0.283)$ & $(0.228)$ & $(0.210)$ \\
\hline
\end{tabular}




\begin{tabular}{|c|c|c|c|}
\hline & \multicolumn{3}{|c|}{ Final teacher assessment } \\
\hline & (1) & $(2)$ & (3) \\
\hline \multirow[t]{2}{*}{ Mother is unemployed } & $0.511^{* *}$ & 0.043 & -0.107 \\
\hline & $(0.257)$ & $(0.215)$ & $(0.185)$ \\
\hline \multirow[t]{2}{*}{ Mother is sick/unable to work } & 0.012 & 0.082 & 0.034 \\
\hline & $(0.233)$ & $(0.159)$ & $(0.155)$ \\
\hline \multirow[t]{2}{*}{ Mother has other labour market position } & -0.188 & -0.047 & -0.087 \\
\hline & $(0.145)$ & $(0.130)$ & $(0.115)$ \\
\hline \multirow[t]{2}{*}{ Child lives with both parents } & $-0.242 * *$ & -0.053 & -0.025 \\
\hline & $(0.117)$ & $(0.091)$ & $(0.075)$ \\
\hline \multirow[t]{2}{*}{ Constant cut 1} & $8.153^{* * *}$ & $8.131^{* * *}$ & $5.823 * * *$ \\
\hline & $(1.434)$ & $(1.085)$ & $(0.783)$ \\
\hline \multirow[t]{2}{*}{ Constant cut2 } & $9.390 * * *$ & $9.092 * * *$ & $6.721 * * *$ \\
\hline & $(1.442)$ & (1.099) & $(0.807)$ \\
\hline \multirow[t]{2}{*}{ Constant cut3 } & $11.149 * * *$ & $10.660 * * *$ & $8.161 * * *$ \\
\hline & $(1.492)$ & $(1.101)$ & $(0.822)$ \\
\hline \multirow[t]{2}{*}{ Constant cut 4} & $11.258^{* * *}$ & $10.750 * * *$ & $8.241 * * *$ \\
\hline & $(1.500)$ & $(1.101)$ & $(0.823)$ \\
\hline \multirow[t]{2}{*}{ Constant cut5 } & $12.305^{* * *}$ & $11.535 * * *$ & $8.928 * * *$ \\
\hline & $(1.526)$ & $(1.125)$ & $(0.845)$ \\
\hline \multirow[t]{2}{*}{ Constant cut6 } & $15.784^{* * *}$ & $13.799 * * *$ & $10.952 * * *$ \\
\hline & $(1.611)$ & (1.150) & $(0.866)$ \\
\hline \multirow[t]{2}{*}{ Constant cut7 } & $17.775^{* * *}$ & $15.194 * * *$ & $12.217^{* * *}$ \\
\hline & (1.649) & (1.169) & $(0.890)$ \\
\hline \multirow[t]{2}{*}{ Constant cut8 } & $19.526 * * *$ & $16.493 * * *$ & $13.391^{* * *}$ \\
\hline & $(1.674)$ & (1.192) & $(0.903)$ \\
\hline School FE & yes & yes & no \\
\hline Classroom FE & yes & no & no \\
\hline Clustered SEs & yes & yes & yes \\
\hline Observations & 1,404 & 1,404 & 1,404 \\
\hline
\end{tabular}

Note: Coefficients are from ordered probit regressions with the final teacher assessment as the dependent variable measured on a scale from 1-9. Standard errors are clustered at the primary school level. ***, **, * represent 1,5 and 10 percent significance levels respectively. Other control variables in all regressions are area code of residence and region. 


\section{G. Differences between math and language scores I}

We investigate whether children's gender is related to their score on the math and language component of the test. These results have also been discussed in the results section of this paper.

We find that on average girls have a lower overall test score than boys. Girls have a significantly higher score on the language component and a significantly lower score on the math component of the test compared to boys. In column 1-3 we find that there are few other covariates that affect the test score, the math score and the language score. We find that fathers that have an 'other labour market position' such as being retired or being a stay at home parent have a positive relation to children's test score. This result is likely driven by a small number of fathers as most fathers are employed. Furthermore, we observe that having a mother who is born abroad has a negative relation to a child's language score and there is a positive relation between mothers who are highly educated and their children's language score. Finally, adding the classroom dummy variables captures a lot of variation as can be observed from the increase in the r-squared. It seems that between classrooms the impact of parents' education level on test scores is substantial. Within classrooms this relation seems to disappear. It is possible that children are sorted into certain schools based on their parents education level. 
Table G: Differences between math and language scores

\begin{tabular}{|c|c|c|c|c|c|c|}
\hline & Test score & Math score & $\begin{array}{l}\text { Language } \\
\text { score }\end{array}$ & Test score & Math score & $\begin{array}{l}\text { Language } \\
\text { score }\end{array}$ \\
\hline & (1) & $(2)$ & (3) & (4) & (5) & (6) \\
\hline \multirow[t]{2}{*}{ Girls } & $-0.232 * * *$ & $-3.576 * * *$ & $1.025^{* *}$ & -0.181 & $-3.458 * * *$ & $1.583^{* *}$ \\
\hline & (0.079) & (0.499) & $(0.493)$ & $(0.120)$ & (0.589) & $(0.613)$ \\
\hline \multirow[t]{2}{*}{ Age (in months) } & 0.007 & -0.030 & 0.052 & $-0.063 * * *$ & $-0.330 * * *$ & $-0.293 * * *$ \\
\hline & $(0.007)$ & $(0.042)$ & $(0.040)$ & $(0.012)$ & $(0.059)$ & $(0.062)$ \\
\hline \multirow[t]{2}{*}{ Child born in other region NL } & 0.011 & 0.494 & -0.602 & -0.113 & 0.383 & -1.464 \\
\hline & $(0.185)$ & $(1.062)$ & (1.071) & $(0.234)$ & $(1.166)$ & (1.329) \\
\hline \multirow[t]{2}{*}{ Child born abroad } & 0.067 & -0.007 & 0.043 & 0.379 & 2.239 & 0.848 \\
\hline & $(0.208)$ & $(1.184)$ & $(1.314)$ & $(0.329)$ & $(1.666)$ & (1.819) \\
\hline \multirow[t]{2}{*}{ Father born in other region NL } & 0.104 & 0.831 & 0.078 & 0.023 & 0.298 & -0.231 \\
\hline & $(0.137)$ & (0.699) & $(0.796)$ & $(0.172)$ & $(0.883)$ & $(0.970)$ \\
\hline \multirow[t]{2}{*}{ Father born abroad } & -0.193 & -1.601 & 0.116 & -0.325 & -1.961 & -1.081 \\
\hline & $(0.151)$ & $(1.011)$ & $(0.808)$ & $(0.245)$ & $(1.236)$ & $(1.308)$ \\
\hline \multirow[t]{2}{*}{ Mother born in other region NL } & 0.066 & 0.814 & 0.130 & 0.199 & 1.263 & 1.030 \\
\hline & $(0.117)$ & $(0.806)$ & $(0.707)$ & $(0.184)$ & $(1.034)$ & $(0.940)$ \\
\hline \multirow[t]{2}{*}{ Mother born abroad } & -0.106 & 0.371 & $-1.502 *$ & 0.070 & 0.925 & -0.380 \\
\hline & $(0.146)$ & $(0.862)$ & $(0.844)$ & $(0.181)$ & $(0.935)$ & $(1.075)$ \\
\hline \multirow[t]{2}{*}{ Father has vocational education } & -0.042 & -0.496 & 0.237 & $0.279 * *$ & 1.052 & $1.564^{* *}$ \\
\hline & $(0.098)$ & $(0.600)$ & $(0.586)$ & $(0.129)$ & $(0.698)$ & $(0.691)$ \\
\hline \multirow[t]{2}{*}{ Father has higher education } & -0.049 & -0.988 & 0.058 & $0.559 * * *$ & $1.834^{* *}$ & $2.777^{* * *}$ \\
\hline & $(0.113)$ & $(0.629)$ & $(0.758)$ & $(0.182)$ & $(0.883)$ & $(1.018)$ \\
\hline \multirow[t]{2}{*}{ Father has university education } & -0.151 & -0.258 & -1.315 & $0.488^{* * *}$ & $2.520 * * *$ & $1.969 *$ \\
\hline & $(0.132)$ & $(0.686)$ & $(0.964)$ & $(0.168)$ & $(0.833)$ & $(1.007)$ \\
\hline \multirow[t]{2}{*}{ Mother has vocational education } & 0.008 & -0.171 & 0.173 & $0.395^{* *}$ & $1.613^{* *}$ & $2.078 * *$ \\
\hline & $(0.086)$ & $(0.507)$ & $(0.592)$ & $(0.162)$ & $(0.808)$ & $(0.851)$ \\
\hline \multirow[t]{2}{*}{ Mother has higher education } & 0.174 & 0.166 & $1.351^{* *}$ & $1.128 * * *$ & $4.473 * * *$ & $6.187^{* * *}$ \\
\hline & $(0.111)$ & $(0.624)$ & $(0.658)$ & $(0.186)$ & $(0.885)$ & $(1.075)$ \\
\hline \multirow[t]{2}{*}{ Mother has university education } & 0.099 & -0.813 & $2.024 * * *$ & $1.262 * * *$ & $4.490 * * *$ & $7.718^{* * *}$ \\
\hline & $(0.128)$ & $(0.750)$ & $(0.741)$ & $(0.190)$ & $(0.939)$ & $(1.038)$ \\
\hline \multirow[t]{2}{*}{ Father is unemployed } & -0.137 & -1.405 & -0.082 & -0.041 & -0.387 & 0.099 \\
\hline & $(0.206)$ & $(1.357)$ & $(1.331)$ & $(0.284)$ & $(1.650)$ & $(1.620)$ \\
\hline \multirow[t]{2}{*}{ Father is sick/unable to work } & -0.254 & -0.701 & -1.005 & -0.023 & 0.208 & 0.202 \\
\hline & $(0.261)$ & $(1.885)$ & $(1.285)$ & $(0.343)$ & $(1.914)$ & $(1.998)$ \\
\hline \multirow{2}{*}{$\begin{array}{l}\text { Father has other labour } \\
\text { market position }\end{array}$} & $0.509 * *$ & $2.302 *$ & $2.960 * * *$ & $-0.668 * *$ & $-2.704^{*}$ & $-3.528 *$ \\
\hline & $(0.208)$ & $(1.336)$ & $(1.090)$ & $(0.314)$ & $(1.513)$ & $(2.034)$ \\
\hline \multirow[t]{2}{*}{ Mother is unemployed } & 0.059 & 0.573 & 0.368 & -0.258 & -1.153 & -1.195 \\
\hline & $(0.282)$ & (1.399) & $(1.798)$ & $(0.383)$ & $(1.795)$ & $(2.174)$ \\
\hline \multirow[t]{2}{*}{ Mother is sick/unable to work } & -0.003 & -0.311 & 1.516 & -0.146 & -1.026 & 1.311 \\
\hline & $(0.167)$ & $(1.017)$ & $(1.222)$ & $(0.260)$ & $(1.330)$ & $(1.426)$ \\
\hline
\end{tabular}




\begin{tabular}{|c|c|c|c|c|c|c|}
\hline & Test score & Math score & $\begin{array}{l}\text { Language } \\
\text { score }\end{array}$ & Test score & Math score & $\begin{array}{l}\text { Language } \\
\text { score }\end{array}$ \\
\hline & (1) & $(2)$ & (3) & (4) & (5) & $(6)$ \\
\hline \multirow{2}{*}{$\begin{array}{l}\text { Mother has other labour } \\
\text { market position }\end{array}$} & -0.074 & -0.436 & -0.984 & -0.218 & -0.797 & $-1.927^{*}$ \\
\hline & $(0.109)$ & $(0.688)$ & $(0.655)$ & $(0.187)$ & $(0.978)$ & $(1.026)$ \\
\hline \multirow[t]{2}{*}{ Child lives with both parents } & -0.009 & -0.373 & -0.045 & $0.213^{*}$ & 0.762 & 0.991 \\
\hline & $(0.089)$ & $(0.557)$ & $(0.483)$ & $(0.128)$ & $(0.698)$ & $(0.669)$ \\
\hline \multirow[t]{2}{*}{ Constant } & $7.227^{* * *}$ & $59.319 * * *$ & $77.372^{* * *}$ & $16.792 * * *$ & $99.837^{* * *}$ & $126.599 * * *$ \\
\hline & $(1.363)$ & $(7.450)$ & $(7.568)$ & $(2.115)$ & $(10.300)$ & $(10.479)$ \\
\hline School FE & yes & yes & yes & yes & yes & yes \\
\hline Classroom FE & yes & yes & yes & no & no & no \\
\hline Clustered SEs & yes & yes & yes & yes & yes & yes \\
\hline Observations & 1,404 & 1,404 & 1,404 & 1,404 & 1,404 & 1,404 \\
\hline R-squared & 0.814 & 0.724 & 0.759 & 0.334 & 0.304 & 0.324 \\
\hline
\end{tabular}

Note: Coefficients are from ordinary least squared regressions with the test score, the math score or the language score as the dependent variable. The test score is measured on a scale from 1-9, the language score ranges from 34 to 100 and the math score ranges from 10 to 60. Standard errors are clustered at the primary school level. $* * * * *, *$ represent 1,5 and 10 percent significance levels respectively. Other control variables in all regressions are area code of residence and region. 


\section{H. Differences between math and language scores II}

We investigate whether the final teacher's assessment is more dependent on the math or the language component of the test. These results have also been discussed in the results section of this paper.

We do not find a significant difference in the relation between the language score and the final teacher's assessment and the math score and the final teacher's assessment. Both measures seem to have a similar positive relation to the final teacher's assessment. Furthermore, when we look at the interaction between gender and having a below/above average language or math score, in column 4, we find that compared to the reference level; lower than average language score and boys, being a girl with a below average score on language has a significantly negative relation to the final teacher's assessment. It seems that girls are more negatively affected by having a below average language score compared to boys. For both boys and girls having an above average language score is significantly positively related to the final teacher's assessment. However, the adjustment effect for boys on the final teacher's assessment is significantly more positive than the adjustment effect for girls. In column 5 we find that there is no difference between boys and girls who have a below or an above average math score on the final assessment.

The regressions in column 1-3 are performed with standardized test scores for math and language. We do not find a significant difference between the predictive power of math and language test scores for the final teacher's assessment. 
Table H: Differences between math and language scores II

\begin{tabular}{|c|c|c|c|c|c|}
\hline & FTA & FTA & FTA & FTA & FTA \\
\hline & $(1)$ & $(2)$ & (3) & $(4)$ & (5) \\
\hline \multirow[t]{2}{*}{ Lower than avg language \& girls } & & & & $-0.303 * * *$ & \\
\hline & & & & $(0.111)$ & \\
\hline \multirow[t]{2}{*}{ Higher than avg language \& boys } & & & & $0.397 * * *$ & \\
\hline & & & & $(0.103)$ & \\
\hline \multirow[t]{2}{*}{ Higher than avg langage \& girls } & & & & $0.304 * * *$ & \\
\hline & & & & $(0.104)$ & \\
\hline \multirow[t]{2}{*}{ Lower than avg math \& girls } & & & & & -0.122 \\
\hline & & & & & $(0.116)$ \\
\hline \multirow[t]{2}{*}{ Higher than avg math \& boys } & & & & & $0.393 * * *$ \\
\hline & & & & & $(0.114)$ \\
\hline \multirow[t]{2}{*}{ Higher than avg math \& girls } & & & & & $0.345^{* * *}$ \\
\hline & & & & & $(0.118)$ \\
\hline \multirow[t]{2}{*}{ Language score } & $0.041 * * *$ & & $0.040 * * *$ & & \\
\hline & $(0.005)$ & & $(0.005)$ & & \\
\hline \multirow[t]{2}{*}{ Math score } & & $0.035^{* * *}$ & $0.034 * * *$ & & \\
\hline & & $(0.006)$ & $(0.006)$ & & \\
\hline \multirow[t]{2}{*}{ ITA } & $0.478^{* * *}$ & $0.474 * * *$ & $0.404^{* * *}$ & $0.520 * * *$ & $0.511^{* * *}$ \\
\hline & (0.029) & $(0.033)$ & $(0.032)$ & (0.029) & $(0.032)$ \\
\hline \multirow[t]{2}{*}{ Girls } & $-0.189 * * *$ & -0.022 & -0.079 & & \\
\hline & $(0.056)$ & $(0.057)$ & $(0.056)$ & & \\
\hline \multirow[t]{2}{*}{ Age (in months) } & -0.004 & -0.001 & -0.004 & -0.004 & -0.002 \\
\hline & $(0.005)$ & $(0.005)$ & $(0.004)$ & $(0.005)$ & -0.005 \\
\hline \multirow[t]{2}{*}{ Child born in other region NL } & 0.041 & 0.000 & 0.037 & 0.043 & -0.029 \\
\hline & $(0.105)$ & $(0.116)$ & $(0.106)$ & $(0.105)$ & (0.119) \\
\hline \multirow[t]{2}{*}{ Child born abroad } & -0.009 & -0.006 & 0.000 & 0.031 & 0.005 \\
\hline & $(0.170)$ & $(0.144)$ & $(0.154)$ & $(0.162)$ & $(0.146)$ \\
\hline \multirow[t]{2}{*}{ Father born in other region NL } & $0.172^{* *}$ & $0.146^{*}$ & $0.142 *$ & $0.194 * *$ & $0.172^{*}$ \\
\hline & $(0.081)$ & $(0.087)$ & $(0.085)$ & $(0.082)$ & $(0.091)$ \\
\hline \multirow[t]{2}{*}{ Father born abroad } & -0.082 & -0.022 & -0.037 & -0.086 & -0.037 \\
\hline & $(0.108)$ & $(0.109)$ & $(0.108)$ & $(0.107)$ & $(0.111)$ \\
\hline \multirow[t]{2}{*}{ Mother born in other region NL } & 0.018 & -0.005 & -0.010 & 0.019 & 0.005 \\
\hline & $(0.078)$ & $(0.075)$ & $(0.073)$ & $(0.078)$ & $(0.076)$ \\
\hline \multirow[t]{2}{*}{ Mother born abroad } & -0.048 & -0.123 & -0.074 & -0.046 & -0.107 \\
\hline & $(0.107)$ & $(0.105)$ & (0.099) & (0.109) & $(0.111)$ \\
\hline \multirow[t]{2}{*}{ Father has vocational education } & 0.096 & 0.123 & 0.115 & 0.092 & 0.115 \\
\hline & $(0.076)$ & $(0.083)$ & $(0.075)$ & $(0.080)$ & $(0.081)$ \\
\hline \multirow[t]{2}{*}{ Father has higher education } & $0.157^{*}$ & $0.194^{*}$ & $0.197^{* *}$ & 0.139 & 0.158 \\
\hline & $(0.094)$ & (0.099) & $(0.093)$ & $(0.096)$ & $(0.096)$ \\
\hline \multirow[t]{2}{*}{ Father has university education } & 0.120 & 0.076 & 0.134 & 0.093 & 0.065 \\
\hline & $(0.083)$ & $(0.091)$ & $(0.082)$ & $(0.085)$ & $(0.089)$ \\
\hline
\end{tabular}




\begin{tabular}{|c|c|c|c|c|c|}
\hline & FTA & FTA & FTA & FTA & FTA \\
\hline & (1) & $(2)$ & (3) & (4) & (5) \\
\hline \multirow[t]{2}{*}{ Mother has vocational education } & 0.018 & 0.031 & 0.024 & 0.001 & 0.021 \\
\hline & $(0.081)$ & $(0.085)$ & $(0.081)$ & $(0.081)$ & $(0.083)$ \\
\hline \multirow[t]{2}{*}{ Mother has higher education } & 0.078 & 0.128 & 0.079 & 0.109 & 0.127 \\
\hline & (0.089) & $(0.095)$ & $(0.090)$ & $(0.093)$ & $(0.095)$ \\
\hline \multirow[t]{2}{*}{ Mother has university education } & 0.016 & 0.128 & 0.049 & 0.067 & 0.103 \\
\hline & (0.099) & $(0.100)$ & $(0.098)$ & $(0.099)$ & $(0.098)$ \\
\hline \multirow[t]{2}{*}{ Father is unemployed } & $-0.323^{*}$ & -0.277 & -0.275 & $-0.344^{*}$ & -0.273 \\
\hline & $(0.183)$ & $(0.179)$ & $(0.178)$ & $(0.180)$ & $(0.183)$ \\
\hline \multirow[t]{2}{*}{ Father is sick/unable to work } & $-0.328^{*}$ & $-0.344^{*}$ & -0.289 & $-0.356^{*}$ & $-0.339 *$ \\
\hline & $(0.196)$ & $(0.190)$ & $(0.181)$ & $(0.204)$ & $(0.202)$ \\
\hline \multirow[t]{2}{*}{ Father has other labour market position } & 0.070 & 0.110 & -0.001 & 0.073 & 0.148 \\
\hline & $(0.167)$ & $(0.158)$ & $(0.158)$ & $(0.166)$ & $(0.153)$ \\
\hline \multirow[t]{2}{*}{ Mother is unemployed } & 0.208 & 0.204 & 0.213 & 0.215 & 0.201 \\
\hline & $(0.150)$ & $(0.155)$ & $(0.145)$ & $(0.150)$ & $(0.159)$ \\
\hline \multirow[t]{2}{*}{ Mother is sick/unable to work } & 0.025 & 0.098 & 0.046 & 0.048 & 0.062 \\
\hline & $(0.176)$ & $(0.168)$ & $(0.169)$ & $(0.173)$ & $(0.162)$ \\
\hline \multirow[t]{2}{*}{ Mother has other labour market position } & -0.086 & -0.111 & -0.083 & -0.112 & -0.138 \\
\hline & $(0.087)$ & $(0.086)$ & $(0.083)$ & $(0.085)$ & $(0.091)$ \\
\hline \multirow[t]{2}{*}{ Child lives with both parents } & $-0.116^{*}$ & $-0.105^{*}$ & $-0.108^{*}$ & $-0.117^{*}$ & $-0.119 *$ \\
\hline & $(0.065)$ & $(0.062)$ & $(0.058)$ & $(0.068)$ & $(0.065)$ \\
\hline \multirow[t]{2}{*}{ Constant } & $-4.315^{* * *}$ & $-3.201 * * *$ & $-5.666 * * *$ & $-1.472^{*}$ & $-1.998 * *$ \\
\hline & $(0.845)$ & $(0.813)$ & $(0.859)$ & $(0.815)$ & $(0.800)$ \\
\hline School FE & yes & yes & yes & yes & yes \\
\hline Classroom FE & yes & yes & yes & yes & yes \\
\hline Clustered SEs & yes & yes & yes & yes & yes \\
\hline Observations & 1,404 & 1,404 & 1,404 & 1,404 & 1,404 \\
\hline R-squared & 0.918 & 0.915 & 0.924 & 0.914 & 0.913 \\
\hline
\end{tabular}

Note: Coefficients are from ordinary least squared regressions with the final teacher assessment (FTA) as the dependent variable. Standard errors are clustered at the primary school level. ***, **, * represent 1,5 and 10 percent significance levels respectively. Other control variables in all regressions are area code of residence and region. 


\section{How ITA and FTA predict track allocation in $9^{\text {th }}$ grade}

Table I presents the results of how well the initial teacher's assessment and the final teacher's assessment predict children's track allocation in $9^{\text {th }}$ grade. The coefficients in column 1-4 are from ordered probit regressions and the coefficients in column 5 are from ordinary least squared regressions. Both the initial teacher's assessment and the final teacher's assessment have a significantly positive relation with children's track allocation in $9^{\text {th }}$ grade, as expected. In column 3 and column 4 we observe that the final teacher's assessment has a stronger correlation with the children's track allocation in $9^{\text {th }}$ grade than the initial teacher's assessment. In both column 3 and column 4 the difference between the covariates is significant at the 5 percent level. In column 4 we observe that the coefficients of the initial teacher's assessment and the final teacher's assessment decrease after adding the test score to the model indicating that these measures partly measure the same latent variable. The test score still seems to capture different aspects of children's ability than what is accounted for by the initial teacher's assessment and the final teacher's assessment. This could be due to different things such as measurement error, the three ability measures can capture different parts of children's ability level, the teacher might not have considered (all of) the information provided by the test score to be relevant. 
Table I: How ITA and FTA predict track allocation in $9^{\text {th }}$ grade

\begin{tabular}{|c|c|c|c|c|c|}
\hline & \multicolumn{5}{|c|}{ Track in 9th grade } \\
\hline & $(1)$ & $(2)$ & (3) & (4) & (5) \\
\hline \multirow[t]{2}{*}{ Initial teacher assessment } & $0.541 * * *$ & & $0.219 * * *$ & $0.179 * * *$ & $0.330 * * *$ \\
\hline & $(0.015)$ & & $(0.031)$ & $(0.031)$ & $(0.044)$ \\
\hline \multirow[t]{2}{*}{ Final teacher assessment } & & $0.563 * * *$ & $0.373 * * *$ & $0.300 * * *$ & $0.397 * * *$ \\
\hline & & $(0.016)$ & $(0.031)$ & $(0.036)$ & $(0.063)$ \\
\hline \multirow[t]{2}{*}{ Test score } & & & & $0.137 * * *$ & $0.304^{* * *}$ \\
\hline & & & & $(0.031)$ & $(0.049)$ \\
\hline \multirow[t]{2}{*}{ Girls } & $0.121^{* *}$ & $0.143^{* * *}$ & $0.139 * * *$ & $0.150 * * *$ & $0.264^{* * *}$ \\
\hline & (0.049) & $(0.045)$ & $(0.043)$ & $(0.042)$ & $(0.079)$ \\
\hline \multirow[t]{2}{*}{ Age (in months) } & $-0.015^{* * *}$ & $-0.012 * * *$ & $-0.010^{* *}$ & $-0.010 * *$ & $-0.024 * * *$ \\
\hline & $(0.006)$ & $(0.005)$ & $(0.005)$ & $(0.005)$ & $(0.008)$ \\
\hline \multirow[t]{2}{*}{ Child born in other region NL } & 0.023 & 0.097 & 0.068 & 0.087 & 0.104 \\
\hline & $(0.135)$ & $(0.106)$ & $(0.110)$ & $(0.113)$ & $(0.213)$ \\
\hline \multirow[t]{2}{*}{ Child born abroad } & 0.091 & -0.013 & 0.005 & 0.017 & 0.089 \\
\hline & $(0.131)$ & $(0.133)$ & $(0.120)$ & $(0.120)$ & $(0.189)$ \\
\hline \multirow[t]{2}{*}{ Mother born in other region NL } & 0.007 & -0.026 & -0.020 & -0.028 & -0.032 \\
\hline & $(0.083)$ & $(0.063)$ & $(0.065)$ & $(0.064)$ & $(0.125)$ \\
\hline \multirow[t]{2}{*}{ Mother born abroad } & 0.017 & 0.050 & 0.039 & 0.024 & 0.027 \\
\hline & $(0.084)$ & $(0.078)$ & $(0.072)$ & $(0.071)$ & $(0.136)$ \\
\hline \multirow[t]{2}{*}{ Father born in other region NL } & -0.005 & -0.094 & -0.058 & -0.068 & -0.054 \\
\hline & $(0.088)$ & $(0.063)$ & $(0.064)$ & $(0.063)$ & $(0.136)$ \\
\hline \multirow[t]{2}{*}{ Father born abroad } & -0.036 & -0.055 & -0.039 & -0.020 & -0.016 \\
\hline & $(0.100)$ & $(0.094)$ & $(0.088)$ & $(0.085)$ & $(0.139)$ \\
\hline \multirow[t]{2}{*}{ Mother has vocational education } & $0.171^{* *}$ & 0.113 & 0.116 & $0.117^{*}$ & 0.154 \\
\hline & $(0.081)$ & $(0.072)$ & $(0.071)$ & $(0.069)$ & $(0.104)$ \\
\hline \multirow[t]{2}{*}{ Mother has higher education } & $0.282 * * *$ & $0.162^{* *}$ & $0.161^{* *}$ & $0.147^{* *}$ & $0.300 * * *$ \\
\hline & $(0.087)$ & $(0.073)$ & $(0.072)$ & $(0.071)$ & $(0.113)$ \\
\hline \multirow[t]{2}{*}{ Mother has university education } & $0.282 * * *$ & $0.210 * *$ & $0.187 * *$ & $0.165 * *$ & $0.487 * * *$ \\
\hline & $(0.091)$ & $(0.087)$ & $(0.082)$ & $(0.081)$ & $(0.149)$ \\
\hline \multirow[t]{2}{*}{ Father has vocational education } & 0.095 & 0.036 & 0.042 & 0.053 & 0.092 \\
\hline & $(0.073)$ & $(0.074)$ & $(0.071)$ & $(0.070)$ & $(0.107)$ \\
\hline \multirow[t]{2}{*}{ Father has higher education } & $0.168^{*}$ & 0.100 & 0.097 & 0.107 & $0.258^{*}$ \\
\hline & $(0.101)$ & $(0.090)$ & $(0.091)$ & $(0.090)$ & $(0.144)$ \\
\hline \multirow[t]{2}{*}{ Father has university education } & $0.181^{*}$ & 0.138 & 0.126 & $0.145^{*}$ & $0.327^{* *}$ \\
\hline & $(0.092)$ & $(0.086)$ & $(0.085)$ & $(0.087)$ & $(0.151)$ \\
\hline \multirow[t]{2}{*}{ Mother is unemployed } & $-0.352 * *$ & $-0.336 * *$ & $-0.335^{* *}$ & $-0.320 * *$ & $-0.511^{* *}$ \\
\hline & $(0.175)$ & $(0.130)$ & $(0.138)$ & $(0.137)$ & $(0.220)$ \\
\hline \multirow[t]{2}{*}{ Mother is sick/unable to work } & -0.170 & -0.191 & -0.184 & -0.160 & $-0.286^{*}$ \\
\hline & $(0.126)$ & $(0.132)$ & $(0.124)$ & $(0.115)$ & $(0.161)$ \\
\hline \multirow[t]{2}{*}{ Mother has other labour market position } & 0.024 & 0.075 & 0.067 & 0.063 & 0.101 \\
\hline & (0.089) & $(0.087)$ & $(0.082)$ & $(0.081)$ & $(0.140)$ \\
\hline
\end{tabular}




\begin{tabular}{|c|c|c|c|c|c|}
\hline & \multicolumn{5}{|c|}{ Track in 9th grade } \\
\hline & $(1)$ & $(2)$ & (3) & $(4)$ & $(5)$ \\
\hline \multirow[t]{2}{*}{ Father is unemployed } & 0.026 & 0.168 & 0.117 & 0.114 & 0.109 \\
\hline & $(0.153)$ & $(0.125)$ & $(0.120)$ & $(0.121)$ & $(0.211)$ \\
\hline \multirow[t]{2}{*}{ Father is sick/unable to work } & 0.077 & $0.257^{*}$ & 0.184 & 0.201 & $0.355^{*}$ \\
\hline & $(0.169)$ & $(0.138)$ & $(0.133)$ & $(0.130)$ & $(0.192)$ \\
\hline \multirow[t]{2}{*}{ Father has other labour market position } & -0.116 & -0.130 & -0.082 & -0.118 & -0.232 \\
\hline & $(0.168)$ & $(0.135)$ & $(0.138)$ & $(0.135)$ & $(0.217)$ \\
\hline \multirow[t]{2}{*}{ Child lives with both parents } & $0.166^{* * *}$ & $0.168 * * *$ & $0.162 * * *$ & $0.149 * * *$ & $0.203^{* *}$ \\
\hline & $(0.064)$ & $(0.058)$ & $(0.056)$ & $(0.056)$ & $(0.087)$ \\
\hline \multirow[t]{2}{*}{ Constant } & 0.718 & $3.250 * * *$ & $1.730 * *$ & 1.087 & \\
\hline & $(0.903)$ & $(0.734)$ & $(0.816)$ & $(0.814)$ & \\
\hline \multirow[t]{2}{*}{ Constant cut1 } & & & & & 0.015 \\
\hline & & & & & $(1.378)$ \\
\hline \multirow[t]{2}{*}{ Constant cut 2} & & & & & $2.295^{*}$ \\
\hline & & & & & $(1.337)$ \\
\hline \multirow[t]{2}{*}{ Constant cut3 } & & & & & $2.944^{* *}$ \\
\hline & & & & & $(1.354)$ \\
\hline \multirow[t]{2}{*}{ Constant cut 4} & & & & & $4.190 * * *$ \\
\hline & & & & & $(1.329)$ \\
\hline \multirow[t]{2}{*}{ Constant cut5 } & & & & & $6.039 * * *$ \\
\hline & & & & & $(1.325)$ \\
\hline Initial teacher assessment/(C5-C1) & & & & & 0.0548 \\
\hline Final teacher assessment/(C5-C1) & & & & & 0.0659 \\
\hline Difference ITA-FTA (p-values) & & & 0.0122 & 0.0484 & 0.4754 \\
\hline School FE & yes & yes & yes & yes & yes \\
\hline Clustered SEs & yes & yes & yes & yes & yes \\
\hline Observations & 1,404 & 1,404 & 1,404 & 1,404 & 1,404 \\
\hline R-squared & 0.764 & 0.793 & 0.808 & 0.813 & \\
\hline
\end{tabular}

Note: Coefficients in column 1-4 are from ordinary least squared regressions. Coefficients in column 5 are from ordered probit. The dependent variable in all columns is the students' track allocation in 9th grade. Standard errors are clustered at the primary school level. ***,**,* represent 1,5 and 10 percent significance levels respectively. Other control variables in all regressions are area code of residence and region. 

Chapter 5:

The impact of changing incentives on

achievement tests and assessment measures:

Evidence from a policy change in

the Netherlands 



\subsection{Introduction}

Throughout children's educational career achievement tests and assessments are used to monitor children's ability level and evaluate their progress. Achievement tests are generally regarded as objective measures of a specific set of children's skills. Teacher's assessments are generally seen as more inclusive, taking into account a wider range of children's skills and personality characteristics. However, this also makes the teacher's assessment subjective and vulnerable to bias. Therefore, one could think about a teacher's assessment as the aggregation of the information that the teacher has available, and one can think of a test as an aggregate measure of the skills of a child. An important question to understand the meaning of assessments and tests is whether the way information is aggregated is stable or varies when the incentives of the assessment or the test change.

The aim of this paper is to investigate whether a change in the incentives changes the way teachers incorporate available information into their teacher's assessment. We use a recent policy change in the Netherlands regarding the use of information for the transition from primary to secondary school to investigate the effect of circumstance on the test and the teacher's assessments. As of the schoolyear 2014-2015, the Dutch government decided that children take the final test only after the teacher has made his assessment and that the track allocation decision is based solely on the teacher's assessment. This change potentially has an impact on how available information is incorporated in the teacher's assessment.

The policy change has two main components. First, the moment at which children take the standardized test in $6^{\text {th }}$ grade is delayed from February until April. Second, the teacher's assessment of children's ability level in $6^{\text {th }}$ grade becomes the measure that determines at which track level children are allocated at the start of secondary school. Before the policy change, the teacher's final assessment is the teacher's assessment that is most important for children's track placement. However, after the policy change, the teacher's initial assessment became the most important teacher's assessment and the final teacher's assessment serves as a correction. ${ }^{43}$ (Rijksoverheid, 2013; Rijksoverheid, 2016a).

Due to the policy change the test score becomes low-stakes for some children. Children who are already satisfied with their teacher's assessment no longer have an incentive to perform well on the test to improve their track allocation in secondary school. For children who are not yet satisfied with their track allocation the test remains high-

\footnotetext{
${ }^{43}$ The only time when the $6^{\text {th }}$ grade test score is relevant for track placement is when the test score and the teacher's assessment do not correspond about a child's track placement and the test score indicates a higher track placement compared to the teacher's assessment. In this case, the teacher has to reconsider, but not necessarily adjust, the child's assessment. Of the children who qualify for a reconsideration of their teacher's assessment approximately 20 percent receives a new teacher's assessment (Ministerie van Onderwijs, Cultuur en Wetenschap, 2016).
} 
stakes. If they receive a significantly better test score compared to their teacher's assessment, the teacher has to reconsider the assessment and the child might receive a higher teacher's assessment that provides access to a higher track in secondary school. Second, it is possible that due to the policy change the heterogeneity in the teacher's assessment across gender and ses increases as the teacher's assessment is now more based on subjective measures and less on objective measures. Third, since the teacher can no longer use the child's $6^{\text {th }}$ grade test score as input for the teacher's assessment it is likely that the teacher reverts to earlier test scores as inputs for this assessment. This could imply that earlier test scores become more important for children's track allocation and that selection effectively starts at an earlier age.

We investigate these questions in three steps. First, we observe the initial teacher's assessment, the test score and the final teacher's assessment before and after the policy change and investigate if changes occur. Second, we split these results by gender and the education level of the mother and the father to investigate whether there is heterogeneity across gender and ses for the test score and the teacher's assessments. Third, we investigate if teachers start to use earlier test scores as inputs for their assessment now that they can no longer use the $6^{\text {th }}$ grade test score. We investigate if there is an increase in the predictive power of the $5^{\text {th }}$ grade test score for the teacher's assessments after the policy change.

The most important findings from this study are as follows. First, we observe that on average there does not seem to be a change in the test score. However, the initial and final teacher's assessment seem to be more alike following the policy change, where the final teacher's assessment appears to be 12 percent of a standard deviation lower on average. Second, we find that the effect of the policy change on the test score and the teacher's assessments is heterogeneous across gender and the parental education level: girls seem to score significantly higher on the test while boys seem to score significantly lower and children whose parents have completed a higher level of education seem to receive a higher initial and final teacher's assessment compared to children whose parents have only completed a lower level of education. Finally, we find that teachers seem to put more emphasis on children's $5^{\text {th }}$ grade test score for their teacher's assessments following the policy change. The estimates suggest that the additional effect of the $5^{\text {th }}$ grade test score on the initial teacher's assessment is on average approximately 15 percent of a standard deviation and the additional effect, on top of the initial teacher's assessment, is approximately 7 percent of a standard deviation for the final teacher's assessment.

This study takes advantage of a dataset that provides information about four yearly cohorts of children before and after the policy change, between 2012 and 2015 . The dataset contains cross-sectional data with information on children's test scores in grades 3-6 in primary education, the teacher's assessments of the children's ability level in $6^{\text {th }}$ grade as well as children's demographic and social-economic background infor- 
mation obtained from questionnaires. Our dataset for the analyses consists of 8531 children.

This paper contributes to a similar set of literature as Feron et al. (2016). First, the consequences of using objective and subjective assessment measures for tracking and successive performance e.g. Dee (2005), Lindahl (2007), Lavy (2008), Gibbons and Chevalier (2008), Cornwell et al. (2012) and Burgess and Greaves (2013). Second, this paper contributes to the literature on early school tracking e.g. Hanushek and Woessmann (2006) and Brunello and Checci (2007). Being allocated to a track is also related to human capital formation (e.g., Carneiro and Heckman, 2003; Cunha and Heckman, 2007).

We proceed as follows. First, we discuss the policy change and the research strategy. Afterwards section 3 describes the data and the descriptive statistics of our key variables. Section 4 presents the results of our analyses. Section 5 concludes. We present additional results and detailed data descriptions in the appendix to this paper.

\subsection{Background and strategy}

\subsubsection{The policy change}

The Dutch government has decided that as of the schoolyear 2014-2015 all children in $6^{\text {th }}$ grade are obligated to take part in a final test. ${ }^{44}$ Schools have the option to choose between a number of different tests that have been approved by the government. For the analyses in this paper we use data from a test called the 'Centrale Eindtoets'. This test is the most widely used final test as approximately 86 percent of all $6^{\text {th }}$ grade children take this test in 2015. The test takes six hours and is spread over three sessions on three consecutive days in which it measures children's knowledge in the areas of language and math. Before the schoolyear 2014-2015 the test was taken in February, however, as of the schoolyear 2014-2015 the test is delayed by approximately two months and is taken between the $15^{\text {th }}$ of April and the $15^{\text {th }}$ of May. Approximately three weeks after taking the test the school receives a report for every individual child. This report shows the child's results per subject. The report also contains the test score the child obtained as well as an explanation regarding the advice for the child's best suitable track allocation in secondary school. Next to receiving reports for every individual child, the school also receives a report at the school level which shows the results for all children in this school. This second report provides an indication of how the results of this school relate to the national average. (College voor Toetsing en Examens (CVTE), 2015).

Due to the policy change the teacher's assessment of children's ability level has become the guiding measure in children's track allocation in secondary school. The final

\footnotetext{
${ }^{44}$ There are exceptions for children in special needs education. See CVTE (2015) for more detailed information.
} 
test in $6^{\text {th }}$ grade is seen as an independent and objective second measure of children's ability level next to the teacher's assessment, or a so-called 'second opinion' (Rijksoverheid, 2013). Every child in $6^{\text {th }}$ grade receives a teacher's assessment of his/her ability level before the $1^{\text {st }}$ of March, which is the final date for application to secondary schools. The teacher's assessment states which type of track allocation is best suited for a child in secondary school. The teacher's assessment should be based on children's learning achievements, ability and development during the entire primary school period. Due to the new timing of the assessment measures in $6^{\text {th }}$ grade, children have to apply at a secondary school based on their teacher's assessment as their $6^{\text {th }}$ grade test score is not available yet. Furthermore, secondary schools are only allowed to place children into tracks based on their teacher's assessment. If the child's test score later appears to be higher than the teacher's initial assessment, the teacher has to re-assess his assessment and he/she can choose to give the same or a higher assessment. It is not possible for a teacher to give a lower assessment. In case the teacher's assessment is adjusted upwards, the child can still be placed in a higher track in secondary school (CVTE, 2015). A timeline of the events before and after the policy change can be found in Figure 1.

Timeline before policy change

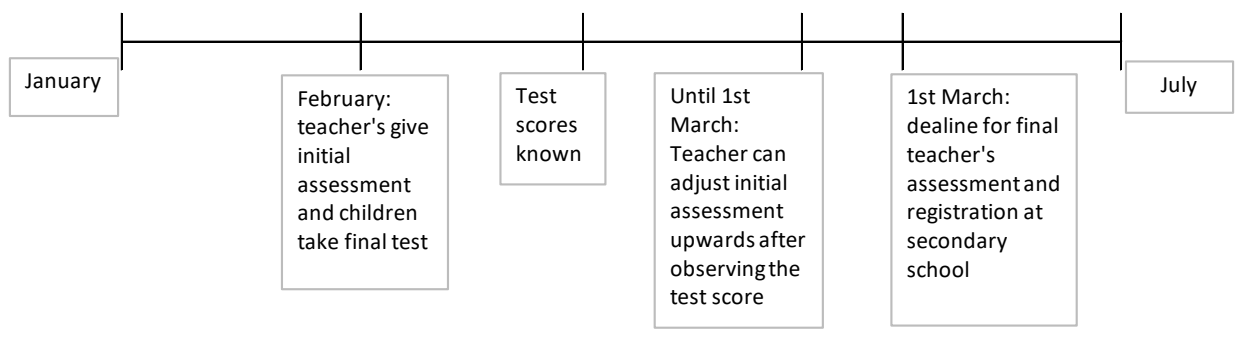

Timeline after policy change

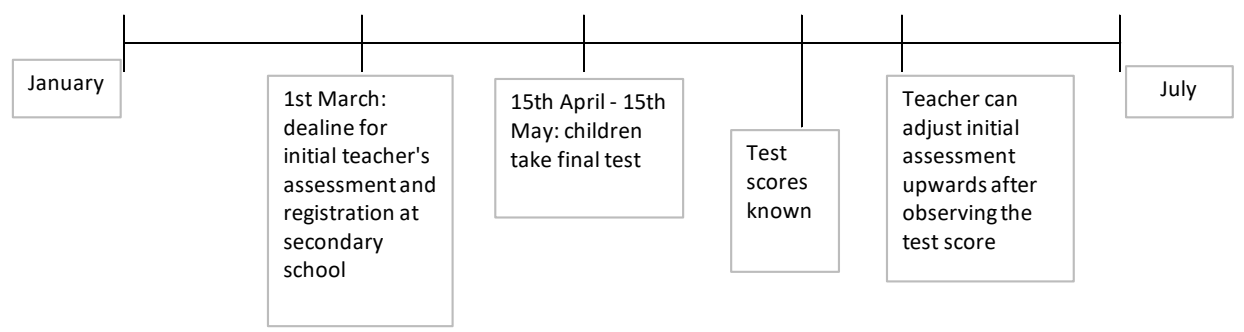

Figure 1: timeline of events 


\subsubsection{Reasons for the policy change}

The government has formulated three main reasons as to why the test should be delayed until later in the schoolyear. First, there is a concern that in the last months in $6^{\text {th }}$ grade less teaching time in spend on basic skills, such as language and math, and more time is spend on 'fun' activities. The idea is that children are less motivated to pay attention because they have already taken their final test and know which track they will be placed in in secondary school. Furthermore, schools might be less motivated to spend additional teaching time on language and math as the school's performance benchmark, that the Inspectorate of Education uses for schools' quality assessment, has already taken place. Delaying the test by a few months might stimulate schools and children to spend more teaching time on language and math skills. Second, when the test is taken later in the schoolyear, secondary schools receive more accurate and timely information about children's level of language and math skills and the skills depreciation is likely to be lower. The idea is that when these skills are not maintained they will start to deteriorate, for example over a summer vacation. Roeleveld et al. (2011) find evidence that children's scores on language and math start to decrease in the second half of $6^{\text {th }}$ grade. Third, by delaying the test taking procedure the timing of the two assessment measures ensures that the teacher's assessment is used for children's track allocation in secondary school as the test score is not yet available. The assumption is that the teacher's assessment takes into account children's ability, their learning achievements, their development during the entire primary school period and children's concentration, motivation and persistence (Rijksoverheid, 2016a; Rijksoverheid, 2016b).

\subsubsection{Possible implications and strategy}

This paper investigates the effect of this policy change on the teacher's assessments in $6^{\text {th }}$ grade. This paper also investigates whether this effect is heterogeneous across groups such as children's gender and their social-economic background measured by the parental education level. In order to investigate this question we assume that in the year of the policy change (schoolyear 2014-2015) there are no other changes that affect our measurements. ${ }^{45}$ Furthermore, we note that any effect we find is likely to be a lower bound as the full effect of this policy change might not materialize after one year. It is possible that for the full effect to be visible the new system needs to be in place for a while so that teachers, parents and children are able to adapt to the new situation.

\footnotetext{
${ }^{45}$ According to the College voor Toetsen en Examens (CVTE) (2015) the final test in 2015 builds on the previous "Eindtoets Basisonderwijs" from Cito and is regarding content, form and test taking possibilities comparable to previous editions of the "Eindtoets Basisonderwijs". However, the CVTE (2016) argues that there are several changes made to the final test in 2015 that make a comparison to the earlier "Eindtoets Basisonderwijs" difficult. These changes are: in the language component of the test the topics "grammatica" en "interpunctie" are added, the part study skills is now incorporated in the language and math components of the test, the topic "kaartlezen" is not included in the new test, the topic "tabellen en grafieken" is not equal to the topic "verbanden" in the new test and the number and proportions of the language and math components differ.
} 
The policy change can have several implications for the behavior of children, parents and teachers. As a result of the policy change, the $6^{\text {th }}$ grade test becomes a less important selection and allocation measure and the teacher's assessments become a more important selection and allocation measure for children's track allocation in secondary school. Also, after the policy change the initial teacher's assessment becomes more important than the final teacher's assessment. It is possible that children, parents and teachers respond to these changes. For schools the situation does not change, because the test scores remain an outcome by which the Inspectorate of Education measures schools' value added.

We describe three effects that might occur as a response to the policy change. First, it is possible that the $6^{\text {th }}$ grade test turns from a high-stakes test into a low-stakes test. The teacher's assessment is binding for children's track placement in secondary school. Therefore, for all children (and parents) who are satisfied with the teacher's assessment the test is no longer a determinant for children's track placement and they might exert less effort. For these children the test becomes a low-stakes test. Nevertheless, for all children (and parents) who are not satisfied with the teacher's assessment, the $6^{\text {th }}$ grade test remains a high-stakes test as the test is their only option to receive a higher teacher's assessment. For these children the test is still a determinant for their track placement in secondary school and they might exert more effort. With a lower motivation to perform well on the test it is likely that the average test score drops, while with a higher motivation it is likely that the average test score rises. By looking at the average effect of the policy change on the test score, these effects might cancel out. In the empirical analysis we take into account the possible presence of both effects. Furthermore, if children's motivation to perform well on the test decreases it is likely that the test is no longer an accurate reflection of the children's language and math skills. This also has consequences for the other functions of the test, such as giving secondary schools more accurate and timely information about children's level of language and math skills as well as the quality control measure used by the Inspectorate of Education.

Second, due to the policy change children's track placement is determined by the teacher's assessment. In general, the teacher's assessment is considered to be a more subjective measure of children's ability compared to the test score. It is unclear what information the teacher exactly incorporates into his assessment and to what extent the different inputs are weighted. There are no guidelines that determine how teachers have to weigh these different types of information (Sluijter, 2013; OECD, 2016). Therefore, assuming that parents want their children to receive the highest possible education track, parents could start to put more pressure on teachers to adjust their children's teacher's assessment upwards. If teachers are susceptible to this pressure it is likely that the teacher's assessments will rise. Nevertheless, as the teacher can only revise his initial teacher's assessment upwards after receiving the information about children's test scores, it is also possible that teachers become more careful regarding 
their assessments. As a result, the average teacher's assessment might decrease. Falk and Zimmermann (2011) find that people show a preference for consistency. One of their findings is that there is a preference for consistency, especially if there is an early commitment. It is possible that the inequality in the teacher's assessment for children from different social-economic backgrounds increases due to the policy change. Timmermans et al. (2015) show that the teacher's assessment can be disadvantageous for children from lower social-economic backgrounds even if they have a similar performance as other children. Furthermore, Feron (2017) shows that teachers heterogeneously adjust their teacher's assessment depending on the parental education level.

Third, after the policy change, the teacher does not have the information previously provided by the $6^{\text {th }}$ grade test score to incorporate into the teacher's assessment. This might affect the teacher's assessment as Feron (2017) shows that teachers adjust their assessment after receiving new information from the test score. If teachers can no longer use the $6^{\text {th }}$ grade test score for the teacher's assessment it is possible that teachers consequently revert to earlier measures of the children's performance, such as earlier tests of language and math skills in primary school. The most recent test before the $6^{\text {th }}$ grade final test are tests in $5^{\text {th }}$ grade that measure children's math and language skills. If, in the new system, teachers revert to the $5^{\text {th }}$ grade test score to incorporate into their assessment it is possible that the timing for selection and allocation into tracks takes place earlier in children's school career. We investigate whether the predictive power of the $5^{\text {th }}$ grade test score increases in the new system compared to the old system.

\section{Strategy}

First, we use descriptive statistics to look at trends in the test score and the teacher's assessment over time, both for all children in our sample and for subgroups by gender and the parental education level. Second, we estimate equation (1), (2) and (3) by running OLS regressions, with the test score and the teacher's assessment as dependent variables, to investigate whether these measures show deviations compared to previous years before the policy change. We use different models to correct for control variables, a time trend, primary school fixed effects and standard errors clustered at the level of the primary schools. Inclusion of a time trend ensures that our estimates do not incorporate any potential pre-existing time trend in the data. The primary school fixed effects ensure that our estimates do not include effects that are specific to a particular school. Furthermore, we use clustered standard errors as children who attend the same school might have specific common characteristics that are picked up by the standard errors. Additionally, we use the predicted $6^{\text {th }}$ grade test score, based on the test scores in the $3^{\text {rd }}, 4^{\text {th }}$ and $5^{\text {th }}$ grade, to avoid endogeneity of the $6^{\text {th }}$ grade test score due to the policy change.

$$
\text { IT }_{i}=C_{1}+a_{1} X_{i}+a_{2} \text { Treatment }_{i}+a_{3} \text { TSpredict }_{-} 345_{i}+\beta_{P_{i}}+\gamma_{y_{i}}+\varepsilon_{i}
$$




$$
\begin{aligned}
& T S_{i}=C_{1}+a_{1} X_{i}+a_{2} \text { Treatment }_{i}+a_{3} \text { TSpredict_345 }_{i}+a_{4} I T A_{i}+\beta_{P_{i}}+\gamma_{y_{i}}+\varepsilon_{i}(2) \\
& \text { FTA }_{i}=C_{1}+a_{1} X_{i}+a_{2} \text { Treatment }_{i}+a_{3} \text { TSpredict_345 }_{i}+a_{4} I T A_{i}+\beta_{P_{i}}+\gamma_{y_{i}}+\varepsilon_{i}
\end{aligned}
$$

In all estimations, $X_{i}$ refers to a set of control variables, $P_{i}$ refers to the primary school dummy variables, $y_{i}$ refers to the dummy variables for the time trend and $\varepsilon_{i}$ represents the error term. Furthermore, we use propensity score matching to observe whether our results are robust. Our data consist of different cohorts of children in every schoolyear meaning that when we apply the before-after analyses we create a cross sectional estimate of the effect. With propensity score matching we aim to get a more precise picture of the true effect as we attempt to compare children with similar characteristics before and after the policy change. Second, we use interaction terms to look at heterogeneity across subgroups for gender and the parental education level in relation to the test score and the teacher's assessment.

Third, we investigate whether the predictive power of the $5^{\text {th }}$ grade test score for the teacher's assessment has increased after the policy change. We estimate equations (4) and (5) by running OLS regressions and observe the interaction effect between the dummy variable for the schoolyear after the policy change and the $5^{\text {th }}$ grade test score variable. This interaction effect should indicate whether teachers make more use of the $5^{\text {th }}$ grade test score to establish their teacher's assessment after the policy change. As a robustness check we run a placebo analysis where we exclude all data from the year after the policy change and observe whether we find a similar effect in the previous schoolyear. If teachers start to make more use of the $5^{\text {th }}$ grade test score for their teacher's assessment as a result of the policy change, we expect to find no significant effect for this analyses in the previous schoolyear.

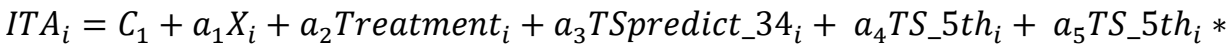

$$
\begin{aligned}
& \text { Treatment }+\beta_{P_{i}}+\gamma_{y_{i}}+\varepsilon_{i} \\
& \text { FT } A_{i}=C_{1}+a_{1} X_{i}+a_{2} \text { Treatment }_{i}+a_{3} \text { TSpredict_34 }_{i}+a_{4} I T A_{i}+a_{5} \text { TS_5th } \text { t }_{i}+ \\
& a_{6} \text { TS_5th } \text { t }_{i} * \text { Treatment }+\beta_{P_{i}}+\gamma_{y_{i}}+\varepsilon_{i}
\end{aligned}
$$

\subsection{Data}

The data consists of four yearly cohorts of children who attended $6^{\text {th }}$ grade between 2012 and 2015 and contains information from school tracking systems, including the test score and the teacher's assessment in $6^{\text {th }}$ grade, as well as questionnaires answered by children and their parents which provide information on children's social-economic background. Furthermore, we have information on children's test scores in grades 3 
through $5 .{ }^{46}$ We first describe the most important aspects of the data before presenting our main results.

\subsubsection{Descriptive statistics}

Table 1 shows the distributions of the main variables of interest, the initial teacher's assessment, the test score and the final teacher's assessment, across the different tracks. ${ }^{47}$ A description of the Dutch education system and the different tracks in secondary education can be found in Chapter 2. For the teacher's assessments the numbers in each row add up to 100 percent. Approximately 50 percent of children have an initial teacher's assessment to attend pre-vocational education. The other 50 percent of children is divided between pre-higher vocational and pre-university education.

Table 1: description of the ITA, the test score and the FTA

\begin{tabular}{|c|c|c|c|c|c|c|c|c|c|}
\hline ITA & $\mathrm{T} 1 \mathrm{a}$ & $\mathrm{T} 1 \mathrm{a} / \mathrm{b}$ & $\mathrm{T} 1 \mathrm{~b}$ & $\mathrm{~T} 1 \mathrm{~b} / \mathrm{c}$ & $\mathrm{T} 1 \mathrm{c} / \mathrm{d}$ & $\mathrm{T} 1 \mathrm{~d} / 2$ & $\mathrm{~T} 2$ & $\mathrm{~T} 2 / 3$ & T3 \\
\hline 2015 & 4.41 & 1.48 & 10.42 & 0 & 19.9 & 9.52 & 20.52 & 8.74 & 25.01 \\
\hline 2014 & 3.89 & 3.67 & 10.63 & 0 & 18.29 & 15.49 & 16.35 & 14.52 & 17.16 \\
\hline 2013 & 5.08 & 3.61 & 8.68 & 0 & 18.59 & 15.54 & 15.39 & 17.57 & 15.54 \\
\hline 2012 & 3.82 & 3.96 & 9.37 & 0 & 21.02 & 15.19 & 16.12 & 14.68 & 15.84 \\
\hline $2012-2015$ & 4.3 & 3.07 & 9.8 & 0 & 19.53 & 13.63 & 17.33 & 13.53 & 18.81 \\
\hline \multicolumn{10}{|l|}{ B } \\
\hline avg test score by FTA & $\mathrm{T} 1 \mathrm{a}$ & $\mathrm{T} 1 \mathrm{a} / \mathrm{b}$ & $\mathrm{T} 1 \mathrm{~b}$ & $\mathrm{~T} 1 \mathrm{~b} / \mathrm{c}$ & $\mathrm{T} 1 \mathrm{c} / \mathrm{d}$ & $\mathrm{T} 1 \mathrm{~d} / 2$ & $\mathrm{~T} 2$ & $\mathrm{~T} 2 / 3$ & T3 \\
\hline 2015 & 519.2 & 524.0 & 527.3 & & 532.9 & 536.3 & 540.2 & 543.4 & 546.8 \\
\hline 2014 & 521.2 & 516.5 & 525.4 & & 530.1 & 535.7 & 538.9 & 542.6 & 547.4 \\
\hline 2013 & 523.4 & 521.5 & 527.3 & & 530.0 & 535.4 & 538.9 & 541.8 & 546.9 \\
\hline 2012 & 523.5 & 524.8 & 523.3 & & 530.9 & 536.4 & 538.9 & 542.0 & 546.8 \\
\hline 2012-2015 & 522.1 & 523.2 & 527.0 & & 531.0 & 536.0 & 539.4 & 542.3 & 547.0 \\
\hline
\end{tabular}

\footnotetext{
${ }^{46}$ In our data the FTA in 2015 is measured by the question: "Now that you know the child's test score what would your teacher's assessment be?". This question makes a comparison with the FTA in previous years easier as in previous years teachers could adjust the FTA upwards and downwards. This question might increase the noise in the measure of FTA for 2015 which could lead to an underestimation of the estimated effects. This question might also lead to more bias as it is a self-reported measure. In this last case, the teacher is more likely to let the FTA reflect his ITA.

47 There are more sub-tracks in pre-vocational education compared to pre-higher vocational and preuniversity education. This is also reflected in the lower amount of children per track in pre-vocational education. We distinguish nine educational tracks based on the initial teacher's assessment. The final teacher's assessment and the test score are recoded so that all variables are comparable on the same scale. The result is that for the final teacher's assessment and the test we combine track T1c with T1c/d and track T1d with $\mathrm{T} 1 \mathrm{~d} / 2$.
} 


\begin{tabular}{|c|c|c|c|c|c|c|c|c|c|}
\hline FTA & T1a & $\mathrm{T} 1 \mathrm{a} / \mathrm{b}$ & $\mathrm{T} 1 \mathrm{~b}$ & $\mathrm{~T} 1 \mathrm{~b} / \mathrm{c}$ & $\mathrm{T} 1 \mathrm{c} / \mathrm{d}$ & $\mathrm{T} 1 \mathrm{~d} / 2$ & $\mathrm{~T} 2$ & $\mathrm{~T} 2 / 3$ & T3 \\
\hline 2015 & 4.56 & 0.78 & 10.38 & 0 & 21.34 & 7.26 & 22.08 & 7.34 & 26.26 \\
\hline 2014 & 7.50 & 0.22 & 1.78 & 0 & 26.17 & 7.77 & 16.30 & 17.86 & 22.40 \\
\hline 2013 & 8.33 & 0.10 & 0.36 & 0 & 28.24 & 5.94 & 15.85 & 15.44 & 25.75 \\
\hline 2012 & 7.55 & 0.47 & 0.42 & 0 & 28.52 & 7.04 & 14.91 & 19.38 & 21.71 \\
\hline $2012-2015$ & 6.82 & 0.42 & 3.69 & 0 & 25.79 & 7.01 & 17.58 & 14.52 & 24.16 \\
\hline
\end{tabular}

Note: For ITA and FTA all rows add up to 100 percent. $\mathrm{N}=8531$. See Chapter 2 for an overview of the educational tracks.

Between 2012 and 2015 there appears to be a shift towards more initial teacher's assessments for pre-higher vocational and pre-university education tracks and less initial teacher's assessments for the pre-vocational education tracks, from 53.4 percent of initial teacher's assessments for pre-vocational education in 2012 to 45.7 percent in 2015. Approximately 45 percent of children have a final teacher's assessment to attend pre-vocational education and 55 percent of children have a final teacher's assessment to attend pre-higher vocational or pre-university education. There does not appear to be a shift towards the higher tracks in the final teacher's assessment. For the final teacher's assessment it is apparent that there is a shift away from double teacher's assessments in the higher tracks in 2015. In panel B of Table 1 we observe the average test score per track. The test score seems to be relatively stable across time. The average overall test score seems to be slightly higher in 2015 compared to previous years.

Table 2 presents the descriptive statistics. Children in $6^{\text {th }}$ grade are on average 12 years old and our sample consists of slightly more girls than boys. Parents have on average completed vocational education and there are more fathers who have paid work compared to mothers. Most parents are born in the region (Limburg) and 80 percent of the children in our sample report to live with both parents. ${ }^{48}$ The initial teacher's assessment and the final teacher's assessment are measured on a scale from 1-9. The average initial and final teacher's assessment corresponds to a T1d/2 track (vmbot/havo track). The average final teacher's assessment is approximately 0.3 track higher than the average initial teacher's assessment. The test score is measured on a scale from 501-550.

In Table 3 we observe that correlations are high, positive and significant among all of our main variables of interest. ${ }^{49}$ We observe some interesting changes over time. First, the correlation between the final teacher's assessment and the test scores in $5^{\text {th }}$ grade has gone up over time. This indicates that teachers in 2015 make more use of test scores in earlier grades compared to the years before. Second, the correlation between the test score in $6^{\text {th }}$ grade and the test score in $5^{\text {th }}$ grade has gone down.

\footnotetext{
${ }^{48}$ The corresponding survey question is: "Do you live at home with both parents?"

${ }^{49}$ See Appendix A for the full correlation table that includes all variables.
} 
Table 2: descriptive statistics

\begin{tabular}{|c|c|c|c|c|c|c|}
\hline & $\mathrm{N}$ & Mean & S.D. & Min & Median & Max \\
\hline Initial teacher assessment & 8531 & 6.18 & 2.24 & 1 & 6 & 9 \\
\hline 6 th grade test score & 8531 & 537.54 & 8.88 & 501 & 539 & 550 \\
\hline Final teacher assessment & 8531 & 6.46 & 2.25 & 1 & 7 & 9 \\
\hline 5th grade test score & 5094 & 0.04 & 0.88 & -3.77 & 0.13 & 2.38 \\
\hline Ivs test scores ( 3 rd- 5 th grade) & 5156 & 0.01 & 0.76 & -3.60 & 0.07 & 2.38 \\
\hline Boys & 8531 & 0.47 & 0.50 & 0 & 0 & 1 \\
\hline Age (in months) & 8531 & 143 & 5.59 & 87 & 142 & 173 \\
\hline Education mother & 8531 & 2.24 & 0.88 & 1 & 2 & 4 \\
\hline Education father & 8531 & 2.33 & 0.98 & 1 & 2 & 4 \\
\hline 1. Lower education & & $22.15 \%$ & & & & \\
\hline 2. Vocational education & & $35.27 \%$ & & & & \\
\hline 3. Higher education & & $28.76 \%$ & & & & \\
\hline 4. University education & & $13.82 \%$ & & & & \\
\hline Labor market participation mother & 8368 & 0.82 & 0.38 & 0 & 1 & 1 \\
\hline Labor market participation father & 8176 & 0.92 & 0.27 & 0 & 1 & 1 \\
\hline Region of birth mother & 8453 & 1.29 & 0.62 & 1 & 1 & 3 \\
\hline Region of birth father & 8398 & 1.30 & 0.64 & 1 & 1 & 3 \\
\hline 1. Limburg & & $79.39 \%$ & & & & \\
\hline 2. The Netherlands outside Limburg & & $10.87 \%$ & & & & \\
\hline 3. Abroad & & $9.74 \%$ & & & & \\
\hline Child lives with both parents & 8515 & 0.80 & 0.40 & 0 & 1 & 1 \\
\hline
\end{tabular}

Note: The description of the variables education and region of birth apply to both the father and the mother. Chrildren's test scores from earlier years: grade 3-5 are standardized. For these measures we use various tests on spelling, comprehensive reading and math. We standardize all of these tests separately and take the average of these standardized tests per year for every child.

Third, the correlation between the initial teacher's assessment and the final teacher's assessment has gone up. This is consistent with the idea that the test score is not used as much as a correction mechanism as in previous years. Fourth, the correlation between the test score in $6^{\text {th }}$ grade and the initial teacher's assessment has gone down. In 2015, due to the policy change, the initial teacher's assessment is the teacher's assessment that is relevant for children's track placement in secondary education. The teacher can no longer use the information provided by the test score in this assessment. Possibly this explains the lower correlation. Finally, the correlation between the test score in $6^{\text {th }}$ grade and the final teacher's assessment has gone down. Based on this first description in terms of simple correlations, it seems that there is less congruence between the test score and the teacher's assessment after the policy change, compared to earlier years. ${ }^{50}$

\footnotetext{
${ }^{50}$ If we observe the correlations for the smaller sample of 4255 children which we use later on in the analyses, we also see an increase in the correlation between the $5^{\text {th }}$ grade test score and the ITA from 0.77 in 2012 to 0.80 in 2015.
} 
Chapter 5

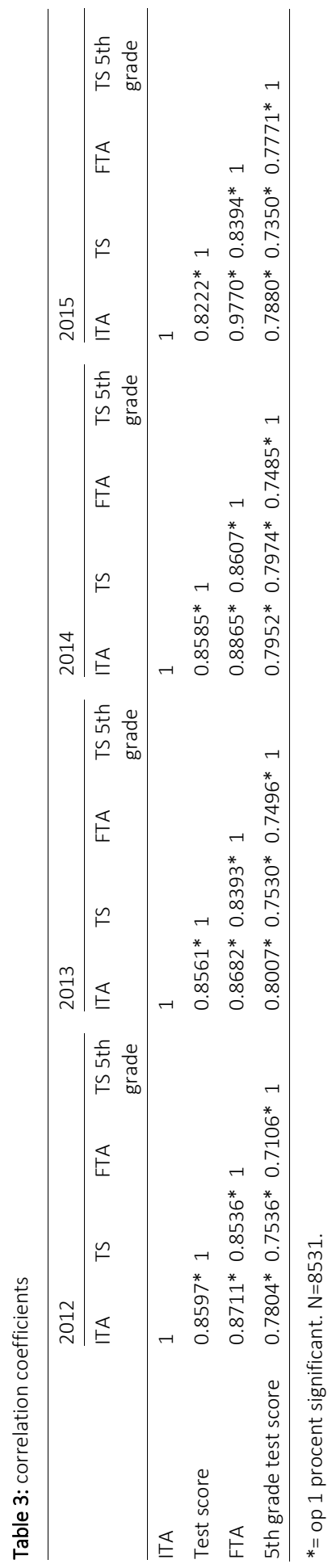




\subsubsection{Selection}

For 8,531 children we have information on the main variables of interest, the initial teacher's assessment, the final teacher's assessment, the $6^{\text {th }}$ grade test score, gender, age and the parental education level. These data include 190 primary schools in Limburg. For 5,156 of these children we have obtained information on the test scores in $3^{\text {rd }}$, $4^{\text {th }}$ and/or $5^{\text {th }}$ grade recorded in the school tracking systems. This is a subset of the original dataset that consists of 22,297 children.

Possible selection issues with regard to the analyses are addressed. We investigate if characteristics of children explain if they end up in our sample for analyses. The main concern regarding selection bias is that schools only report data on their wellperforming children and neglect to report data on their poorer performing children. There seems to be a small effect of mother's parental education: children whose mother has finished vocational education, higher vocational education or university education are slightly more likely to be included in the sample compared to children whose mothers have finished lower levels of education only. This effect is not present for father's education levels. Additionally, there seems to be no difference between the determinants of selection into the sample for children for whom we have and for whom we do not have information on the test score. Finally, there seems to be no selection at the school level. There are no schools for which a large number of children drop out of our sample for analysis. ${ }^{51}$

\subsection{Results}

This section presents our estimation results. First, we investigate whether there has been a change in the teacher's assessments and the test score after the policy change. Second, we investigate whether these effects are heterogeneous across gender and parental education level. Finally, we investigate if the predictive power of the $5^{\text {th }}$ grade test score for the teacher's assessments has increased following the policy change. This section concludes with two robustness checks. The most salient results are shown in the main text and an appendix reports additional supportive findings.

\subsubsection{Before-after results}

The four panels in Table 4 show the values of the initial teacher's assessment, the test score, the final teacher's assessment and the predicted test score for the gender of the child and the education level of the mother and the father. Panel A shows the values for the initial teacher's assessment. Girls seem to have a slightly lower initial teacher's as-

\footnotetext{
${ }^{51}$ See Appendix B for the analysis of selection into the sample.
} 
sessment than boys and the assessment went slightly up over time for both genders. The second panel shows the values of the test score. Overall, girls have a lower test score. However, in 2015 girls have a higher test score than boys. Panel C shows the values of the final teacher's assessment. The values of the final teacher's assessment slightly decrease over time. This is in line with a conclusion of the Inspectorate of Education (2014) who finds that as of 2011 there is a slightly downward trend in the teacher's assessment. Panel D shows the predicted test score based on the children's earlier test scores in grades 3-5. Panel D shows that the predicted test scores are in line with the actual test scores for the years 2012-2014. However, for 2015 the predicted test score seems higher than the actual test score. Furthermore, the predicted test score shows that girls still score slightly lower than boys on the test. The average initial teacher's assessment, test score and final teacher's assessment all increase with the education level of the father and the mother.

When comparing the average initial teacher's assessment with the average final teacher's assessment we observe that the average final teacher's assessment seems to be higher than the average initial teacher's assessment. Teachers seems to give higher final recommendations for tracks compared to their initial recommendations. Feron (2017) shows that teachers adjust their initial assessment after receiving information about children's test score. In 2015, the final teacher's assessment is slightly lower compared to previous years. The initial teacher's assessment is slightly higher in 2015 compared to previous years. Possibly this is due to the fact that 2015 is the first year in which the initial teacher's assessment is already the relevant teacher's assessment for children's track placement in secondary school. Therefore, the initial teacher's assessment closely resembles the final teacher's assessment of previous years. However, the initial teacher's assessment remains lower than the final teacher's assessment in 2015. Furthermore, since the initial teacher's assessment has become the relevant teacher's assessment it is possible that teacher's find it now more important to stay consistent in their teacher's assessment, as the initial teacher's assessment was already the formal assessment. 


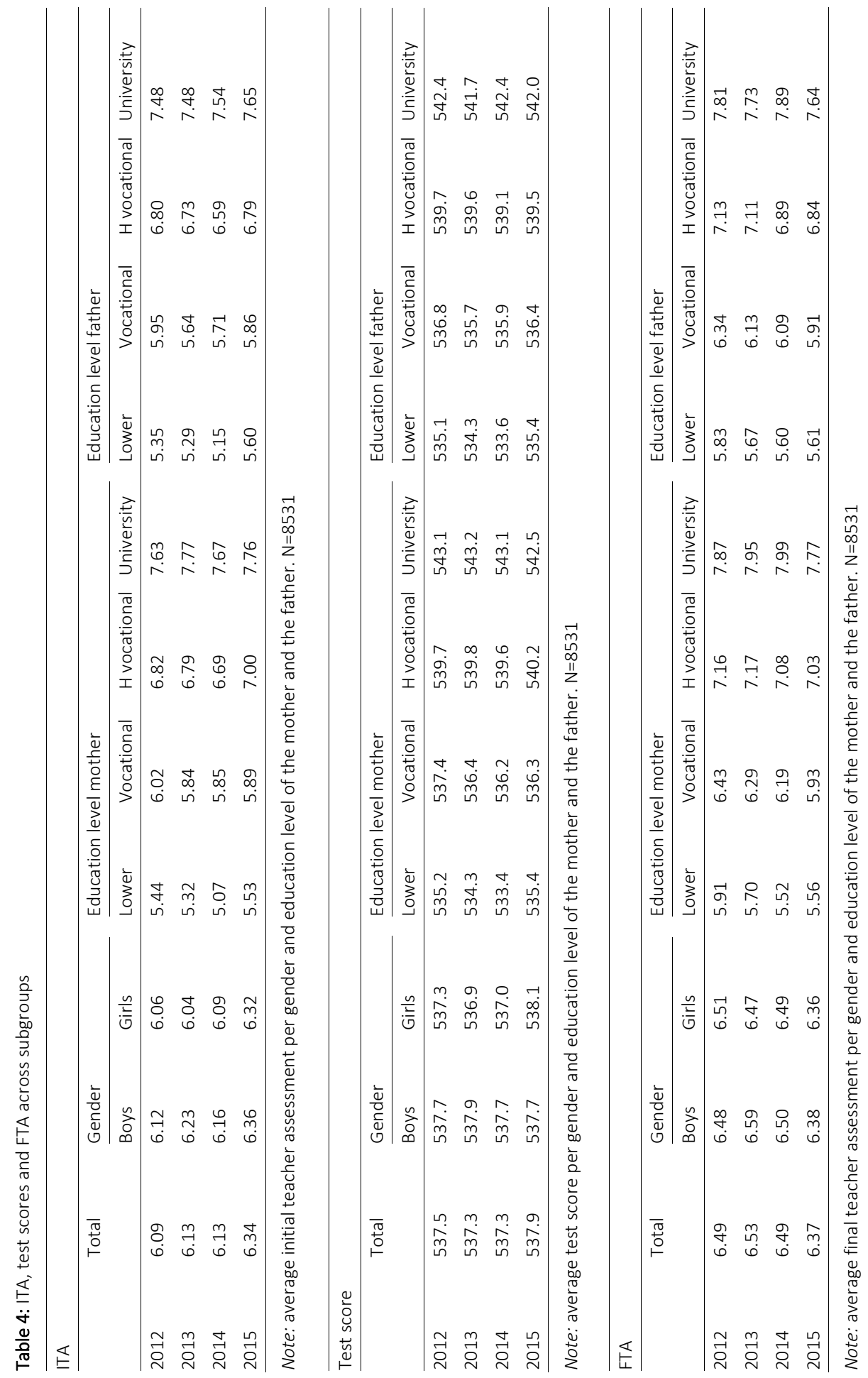




\section{Chapter 5}

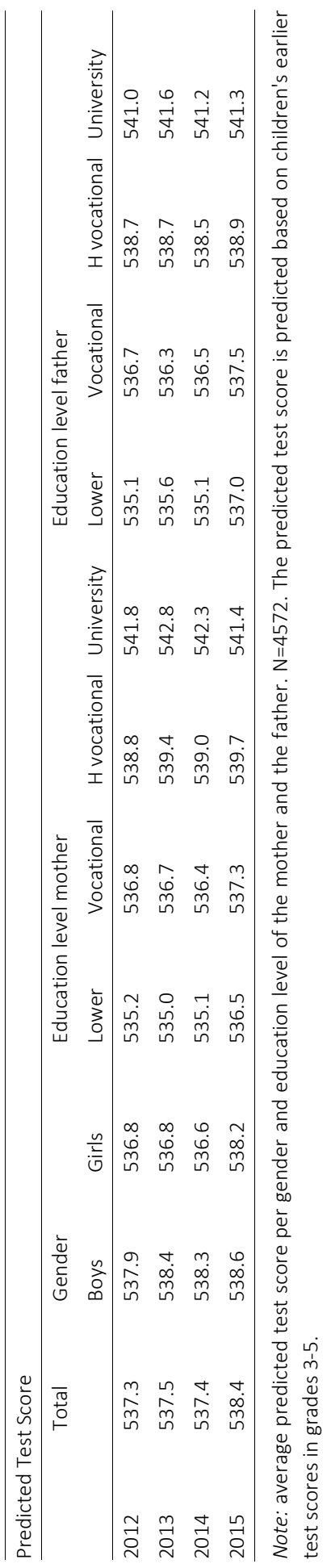


The data and the methodology of this paper do not allow for a strict causal interpretation of our findings. However, under the assumptions that there are no other significant changes that occurred simultaneously to the policy change and that the children in the different cohorts are comparable we interpret our results as an indication of a causal relationship. Table 5 shows the effect of the policy change on the initial teacher's assessment, the test score and the final teacher's assessment. ${ }^{52}$ The first set of regressions with the initial teacher's assessment as the dependent variable shows that conditional on the children's predicted test score, the average initial teacher's assessment in schoolyear 2014-2015 does not differ from previous schoolyears. ${ }^{53}$ The second set of estimates shows that the average test score in schoolyear 2014-2015 does not differ from previous schoolyears. Other estimates conditional on the predicted test score and/or the initial teacher's assessment confirm this finding. ${ }^{54}$ The third set of estimates shows that the average final teacher's assessment in schoolyear 2014-2015 seems to be significantly lower than the average final teacher's assessment in previous years. Based on the coefficient of -0.260 in column 10 of table 5 the final teacher's assessment seems to decrease by 12 percent of a standard deviation. Other estimates conditional on the predicted test score and/or the initial teacher's assessment confirm this finding. ${ }^{55}$

\footnotetext{
${ }^{52}$ The effect of the policy change is a dummy variable that equals 1 if the schoolyear is 2014-2015 and equals 0 for all other schoolyears.

${ }^{53}$ The predicted test score is a prediction of children's $6^{\text {th }}$ grade test score based on their earlier test scores in grades 3-5. We use the predicted test score since the actual test score in schoolyear 2014-2015 might have been influenced by children's response to the new policy.

${ }^{54} \mathrm{An}$ interaction term with the year of the policy change and the ITA does not show a relation with the test score.

${ }^{55}$ In these estimates we include the control variables 'positive difference ITA - predicted test score' and 'negative difference ITA - predicted test score' to observe whether and how children react to the teacher's assessment they received. If the dummy 'positive difference ITA - test score' equals 1 the child received a teacher's assessment that was higher than the predicted test score, if the dummy 'negative difference ITA test score' equals 1 the child received a teacher's assessment that was lower than the predicted test score. We expect that if the teacher's assessment is lower than the predicted test score children will perform better than expected on the test score. If the teacher's assessment is higher than the predicted test score we expect that children (and parents) are satisfied with the teacher's assessment and have no incentive to perform well on the test, which for these children is now a low-stakes test.
} 


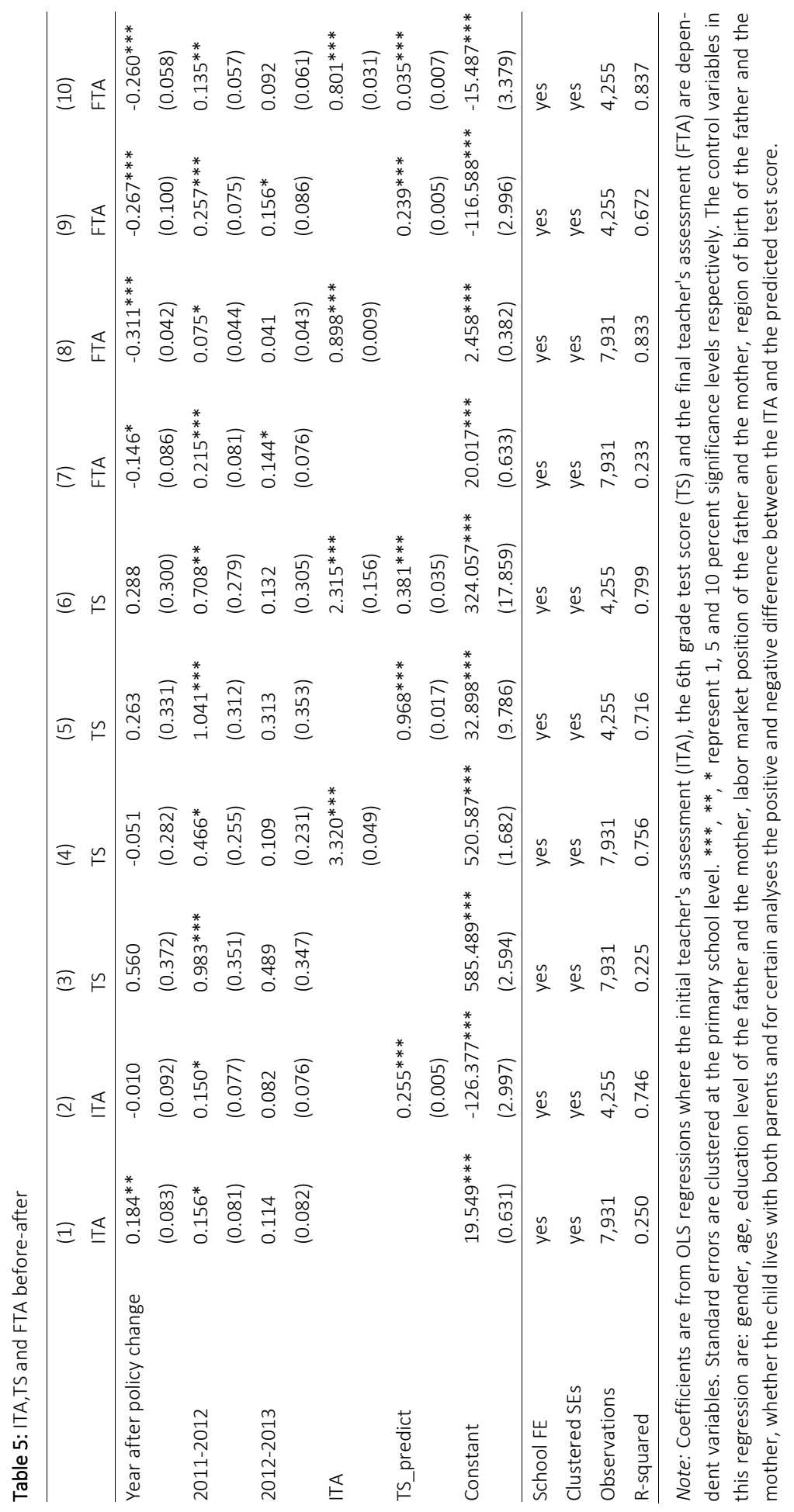




\subsubsection{Heterogeneity in gender and education level of parents}

Our estimates suggest that on average the policy change does not seem to affect the initial teacher's assessment and the test score but it seems to result in significantly lower final teacher's assessments. We want to investigate whether these effects differ across gender and the education level of parents as the teacher's assessments are now based on more subjective measures. Previous research by Attali, Neeman and Schlosser (2011) suggests that boys and girls respond with a different effort level to low-stakes and high-stakes test. Furthermore, research by Timmermans et al. (2015) and Feron (2017) shows that teacher's assessments and adjustments to teacher's assessments can differ based on the parental education level.

Panel A of Table 6 shows the estimates of the interaction effects for the initial teacher's assessment, the test score, the final teacher's assessment with gender. The first two columns show the interaction effect for the initial teacher's assessment. The estimates in column 2 seem to suggest that there is no difference in the effect on the initial teacher's assessment between boys and girls. Columns 3-6 report the estimates of the interaction effect for the test score. In column 6 we observe that there is a significant difference related to the policy change on the test score for boys and girls. It seems that girls generally have a significantly higher test score, with a coefficient of 0.795, after the policy change. Furthermore, boys have a significantly lower test score after the policy change with a coefficient of $(0.795-1.067)-0,272$. Columns $7-10$ report the estimates of the interaction effect for the final teacher's assessment. In column 10 we observe that there seems to be a significantly negative effect of the policy change on the final teacher's assessment, however, this effect does not differ across gender.

Panel B of Table 6 reports the estimates of the interaction effects for the initial teacher's assessment, the test score, the final teacher's assessment with the education level of the mother. The first two columns show the interaction effect for the initial teacher's assessment. The estimates in column 2 suggest that in the years before the policy change the children with higher educated parents, compared to children whose parents have only lower education, obtain a higher initial teacher's assessment. We observe only a slight effect of mother's education on the initial teacher's assessment after the policy change: only the interaction coefficient for mothers who have university education is significant at the 10 percent level. Columns 3-6 report the estimates of the interaction effect for the test score. The estimates in column 6 show that there are no interaction effects between mothers' education level and the policy change on children's test score. Columns 7-10 report the estimates of the interaction effect for the final teacher's assessment. In column 10 we observe that children whose mothers have university education, compared to children whose mothers only have finished lower education, have a significantly higher final teacher's assessment with a coefficient of 0.245 . Children from university educated mothers seems to have a 0.245 higher final 
teacher's assessment compared to mothers who have only finished lower education. Based on the coefficient of 0.245 this effect is 11 percent of a standard deviation.

Panel C of Table 6 reports the estimates of the interaction effects for the initial teacher's assessment, the test score, the final teacher's assessment with the education level of the father. The first two columns show the interaction effect for the initial teacher's assessment. The estimates in column 2 suggest that children whose parents have a higher level of education receive higher initial teacher's assessments compared to children whose parents only have finished lower levels of education. There do not appear to be interaction effects between the policy change and the education level of the father. Columns 3-6 report the interaction effect for the test score. The estimates in column 6 suggest that overall there is no effect of the policy change or the father's education level on the test score, except for fathers who completed higher education. Children of these fathers seem to have a slightly higher test score after the policy change. This effect is not present in other education levels. Columns 7-10 report the interaction effect for the final teacher's assessment. The estimates in column 10 suggest that there seems to be an interaction effect with the education level of fathers: children of fathers who completed higher or university education seem to receive a higher final teacher's assessment compared to children whose fathers only completed lower education. These coefficients represent 8 and 10 percent of a standard deviation respectively.

The estimates for the initial teacher's assessment, the test score and the final teacher's assessment across gender and parental education level show heterogeneity. The effects on the test score are different for boys and girls, where girls score higher on the test after the policy change. A possible explanation for this effect is that boys and girls respond differently to low-stakes and high-stakes tests. Attali, Neeman and Schlosser (2011) find that males exhibit a larger difference in performance between low-stakes and high-stakes examinations. This is in line with the interaction effect we find for gender. The effect for the parental education level indicates that children whose mothers and father have completed higher levels of education receive higher teacher's assessments following the policy change compared to children whose parents have only completed lower levels of education. This is in line with previous findings of Timmermans et al (2015) and Feron (2017). One possible mechanism at work here could be that higher educated parents put more pressure on teachers to give children a higher assessment. After the policy change the measure for children's track allocation became more subjective and there is more opportunity for parents to influence the teacher's assessment. 


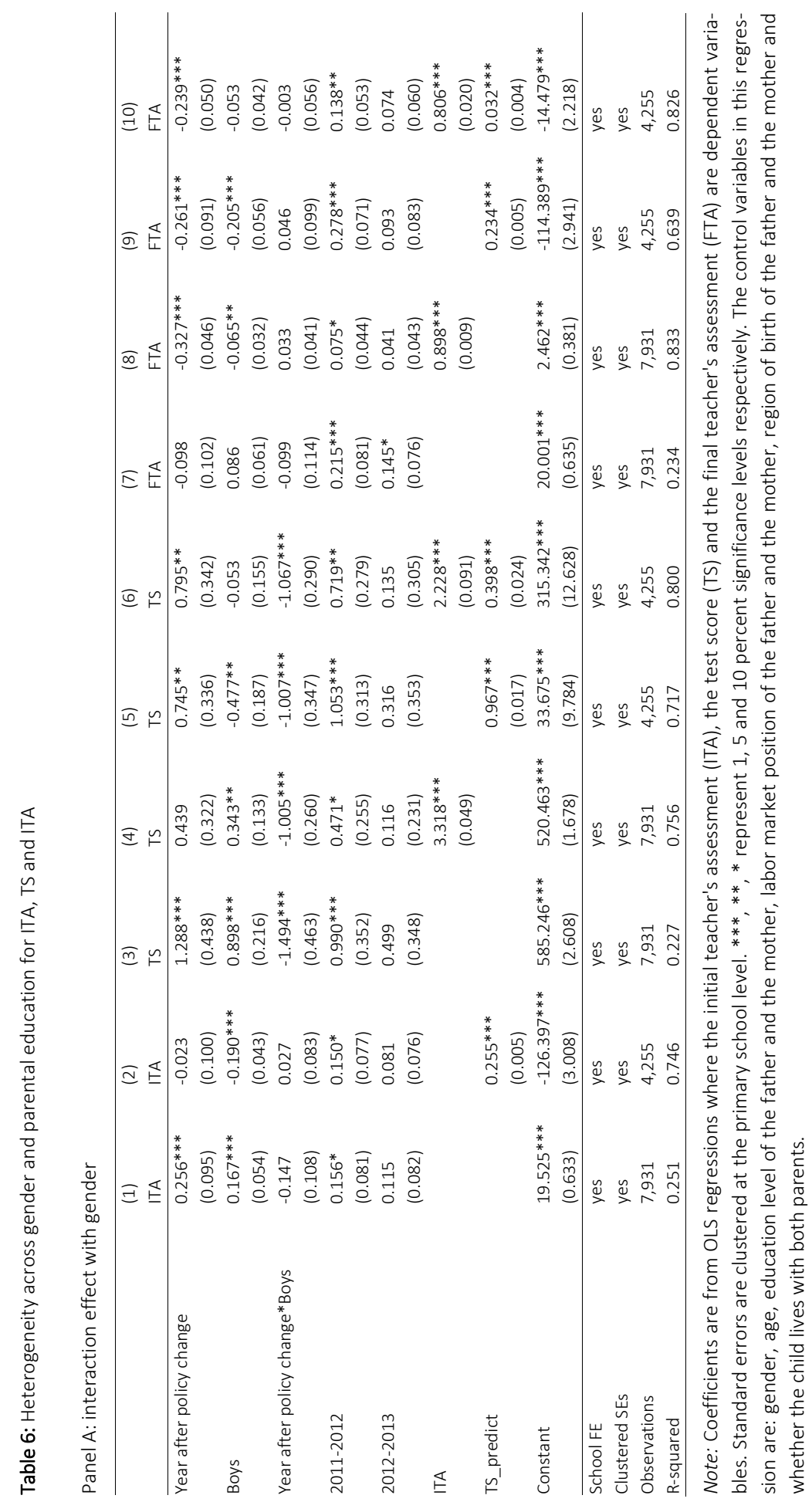




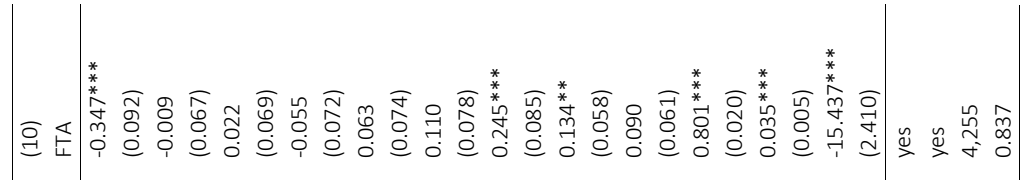
을 它 要这

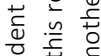

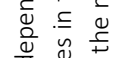

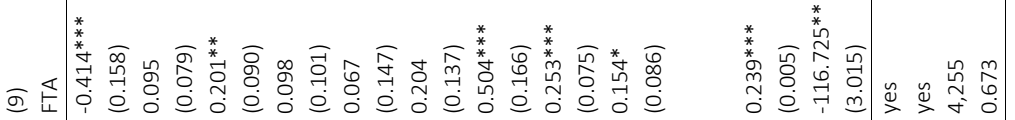
일

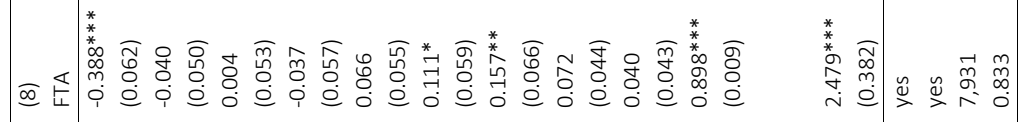

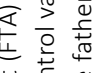

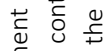

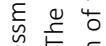
保

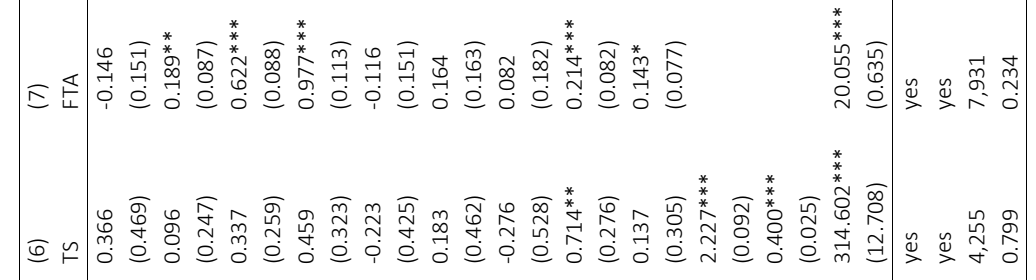

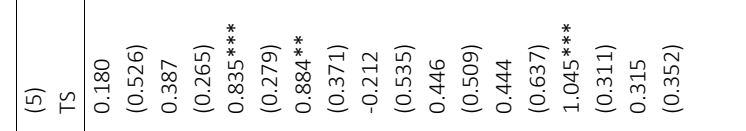

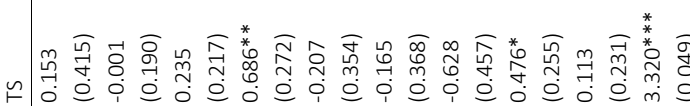

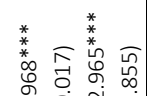
के | a

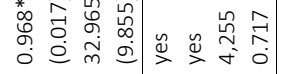

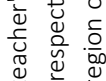

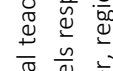

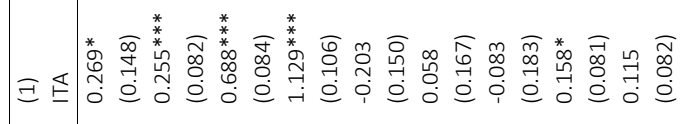

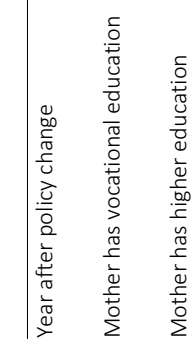

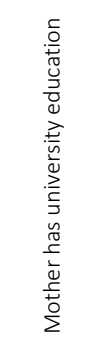
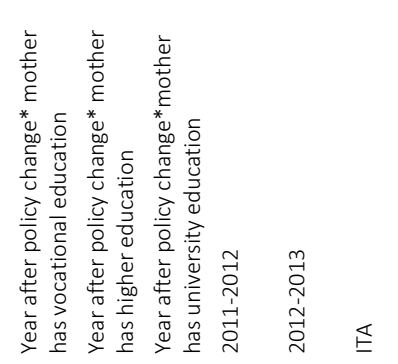

\section{* *}

菜

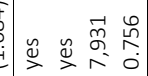

م્ઞ $\stackrel{2}{\rightleftarrows}$ 듐ำ

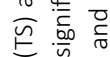

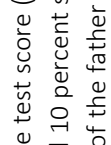
告 定演 華苍苞 हू ญे 


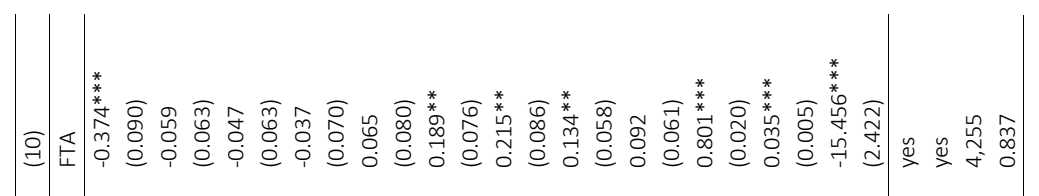

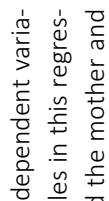
×

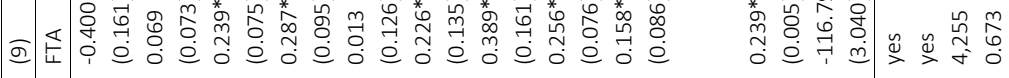

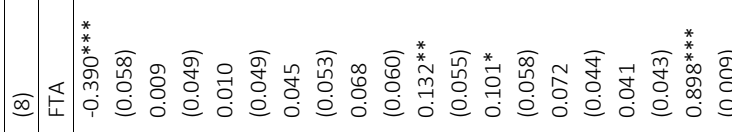

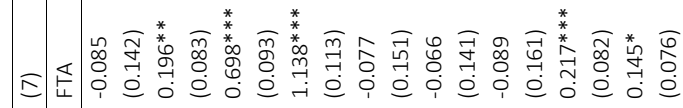
(1)

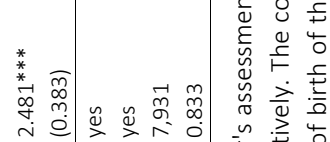
离

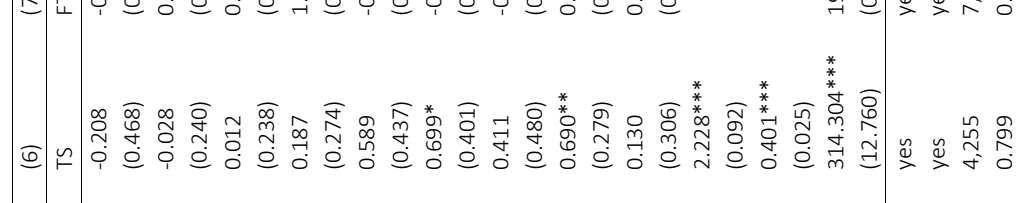

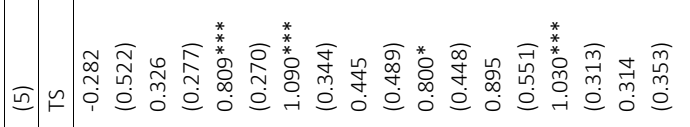

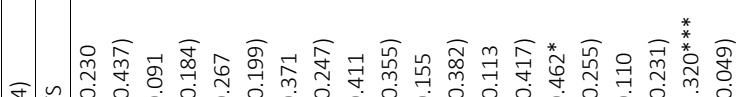

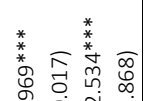
(1) 


\subsubsection{Predictive power of the $5^{\text {th }}$ grade test score}

We are interested in observing whether teachers start looking at earlier test scores now that they cannot make use of the $6^{\text {th }}$ grade test score for their teacher's assessment. Feron (2017) shows that teachers make use of the test score when composing their final assessment. Therefore, we expect that teachers will now turn to the $5^{\text {th }}$ grade test score as input for their assessment. The average test score in $5^{\text {th }}$ grade does not differ across schoolyears. Therefore, we assume that children who are in $6^{\text {th }}$ grade in schoolyear 2014-2015 did not change their test taking behaviour in $5^{\text {th }}$ grade in anticipation of the policy change. ${ }^{56}$ In Table 7 we investigate whether the $5^{\text {th }}$ grade test score has a larger predictive power for the teacher's assessments in schoolyear 2014-2015 compared to earlier schoolyears. In column 1 we observe that the interaction effect between the dummy variable for schoolyear 2014-2015 and the $5^{\text {th }}$ grade standardized test score is significantly positive with a coefficient of 0.337 . This suggests that following the policy change teachers have started to incorporate more information from the $5^{\text {th }}$ grade test score into their initial assessment compared to previous years. In column 3 we observe similar estimates for the final teacher's assessment. We find a significant positive coefficient of 0.153 for the interaction effect between the dummy variable for schoolyear 2014-2015 and the $5^{\text {th }}$ grade standardized test score. ${ }^{57}$ The drop in the coefficient of the interaction term in column 3 is due to the inclusion of ITA as a control variable. In column 4 we add an interaction term between the year after the policy change and the ITA to control for the potentially increased importance of the ITA compared to the FTA following the policy change. In column 4 we observe that this interaction coefficient is significant with a coefficient of 0.176 and leads to a negative interaction coefficient between the year after the policy change and the $5^{\text {th }}$ grade test score. It seems that if we control for the fact that ITA had a larger effect on FTA after the policy change then the $5^{\text {th }}$ grade test score becomes less important for the FTA. It is likely that the effect of the $5^{\text {th }}$ grade test score works via the ITA after the policy change. In conclusion, these findings indicate that the predictive power of the $5^{\text {th }}$ grade test score has increased for both the initial teacher's assessment and the final teacher's assessment (via the ITA) in schoolyear 2014-2015 compared to earlier years. The interaction effects represent effect sizes of 15 and 7 percent of the standard deviations of the initial and final teacher's assessments respectively. ${ }^{58}$

\footnotetext{
${ }^{56}$ The results of these estimates can be found in Appendix C.

${ }^{57}$ The $5^{\text {th }}$ grade standardized test score is the mean of all the available standardized test scores per child in $5^{\text {th }}$ grade on the topics, spelling, reading comprehension and calculus/math. The $5^{\text {th }}$ grade test scores are standardized separately as they have different scales. The $5^{\text {th }}$ grade test score is the average of all $5^{\text {th }}$ grade standardized test scores.

${ }^{58}$ Effect sizes for the initial and final teacher's assessments in schoolyear 2014-2015, where the mean and the standard deviation for the initial teacher's assessment are 6.34 and 2.27 and for the final teacher's assessment are 6.37 and 2.27 .
} 
Table 7: Predictive power of the $5^{\text {th }}$ grade test score

\begin{tabular}{|c|c|c|c|c|}
\hline & (1) & $(2)$ & (3) & (4) \\
\hline & ITA & FTA & FTA & FTA \\
\hline \multirow[t]{2}{*}{ Year after policy change } & -0.050 & $-0.317 * * *$ & $-0.278 * * *$ & $-1.356 * * *$ \\
\hline & (0.099) & $(0.107)$ & $(0.060)$ & $(0.185)$ \\
\hline \multirow[t]{2}{*}{ TS 5th grade } & $1.070 * * *$ & $0.990 * * *$ & $0.137 * * *$ & $0.208^{* * *}$ \\
\hline & $(0.045)$ & $(0.052)$ & $(0.038)$ & $(0.044)$ \\
\hline \multirow[t]{2}{*}{ Year after policy change*TS 5 th grade } & $0.337^{* * *}$ & $0.422 * * *$ & $0.153^{* * *}$ & $-0.161^{* *}$ \\
\hline & $(0.070)$ & $(0.069)$ & $(0.040)$ & $(0.069)$ \\
\hline \multirow[t]{2}{*}{ 2011-2012 } & $0.157^{* *}$ & $0.264^{* * *}$ & $0.139 * *$ & $0.144^{* *}$ \\
\hline & $(0.078)$ & $(0.076)$ & $(0.057)$ & $(0.057)$ \\
\hline \multirow[t]{2}{*}{ 2012-2013 } & 0.082 & $0.159 *$ & 0.093 & 0.094 \\
\hline & $(0.076)$ & $(0.087)$ & $(0.061)$ & $(0.061)$ \\
\hline \multirow[t]{2}{*}{ TS 3rd grade } & $0.358^{* * *}$ & $0.342 * * *$ & 0.057 & 0.061 \\
\hline & $(0.047)$ & $(0.059)$ & $(0.040)$ & $(0.053)$ \\
\hline \multirow[t]{2}{*}{ TS 4th grade } & $0.721^{* * *}$ & $0.655^{* * *}$ & $0.080 *$ & $0.114^{* *}$ \\
\hline & $(0.050)$ & $(0.060)$ & $(0.045)$ & $(0.055)$ \\
\hline \multirow[t]{2}{*}{ ITA } & & & $0.797 * * *$ & $0.747 * * *$ \\
\hline & & & $(0.020)$ & $(0.024)$ \\
\hline \multirow[t]{2}{*}{ Year after policy change*ITA } & & & & $0.176^{* * *}$ \\
\hline & & & & $(0.027)$ \\
\hline \multirow[t]{2}{*}{ Constant } & $10.648 * * *$ & $11.706^{* * *}$ & $3.218 * * *$ & $3.550 * * *$ \\
\hline & $(0.533)$ & $(0.580)$ & $(0.483)$ & $(0.479)$ \\
\hline School FE & yes & yes & yes & yes \\
\hline Clustered SEs & yes & yes & yes & yes \\
\hline Observations & 4,255 & 4,255 & 4,255 & 4,255 \\
\hline R-squared & 0.749 & 0.676 & 0.838 & 0.839 \\
\hline
\end{tabular}

Note: Coefficients are from OLS regressions where the initial teacher's assessment (ITA) and the final teacher's assessment (FTA) are dependent variables. Standard errors are clustered at the primary school level. $* * *, * *, *$ represent 1,5 and 10 percent significance levels respectively. The control variables in this regression are: gender, age, education level of the father and the mother, labor market position of the father and the mother, region of birth of the father and the mother, whether the child lives with both parents and for certain analyses the positive and negative difference between the ITA and the predicted test score.

\subsubsection{Robustness checks}

In Table 6 and in Table 7 we show that there is a positive interaction effect between the schoolyear 2014-2015 dummy variable and the $5^{\text {th }}$ grade test score which indicates that there is an increase in the predictive power of the $5^{\text {th }}$ grade test score for the initial and final teacher's assessments after the policy change. As a robustness check for these findings we repeat the same analysis but exclude the schoolyear 2014-2015 from the analysis. The dummy variable in the analysis is one if the schoolyear is schoolyear 20132014 and zero otherwise. The results of these estimations are shown in Appendix D. If the effect is due to the policy change we expect to find no significant positive interac- 
tion effect. The estimates in Appendix $D$ show no significant interaction effect between the dummy variable schoolyear 2013-2014 and the $5^{\text {th }}$ grade test score for the initial teacher's assessment or the final teacher's assessment. This confirms our earlier finding that the predictive power of the $5^{\text {th }}$ grade test score for the initial and the final teacher's assessment has increased following the policy change.

To test whether the policy change has led to causal effects we would ideally observe the same children before and after the policy change and observe whether there is a change in the outcome variables. As we do not observe the same children but children in different yearly cohorts, an alternative is to match similar children before and after the policy change and observe whether there is a difference in the outcome variables between these matched children. We use estimates from propensity score matching to check our results for robustness. We match children based on gender, age and the parental education level. We assume that these covariates are the most important characteristics of children in our sample and that they determine children's outcomes for the test score and the teacher's assessments. Matching children on more variables is possible but there is a tradeoff. A lower amount of variables to match on leads to more matches being found but they might be less exact. A higher amount of variables to match on likely leads to more exact matches, however, the amount of children we can match is lower. In our case, where the identification comes from the policy change, we want to use propensity score matching as a robustness check to observe whether our results are the same if we had the same set of children before and after the policy change. Therefore, we choose to match on the three variables, gender, age and parental education level. ${ }^{59}$ Our estimates in Appendix E suggest that for the initial teacher's assessment and the test score there is no difference following the policy change. Nevertheless, the final teacher's assessment seems to be significantly lower after the policy change. These results confirm our OLS results in Table 5.

\subsection{Policy perspective}

The results of this research suggest three things. First, on average the test score seems to be unaffected by the policy change. At first sight, the average initial teacher's assessment also seems to be unaffected by the policy change. However, after the policy change, the initial teacher's assessment and the final teacher's assessment become more alike. Furthermore, the average final teacher's assessment seems to have decreased following the policy change. Second, the effect of the policy change on the initial teacher's assessment, the test score and the final teacher's assessment seems to vary with gender and the parental education level. Third, the predictive power of the $5^{\text {th }}$ grade test score seems to have increased for the initial teacher's assessment and the

\footnotetext{
${ }^{59}$ Results from matching based on a more extensive set of matching variables provides similar results.
} 
final teacher's assessment. It is possible that these effects represent a lower bound of the true effect of the policy change as we only observe the first cohort of children after the policy change. Possibly, parents and children have not fully anticipated the effect of this policy change on children's (earlier) test scores and teacher's assessments as well as their consequent track placement. In a few years, when these children are in the third year of secondary education we can also investigate whether this policy change has an effect on children's track placement and track switching.

That the initial and the final teacher's assessments look more alike following the policy change is caused by an increase in the average initial teacher's assessment and a decrease in the average final teacher's assessment. There could be several explanations for this finding. The increase in the initial teacher's assessment could be due to a correction for these children being a slightly better scoring cohort, based on their predicted test scores. It is also likely that this is due to the fact that the initial teacher's assessment has become more important compared to previous years. The fact that, after the policy change, the initial teacher's assessment is still slightly lower than the final teacher's assessment could also be due to a timing and/or information gap. It is also possible that after the policy change, teachers update their final assessment less compared to previous years as they have a preference for consistency between their initial and their final assessment as suggested by Falk and Zimmermann (2011).

On average we find no effect of the test becoming a low-stakes or a high-stakes test following the policy change for children who had a different teacher's assessment compared to their predicted test score based on tests from $3^{\text {rd }}$ and $4^{\text {th }}$ grade. ${ }^{60}$ Our estimates do suggest that girls seem to have a higher test score following the policy change. Furthermore, the initial and the final teacher's assessment are more favorable for children whose parents obtained a higher level of education, compared to children whose parents only obtained a lower level of education. This finding is in line with previous research, e.g., Timmermans et al. (2015), who show that the teacher's assessment can be disadvantageous for children from lower social-economic backgrounds even if they have a similar performance as other children. Our results suggest that the influence of parental education increases with the policy change.

Finally, our results indicate that teachers make more use of the $5^{\text {th }}$ grade test score when establishing their teacher's assessment, following the policy change, when the $6^{\text {th }}$ grade test score is not available to them. This result shows that teachers look for earlier cognitive measures of children's ability level to base their assessment on. It is possible that parents and children will react to this change in the future and put more emphasis on the $5^{\text {th }}$ grade test score as a decisive measure of children's track placement in secondary school. This will likely make the $5^{\text {th }}$ grade test score a more high-stakes test and possibly move the selection process forward. National as well as international institu-

\footnotetext{
${ }^{60}$ These results were not shown in a table since we do not find any significant differences. These results are available upon request.
} 
tions have argued for a more flexible and delayed selection process in the transition from primary to secondary education (OECD, 2016; Onderwijsraad, 2014; Onderwijsraad 2015).

There are two things that should be considered regarding the interpretation of our results. First, other trends that might affect our estimates is the shift away from the 'double' teacher's assessments where teachers recommend more than one track, e.g. T1d/T2 or 'vmbo-t/havo', towards 'single' teacher's assessments where teachers recommend only one track. Second, the effects we find for the test score regarding the heterogeneity of gender might be related to changes that have been made to the test in the schoolyear 2014-2015. Nevertheless, these changes in the test should not affect our estimates of the effect of the policy change on the initial teacher's assessment and the final teacher's assessment.

\subsection{Conclusion}

Generally achievement tests are seen as objective measures of children's ability and teacher's assessments are seen as subjective measures of children's ability. An important question to understand the meaning of tests and assessments is whether the way information is aggregated is stable or varies when the incentives of the test or the assessment change. We investigate this question using a policy change in the Dutch education system as of the schoolyear 2014-2015.

This paper investigates whether a change in the incentives changes the way teachers incorporate available information into their teacher's assessment. We use a recent policy change in the Netherlands regarding the use of information for the transition from primary to secondary school to investigate the effect of circumstance on the test and the teacher's assessments. The policy change has two main components. First, the moment at which children take the standardized test in $6^{\text {th }}$ grade is delayed from February until April. Second, the teacher's assessment of children's ability in $6^{\text {th }}$ grade becomes the measure that determines to which track children are allocated at the start of secondary school. This policy change potentially has an impact on how available information is incorporated in the teacher's assessment.

This study has three main findings. First, on average the test score seems to be unaffected by the policy change. The average initial teacher's assessment also seems to be unaffected by the policy change. However, after the policy change, the initial teacher's assessment and the final teacher's assessment become more alike. Furthermore, the average final teacher's assessment seems to have decreased following the policy change, by 12 percent of a standard deviation. Second, it seems that the effect of the policy change on the test score and the teacher's assessments is heterogeneous across gender and the parental education level: girls score significantly higher on the test while boys score significantly lower and children whose parents completed a higher level of 
education seem to receive higher teacher's assessments compared to children whose parents completed only lower education. Finally, we find that teachers seem to put more emphasis on children's $5^{\text {th }}$ grade test score for their teacher's assessments following the policy change. The estimates suggest that the additional effect of the $5^{\text {th }}$ grade test score on the initial teacher's assessment is on average approximately 15 percent of a standard deviation and the additional effect is approximately 7 percent of a standard deviation for the final teacher's assessment. 


\section{References}

Attali, Y., Neeman, Z. and Schlosser, A. (2011). Rise to the challenge or not give a damn: differential performance in high vs. low stakes tests. IZA Working paper no. 5693.

Brunello G. and D. Checchi (2007). Does school tracking affect equality of opportunity? New international evidence, Economic Policy, vol. 22, no. 52, pp. 781-861.

Burgess, S. and E. Greaves (2013). Test scores, subjective assessment, and stereotyping of ethnic minorities, Journal of Labor Economics, vol. 31, no. 3, pp. 535-576.

Carneiro, P. M. and Heckman J., (2003), Human Capital Policy, IZA discussion paper no. 821.

College voor Toetsen en Examens (CvtE) (2015), Centrale eindtoets primair onderwijs. Handleiding 2015, Utrecht.

College voor Toetsen en Examens (2015), De centrale eindtoets in 2016, Informatie voor scholen, Utrecht.

College voor Toetsen en Examens (2016), Terugblik 2015. Resultaten centrale eindtoets 2015, Utrecht.

Cornwell, C., D.B. Mustard and J. van Parys (2012). Noncognitive skills and the gender disparities in test scores and teacher assessments: evidence from primary school, Journal of Human Resources, vol. 48, no. 1, pp. 236-264.

Cunha, F. and Heckman, J., (2007) The Technology of Skill Formation, American Economic Review, Vol. 97 No. 2. pp. 31-47.

Dee, T.S. (2005). A teacher like me: does race, ethnicity or gender matter? American Economic Review, vol. 95, no. 2, pp. 158-165.

Falk, A. and Zimmermann, F. (2011) Preferences for consistency. IZA discussion paper no. 5840.

Feron, E., Schils, T. and ter Weel, B. (2016) Does the teacher beat the test? The value of the teacher's assessment in predicting student ability, De Economist, Vol. 164, no. 4, pp. 391-418.

Feron, E. (2017) Updating teacher's assessment of children's ability. Chapter 4 in PhD dissertation: the role of cognitive tests and teachers in the transition from primary to secondary education.

Gibbons, S. and A. Chevalier (2008). Assessment and age 16+ education participation, Research Papers in Education, vol. 23, no. 2, pp. 113-123.

Hanushek, E. and L. Woessmann (2006) Does early tracking affect educational inequality and performance? Differences-in-differences evidence across countries, Economic Journal, vol. 116, no. 510, pp. c63-c76.

Inspectie van het Onderwijs, (2014) De kwaliteit van het basisschooladvies; een onderzoek naar de totstandkoming van het basisschooladvies en de invloed van het basisschooladvies op de verdere schoolloopbaan.

Lavy, V. (2008) Do gender stereotypes reduce girls' human capital outcomes? Evidence from a natural experiment, Journal of Public Economics, vol. 92, no. 10-11, pp. 2083-2105.

Lindahl, E. (2007) Comparing teachers' assessments and national test results - evidence from Sweden, IFAU Working Paper no. 2007:24.

Ministerie van Onderwijs, Cultuur en Wetenschap (2016) Eindtoetsresultaten en de overgang van leerlingen naar het voortgezet onderwijs in schooljaar 2015-2016.

OECD (2016), Netherlands 2016: Foundations for the future, Reviews of National Policies for Education, OECD Publishing, Paris. DOI: http://dx.doi.org/10.1787/9789264257658-en

Onderwijsraad (2014) Een onderwijsstelsel met veerkracht.

Onderwijsraad (2015) Overgangen in het onderwijs.

Rijksoverheid, Ministerie van Onderwijs, Cultuur en Wetenschap (2013) Wetsvoorstel centrale eindtoets en leerling- en onderwijsvolgsysteem primair onderwijs.

Rijksoverheid (2016a) Toelating voortgezet onderwijs gebaseerd op schooladvies. https://www.rijksoverheid.nl/onderwerpen/toelating-middelbare-school/inhoud/toelating-voortgezetonderwijs-gebaseerd-op-schooladvie

Rijksoverheid (2016b) Verplichte eindtoets basisonderwijs. https://www.rijksoverheid.nl/onderwerpen/toelating-middelbare-school/inhoud/verplichte-eindtoetsbasisonderwijs 
Roeleveld, J., Mulder, L and Paas, T. (2011), De gevolgen van een latere afname van de Cito Eindtoets Basisonderwijs, ITS, Radboud Universiteit Nijmegen / Kohnstamm Instituut, Amsterdam.

Sluijter, C. (2013), Selectie bij overgangen in het onderwijs. Een beknopte literatuurstudie.

Timmermans, A., Kuyper, H. and van der Werf, G. (2015), Schooladviezen en onderwijsloopbanen. Voorkomen, risicofactoren en gevolgen van onder- en overadvisering. 


\section{Appendix}

This appendix presents supporting material. In Section A we discuss the bivariate correlation coefficients of all of our outcome measures and covariates used in our analyses. In section B we investigate whether or not individual characteristics are able to predict whether children end up in our sample for analyses. Section $\mathrm{C}$ presents the estimates of the $5^{\text {th }}$ grade test score across years. Section $D$ presents the placebo analysis for the initial teacher's assessment and the final teacher's assessment. Section E presents the results of the analysis using propensity score matching. 


\section{A. Correlations}

Table A shows the bivariate correlation coefficients of our main variables of interest, the initial teacher's assessment, the test score and the final teacher's assessment as well as the covariates used in the analysis for the schoolyears 2011-2012 until 2014-2015 combined. First of all, we observe that the correlation coefficients between our main variables of interest are all high and significant. The correlation coefficients between the initial teacher's assessment and the $6^{\text {th }}$ grade test score are approximately equal to the correlation coefficients of the final teacher's assessment and the $6^{\text {th }}$ grade test score. Possibly this is due to the lower final teacher's assessment in schoolyear 2014-2015 compared to previous years. The $5^{\text {th }}$ grade test score has a lower correlation with the initial and final teacher's assessments compared to the $6^{\text {th }}$ grade test score. Furthermore, children who are older have a negative correlation with the test scores and the teacher's assessments. Boys seem to have (slightly) higher test scores compared to girls. The parental education level, the mother's region of birth, the labor market position of the mother and father and whether the child lives with both parents, are all positive and significantly correlated with children's test scores and their teacher's assessments. Overall, the covariates used in the analysis do not show any surprising relationships with the children's test score and teacher's assessments. 
Chapter 5

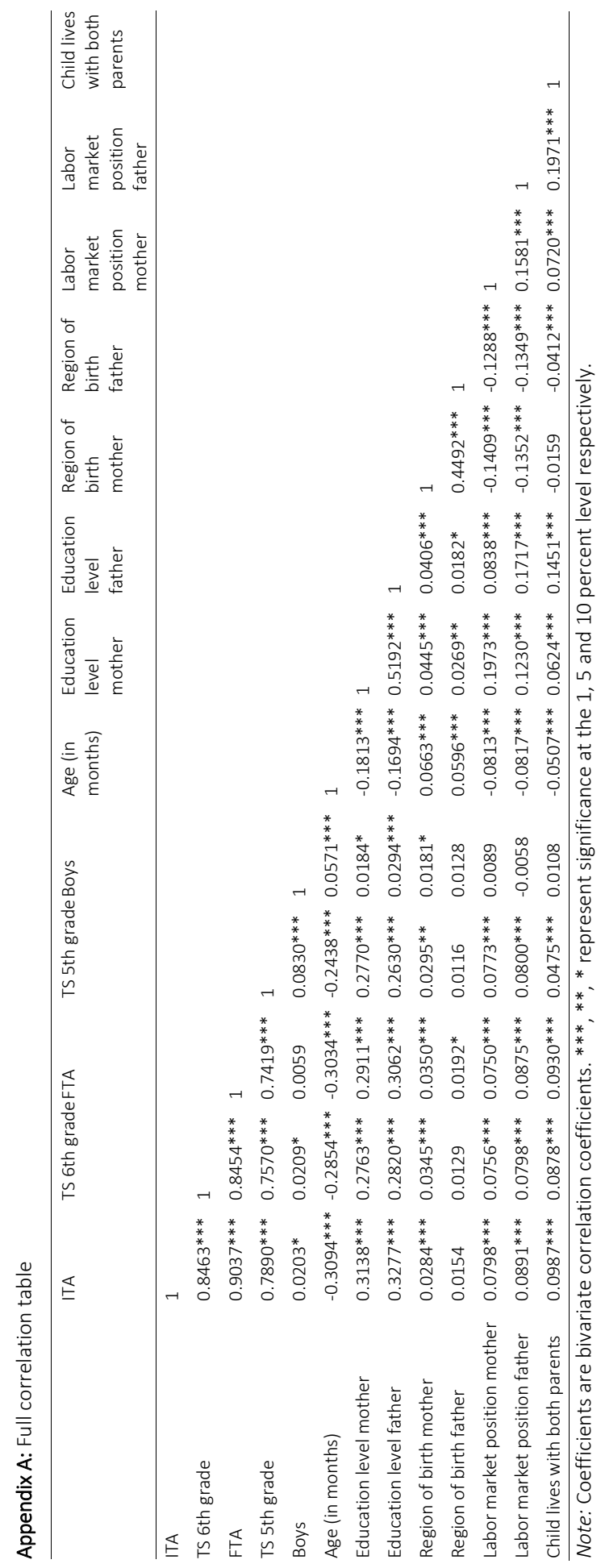




\section{B. Selection into the sample}

We address selection issues with regard to the sample we use for our analyses in Table B. Table B shows probit and OLS estimates of whether characteristics of children are able to predict whether the child ends up in our sample for analyses or has missing data. The dependent variable is whether the child ends up in our sample (1) or has missing data (0). Children who end up in our sample for analyses are children for whom we have data on the initial teacher's assessment, the test score, the final teacher's assessment, gender, age and the parental education level, this are 8,531 children. In total our sample consists of 22,297 children.

Table B shows that after controlling for primary school fixed effects and clustering the standard errors at the primary school level there are almost no individual characteristics that predict whether children end up in our sample for analysis or not. We use primary school fixed effects since we are concerned mainly about selection within schools, where schools only provide us with data about their best performing children and might leave out data about lower performing children. We expect that such selection would show up on children's SES data, such as the education levels of their parents. We cluster standard errors at the primary school level since observations of children are likely not independent within the primary school they attend. The results in column 4 show that when parents have higher or university education the child is approximately 3 to 4 percentage points more likely to end up in our sample compared to when the parents have lower education. In column 2 and column 5 we only use those children for whom we have information on their test score. There are only a few children for whom we have information on teacher's assessments but not on their test score. There does not seem to be a difference between the characteristics of children for whom we have a test score and for whom we do not have a test score. We find minor evidence that there are observable characteristics of children that are able to predict whether the child ends up in the sample. Since we do not find strong evidence that observable characteristics of children predict whether the child ends up in our sample, we assume that there are also no unobservable characteristics that distinguish the children in our sample from the children who are not in our sample.

Note that there are missing observations in our analyses. This is due to the fact that we do not have information on all covariates for all children. Since we are specifically interested in whether any of these covariates predict selection into our sample of analyses we lose observations when data on covariates is missing. 
Chapter 5

Appendix B: Selection into the sample

\begin{tabular}{|c|c|c|c|c|c|c|}
\hline & $(1)$ & $(2)$ & (3) & (4) & (5) & (6) \\
\hline \multirow[t]{2}{*}{ Boys } & -0.031 & -0.046 & -0.033 & -0.007 & -0.009 & -0.012 \\
\hline & $(0.036)$ & $(0.035)$ & $(0.026)$ & $(0.006)$ & $(0.006)$ & (0.009) \\
\hline \multirow[t]{2}{*}{ Age (in months) } & $-0.006^{*}$ & -0.002 & -0.002 & -0.001 & -0.000 & -0.001 \\
\hline & $(0.003)$ & $(0.003)$ & $(0.003)$ & $(0.001)$ & $(0.001)$ & $(0.001)$ \\
\hline \multirow[t]{2}{*}{ Mother has vocatonal education } & $0.093^{*}$ & $0.116^{* *}$ & 0.014 & 0.015 & $0.017^{*}$ & 0.005 \\
\hline & $(0.057)$ & $(0.059)$ & $(0.045)$ & $(0.010)$ & $(0.009)$ & $(0.016)$ \\
\hline \multirow[t]{2}{*}{ Mother has higher education } & $0.160^{* * *}$ & $0.184^{* * *}$ & 0.028 & $0.029 * *$ & $0.031^{* * *}$ & 0.010 \\
\hline & $(0.061)$ & $(0.063)$ & $(0.052)$ & $(0.011)$ & $(0.011)$ & (0.019) \\
\hline \multirow[t]{2}{*}{ Mother has university education } & $0.239 * * *$ & $0.272 * * *$ & 0.063 & $0.046^{* * *}$ & $0.049 * * *$ & 0.023 \\
\hline & $(0.076)$ & $(0.079)$ & $(0.080)$ & $(0.014)$ & $(0.014)$ & (0.029) \\
\hline \multirow[t]{2}{*}{ Father has vocational education } & -0.001 & -0.027 & -0.054 & 0.000 & -0.003 & -0.019 \\
\hline & $(0.051)$ & $(0.054)$ & $(0.042)$ & $(0.009)$ & $(0.008)$ & $(0.015)$ \\
\hline \multirow[t]{2}{*}{ Father has higher education } & 0.029 & 0.019 & $-0.118 * *$ & 0.005 & 0.004 & $-0.042 * *$ \\
\hline & $(0.067)$ & $(0.070)$ & $(0.051)$ & $(0.012)$ & $(0.012)$ & (0.019) \\
\hline \multirow[t]{2}{*}{ Father has univerity education } & 0.006 & -0.036 & -0.088 & -0.001 & -0.007 & -0.031 \\
\hline & $(0.074)$ & $(0.078)$ & $(0.064)$ & $(0.013)$ & $(0.013)$ & $(0.023)$ \\
\hline \multirow[t]{2}{*}{ Mother born in other region NL } & 0.020 & 0.021 & 0.001 & 0.004 & 0.003 & 0.000 \\
\hline & $(0.065)$ & $(0.067)$ & $(0.054)$ & $(0.013)$ & $(0.012)$ & (0.019) \\
\hline \multirow[t]{2}{*}{ Mother born abroad } & -0.077 & -0.069 & 0.031 & -0.013 & -0.012 & 0.010 \\
\hline & $(0.069)$ & $(0.073)$ & $(0.060)$ & $(0.012)$ & $(0.011)$ & $(0.021)$ \\
\hline \multirow[t]{2}{*}{ Father born in other region NL } & -0.001 & -0.011 & 0.010 & -0.000 & -0.002 & 0.004 \\
\hline & $(0.050)$ & $(0.052)$ & $(0.052)$ & $(0.010)$ & $(0.009)$ & (0.019) \\
\hline \multirow[t]{2}{*}{ Father born abroad } & -0.016 & -0.006 & $0.131^{* *}$ & -0.003 & 0.000 & $0.045^{* *}$ \\
\hline & $(0.074)$ & $(0.076)$ & $(0.057)$ & $(0.012)$ & $(0.011)$ & (0.019) \\
\hline \multirow[t]{2}{*}{ Mother has paid work } & 0.015 & -0.029 & -0.002 & 0.002 & -0.004 & -0.000 \\
\hline & $(0.055)$ & $(0.056)$ & (0.039) & $(0.010)$ & $(0.009)$ & $(0.014)$ \\
\hline \multirow[t]{2}{*}{ Father has paid work } & -0.053 & -0.096 & -0.079 & -0.007 & -0.014 & -0.027 \\
\hline & $(0.062)$ & $(0.068)$ & $(0.051)$ & $(0.010)$ & $(0.010)$ & $(0.018)$ \\
\hline \multirow[t]{2}{*}{ Child lives with both parents } & 0.090 & $0.102^{*}$ & 0.039 & 0.013 & $0.016^{*}$ & 0.014 \\
\hline & $(0.055)$ & $(0.054)$ & (0.039) & $(0.009)$ & $(0.009)$ & $(0.014)$ \\
\hline \multirow[t]{2}{*}{ Constant } & 0.726 & 0.358 & $0.887^{*}$ & $1.103^{* * *}$ & $1.039 * * *$ & $0.831^{* * *}$ \\
\hline & $(0.466)$ & $(0.469)$ & $(0.461)$ & $(0.087)$ & $(0.083)$ & $(0.163)$ \\
\hline Model & Probit & Probit & Probit & OLS & OLS & OLS \\
\hline School FE & yes & yes & no & yes & yes & no \\
\hline Clustered SEs & yes & yes & yes & yes & yes & yes \\
\hline Observations & 9,297 & 7,647 & 11,698 & 11,698 & 11,441 & 11,698 \\
\hline
\end{tabular}

Note: The coefficients are from probit regressions and from ordinary least squares regressions with a dummy variable for selection into the sample as the dependent variable. Selected into the sample equals 1 , all other observations equal 0 . In colomn 2 and 5 only children for whom we have information on the test score are included. Standard errors are clustered at the primary school level. ***,**, * represent 1, 5 and 10 percent significance levels respectively. 


\section{Test for $5^{\text {th }}$ grade test score across years}

We are interested in observing whether teachers start looking at earlier test scores now that they cannot make use of the $6^{\text {th }}$ grade test score for their teacher's assessment. In order to use the $5^{\text {th }}$ grade test score in our analysis, we assume that children in schoolyear 2014-2015 have not anticipated the policy change and did not change their test taking behavior for the test in $5^{\text {th }}$ grade. We use OLS regressions to investigate whether the test score in $5^{\text {th }}$ grade deviates for children in schoolyear 2014-2015 compared to earlier years. Table $\mathrm{C}$ reports that the coefficient for the policy effect is not significantly different from zero. Therefore, we conclude that children have not anticipated the policy change as they have not changed their test taking behavior for the $5^{\text {th }}$ grade test. 


\section{Chapter 5}

Appendix C: Test for difference in $5^{\text {th }}$ grade test score across years

\begin{tabular}{llll}
\hline & \multicolumn{2}{l}{ Test score 5th grade } & $(3)$ \\
\cline { 2 - 4 } & $(1)$ & $(2)$ & -0.001 \\
\hline Year after policy change & 0.082 & -0.017 & $(0.040)$ \\
& $(0.055)$ & $(0.041)$ & -0.033 \\
2011-2012 & 0.038 & -0.000 & $(0.028)$ \\
& $(0.043)$ & $(0.036)$ & $-0.065^{*}$ \\
ITA & 0.009 & -0.059 & $(0.035)$ \\
TS_predict34 & $(0.056)$ & $(0.042)$ & $0.125^{* * *}$ \\
FTA & & & $(0.016)$ \\
Constant & & & $0.062^{* * *}$ \\
& & $0.103^{* * *}$ & $(0.003)$ \\
School FE & & $(0.002)$ & $0.040^{* * *}$ \\
Clustered SEs & & & $(0.009)$ \\
Observations & & & $-34.593^{* * *}$ \\
\hline
\end{tabular}

Note: Coefficients are from OLS regressions where the test score in 5 th grade is the dependent variable. Standard errors are clustered at the primary school level. ***,**, * represent 1,5 and 10 percent significance levels respectively. The control variables in this regression are: gender, age, education level of the father and the mother, labor market position of the father and the mother, region of birth of the father and the mother, whether the child lives with both parents and for certain analyses the positive and negative difference between the ITA and the predicted test score. 


\section{Placebo analysis}

In Table 7 we show that there is a positive interaction effect between the schoolyear 2014-2015 dummy variable and the $5^{\text {th }}$ grade test score which indicates that there is an increase in the predictive power of the $5^{\text {th }}$ grade test score for the initial and final teacher's assessments after the policy change. As a robustness check for these findings we repeat the same analysis but exclude the schoolyear 2014-2015 from the analysis. If the effect is due to the policy change we expect to find no significant positive interaction effect. We run OLS regressions to investigate whether the interaction effect we observe in Table 7 disappears once we eliminate the year after the policy change. The dummy variable in the analysis is one if the schoolyear is schoolyear 2013-2014 and zero otherwise. In columns 1-2 we report the estimates for the initial teacher's assessment and in columns 3-4 we report the estimates for the final teacher's assessment. The estimates in Table $D$ show no significant interaction effect between the dummy variable schoolyear 2013-2014 and the $5^{\text {th }}$ grade test score for the initial teacher's assessment or the final teacher's assessment. We conclude that the interaction effect is not present in the year before the policy change. 
Chapter 5

Appendix D: Placebo analysis

\begin{tabular}{|c|c|c|c|c|}
\hline & $(1)$ & $(2)$ & (3) & (4) \\
\hline & ITA & ITA & FTA & FTA \\
\hline \multirow[t]{2}{*}{ Year after policy change - placebo } & -0.057 & -0.054 & -0.141 & -0.099 \\
\hline & $(0.079)$ & $(0.080)$ & $(0.089)$ & $(0.064)$ \\
\hline \multirow[t]{2}{*}{ TS 5 th grade } & $1.111^{* * *}$ & $1.114^{* * *}$ & $1.013^{* * *}$ & $0.185^{* * *}$ \\
\hline & $(0.056)$ & $(0.056)$ & $(0.059)$ & $(0.045)$ \\
\hline \multirow[t]{2}{*}{ Year after policy change placebo*TS 5th grade } & -0.066 & -0.065 & 0.045 & 0.095 \\
\hline & $(0.064)$ & $(0.064)$ & $(0.069)$ & $(0.058)$ \\
\hline \multirow[t]{2}{*}{ 2011-2012 } & 0.090 & 0.088 & $0.120 *$ & 0.053 \\
\hline & $(0.069)$ & $(0.070)$ & $(0.071)$ & $(0.049)$ \\
\hline \multirow[t]{2}{*}{ ITA } & & & & $0.745^{* * *}$ \\
\hline & & & & $(0.024)$ \\
\hline \multirow[t]{2}{*}{ TS 3rd grade } & $0.306^{* * *}$ & & $0.286 * * *$ & \\
\hline & $(0.051)$ & & $(0.068)$ & \\
\hline \multirow[t]{2}{*}{ TS 4 th grade } & $0.759 * * *$ & & $0.678^{* * *}$ & \\
\hline & $(0.058)$ & & $(0.068)$ & \\
\hline \multirow[t]{2}{*}{ TS_predict34 } & & $0.131^{* * *}$ & & $0.021 * * *$ \\
\hline & & $(0.007)$ & & $(0.006)$ \\
\hline \multirow[t]{2}{*}{ Constant } & $10.716^{* * *}$ & $-59.578 * * *$ & $11.754^{* * *}$ & $-7.423^{* *}$ \\
\hline & $(0.626)$ & $(3.726)$ & $(0.729)$ & $(2.957)$ \\
\hline School FE & yes & yes & yes & yes \\
\hline Clustered SEs & yes & yes & yes & yes \\
\hline Observations & 3,024 & 3,024 & 3,024 & 3,024 \\
\hline R-squared & 0.753 & 0.753 & 0.658 & 0.796 \\
\hline
\end{tabular}

Note: Coefficients are from OLS regressions where the initial teacher's assessment (ITA) and the final teacher's assessment (FTA) are dependent variables. Standard errors are clustered at the primary school level. $* * *, * *, *$ represent 1,5 and 10 percent significance levels respectively. The control variables in this regression are: gender, age, education level of the father and the mother, labor market position of the father and the mother, region of birth of the father and the mother, whether the child lives with both parents and for certain analyses the positive and negative difference between the ITA and the predicted test score. 


\section{E. Propensity score matching}

To test whether the policy change has led to causal effects we would ideally observe the same children before and after the policy change and observe whether there is a change in the outcome variables. As we do not observe these data an alternative is to match similar children before and after the policy change and observe whether there is a difference in the outcome variables between these children. We use estimates from propensity score matching to check our results for robustness. We match children based on gender, age and the parental education level. We assume that these covariates are the most important characteristics of children in our sample and that they determine children's outcomes for the test score and the teacher's assessments. Matching children on more variables is possible but there is a tradeoff. A lower amount of variables to match on leads to more matches being found but they might be less exact. A higher amount of variables to match on likely leads to more exact matches, however, the amount of children we can match is lower. In our case, where the identification comes from the policy change, we want to use propensity score matching as a robustness check to observe whether our results are the same if we had the same set of children before and after the policy change. Therefore, we choose to match on the three variables, gender, age and parental education level. Our estimates in Table E suggest that for the initial teacher's assessment and the test score there is no difference following the policy change. Nevertheless, the final teacher's assessment seems to be significantly lower after the policy change. These results confirm our OLS results in Table 5. 
Chapter 5

Appendix E: Propensity score matching

\section{Initial teacher's assessment}

Treatment-effects estimation

Estimator : propensity-score matching

Outcome model : matching

$\begin{aligned} \text { Number of obs } & = \\ \text { Matches: requested } & = \\ \min & =\end{aligned}$

8,531

Treatment model: probit

$\max =$

\begin{tabular}{|c|c|c|c|c|c|c|}
\hline pre2 & Coef. & $\begin{array}{l}\text { AI Robust } \\
\text { Std. Err. }\end{array}$ & $\mathrm{z}$ & $P>|z|$ & [95\% Conf. & Interval] \\
\hline ATE & & & & & & \\
\hline $\begin{array}{l}\text { treatment } \\
\left(\begin{array}{lll}1 & \text { vs } & 0\end{array}\right)\end{array}$ & .0677447 & .0511627 & 1.32 & 0.185 & -.0325324 & .1680218 \\
\hline
\end{tabular}

\section{Test score $6^{\text {th }}$ grade}

Treatment-effects estimation

Estimator : propensity-score matching

Outcome model : matching

Number of obs $\quad=\quad 8,531$

Treatment model: probit

\begin{tabular}{|c|c|c|c|c|c|c|}
\hline \multicolumn{7}{|l|}{ ATE } \\
\hline treatment & & & & & & \\
\hline$\left(\begin{array}{lll}1 & \mathrm{vs} & 0\end{array}\right)$ & -.0886596 & .2133764 & -0.42 & 0.678 & -.5068697 & .3295504 \\
\hline
\end{tabular}

Final teacher's assessment

\section{Treatment-effects estimation}

Estimator : propensity-score matching Outcome model : matching

Treatment model: probit

$\begin{array}{rlr}\text { Number of obs } & = & 8,531 \\ \text { Matches: requested } & = & 1 \\ \min & = & 1 \\ \max & = & 57\end{array}$

\begin{tabular}{|c|c|c|c|c|c|c|}
\hline treatment & & & & & & \\
\hline$\left(\begin{array}{lll}1 & v s & 0\end{array}\right)$ & -.2971852 & .0516922 & -5.75 & 0.000 & -.3985 & -.1958704 \\
\hline
\end{tabular}


Chapter 6:

Motivation and its effect on school performance:

A randomized field experiment among underachievers 



\subsection{Introduction}

Investment in human capital is crucial for labour-market outcomes. The path of optimal human capital investment has been documented by Ben-Porath (1967). It boils down to people making most of their investments when they are young, and to a large extent by foregoing current earnings, to build a stock of human capital which is used to make a living later on in life. This means that too low investments or underachievement in school is detrimental to a person's earnings capacity. Preventing underachievement when raising and educating children seems to be beneficial from a human capital perspective. Empirically it has been shown that underachieving children often have lower levels of motivation, lower future expectations, more behavioural problems, a higher risk of dropping out of school, and lower wages and more health problems when working compared to children who perform up to level (Uno et al., 2010; van Rooij et al., 2010; Mercer and Pullen, 2009; Dianda, 2008; Mulder et al., 2007; Lan and Lanthier, 2003 and Heckman and Rubinstein 2001).

The empirical literature about the effects of underachievement in school on laterlife outcomes is often plagued by two problems. First, it is hard to define underachievement in school because a child's innate ability cannot be observed directly. Researchers only observe behaviour in school, a number of intermediate outcomes, such as grades, and sometimes later-life outcomes, such as wages, employment and health outcomes. The preferences and the rationality of choices made by children remain unobserved. In this paper we define children as underachievers when their current achievement in school is below their expected potential achievement. ${ }^{61}$ Underachievement is defined in several ways in the literature, either in terms of some groups of children underperforming in relation to other groups, for example boys versus girls, (Bertrand and Pan, 2013), or individual children underperforming in relation to their own ability (Smith, 2003). In this paper we use the latter definition of underachievement. We select children for whom we observe that their individual achievement is lower in 9th grade compared to 6 th grade. Important is also that we include children across the full ability distribution, i.e. we do not only focus on the underachievement of gifted children.

The second problem in this literature is that it is hard to establish a causal relationship between observed behaviour and underachievement in school. This makes it hard to design interventions to lower underachievement. The approach taken in this paper is to use a network of schools that participates in a long term data collection process to improve education outcomes in the south of the Netherlands (Onderwijs Monitor Lim-

\footnotetext{
${ }^{61}$ Where children's current achievement is measured by their score on a math and language test in $9^{\text {th }}$ grade and by the child's teacher in $9^{\text {th }}$ grade. Children's expected potential achievement is measured by a high stakes test score on math and language in $6^{\text {th }}$ grade. In this study we select the bottom 25 percent of the children who experience the largest drop in achievement scores over time. For every child we consult the child's teacher in $9^{\text {th }}$ grade about his/her opinion on the child's achievement.
} 
burg $(\mathrm{OML})$ ). During the $\mathrm{OML}$ project teachers in these schools had meetings with researchers to discuss the results of the project for their school. The results of these meetings reveal that underachievement is a major concern among teachers. Motivational problems seem to be at the core of underachievement. This research was set up jointly with schools that participated in the OML project. This ensured us that schools had an actual interest in the topic of the intervention and that they would put effort in their children's participation. Furthermore, designing the intervention together with schools minimizes application problems in practice and increases scalability. The lack of motivation among underachieving children is a challenge for interventions because children could be more likely to drop out of a targeted intervention study which could lead to biased estimated effects of an intervention. As pointed out by Paunesku et al. (2015) many interventions that are targeted at academic achievement are researchoriented, i.e. they are designed by researchers, usually not in cooperation with educational practitioners. This could raise difficulties when the intervention has to be implemented by teachers that might not understand all important features of the interventions, or in schools with different environments that do not fit the design of the intervention (Borghans et al., 2015).

The aim of this study is to investigate whether an intervention targeted at underachieving secondary school children's school attitude and motivation raises their performance in terms of grades. We use a randomized field experiment to investigate this question. We use test scores for math and language from 6th and 9th grade as well as teacher evaluations in 9th grade to identify the target group. During seven months, underachieving children receive monthly assignments that target their study skills by raising awareness in the field of self-discipline, critical thinking, decision making and problem solving, school motivation and future orientation by raising awareness of the usefulness of performance in school and obtaining a degree. Several studies show that aspects like being able to plan and organize tasks, self-discipline, future goal orientation, self-confidence, daily learning routines and being able to focus on important tasks are positively related to school performance (Andriessen et al., 2006; Corker \& Donnellan, 2012; Deci \& Ryan, 2000; Dietz et al., 2007; Dignath \& Büttner, 2008; Hodis et al., 2011; Lee et al., 2010; McClure et al., 2011). The program confronts children with their study behaviour and school attitude. Outcomes are both continued participation in the intervention and grade point average (GPA). The intervention consists of 363 children of which 161 children are in the control group and 202 children are in the treatment group. $^{62}$

The main results from the experiment are threefold. First, we show that continued participation in the treatment is selective. Children who have a lower GPA and children who report to have a higher motivation before the treatment are more likely to comply with the treatment. Specifically, children with higher grades are approximately 22 per-

\footnotetext{
${ }^{62}$ For 337 of these children we have information on GPA.
} 
cent less likely and children who report to have a higher motivation are approximately 16 percent more likely to complete at least four assignments. The effects of GPA and motivation are interesting as higher motivated children remain in the treatment, but also those with lower grades. Second, we investigate the effect of the treatment on children's GPA, motivation, homework and self-confidence. We find no significant effect of our treatment on children's GPA, motivation, homework or self-confidence. Thirdly, we investigate if there is heterogeneity in the treatment effect across gender, track, GPA before treatment or motivation before treatment. Our estimates suggest that there are no heterogeneous treatment effects for GPA and motivation across gender, track, GPA before treatment and motivation before treatment.

There is a growing awareness in the literature that children's performance does not only reflect their ability, knowledge and intelligence but also seems to have powerful components related to children's non-cognitive skills such as personality traits and motivation. As stated by Borghans et al. (2011, p. 318) "Grades and achievement test scores predict adult outcomes better than IQ because they also capture personality traits". Work on Perry Preschool (Heckman, 2000; Carneiro and Heckman, 2003; Heckman and Masterov, 2007; Heckman, Pinto and Savelyev, 2013) and the GED (Heckman and Rubinstein, 2001; Heckman, Stixrud and Urzua, 2006; Heckman, Humphries and Kautz, 2014) show that next to cognitive skills there is a second dimension that is crucial in understanding the development of children and their future success and behavior. An increasing number of studies, in the US and Europe, show the importance of both cognitive and noncognitive factors in skill acquisition and later life outcomes varying from labor market success to risky behavior and health (Cunha, Heckman and Schennach, 2010; Campbell et al., 2014; Frijters et al., 2014; Kautz et al., 2014; Lundborg et al., 2014; Cunha and Heckman, 2007). For example, being able to plan and organize tasks, self-discipline, strategic thinking, self-confidence and being able to focus on important tasks is positively related to school performance (Sligte et al. 2009, van Rooij et al. 2010).

Studies have also shown that in the Netherlands about ten percent of the children in secondary education show lower performance than could be expected based on their talents (Dutch Education Council, 2007). It has been shown that underachievement in general is mainly present among children from lower social-economic backgrounds or from ethnic minorities and that this often coincides with behavioural problems, low motivation and unclear or low future expectations (Mulder et al., 2007; Lens and Decruyenaere 1991). For example, focusing resources on weaker children may be more effective (Banerjee et al., 2007). Holmlund and Silva (2009) find little evidence that their remedial education program significantly helped children to improve test outcomes. Other studies such as Lavy and Schlosser (2005) find a significant improvement of children's mean matriculation scores. However, this program was not found to be cost effective compared to alternative interventions. 
The number of (quasi-) experimental studies targeting children's non-cognitive skills is scarce but there is some evidence that there is a positive causal relation between non-cognitive skills and child performance at various ages (Heller et al., 2013; Algan et al., 2012; Laird, 2009; Machin et al., 2004; Eisen et al., 2003; Heckman and Rubinstein, 2001; Laird and Syropoulos, 1995; Laird and Roden, 1991). For example, Heller et al. (2013) show, by means of a randomized experiment where underachieving children in the treatment group receive special sports activities targeted to boost their selfconfidence and motivation, that such a program improves schooling outcomes. They observe a 0.14 standard deviation increase in an index comprising absenteeism, grades and participation in the program during the intervention period. In addition, positive effects from these types of experiments on school success are observed from the "Lions Quest Skills for Adolescence" program. This is a comprehensive life skills education program designed for school-wide as well as classroom implementation in grades 6-8, using group-randomized trials where schools are the unit of assignment. Results of the program are, among others, lower absenteeism during and after the intervention period and on average an increase in children's GPA, from 2.1 to 2.3 on a scale from 0-4 (Laird and Roden, 1991; Laird and Syropoulos, 1995). These results are based on the treatment of the whole classroom or school, not just on targeting a number of underachieving children per classroom or school.

In addition, some authors argue that many interventions that are targeted at academic achievement are research-oriented, i.e. they involve a lot of support by, or even depend on, researchers (Dignath \& Büttner, 2008; Paunesku et al., 2015). This could raise difficulties when the intervention has to be transferred to school practice by teachers that might not understand all important features of the interventions, or in schools with different environments that do not fit the design of the intervention (Borghans et al., 2016).

The paper proceeds as follows. We start with a detailed description of the intervention including our definition of underachieving children, the aim of the intervention, the selection of schools and children and our outcome measures and empirical strategy. Afterwards we present the results where we focus on two types of outcomes. First, children's compliance with assignment to the treatment group and second, the treatment effect estimates on cognitive outcomes (gpa) and non-cognitive outcomes (motivation, homework and self-confidence).

\subsection{The intervention}

\subsubsection{Defining underachievement}

The intervention is only targeted at children who underperform in relation to their expected performance. Our measure for underachievement has two important features. 
First, information from both primary school and secondary school is used. Second, objective and subjective information is combined by using both test scores in 6th and 9th grade as well as the teacher's evaluation in 9th grade. ${ }^{63}$ We determine underachievement in two steps. First, we use a high stakes standardized test score at the end of 6th grade as a proxy for the children' expected performance and a test score in 9th grade as a proxy for the children' current performance. The test score in 6th grade seems especially suited to test a child's potential because this test score is used as one of the measures to determine children's track placement in secondary education. The test in 9 th grade is part of a long term data collection process and contains similar questions on math and language as the test in 6th grade. The test in 9th grade is a low stakes test. Appendix A provides a detailed description of the data. Both tests include measures of math and language. Children are flagged as underachievers when their performance on the test in 9th grade is substantially below their score on the test in 6th grade. As a cut off, we take the 25 percent of children per class and per school who underperform the most. For the region in which our study takes place this leads to 1,066 children who are flagged as underachievers across all schools, not only the schools that eventually participate in the experiment.

We choose the 25 percent cut off for several reasons. First, enough children need to participate in the experiment in order to measure an effect. ${ }^{64}$ Furthermore, there are more pragmatic reasons, such as schools preferring to participate in an experiment if they know that at least a certain number of children are able to participate. As this study is dependent on the cooperation with schools this is a necessary condition. Other reasons include the number of schools that participate in the experiment and the associated costs of the experiment.

To confirm the validity of our selection method we asked teachers and mentors at the children' schools to evaluate the group of children that we find eligible for treatment, a procedure also used in previous studies (e.g., Holmlund and Silva, 2009 and Lavy and Schlosser, 2005). ${ }^{65}$ Feron et al. (2016) show that the information provided by teachers complements the assessment of children's ability provided by test scores. In some cases teachers and mentors argued that certain children should not be eligible for treatment. The main reason for removing these children from the pool of underachievers was that their underachievement was only of a temporary nature and/or due to personal circumstances. In addition, in a pilot phase of this experiment we used the same selection criteria and found that our method corresponds well with the teachers' evaluation.

\footnotetext{
${ }^{63}$ Figure 1 shows a timeline of the events.

${ }^{64}$ Appendix $\mathrm{C}$ shows a power analysis for this experiment.

${ }^{65}$ Both Holmlund and Silva (2009) and Lavy and Schlosser (2005) use a similar method for the selection of children. Holmlund and Silva base their selection on teachers' assessment of children's risk of educational exclusion, perceptions of worsening educational performance and school disengagement, while Lavy and Schlosser base their selection on teachers' estimation of the likelihood of children passing their matriculation exams.
} 


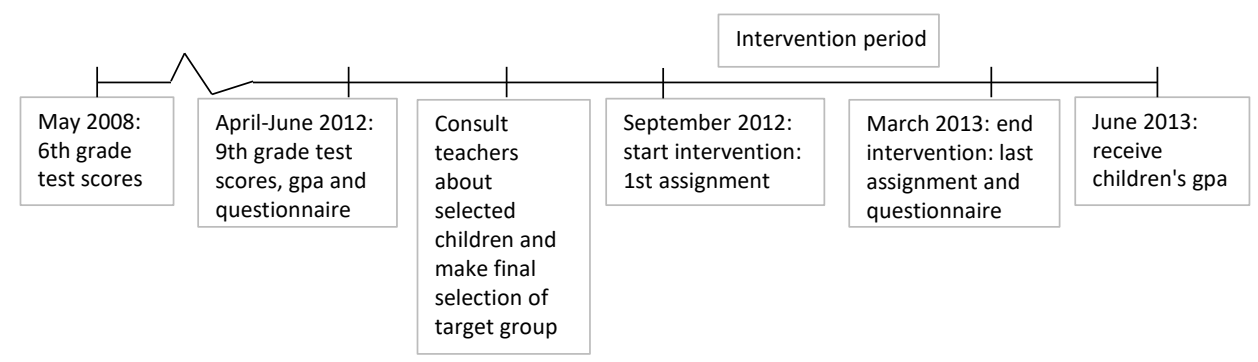

Figure 1: Timeline of events

\subsubsection{Design of the intervention}

The intervention is designed to improve the performance of underachieving children by increasing their motivation. During the intervention period the treatment group is offered seven monthly assignments. The assignments are aimed at raising children's awareness about their school attitude and study behaviour by answering questions using self-reflection. Every assignment has a different topic including planning, selfimage, self-confidence, skill creation, teamwork, responsibility and expectations about the future. ${ }^{66}$

The assignments used in this study are inspired by the program 'Skills for Adolescence' (Lionsquest, 2002) and the book ' 7 habits of highly effective teens' (Covey, 2002). The 'Skills for Adolescence' program is a comprehensive life skills education program designed for school-wide and classroom implementation in grades 6-8, using a group-randomized trial with schools as the unit of assignment. Reported results of the program are, among others, lower absenteeism during and after the intervention period and a higher average GPA, from 2.1 to 2.3 on a scale from 0-4 (Laird and Roden, 1991; Laird and Syropoulos, 1995). These findings are based on the treatment of the whole classroom or school and not only the underperforming children. The 'Seven habits of highly effective teens' demonstrates the importance of certain habits, such as having a proactive attitude towards studying, prioritizing and goal orientation and in being able to respond to and manage changes in life (Prevoo, 2013).

Participation in the assignments is supervised by a teacher or mentor at the children's school. Supervision is expected to increase participation in the treatment, since it ensures that children receive the treatment in a fostering learning environment and allows them to ask questions. An important aspect of this intervention is the ease and limited costs with which it can be scaled up. The tasks have a low time-intensity and children complete the tasks online. Furthermore, the intervention does not interfere with the children's courses as the sessions of the intervention are scheduled at school in hours when they do not have classes. The possible disadvantage of the low-time inten-

\footnotetext{
${ }^{66}$ In appendix D the assignments are presented (in Dutch).
} 
sity of the intervention is that the time scheduled for the intervention is too short to observe any effects.

\subsubsection{Selection of schools and children}

A power analysis shows ${ }^{67}$ that to find an effect of 0.4 points increase in children's GPA, a sample size of 200 children (or about 10 schools) is sufficient. To find a slightly more modest effect of 0.3 points increase in children' GPA, a sample size of 300 children (or about 15 schools) is needed. These effect sizes are comparable to the ones found in the literature of the 'Skills for Adolescence' program. The intervention targets children in 9th grade who attend either the pre-vocational education track (vmbo and in particular the upper theoretical track) or the pre-higher vocational education track (havo). These tracks are selected because these children are expected to gain the most from the intervention. It has been shown that underachievement, in relation to motivational problems, is most common in these two tracks (Dutch education council, 2007). Children in these tracks are generally concentrated in the middle of the overall ability distribution and comprise a more heterogeneous group in terms of performance than children in the lowest and highest tracks. The 9th grade is selected because some of the performance related problems that children encounter in 7th grade are likely related to the transition from primary to secondary school (Driessen et al., 2005). These transitionspecific problems are expected to disappear over the first two years of secondary school. The intervention focuses on problems that are more persistent. Furthermore, children in 9th grade still have at least one year before graduation. This leaves some time for the effect of the program to materialize.

School visits to all schools that responded positively were organized to explain the intervention study and the procedures and to receive information from the schools on how they organized their education practice and on aspects they considered to be of importance when participating in the study. Important points to take into account were timely planning of the intervention and sufficient information for the children's parents. This way of involving schools in the study is very time consuming, yet a minimum requirement for cooperation.

\subsubsection{Sample of schools}

18 schools participate in the study, 10 pre-vocational education schools (vmbo) and 8 pre-higher vocational education schools (havo). ${ }^{68}$ Within each track, schools are randomly assigned to the treatment or the control group. ${ }^{69}$ This randomization results in

\footnotetext{
${ }^{67}$ Appendix $\mathrm{C}$ describes the power analysis.

${ }^{68}$ In this study, a school is defined as an educational track (usually separate school location). Two schools in the sample participate with both the pre-vocational and pre-higher education track.

${ }^{69}$ The randomized assignment to treatment or control group is performed by an external party, in this case The Netherlands Bureau for Economic Policy analysis.
} 
five treatment schools and five control schools for the pre-vocational education track (vmbo) and four treatment schools and four control schools for the pre-higher vocational education track (havo). Using the selection procedure described earlier, the underachieving children are selected per school. This selection results in 202 children in the treatment and 161 children in the control group.

An important question is whether schools that participate in this experiment are a selective group of schools. It is possible that schools are more willing to participate in this experiment when they experience problems with children's motivation and underachievement. Other schools might have decided not to participate because of the randomized assignment to the intervention and control groups. Fortunately, we have additional information on the schools that did not participate in the study that allow us to make a comparison on child and school characteristics between participating and nonparticipating schools. Table 1 gives an overview of the child characteristics in the different groups. The first two columns report the intervention and control group of the underachieving children at the participating schools. Column 3 shows the descriptive statistics for the target population of underachieving children at non-participating schools. From table 1 we conclude that children's demographic characteristics are not significantly different in schools that participate in the study compared to those that do not participate. The share of pre-higher education schools is slightly lower in this study compared to the non-participating schools. In addition, we checked for differences in the size of the schools' child population and the location of the school. We do not find any significant differences on these school characteristics (Feron and Schils, 2015). Overall, we observe that the schools that participate in the intervention do not differ strongly from schools that do not participate in the intervention based on child and school characteristics. We assume that the same holds for their non-observable characteristics. Therefore, we conclude that schools that participate in this study are not significantly different from schools that do not participate in the study and that selection bias is not likely to be a major problem. 
Table 1: Descriptive statistics

\begin{tabular}{|c|c|c|c|}
\hline & \multicolumn{2}{|c|}{ Participating schools } & \multirow{2}{*}{$\begin{array}{l}\text { Non-participating } \\
\text { schools } \\
\text { All }\end{array}$} \\
\hline & Treatment group & Control group & \\
\hline \multicolumn{4}{|l|}{ Cognitive and non-cognitive variables } \\
\hline GPA $9^{\text {th }}$ grade & 6.24 & 6.22 & \\
\hline Motivation $^{1}$ & -0.03 & -0.22 & 0.07 \\
\hline Homework (hours) & 6.3 & 5.55 & 5.8 \\
\hline Self-confidence ${ }^{1}$ & -0.11 & 0.12 & $0.10^{*}$ \\
\hline \multicolumn{4}{|l|}{ Demographic variables } \\
\hline Pre-higher education track (share) & 0.42 & 0.43 & $0.52 * *$ \\
\hline Age (in years) & 15.74 & 15.76 & 15.71 \\
\hline Girls & 0.43 & 0.36 & 0.43 \\
\hline Education level parents & 2.20 & 2.19 & 2.11 \\
\hline 1. Lower education & $21.34 \%$ & $25 \%$ & $25.12 \%$ \\
\hline 2. Vocational education & $37.80 \%$ & $32.25 \%$ & $38.66 \%$ \\
\hline 3. Higher/university education & $40.85 \%$ & $43.75 \%$ & $36.22 \%$ \\
\hline Child born in the Netherlands & 0.92 & 0.90 & 0.90 \\
\hline Observations & 202 & 161 & 703 \\
\hline
\end{tabular}

Note: The first two columns show student characteristics, before the start of the experiment, for the treatment and control groups that participate in the study and the third column shows student characteristics at schools that did not participate in the study. We selected 202 underachieving students for the treatment group, 161 students for the control group and 703 students that did not participate in the study. Differences reported between the treatment and control group(s) at *,**,***, at 10 percent, 5 percent and 1 percent significance levels respectively, based on t-tests. Not for all students there is information available on all control variables. We do not have information on grades for the non-participating schools. A detailed description of the data is provided in the appendix.

${ }^{1}$ Standardized variables. We standardize these variables before treatment using the full population of students and anchor the outcomes after the treatment to the first outcomes using only the scores of the students in the control group that do not drop out of the study. More details on the standardization approach are found in Appendix B.

\subsubsection{Outcome measures and empirical strategy}

In this paper we look at two types of outcome measures: school performance in terms of grades and motivation, time spend on homework and self-confidence. During secondary school children's performance is assessed throughout the year by means of formal tests. The grades children receive for these tests are measures on a scale from 110, where 1 represents the lowest and 10 the highest grade. Children receive an official report card that lists the average grades they have obtained in all of their courses several times per year. We collect these report cards, before and after the intervention period, i.e. at the end of 9th grade and at the end of 10th grade. Based on these grades, 
we calculate the grade point average for all children. For 337 out of the 363 children we have information on their grades. ${ }^{70,71}$

Before and after the intervention period, children in both the treatment and the control group completed a questionnaire that includes questions on school motivation, hours spent on homework and self-confidence. The questionnaire after the intervention was taken at the end of the experiment. Therefore, information on these variables is only available for those children that completed the full treatment. To prevent children from dropping out of the program we use monetary incentives, next to the involvement of the teacher. Bettinger (2012) shows a positive relation between paying children for successful completion of standardized tests and their test scores. Furthermore, Bettinger (2012) and Kremer et al. (2009) find no evidence that financial incentives weaken intrinsic motivation to learn or lead to gaming or cheating. Children in the treatment group who complete at least five out of the seven assignments in the intervention receive 25 Euro for their participation. Participants in the intervention were informed about the monetary incentives before the start of the program.

We look at two types of results in this study. First, we investigate which children complete the treatment and which children do not. Especially since we target underachievers this is a relevant outcome variable, as completion of the treatment might be related to motivational attitudes. Due to some minor issues with the logistics at schools, some children were unable to participate in all assignments. We define children as treatment group compliers when they completed at least four out of the seven assignments. ${ }^{72}$ Second, we look at the effect of the treatment on several outcomes. Our main interest is whether the treatment has an effect on children's GPA. In addition, we observe whether the treatment has an effect on children's motivation, hours spend on homework and self-confidence.

To analyse the treatment effect, we use two types of models. We use linear models of the effect of the treatment on child outcomes where we include the levels of these outcomes before the treatment as lagged variables, or

$$
Y_{i, t}=\beta_{0}+\beta_{1} D_{i}+\beta_{2} Y_{i, t-1}+\varepsilon_{i}
$$

where $Y_{i, t}$ represents the child's GPA, motivation, hours spent on homework or selfconfidence in period $t$ after the treatment, $D_{i}$ equals 1 if the child is in the treatment group and equals 0 otherwise, $Y_{i, t-1}$ represents the child's GPA, motivation, hours spent on homework or self-confidence in period $t$-1 before the treatment and $\varepsilon_{i}$ represents the error term.

\footnotetext{
${ }^{70}$ Appendix A provides a detailed overview of the data used for this study.

${ }^{71}$ Since we have information on grades for 337 children these children make up our sample for the analyses.

72 In the results section we show the estimates for the group of children who have participated in at least four assignments. We choose to show this group as we have more observations in this group. There is a gradual decline in the children who drop out of doing the assignments during the intervention period. Figure 2 shows there is no jump at participating in at least five assignments. The estimates are similar when we use the group of children who have participated in at least five assignments.
} 
In addition, we use a generalized difference-in-differences method. We estimate panel fixed-effects models with period fixed effects and child fixed effects to better isolate the treatment effect as the fixed effects soak up some of the residual variation, or

$$
Y_{i, t}=\beta_{0}+\beta_{1}\left(P_{t} * D_{i}\right)+\alpha_{i}+\delta_{t}+\mu_{i, t}
$$

where $Y_{i, t}$ represents the child's GPA, motivation, hours spent on homework or selfconfidence in period $t, P_{t}$ represents the times-series simple difference estimate. $P$ equals 1 if period $t$ occurs after treatment and equals 0 otherwise. $D_{i}$ equals 1 if the child is in the treatment group and equals 0 otherwise. The coefficient $\beta_{1}$ of the interaction variable $P_{t}{ }^{*} D_{i}$ represents the treatment effect estimate. $\alpha_{i}$ represents the child fixed effects, $\delta_{t}$ represents the period fixed effects and $\mu_{i, t}$ represents the error term.

We use three different ways of defining the treatment effect. The first definition is based on assignment to treatment (intention to treat or ITT). In the above models this implies that $D=1$ for all children who were assigned to the treatment group at the start of the intervention. However, a part of the treatment group might not receive the actual treatment due to dropping out early, the treatment group non-compliers. The second definition is based on actual treatment participation. This implies that $D=1$ for all children who have completed at least four assignments. This model assumes that those who dropped out of the treatment also did not benefit from the assignment to treatment. If children self-select into completing the actual treatment or if participation is based on the expected gains from treatment we expect that the conditional mean independence assumption is violated and we can no longer make causal inferences. Such selection sounds quite plausible in our case due to the large number of children who drop out of the intervention. Therefore, a third definition is used, which uses an instrumental variable approach. Assignment to the treatment is used as an instrument for the actual treatment taken (treatment effect on the treated or TOT).

Finally, all models are estimated both with robust standard errors and with standard errors clustered at the school level, because observations might not be independent within schools. Moreover, models that show significant effects are also estimated with standard errors cluster bootstrapped with clusters at the school level. The bootstrap is used to see whether results hold when simulating a larger sample of schools, since we only have 18 schools in our sample.

\subsection{Results}

\subsubsection{Descriptive statistics}

Table 1 shows the descriptive statistics for the three groups before the start of the treatment. The children in our sample are on average 15 years old and there are slightly more boys than girls in our sample. Most parents have completed at least vocational 
education and approximately 90 percent of the children in our sample are born in the Netherlands. Furthermore, the children have an average gpa of 6.2 and spend approximately 6 hours on homework. Children in our sample seem to be slightly less motivated compared to children who do not participate and children in our treatment group report a lower level of self-confidence.

Table 2 shows the correlation table for the variables we use in the analyses. There are some interesting correlations regarding motivation and gpa. Motivation before treatment is significantly positively correlated with completing at least four assignments and with gpa before treatment. Motivation after treatment is significantly positively correlated with gpa before and after treatment and with motivation after treatment. Furthermore, girls report to be more motivated than boys. Regarding gpa we observe that gpa before treatment is significantly positively correlated with gpa after treatment, children in the pre-higher education track appear to have a lower gpa than children in the pre-vocational track, children who are born in the Netherlands appear to have a higher gpa than children who are not born in the Netherlands and children who report a higher level of self-confidence appear to have a lower gpa.

\subsubsection{Randomization}

The results in table 1 indicate that the randomization was successful. Another check to see if the randomization was successful is to observe if any of the covariates predict assignment to treatment. Table 3 reports the marginal effects of a probit model where the dependent variable equals 1 when the child is assigned to the treatment group and equals zero when the child is assigned to the control group. In column 1 we observe all 337 children in the treatment and control group for whom we have information on their GPA. If the randomization is successful the covariates should not be different between the two groups. The results in table 3 show that generally no variable is able to predict whether children end up in the treatment or in the control group. These results indicate that the randomization was successful. 
Motivation and its effect on school performance

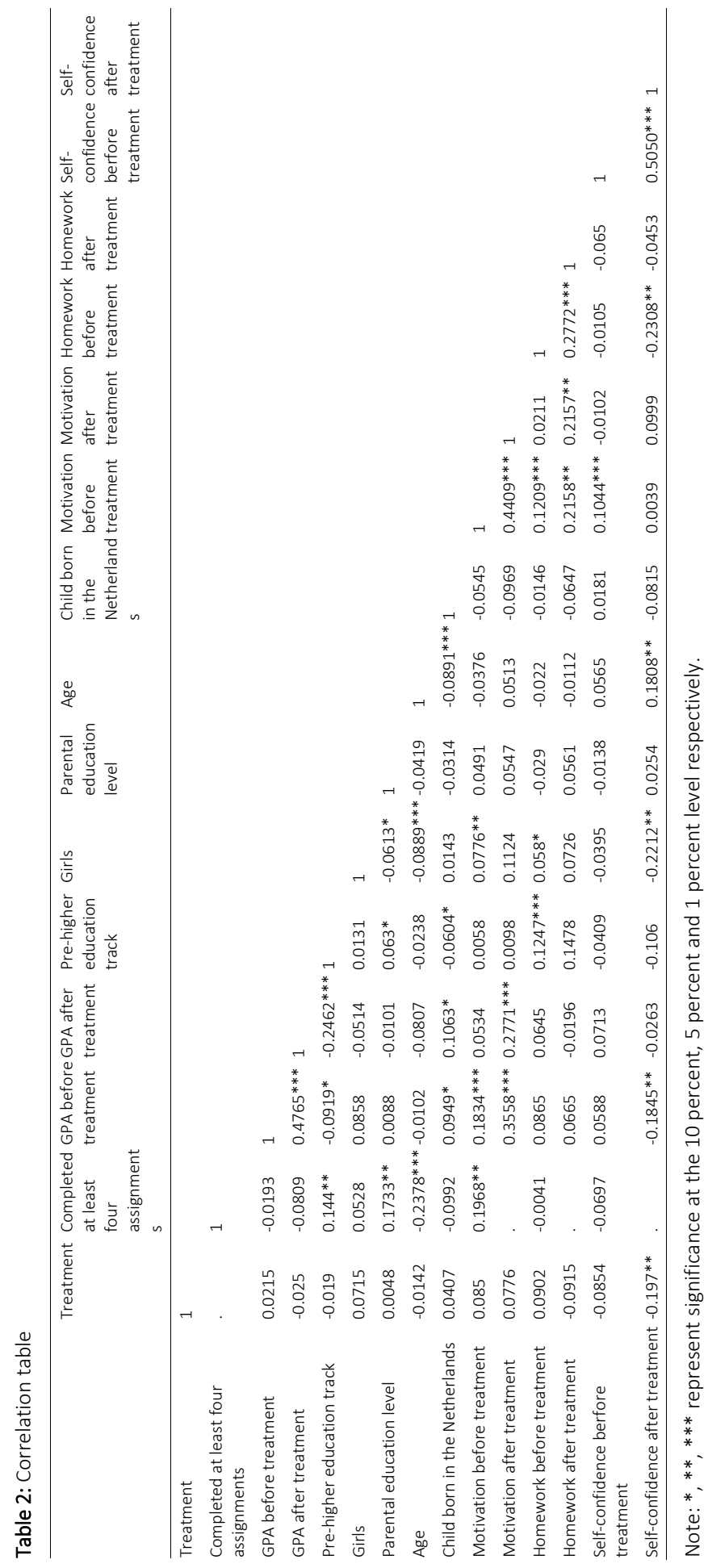


Table 3: Randomization

\begin{tabular}{|c|c|c|c|c|}
\hline & \multicolumn{4}{|c|}{ treatment } \\
\hline & $(1)$ & $(2)$ & (3) & (4) \\
\hline \multirow[t]{2}{*}{ GPA before treatment } & 0.028 & 0.014 & 0.014 & 0.014 \\
\hline & $(0.051)$ & $(0.063)$ & $(0.095)$ & $(0.102)$ \\
\hline \multirow[t]{2}{*}{ Pre-higher education track } & -0.010 & 0.048 & 0.048 & 0.048 \\
\hline & $(0.058)$ & $(0.065)$ & $(0.269)$ & $(0.298)$ \\
\hline \multirow[t]{2}{*}{ Girls } & 0.093 & 0.072 & 0.072 & 0.072 \\
\hline & $(0.057)$ & $(0.067)$ & $(0.061)$ & $(0.068)$ \\
\hline \multirow[t]{2}{*}{ Parents have vocational education } & 0.092 & 0.044 & 0.044 & 0.044 \\
\hline & $(0.078)$ & $(0.087)$ & $(0.088)$ & $(0.094)$ \\
\hline \multirow[t]{2}{*}{ Parents have higher/university education } & 0.004 & -0.023 & -0.023 & -0.023 \\
\hline & $(0.077)$ & $(0.083)$ & $(0.076)$ & $(0.090)$ \\
\hline \multirow[t]{2}{*}{ Parents' education unknown } & 0.070 & 0.076 & 0.076 & 0.076 \\
\hline & $(0.111)$ & $(0.202)$ & $(0.198)$ & $(0.221)$ \\
\hline \multirow[t]{2}{*}{ Age (in months) } & -0.002 & 0.001 & 0.001 & 0.001 \\
\hline & $(0.004)$ & $(0.005)$ & $(0.006)$ & $(0.006)$ \\
\hline \multirow[t]{2}{*}{ Child born in the Netherlands } & 0.026 & 0.090 & 0.090 & 0.090 \\
\hline & $(0.102)$ & $(0.107)$ & $(0.115)$ & $(0.135)$ \\
\hline \multirow[t]{2}{*}{ Child's country of birth unknown ${ }^{1}$} & 0.196 & & & \\
\hline & $(0.127)$ & & & \\
\hline \multirow[t]{2}{*}{ Motivation } & & $0.065 * *$ & $0.065^{* *}$ & $0.065^{* *}$ \\
\hline & & $(0.031)$ & $(0.028)$ & $(0.031)$ \\
\hline \multirow[t]{2}{*}{ Homework (in hours) } & & 0.008 & $0.008^{*}$ & 0.008 \\
\hline & & $(0.008)$ & $(0.005)$ & $(0.006)$ \\
\hline \multirow[t]{2}{*}{ Self-confidence } & & -0.036 & $-0.036^{*}$ & -0.036 \\
\hline & & $(0.025)$ & $(0.020)$ & $(0.024)$ \\
\hline Robust SEs & yes & yes & no & no \\
\hline Clustered SEs & no & no & yes & no \\
\hline Cluster bootstrapped SEs & no & no & no & yes \\
\hline Observations & 337 & 259 & 259 & 259 \\
\hline
\end{tabular}

Note: This table shows the marginal effects from probit models with the dependent variable being equal to 1 if the student is assigned to the treatment group and 0 if he is assigned to the control group. Standard errors are reported between brackets. ${ }^{*}, * * * *$, represent 10 percent, 5 percent and 1 percent significance levels respectively.

${ }^{1}$ This category is used to keep all students in the first model. In the later models, no information on the personality traits is available for the students in this category and therefore it drops from the analysis.

In column 1 we have 337 observations, this are all children for who we have information on their GPA. In column 2 we add motivation, homework and self-confidence before treatment. We only have this information for children who answered the first questionnaire. 


\subsubsection{Compliance}

A first result to evaluate is to what extent children comply with the intervention. Since the children in our target group are selected because they are currently underperforming, we expect that these children have a higher probability of dropping out as their motivation to take up and complete the treatment is likely lower compared to regular children. During the seven months that the treatment was provided children had ample opportunities to drop out of the treatment. Participation in the experiment is voluntary and when children decide to participate in the experiment they stay one additional hour in school every month to complete the online tasks. Teachers and mentors can remind children to participate in the experiment but they do not force children to participate. It is unlikely that forcing unwilling children to just sit behind a computer for one hour a month will contribute to their school motivation and their school performance.

We define children as treatment group compliers when they participate in at least four out of the seven assignments. Figure 2 shows the number of treatment group compliers per assignment. The children in our target group have a relatively high probability of dropping out of the treatment. Over the duration of the experiment children gradually drop out. 51 percent of the children participate in at least four assignments. A first step in the analysis is to see whether the children who complete the treatment systematically differ from those who do not.

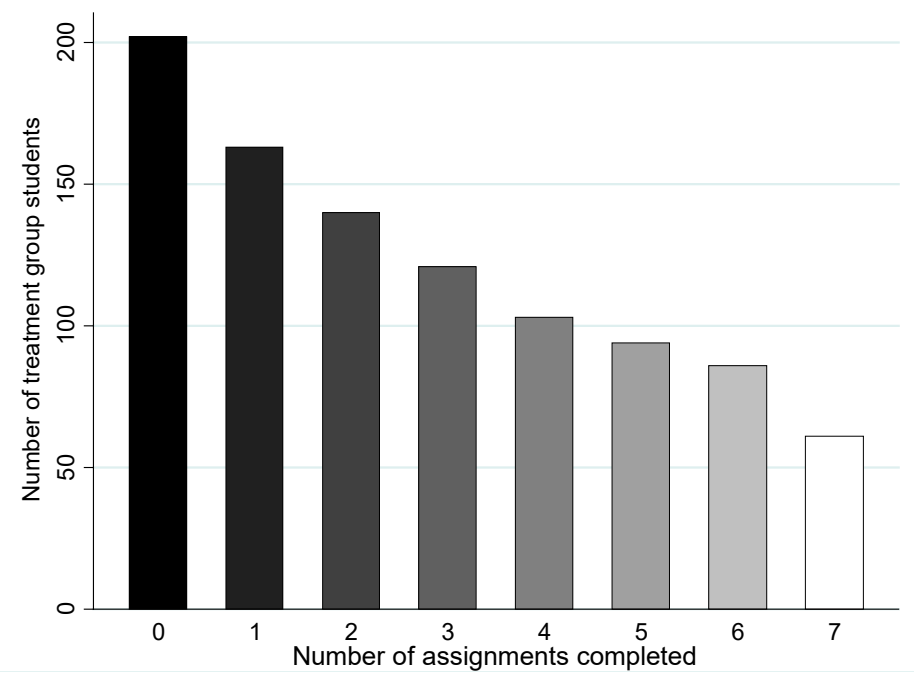

Figure 2: Compliance with treatment

Note: This figure shows the number of children that completed a different number of assignments, ranging from 0 (no assignments made at all) to 7 (completed full treatment). 
Table 4 shows the results of probit models for the probability to complete at least four assignments for children in the treatment group. In column 1 we observe all 202 children in the treatment group. The results show that children's gpa, age and motivation seem to be consistent predictors of completing at least four assignments. If gpa goes up by 1 , children are on average approximately 22 percent less likely to complete at least four assignments, younger children and children who report higher levels of motivation seem more likely to complete at least four assignments. Motivation is measured on a Likert scale from 1-5 and is later standardized. A standard deviation increase in reported motivation is related to a 16 percent increase in completing at least four assignments. Possibly, older children are those who have repeated a year either in primary or secondary school. We lose observations when we add motivation, homework and selfconfidence to the regression models as not all children answered the questionnaire (fully). The positive relation between motivation and completing at least four assignments is particularly interesting. This suggests that children who report a lower motivation are less likely to complete the assignments. This part of the distribution of children is exactly the part that the intervention is trying to reach.

Based on these results, it seems to be the case that continued participation in the treatment is selective. Children who do not comply with all assignments are likely to not benefit from the treatment. This means that our treatment effect estimates are biased downwards. For this reason, we argue that estimating an Intention-To-Treat (ITT) effect for these children would dilute our estimate of the treatment effect, and estimating a Treatment-on-Treated (TOT) effect is likely to be more accurate. In our analyses of the treatment effect on cognitive and non-cognitive outcomes we will show both models. 
Table 4: Compliance

\begin{tabular}{|c|c|c|c|c|}
\hline & \multicolumn{4}{|c|}{ Completed at least four assignments } \\
\hline & $(1)$ & $(2)$ & (3) & (4) \\
\hline \multirow[t]{2}{*}{ GPA before treatment } & & $-0.219 * *$ & $-0.219 * * *$ & $-0.219 * *$ \\
\hline & & $(0.093)$ & $(0.081)$ & $(0.089)$ \\
\hline \multirow[t]{2}{*}{ Pre-higher education track } & $0.146^{*}$ & 0.097 & 0.097 & 0.097 \\
\hline & (0.079) & $(0.095)$ & $(0.258)$ & $(0.277)$ \\
\hline \multirow[t]{2}{*}{ Girls } & 0.013 & -0.073 & -0.073 & -0.073 \\
\hline & $(0.075)$ & $(0.094)$ & $(0.077)$ & $(0.080)$ \\
\hline \multirow[t]{2}{*}{ Parents have vocational education } & 0.058 & 0.081 & 0.081 & 0.081 \\
\hline & $(0.113)$ & $(0.124)$ & $(0.142)$ & $(0.171)$ \\
\hline \multirow[t]{2}{*}{ Parents have higher/university education } & $0.184^{*}$ & 0.191 & 0.191 & 0.191 \\
\hline & $(0.108)$ & $(0.117)$ & $(0.126)$ & (0.139) \\
\hline \multirow[t]{2}{*}{ Parents education unknown } & 0.024 & -0.287 & -0.287 & $-0.287 * *$ \\
\hline & (0.149) & $(0.269)$ & $(0.185)$ & $(0.135)$ \\
\hline \multirow[t]{2}{*}{ Age (in months) } & $-0.019 * * *$ & $-0.019 * * *$ & $-0.019 * * *$ & $-0.019 * * *$ \\
\hline & $(0.006)$ & $(0.007)$ & $(0.006)$ & $(0.006)$ \\
\hline \multirow[t]{2}{*}{ Child born in the Netherlands } & -0.189 & -0.151 & -0.151 & -0.151 \\
\hline & $(0.143)$ & $(0.155)$ & $(0.197)$ & $(0.192)$ \\
\hline \multirow[t]{2}{*}{ Child's country of birth unknown } & -0.134 & & & \\
\hline & $(0.188)$ & & & \\
\hline \multirow[t]{2}{*}{ Motivation } & & $0.159 * * *$ & $0.159 * *$ & $0.159 *$ \\
\hline & & $(0.057)$ & $(0.063)$ & $(0.095)$ \\
\hline \multirow[t]{2}{*}{ Homework } & & -0.006 & -0.006 & -0.006 \\
\hline & & $(0.011)$ & $(0.009)$ & $(0.010)$ \\
\hline \multirow[t]{2}{*}{ Self-confidence } & & -0.026 & -0.026 & -0.026 \\
\hline & & $(0.037)$ & $(0.031)$ & $(0.034)$ \\
\hline Robust SEs & yes & yes & no & no \\
\hline Clustered SEs & no & no & yes & no \\
\hline Cluster bootstrapped SEs & no & no & no & yes \\
\hline Observations & 202 & 135 & 135 & 135 \\
\hline
\end{tabular}

Note: This table shows the marginal effects from probit regressions where the dependent variable is equal to 1 if the student completed at least four assignments and 0 otherwise (students in the treatment group only). Robust standard errors are reported between brackets. ${ }^{*}, * * * * *$, at 10 percent, 5 percent and 1 percent significance levels respectively.

\subsubsection{Treatment effects}

Table 5 reports the estimated coefficients of the treatment on children's GPA. In column 1-3 we use the data as cross-sectional data and control for GPA before the treatment, the children's track, gender, parental education level, age and country of birth. In column 1 we use assignment to treatment as the treatment variable (Intention-to-treat or ITT), in column 2 we use completion of at least four assignments as the treatment 
variable and in column 3 we use assignment to the treatment group as an instrument for completion of at least four assignments (Treatment-on-treated or TOT). Furthermore, in column 4-6 we use the data as panel data where we use period and child fixed effects.

The results in table 5 show that we find no treatment effect of the intervention on GPA. The results in column 4-6 show a negative time trend for GPA. Furthermore, we observe that the treatment effects in column 3 and 6 , where we use assignment to treatment as an instrument for treatment taken, are approximately twice the size of the ITT estimates in column 1 and 4. This is consistent with approximately 50 percent of our children dropping out of the treatment.

In table 6 we present the results of the treatment on motivation, homework and self-confidence. The results show that we find no treatment effect of the intervention on motivation, homework and self-confidence. This might be due to the low number of observations that resulted after treatment, since the non-cognitive skills are measured after the seventh assignment was completed and about 70 percent of the children in the treatment group has left the study by that time.

Table 5: Treatment effect on cognitive outcome

\begin{tabular}{|c|c|c|c|c|c|c|}
\hline & \multicolumn{6}{|c|}{ Grade Point Average } \\
\hline & ITT & TOT & TOT with IV & $\mathrm{ITT}$ & TOT & TOT with IV \\
\hline & $(1)$ & $(2)$ & (3) & $(4)$ & (5) & $(6)$ \\
\hline \multirow[t]{2}{*}{ Treatment } & -0.059 & -0.048 & -0.110 & -0.031 & -0.025 & -0.056 \\
\hline & $(0.067)$ & $(0.079)$ & $(0.123)$ & $(0.073)$ & $(0.078)$ & $(0.132)$ \\
\hline \multirow[t]{2}{*}{ Post } & & & & $-0.160 * * *$ & $-0.169 * * *$ & $-0.160 * * *$ \\
\hline & & & & $(0.055)$ & $(0.044)$ & $(0.055)$ \\
\hline \multirow[t]{2}{*}{ Constant } & $3.119 * * *$ & $3.195^{* * *}$ & $3.386 * * *$ & $6.332 * * *$ & $6.332 * * *$ & \\
\hline & $(1.163)$ & $(1.209)$ & $(1.190)$ & $(0.026)$ & $(0.026)$ & \\
\hline Robust SEs & yes & yes & yes & yes & yes & yes \\
\hline Clustered SEs & no & no & no & no & no & no \\
\hline Cluster bootstrapped SEs & no & no & no & no & no & no \\
\hline Observations & 294 & 294 & 294 & 601 & 601 & 588 \\
\hline R-squared & 0.309 & 0.308 & 0.306 & 0.076 & 0.076 & 0.075 \\
\hline
\end{tabular}

Note: This table shows coefficients from OLS regressions in cross sectional data and panel data. In the cross sectional data we use GPA before treatment, track, gender, parental education level, age and region of birth as control variables. In the panel data regressions we use period and student fixed effects. Robust standard errors are reported between brackets. Clustered standard errors and cluster bootstrapped standard errors give similar results. ${ }^{*}, * *, * *$, at 10 percent, 5 percent and 1 percent significance levels respectively. Models with standard errors clustered at the school level and with bootstrapped standard errors showed similar results. 
Table 6: Treatment effect on non-cognitive outcomes

\begin{tabular}{lllllll}
\hline & Motivation & Homework & $\begin{array}{l}\text { Self- } \\
\text { confidence }\end{array}$ & Motivation & Homework & $\begin{array}{l}\text { Self- } \\
\text { confidence }\end{array}$ \\
\hline & ITT and TOT is the same & & & & \\
& $(1)$ & $(2)$ & $(3)$ & $(4)$ & $(5)$ & $(6)$ \\
\hline Treatment & 0.073 & -1.778 & -0.499 & -0.075 & -1.330 & -0.498 \\
& $(0.210)$ & $(1.165)$ & $(0.315)$ & $(0.220)$ & $(1.162)$ & $(0.330)$ \\
Post & & & & -0.003 & $2.443 * * *$ & -0.150 \\
& & & & $(0.173)$ & $(0.911)$ & $(0.267)$ \\
Constant & $-6.829 * * *$ & -2.485 & -0.467 & 0.009 & $6.107 * * *$ & -0.003 \\
& $(2.550)$ & $(17.178)$ & $(4.339)$ & $(0.077)$ & $(0.409)$ & $(0.114)$ \\
Robust SEs & yes & yes & yes & yes & yes & yes \\
\hline Clustered SEs & no & no & no & no & no & no \\
Cluster bootstrapped SEs & no & no & no & no & no & no \\
Observations & 108 & 104 & 101 & 231 & 227 & 221 \\
R-squared & 0.340 & 0.177 & 0.365 & 0.003 & 0.086 & 0.104 \\
\hline
\end{tabular}

Note: This table shows coefficients from OLS regressions in cross sectional data and panel data. In the cross sectional data we use GPA before treatment, track, gender, parental education level, age, region of birth and the respective dependent variable before treatment as control variables. In the panel data regressions we use period and student fixed effects. Robust standard errors are reported between brackets. Clustered standard errors and cluster bootstrapped standard errors give similar results. ${ }^{*}, * *, * * *$, at 10 percent, 5 percent and 1 percent significance levels respectively. Models with standard errors clustered at the school level and with bootstrapped standard errors showed similar results.

In a next step, we analyse whether there is any heterogeneity in the treatment effects. Table 7 and table 8 show the results of the interaction variables female, track (havo), GPA above mean and motivation above mean. In table 7 we find no heterogeneity in treatment effects for GPA. We do observe that children in the pre-higher education (havo) track generally have a lower GPA compared to children in the pre-vocational education (vmbo) track. Furthermore, column 3 shows that children in the control group who have a GPA above the mean before the treatment, have a higher GPA after treatment. In table 8 we find no heterogeneity in treatment effects for motivation. We do find a similar relation for GPA above the mean as in table 7. Furthermore, we find that above average reported motivation before the treatment is related to higher reported motivation after treatment. 
Chapter 6

Table 7: Heterogeneity in treatment effect cognitive outcome

\begin{tabular}{|c|c|c|c|c|}
\hline & \multicolumn{4}{|c|}{ Grade Point Average } \\
\hline & $(1)$ & $(2)$ & (3) & $(4)$ \\
\hline \multirow[t]{2}{*}{ Treatment } & -0.032 & 0.034 & -0.032 & -0.141 \\
\hline & $(0.095)$ & $(0.079)$ & $(0.107)$ & $(0.094)$ \\
\hline \multirow[t]{2}{*}{ Girls } & -0.011 & & & \\
\hline & $(0.097)$ & & & \\
\hline \multirow[t]{2}{*}{ Treatment\#Girls } & -0.066 & & & \\
\hline & $(0.137)$ & & & \\
\hline \multirow[t]{2}{*}{ Pre-higher education track } & & $-0.240 * *$ & & \\
\hline & & $(0.099)$ & & \\
\hline \multirow[t]{2}{*}{ Treatment\#pre-higher education track } & & -0.219 & & \\
\hline & & $(0.136)$ & & \\
\hline \multirow[t]{2}{*}{ GPA before treatment, above mean } & & & $0.513^{* * *}$ & \\
\hline & & & $(0.104)$ & \\
\hline \multirow[t]{2}{*}{ Treatment\#GPA before treatment above mean } & & & -0.019 & \\
\hline & & & $(0.143)$ & \\
\hline \multirow[t]{2}{*}{ Motivation above mean } & & & & -0.057 \\
\hline & & & & $(0.098)$ \\
\hline \multirow[t]{2}{*}{ Treatment\#Motivation above mean } & & & & 0.156 \\
\hline & & & & $(0.132)$ \\
\hline \multirow[t]{2}{*}{ Constant } & $3.137 * * *$ & $2.870 * *$ & $7.112^{* * *}$ & $3.101^{* * *}$ \\
\hline & $(1.161)$ & $(1.165)$ & $(1.046)$ & $(1.156)$ \\
\hline Robust SEs & yes & yes & yes & yes \\
\hline Clustered SEs & no & no & no & no \\
\hline Cluster bootstrapped SEs & no & no & no & no \\
\hline Observations & 294 & 294 & 294 & 294 \\
\hline R-squared & 0.309 & 0.315 & 0.222 & 0.312 \\
\hline
\end{tabular}

Note: The regressions show coefficients from OLS regressions with interaction variables for female, studytrack, gpa above mean and motivation above mean. We use GPA before treatment, track, gender, parental education level, age, and region of birth as control variables. Robust standard errors are reported between brackets. Models with standard errors clustered at the school level and with cluster bootstrapped standard errors show similar results. $*, * *, * *$, at 10 percent, 5 percent and 1 percent significance levels respectively. 
Table 8: Heterogeneity in treatment effect non-cognitive outcome

\begin{tabular}{|c|c|c|c|c|}
\hline & \multicolumn{4}{|l|}{ Motivation } \\
\hline & $(1)$ & $(2)$ & (3) & (4) \\
\hline \multirow[t]{2}{*}{ Treatment } & -0.099 & 0.196 & 0.024 & 0.344 \\
\hline & $(0.258)$ & $(0.303)$ & $(0.268)$ & $(0.322)$ \\
\hline \multirow[t]{2}{*}{ Girls } & -0.148 & & & \\
\hline & $(0.274)$ & & & \\
\hline \multirow[t]{2}{*}{ Treatment\#Girls } & 0.429 & & & \\
\hline & $(0.377)$ & & & \\
\hline \multirow[t]{2}{*}{ Pre-higher education track } & & 0.019 & & \\
\hline & & $(0.302)$ & & \\
\hline \multirow[t]{2}{*}{ Treatment\#pre-higher education track } & & -0.265 & & \\
\hline & & $(0.428)$ & & \\
\hline \multirow[t]{2}{*}{ GPA before treatment, above mean } & & & $0.484^{*}$ & \\
\hline & & & $(0.278)$ & \\
\hline \multirow[t]{2}{*}{ Treatment\#GPA before treatment above mean } & & & 0.291 & \\
\hline & & & $(0.408)$ & \\
\hline \multirow[t]{2}{*}{ Motivation above mean } & & & & $1.082 * * *$ \\
\hline & & & & $(0.333)$ \\
\hline \multirow[t]{2}{*}{ Treatment\#Motivation above mean } & & & & -0.605 \\
\hline & & & & $(0.455)$ \\
\hline \multirow[t]{2}{*}{ Constant } & $-7.065^{* * *}$ & $-7.297 * * *$ & -3.477 & $-6.983 * * *$ \\
\hline & $(2.537)$ & $(2.551)$ & $(2.232)$ & $(2.548)$ \\
\hline Robust SEs & yes & yes & yes & yes \\
\hline Clustered SEs & no & no & no & no \\
\hline Cluster bootstrapped SEs & no & no & no & no \\
\hline Observations & 108 & 108 & 108 & 108 \\
\hline R-squared & 0.348 & 0.342 & 0.354 & 0.299 \\
\hline
\end{tabular}

Note: The regressions show coefficients from OLS regressions with interaction variables for female, studytrack, gpa above mean and motivation above mean. We use GPA before treatment, track, gender, parental education level, age, and region of birth as control variables. Robust standard errors are reported between brackets. Models with standard errors clustered at the school level and with cluster bootstrapped standard errors show similar results. OLS regressions with homework and self-confidence as the dependent variable show no significant interaction effects. ${ }^{*}, * * * * *$, at 10 percent, 5 percent and 1 percent significance levels respectively.

\subsection{Conclusion}

The aim of this study is to investigate whether an intervention targeted at underachieving secondary school children's motivation raises their performance, measured by GPA. Since lack of motivation is likely to be at the core of underachievement problems, a challenge for interventions targeted at underachievers is to keep them participating in 
the activities of the intervention. A question is whether those that could benefit the most from the intervention, i.e. those with the lowest motivation and performance, have a higher likelihood of dropping out of the intervention and whether observed effects of the intervention differ between those that have most to gain and the other children. We use a randomized field experiment to investigate these questions.

An important feature of our study is that the experiment was designed in response to a growing concern among teachers at secondary schools about the motivation and school performance of certain groups of children. Both for the successful implementation and usefulness of the results, the participation of schools in experimental research is of primary importance. Not only in the phase of execution of the experiment, but already in the phase where the research question is formulated and the experimental design is made. ${ }^{73}$

The results of our intervention show that continued participation in the treatment is selective. Children who have a lower gpa and children who report a higher motivation before the treatment are more likely to complete the treatment. The effects of GPA and motivation are interesting: higher motivated children remain in the treatment, but also those with lower grades. We observe no significant effect of the treatment on GPA and motivation. This results might be partly explained by the large number of children who drop out of the treatment.

Our results show how difficult it is to reach this particular target group of children with a school intervention. It also indicates the importance of the classroom environment and teacher support. As discussed in Borghans et al. (2016) for children to be motivated to participate in the intervention it is important that schools and teachers support the intervention and facilitate children in participating in the intervention. In this case, even a close cooperation between schools and researchers could not prevent children from dropping out of the experiment.

\footnotetext{
${ }^{73}$ A pilot was executed to optimize both the detection procedure and the intervention. With respect to the content of the intervention, from the pilot we established that our method for child selection was very similar to the teacher evaluation. The pilot contributed to the creation of the tasks that are used in the experiment. Parts of the content as well as the language used in the tasks was adjusted based on the feedback we received.
} 


\section{References}

Algan, Y., E. Beasley, F. Vitaro, and R. Tremblay (2012). The long-term impact of social skills training at school entry: A randomized controlled trial. Sciences Po Working Paper.

Andriessen, I., Phalet, K. \& Lens, W. (2006). Future goal setting, task motivation and learning of minority and non-minority students in Dutch schools. British Journal of Educational Psychology, 76, 827-850. doi:10.1348/000709906X148150

Banerjee, A. V., S. Cole, E. Duflo, and L. Linden (2007). Remedying education: Evidence from two randomized experiments in india. Quarterly Journal of Economics 122 (3), 1235 - 1264.

Ben-Porath, Y. (1967) The production of human capital and the life cycle of earnings. The Journal of Political Economy, Vol.75, No. 4, pp. 352-365.

Bertrand, M. and J. Pan (2013). The trouble with boys: social influences and the gender gap in disruptive behaviour, American Economic Journal: Applied Economics 5(1), 32-64.

Bettinger, E. P. (2012). Paying to learn: the effect of financial incentives on elementary school test scores. The Review of Economics and Statistics 94 (3), 686-698.

Borghans, L., B. Golsteyn, J. Heckman, and J. Humphries (2011). Identification problems in personality psychology. Personality and individual differences. Vol. 51. (3) pp. 315-320.

Borghans, L., Schils, T. and de Wolf, I., (2016), Experimentalism in Dutch education policy. OECD, Governing education in a complex world, Paris: OECD.

Campbell, F., G. Conti, J.J. Heckman, S.H. Moon, R. Pinto, E. Pungello and Y. Pan (2014) "Early Childhood Investments Substantially Boost Adult Health." Science. 343: 1478-1485.

Carneiro, P. and J. Heckman (2003). Human capital policy. NBER Working paper no. 9495.

Corker, K. S., \& Donnellan, M. B. (2012). Setting lower limits high: The role of boundary goals in achievement motivation. Journal of Educational Psychology, 104, 138-149. doi:10.1037/a0026228.

Covey, S. (2002). The 7 habits of highly effective teens. Simon Schuster New York.

Cunha, F. and J.J. Heckman (2007). The technology of skill formation. American Economic Review, 97(2), 3147.

Cunha, F., J. J. Heckman, and S. M. Schennach (2010). Estimating the technology of cognitive and noncognitive skill formation. Econometrica 78 (3), 883-931.

Deci, E. L., \& Ryan, R. M. (2000). The 'what' and 'why' of goal pursuits: Human needs and the selfdetermination of behaviour. Psychological Inquiry, 11, 227-268. doi:10.1207/S15327965PLI1104_01.

Dianda, M. R. (2008). Preventing future high school dropouts: An advocacy and action guide for NEA state and local affiliates. Washington, DC: National Education Association.

Dietz, F., Hofer, M. \& Fries, S. (2007). Individual values, learning routines and academic procrastination. British Journal of Educational Psychology, 77, 893-906. doi:10.1348/000709906X169076

Dignath, C. \& Büttner, G. (2008). Components of fostering self-regulated learning among students: A metaanalysis on intervention studies at primary and secondary school level. Metacognition Learning, 3, 231264. doi:10.1007/s11409-008-9029-x

Driessen, G., J. Doesborgh, G. Ledoux, M. Overmaat, J. Roeleveld, and I. van der Veen (2005). Van basis- naar voortgezet onderwijs. ITS.

Dutch education council (2007). Presteren naar vermogen. Technical report, Dutch education council.

Eisen, M., G. L. Zellman, and D. M. Murray (2003). Evaluating the lions-quest skills for adolescence drug education program: Second-year behavior outcomes. Addictive behaviors 28 (5), 883-897.

Feron, E. and Schils, T. (2015) Doen wat ik kan! Leidt herhaalde zelfreflectie tot verbetering van schoolprestaties? Lessen uit een gerandomiseerd experiment.

Feron, E., T. Schils, and B. ter Weel (2016). "Does the teacher beat the test? The value of teacher's assessment in predicting child ability", De Economist, Vol. 164, No. 4, pp. 391-418.

Frijters, P., D. W. Johnston and M.A. Shields (2014) "Does Childhood Predict Adult Life Satisfaction? Evidence from British Cohort Surveys." The Economic Journal, 124: F688-F719.

Heckman, J. J. (2000). Policies to foster human capital. Research in Economics 54, 3-56. 
Heckman, J. J. and Y. Rubinstein (2001). The importance of noncognitive skills: Lessons from the ged testing program. The American Economic Review 91 (2), 145-149.

Heckman, J. J., J. Stixrud, and S. Urzua (2006). The effects of cognitive and noncognitive abilities on labor market outcomes and social behavior. Journal of Labor Economics 24 (3), $411-482$.

Heckman, J. J. and D. V. Masterov (2007). The productivity argument for investing in young children. Applied Economic Perspectives and Policy 29 (3), 446-493.

Heckman, J.J., R. Pinto and P.A. Savelyev. 2013. "Understanding the Mechanisms through which an Influential Early Childhood Program Boosted Adult Outcomes." American Economic Review. 103(6): 2052-2086.

Heckman, J.J., J. E. Humphries and T. Kautz. 2014. The Myth of Achievement Tests: The GED and the Role of Character in American Life. Chicago: University of Chicago Press.

Heller, S., H. A. Pollack, R. Ander, and J. Ludwig (2013). Preventing youth violence and dropout: A randomized field experiment. Technical report, National Bureau of Economic Research.

Hodis, F., Meyer, L. H., McClure, J., Weir, K. F., \& Walkey, F. H. (2011). A longitudinal investigation of secondary school achievement using Growth Mixture Modeling. Journal of Educational Psychology, 103, 312323. doi:10.1037/a0022547.

Holmlund, H. and O. Silva (2009). Targeting non-cognitive skills to improve cognitive outcomes: Evidence from a remedial education intervention. IZA Discussion paper no. 4476, Institute of Labor Studies Bonn.

Kautz, T., J. J. Heckman, R. Diris, B. Ter Weel and L. Borghans. 2014. Fostering and Measuring Skills: Improving Cognitive and Non-cognitive Skills to Promote Lifetime Success. NBER Working paper no.20749. Cambridge: NBER.

Kremer, M., E. Miguel, and R. Thornton (2009). Incentives to learn. The Review of Economics and Statistics 91 (3), 437-456.

Laird, M., and Roden, J. (1991). Supplemental final report: Additional technical analysis of data on Quest's Skills for Adolescence program in Detroit schools. Newark, OH: Quest International.

Laird, M., and Syropoulos, M. (1995). An evaluation of Lions-Quest's Skills for Adolescence.

Laird (2009). An evaluation report of child attitude and behaviour changes to the learn and serve America school-based program. Technical report, The Tennessee department of education and volunteer Tennessee.

Lan, W. and R. Lanthier (2003). Changes in children' academic performance and perceptions of school and self before dropping out of schools. Journal of Education for Children Placed at Risk 8 (3), 309-332.

Lavy, V. and A. Schlosser (2005). Targeted remedial education for underperforming teenagers: Costs and benefits. Journal of Labor Economics 23 (4), $839-874$.

Lee, J. Q., Mclnerney, D. M., Liem, G. A., \& Ortiga, Y. P. (2010). The relationship between future goals and achievement goal orientations: An intrinsic-extrinsic motivation perspective. Contemporary Educational Psychology, 35, 264-279.

Lens, W. and M. Decruyenaere (1991), Motivation and demotivation in secondary education: child characteristics, Learning and Instruction, Vol. 1, pp.145-159.

Lionsquest (2002). Skills for action. www.lions-quest.org/skillsaction.php .

Lundborg, P. L., P. Nystedt and D. Rooth (2014) "Height and Earnings: The Role of Cognitive and Noncognitive Skills." Journal of Human. Resources. 49(1): 141-166.

Machin, S., S. McNally, and C. Meghir (2004). Improving pupil performance in english secondary schools: excellence in cities. Journal of the European Economic Association 2 (2-3), 396-405.

McClure, J., Meyer, L. H., Garisch, J., Fischer, R., Weir, K. F., \& Walkey, F. H. (2011). Students' attributions for their best and worst marks: Do they relate to achievement? Contemporary Educational Psychology, 36, 71-81. doi:10.1016/j.cedpsych.2010.11.001.

Mercer, C. and P. Pullen (2009). Children with Learning Disabilities. Upper Sadle River: Merrill-Prentice Hall.

Mulder, L., J. Roeleveld, and H. Vierke (2007). Onderbenutting van capaciteiten in basis-en voortgezet onderwijs. Number 20060423/868. Onderwijsraad.

Paunesku, D., G.M. Walton, C. Romero, E.N. Smith, D.S. Yeager and C.S. Dweck (2015), Mind-set interventions are a scalable treatment for academic underachievement, Psychological Science, Vol(April), pp.1-10. 
Prevoo T. (2013), 'Stimulating effective habits in teenagers', chapter 5 in The relevance, variability, and malleability of personality traits, $\mathrm{PhD}$. Thesis Maastricht University School of Business and Economics.

Sligte, H., J. Bulterman-Bos, and M. Huizinga (2009). Maatwerk voor latente talenten. Uitblinken op alle niveaus. Amsterdam: SCO-Kohnstamminstituut .

Smith, E. (2003), Understanding underachievement: an investigation into the differential attainment of secondary school pupils, British Journal of Sociology and Education, Vol. 24 (5), pp. 575-586.

Uno, M., J.T. Mortimer, M. Kim and M. Vuolo (2010), "Holding on" or "coming to terms" with educational underachievement: a longitudinal study of ambition and attainment, New Directions for Child and Adolescent Development, No. 130, pp. 41-56.

van Rooij, E., J. Pass, and A. van den Broek (2010). Geruisloos uit het onderwijs. Het verschil tussen klassieke en geruisloze risicofactoren van voortijdig schoolverlaten. Nijmegen: ResearchNed. 


\section{Appendix}

This appendix presents supporting material. In Section A we discuss the data description which includes the definition for underachievement, our outcome measures and an explanation of the control variables we use in the analyses. In section B we describe the standardization procedure we use for the analyses. In section C we present our power analyses and show how many children we need to be able to find certain effect sizes. In section $D$ we present the seven assignments as well as the questionnaire used for this study. Finally, in section $E$ we present the results from the pilot phase. 


\section{A. Data description}

Many variables that are used in this study stem from the Onderwijs Monitor Limburg $(\mathrm{OML})$ which is a cooperative project between Maastricht University and (primary and secondary) schools, school boards and government bodies in Limburg, a region in the south of the Netherlands. The project aims to collect and analyse information about the educational development of children in order to foster educational improvement. The collected information is a combination of administrative child data from schools, including test results, and survey data from questionnaires among children and their parents at these schools. In secondary education, which is the focus of this study, about 90 percent of the schools in the region participate in this project. The schools which do not participate are special education schools, schools that have a philosophy not to test children, and schools which were unable to plan the survey activities. We only select children that are in the pre-vocational education (vmbo) and pre-higher vocational education (havo) track. The total population of children in these tracks in the region is 4,814 children. The variables that are used for our study are described in more detail below.

\section{Defining underachievement}

To define underachievement we first look at the children's expected performance. For this, we use a high stakes standardized test in $6^{\text {th }}$ grade. In this final year of primary education, children take a three-day standardized achievement test (Cito test), accompanied with a lot of media attention, which is very important to determine in which track they are selected for secondary education. Therefore, this test is high-stakes for the children. About 85 percent of the schools use this test. The test is developed and assessed by Cito, a testing company which is independent from the schools. The test contains 290 multiple choice questions testing the children on three main domains: Dutch language, mathematics, and world orientation (e.g. geography, biology and history). The score ranges from 501 to 550. This test score is available for 4,231 children, which is 87.9 percent of all children in the two tracks that we consider for our study.

For some of the children for whom we do not have this test score, we have an alternative. In 9th grade children completed an IQ-test as part of the research project in the region. For 501 children this is used as an alternative measure to determine whether they are underachievers or not. This is not an high stakes test as the test in 6th grade, but it can be shown that the IQ-test should deliver a proxy of a child's potential performance. ${ }^{74}$ Moreover, we validate the selection of children among their teachers and mentors. In this way we screen our selection to either deselect 'wrongly accused' underachievers or add underachievers that were not picked up by our procedure.

\footnotetext{
${ }^{74}$ For children for whom we have both cito and iq, we find that for about 67 percent of the children there is about one standard deviation of the mean difference between the two percentile distributions.
} 
Second, we look at children's current performance. For this we use a test that children take in $9^{\text {th }}$ grade. Children completed questions on both math and language as part of the research project. The score ranges from 0 to 1 . Test scores are available for 4,017 children. For all these children either the $6^{\text {th }}$ grade test or the IQ-test is available to determine their expected performance.

Both scores on expected and current performance are divided in percentiles, by school and by study track, and the difference between current and expected performance is calculated. A negative difference implies that children performed better in $6^{\text {th }}$ grade than in $9^{\text {th }}$ grade. As a cut-off, we take the 25 percent of children per class and per school that underperform the most. This is the target population of underachievers, which consists of 1,066 children.

\section{Outcome measures}

To determine GPA, we take all courses that children have in the period before and after the intervention. Some courses only run for half a year and we left these outside the calculation of GPA. For the pre-vocational education track (vmbo) we include Dutch, English, French, German, math, science, biology, economics, geography, history and civics. For the pre-higher vocational education track (havo) we include Dutch, English, French, German, math, physics, chemistry, biology, economics, geography and history. Not all children take all courses, but the GPA is calculated over the courses they take. Table A1 shows the mean grades of all courses separately and the GPA. GPA before intervention available for 337 children (153 control and 184 treatment) and after the intervention for 307 children (134 control and 173 treatment).

Table A1: mean grades before the intervention

\begin{tabular}{llll}
\hline Course & Number of observations & Mean & Sd \\
\hline Dutch & 337 & 6.32 & 0.64 \\
English & 337 & 6.42 & 0.91 \\
French & 202 & 5.95 & 1.03 \\
German & 314 & 6.26 & 0.90 \\
Math & 329 & 6.11 & 1.02 \\
Science 1 & 138 & 6.08 & 0.86 \\
Science 2 & 87 & 6.12 & 0.86 \\
Physics & 149 & 5.96 & 0.97 \\
Chemistry & 150 & 6.27 & 0.85 \\
Biology & 196 & 6.25 & 0.62 \\
Economics & 312 & 6.24 & 0.82 \\
Geography & 243 & 6.37 & 0.63 \\
History & 287 & 6.15 & 0.91 \\
Civics & 76 & 6.72 & 0.69 \\
Overall GPA & 337 & 6.23 & 0.54 \\
\hline
\end{tabular}

Grades are only available for schools that participate in the study. See details on the selection of schools in the text. 
Next to the cognitive outcomes, we look at non-cognitive outcomes. A first noncognitive outcome that we include is children's motivation. Children had to indicate whether they agree or disagree with eight statements about their motivation to go to school and their attitude towards learning in general. Each statement was measured on a 5-point scale ranging from "fully disagree" to "fully agree". Looking at the inter-item correlation, two items are removed as they seemed not to fit to the others. From the remaining six statements, the overall factor score is calculated, with negative items being reversed. Table A2 shows the scoring coefficients of the various statements.

For the analyses we standardized the variables to be able to compare before and after outcomes. In our standardization approach we take three aspects of our study into consideration: (1) we select only underachieving children for our study, (2) some children are treated while others are not, and (3) there might be selective non-compliance with the treatment. We standardize the outcome before treatment using the full population of children and anchor the outcome after treatment to the first outcome using only the scores of the children in the control group that do not drop out of the study. ${ }^{75}$ The motivation score before intervention is available for 291 children, or 85 percent of the population in our study ( 87 percent of the control group and 84 percent of the treatment group), and after the intervention for 122 children, or 36 percent of the population in our study (28 percent of the control group and 43 percent in the treatment group). The questionnaire after the intervention was taken at the very end, so these non-cognitive variables are only available for those children that completed the full treatment.

Table A2: statements and scoring coefficients on factor score for motivation

\begin{tabular}{ll}
\hline Motivation & \\
\hline -As soon as I can, I quit school (-) & 0.201 \\
-I am motivated to continue learning & 0.235 \\
-I am going to learn interesting things & 0.181 \\
-I am continuing to learn because I like it & 0.236 \\
-I am continuing to learn for a long time & 0.276 \\
-As soon as I have a job, I quit school (-) & 0.139 \\
\hline
\end{tabular}

Negative items have been reversed.

A second non-cognitive outcome that we include is the average hours that children spent on homework. We include both hours spent on homework at home and at school during hours that children do not have courses. Before the intervention, children spent on average 5.8 hours on homework. We have information on this variable for 269 children before intervention, or 80 percent of the population in our study (83 percent of the control group and 77 percent of the treatment group) and for 123 children after the

\footnotetext{
${ }^{75}$ Appendix C provides a detailed description of our standardization procedure.
} 
intervention, or 36 percent of the population in our study (29 percent of the control group and 38 percent in the treatment group).

The final non-cognitive outcome we consider is children's self-confidence. Children were asked to rate themselves on a range of skills, including social skills like socializing with others, instrumental skills like taking the lead, study skills like mental arithmetic and computer skills. Table A3 provides an overview of the skills. The skills were rated on a 1-10 scale. We standardized the outcome variable using the standardization approach mentioned before. We have information on this variable for 287 children before intervention, or 85 percent of the population in our study (88 percent of the control group and 83 percent of the treatment group) and for 120 children after intervention, or 36 percent of the population in our study $(27$ percent of the control group and 43 percent in the treatment group).

Table A3: statements used for self-confidence

\begin{tabular}{ll}
\hline Giving my own opinion & $\begin{array}{l}\text { Searching something on the computer } \\
\text { Getting what I want }\end{array}$ \\
Chatting on the computer \\
Taking the lead & Chatting on a mobile device \\
Debating & Using Microsoft Word \\
Comforting somebody & Using Microsoft Excel \\
Listening to somebody with problems & Browsing the internet for fun \\
Socializing with other children & Playing computer games \\
Choosing nice clothes and looking good & \\
& \\
Mental arithmetic & \\
Writing without mistakes & \\
Drawing, painting or making music & \\
Following the news & \\
Concentrating &
\end{tabular}

\section{Control variables}

We include a small range of control variables in our analysis. Table 1 (in the main text) shows these variables and their means. Demographic information includes children's age, gender, parental education level and region of birth. Age is measured in years. For parental education level we take the level of education of the highest educated parent and distinguish between three levels: (1) primary or lower secondary education; (2) upper secondary education or lower tertiary education; and (3) higher tertiary education or academic education. Region of birth distinguishes between: (1) the Netherlands (2) outside of the Netherlands (3) place of birth unknown. 


\section{B. Details on the standardization procedure used in the analysis}

Some of the outcome measures that we use have no natural scale. To assess the size of the effect we choose to standardize these variables. Three aspects of our study complicate this standardization approach: (1) we select underachieving children, (2) some children are treated while others are not, and (3) there might be selective noncompliance with the treatment. We discuss these issues and our strategy to deal with them below in more detail.

For our study, we only select underachieving children. After the intervention, we only have the outcome variable for this selection of children. This is only a part of the distribution of all children and the variance in this subset is lower than the overall variance of the full population (see figure C1). This implies that when we standardize the variables based on this selection only, effect sizes will be overestimated. Yet, we are more interested in the size of the possible effects in relation to the full population of children. Therefore, we first standardize the variable with mean zero and standard deviation one for the full population. We then take the mean and standard deviation of the standardized variable but only for the target population of underachieving children. We use this to 'correct' or anchor the outcome after the intervention.

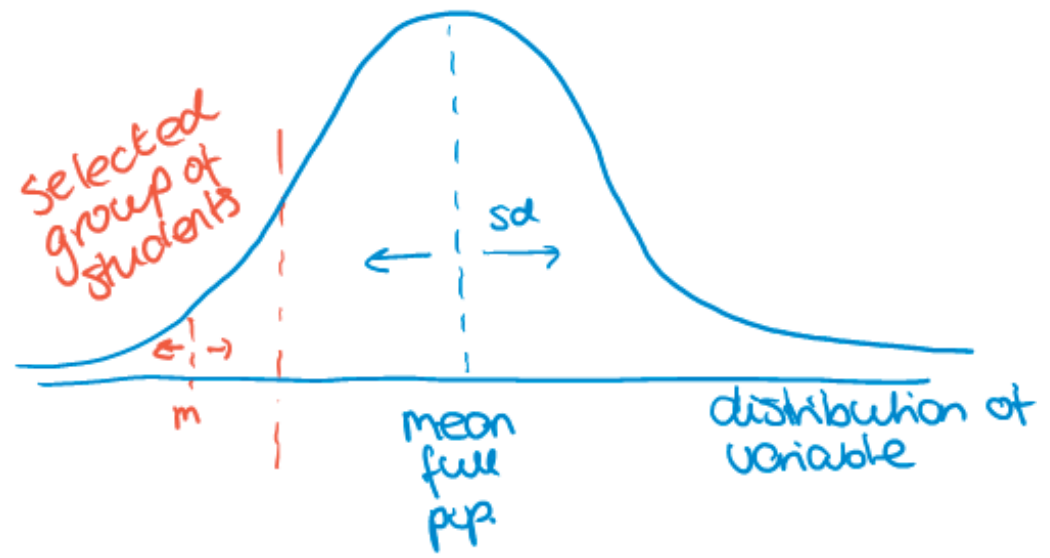

Figure C1: Selection of underachieving children

From the selected population for this study, about half of them are randomly assigned to the treatment group and others are placed in the control group. It is expected that the treatment increases the scores on the variables for the treated population, in relation to those of the control group. Figure C2 shows the expected distribution of the outcome variable after treatment: the outcome of the treatment group has improved and the distribution is next to the one of the control group. This is also shown in the scatter of panel b. The scores of the treated population are, for every given score before the treatment, above that of the control group. 


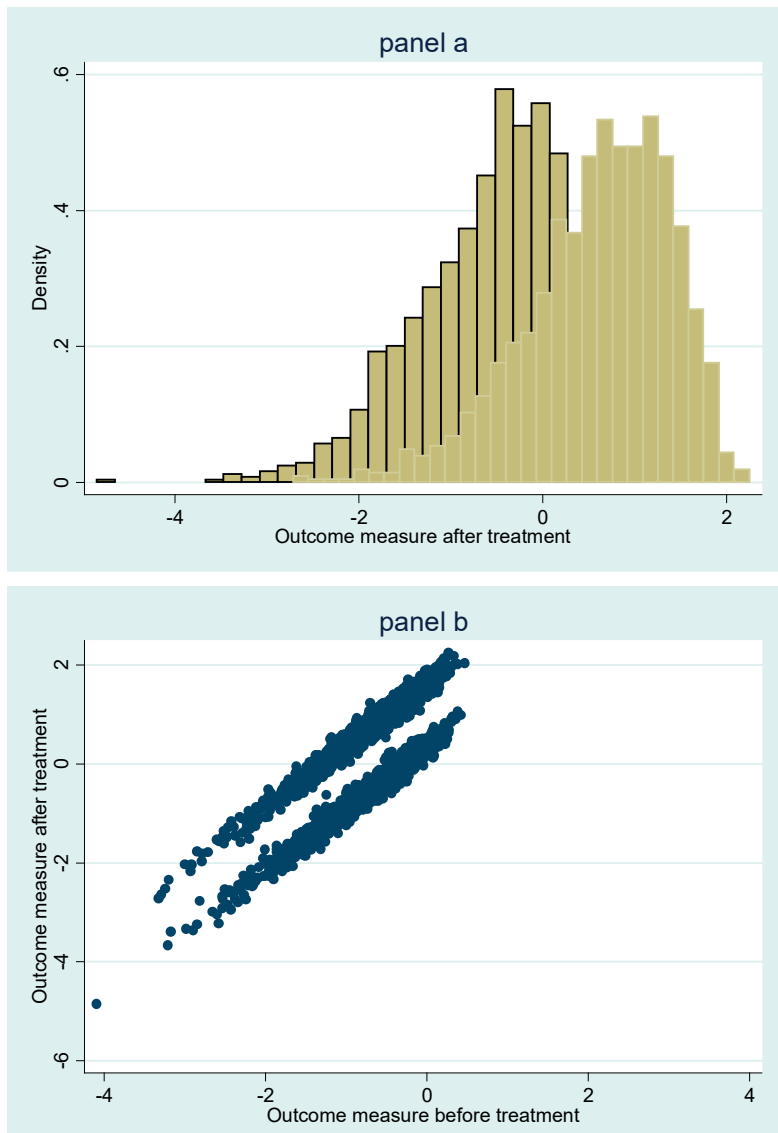

Figure C2: Outcome measure before and after treatment, standardized on full population

The populations before and after treatment are no longer comparable due to the improvement of the treated population. Standardizing on the full population, i.e. ignoring this, could lead to a biased estimate of the treatment effect, or an underestimation in this example.

A final issue that diffuses the comparison of variables between the population before and after treatment is that some of the children do not comply with the intervention and drop out of the study. If the drop out was random over both the control and treatment group, this would be no additional issue, yet if the drop out is selective it creates a similar problem as described above and could lead to biased estimates of the treatment effect. Consequently, we only use the complying children in the control group as the basis of the standardization of variables in both outcomes. 


\section{Power analysis}

To select the number of children for the study, power analysis has been applied. Children's GPA is the main outcome variable and is defined as follows:

$$
G P A=(f * T)+\left(b * e_{1}\right)+\left(c * e_{2}\right)+\left(d * e_{3}\right)+a
$$

Where:

- $T$ is whether the child is in the treatment group and $f$ is the expected effect of the treatment. Based on previous studies discussed earlier, it could be expected that the intervention leads to an increase of 0.4 point in the child's GPA. In the power analysis we also included an increase of 0.3 and 0.5 points in GPA.

- $e_{1}$ is the measurement error due to the differences in grades between children not caused by the treatment. To get a proxy for this, we used a sample of children from a secondary school in the Netherlands, which was used for another study (Borghans et al., 2011). We selected children from the pre-higher education (havo) track since this track is also a part of our study and we are left with 93 children. The standard deviation of mean GPA in this sample is 0.48 .

- $e_{2}$ is the measurement error due to differences in grades between tests. To get a proxy for this, we used the same sample as described for $e_{1}$. Using a panel regression with a constant only, the measurement error due to differences in grades between tests is 0.29 .

- $\quad e 3$ is the measurement error due to differences in grades between schools. To get a proxy for this, we looked at the difference in math test scores between schools in a research project in the region. We find that the between-school variance in GPA is about 0.19 .

- $\quad a$ is a constant. To get a proxy for this, we used the same sample as described for $e_{1}$. The average GPA is 6.11.

In the definition of underachievement, we take the 25 percent of children per class and per school that underperform the most, i.e. that have the largest difference between test results in $6^{\text {th }}$ and $9^{\text {th }}$ grade. This is about 20 children per school. We include this as an assumption in our power analysis. In addition, it can be expected that not all children complete the intervention. Especially since the target group is underachieving and less motivated children, non-compliance can become an issue. To see how this affects the size of the sample to start with, we include the probability that only half of the children complies with the assignment to treatment.

Using this information, we looked at three types of definitions of GPA in our power analysis:

1. fixed-effect panel regression with assignment to treatment as the treatment variable (intention-to-treat)

2. fixed-effect panel regression with actual treatment as an instrument for the treatment variable (treatment effect on the treated); 
3. linear regression with assignment to treatment as the treatment variable and GPA before treatment included as a lagged variable.

Each regression is estimated 500 times to calculate the power. Table B2 shows the results. The number of respondents varies from 100 to 500. The program OnderwijsBewijs, of which this study received a subsidy, demanded a minimum level of power of 75 percent. From the table we can conclude that to find an effect of 0.4 points increase in GPA, a sample size of 200 children is sufficient. To find a slightly more modest effect of 0.3 points increase in GPA, a sample size of 300 children is needed, which is about 15 schools.

Table B2. Results from power analysis to calculate number of children in the study ${ }^{1}$

\begin{tabular}{lllll}
\hline Expected increase in GPA Number of children & Model [1] & Model [2] & Model [3] \\
\hline 100 & 0.38 & 0.40 & 0.51 \\
200 & 0.68 & 0.70 & 0.70 \\
300 & 0.90 & 0.91 & 0.87 \\
400 & 0.95 & 0.96 & 0.93 \\
0.4 points & 0.98 & 0.99 & 0.98 \\
& 100 & 0.64 & 0.70 & 0.72 \\
& 0.89 & 0.91 & 0.88 \\
& 300 & 0.98 & 0.98 & 0.97 \\
0.5 points & 1.00 & 1.00 & 1.00 \\
& 400 & 1.00 & 1.00 & 1.00 \\
& 500 & 0.79 & 0.83 & 0.85 \\
& 100 & 0.99 & 0.99 & 0.97 \\
& 1.00 & 1.00 & 1.00 & 0.99 \\
& 300 & 1.00 & 1.00 & 1.00 \\
& 400 & & 1.00 \\
\hline
\end{tabular}

${ }^{1}$ Model 1: xtreg gpa treatment i.jaar, fe i(id)

Model 2: xtivreg gpa (realtreatment=treatment) i.jaar, fe i(id)

Model 3: reg gpa treatment gpa1 if jaar==2, cluster(school) 


\section{Assignments (in Dutch)}

\section{Assignment 1:}

Beste leerling,

Zoals je wellicht hebt gehoord is er momenteel veel te doen rondom het voortgezet onderwijs in de politiek. De huidige discussie rondom het onderwijs is deels gericht op de prestatieverhoging van leerlingen. Om meer duidelijkheid te scheppen in de discussie over hoe prestaties van leerlingen verhoogd kunnen worden, worden er door verschillende instanties onderzoeken op dit gebied uitgevoerd. De Universiteit Maastricht is een van deze instanties die onderzoek uitvoert naar de prestaties van leerlingen. Het onderzoek waarvoor jullie medewerking wordt gevraagd probeert te achterhalen of de prestaties van leerlingen in het voortgezet onderwijs kunnen worden verhoogd door leerlingen specifieke opdrachten te laten maken.

Wij waarderen je deelname aan dit onderzoek.

Met vriendelijke groet,

Eva Feron en Trudie Schils 
Opgave 1: Het bijhouden van een studie dagboek

Ben jij je bewust van de tijd die je besteedt aan het maken van huiswerk en het leren voor de verschillende vakken die je volgt? Uit een onderzoek in 2010 van Universiteit Maastricht blijkt dat vmbo-tl leerlingen gemiddeld 1,2 uur per dag huiswerk maken en havo leerlingen gemiddeld 1,7 uur. Dit naast de tijd die ze op school krijgen om aan hun huiswerk te werken. Planning van je schoolwerk is een belangrijk onderdeel van het op tijd afhebben van je huiswerk en helpt om de leerstof beter te begrijpen. Ook helpt het je als je leert voor een toets of proefwerk omdat je al meer van de leerstof hebt opgenomen en je daardoor minder snel in tijdnood komt.

Om je bewust te worden van je studieplanning is het de bedoeling dat je in ieder geval de komende maanden (vanaf nu tot en met april), voor de periode dat je participeert aan dit onderzoek, een dagboek bijhoudt van de tijd die je besteedt aan je studie. In dit dagboek beschrijf je allereerst de tijd die je nodig denkt te hebben om aan al je verschillende huiswerk- en studieopdrachten te voldoen per onderdeel/vak per dag. De geplande tijdsbesteding per onderdeel kun je samenstellen in overleg met je leraar/mentor.

Nadat je de planning hebt ingevuld, begin je met het bijhouden van de tijd die je daadwerkelijk besteedt aan het maken van je huiswerk en het leren. Het is de bedoeling dat je iedere dag in een studiedagboek schrijft hoeveel tijd je werkelijk besteed hebt aan het maken van huiswerk en het leren en of je het idee hebt dat de tijd die je eraan gespendeerd hebt voldoende is voor de prestatie die je op school voor je huiswerk/toets moet leveren.

Aan het einde van iedere maand geef je aan hoe goed je je aan je eigen studieplanning gehouden hebt en of je tevreden bent met het resultaat dat je behaald hebt. Deze informatie is vertrouwelijk en wordt niet met je leraar/mentor besproken. Je wordt hier dus ook niet op beoordeeld.

Klik dadelijk op verder en geef dan aan hoe jij je tijd het beste kan besteden. 


\section{Assignment 2:}

Opgave 2: Ideaal zelfbeeld

Stel je voor dat je over een aantal jaar je diploma van de middelbare school behaalt. Je mentor/decaan houdt op je diploma uitreiking een korte toespraak over jou. Hij/zij heeft deze toespraak geschreven op basis van dingen die mensen in jouw omgeving over jou gezegd hebben. Dit zijn bijvoorbeeld je vrienden/vriendinnen, je familie, je leraren of mensen die jou kennen van de sportclub of van de muziekschool.

Wat wil jij dat er in de toespraak komt te staan?

Denk hierbij niet alleen aan je schoolprestaties maar vooral aan je gedrag tegenover andere mensen, je karakter, je persoonlijkheid, je sociale vaardigheden en je ambities (wat je graag zou willen bereiken in je leven).

Het gaat er bij deze opgave dus niet om hoe je in werkelijkheid overkomt bij mensen in je omgeving maar over hoe jij graag wilt dat mensen om je heen jou zien en zich jou herinneren.

Klik dadelijk op verder en schrijf dan deze korte toespraak zoals jij hem het liefst zou horen!

Als je hiermee klaar bent beantwoord je nog twee andere vragen over dit onderwerp. Als laatste krijg je nog een paar vragen over de omgeving waarin je deze opgave maakt en nog een paar vragen over de vorige opgave.

Beschrijf je ideale toespraak.

In hoeverre denk je dat je nu al aan dit beeld voldoet?

Geef dit aan op onderstaande schaal.

$\begin{array}{llllllllll}1 & 2 & 3 & 4 & 5 & 6 & 7 & 8 & 9 & 10\end{array}$

Leg uit waarom je denkt dat je dit cijfer scoort. 
Welke dingen (waaraan je wilt dat andere mensen zich jou herinneren) wil je nog verder ontwikkelen? Leg ook uit waarom je dit wilt.

Standaardvragen ${ }^{76}$

Kruis het antwoord aan dat van toepassing is.

Wie heeft je begeleid bij het maken van de opgave?

- Leraar/lerares

- Mentor

Hoe heb je deze opgave gemaakt?

- Klassikaal (tegelijkertijd met andere leerlingen)

- Individueel (zonder andere leerlingen erbij)

Was het duidelijk wat je bij deze opgave moest doen?

- Ja, helemaal ++

$0+$

- Neutraal 0

○ Nee, helemaal niet -

Reflectie eerdere opgave

Kruis het antwoord aan dat van toepassing is.

Eerder heb je een opgave over een studie dagboek gemaakt. Hierin heb je aangegeven hoe je je studie en andere bezigheden wilt plannen.

1. Heb je je de afgelopen maand aan je studie dagboek kunnen houden?
○ Ja, helemaal ++
○+
- Neutraal 0
○ -
○ Nee, helemaal niet -

Als je bij bovenstaande vraag een van de laatste 4 antwoordmogelijkheden hebt gekozen ga dan verder naar vraag 2 . Als je de eerste antwoordmogelijkheid hebt gekozen ga dan verder met vraag 3 .

\footnotetext{
${ }^{76}$ Deze standaardvragen en reflectievragen op de eerdere opgave worden in elke volgende opdracht herhaald.
} 
2. Leg uit waarom je je de afgelopen maand niet altijd aan je studie dagboek hebt gehouden?

3. Heb je door het bijhouden van het studie dagboek het idee dat je de planning van je schoolwerk beter in de hand hebt?
○ Ja, helemaal mee eens ++
$0+$
- Neutraal 0
$\circ-$
- Nee, helemaal niet mee eens --

4. Heb je meer vertrouwen in je schoolwerk door het bijhouden van je studie dagboek? ○ Ja, helemaal mee eens ++

$0+$

o Neutraal 0

$0-$

o Nee, helemaal niet mee eens -

5. Ben je door het bijhouden van je studie dagboek minder in tijdnood gekomen met je huiswerk of het leren voor een toets?
○ Ja, helemaal mee eens ++
$0+$
- Neutraal 0
○ -
○ Nee, helemaal niet mee eens -

6. Heb je de opgave over het studie dagboek afgelopen maand met iemand besproken?
○ Ja
○ Nee

Als je vraag 6 met "Ja" hebt beantwoord ga dan verder naar vraag 7 .

7. Met wie heb je de opgave over je eigen studie dagboek besproken?
- Moeder
- Vader
- Broer/zus 
Chapter 6

- Vrienden/vriendinnen

o Anderen

Bedankt voor het maken van de opgave! 


\section{Assignment 3:}

Opgave 3: Zelfvertrouwen

Het verhogen van je zelfvertrouwen kan ervoor zorgen dat je beter gaat presteren op school doordat je meer overtuigd bent van je eigen kunnen en je lekkerder in je vel zit.

Bij deze opdracht is het belangrijk dat je dat wat je weet over zelfvertrouwen toepast en ontwikkelt door middel van bewustwording en zelfreflectie.

In deze opdracht ga je kijken naar zelfvertrouwen.

Klik dadelijk op verder en beantwoordt dan de vragen over zelfvertrouwen.

Als laatste krijg je nog een paar vragen over de omgeving waarin je deze opgave maakt en nog een paar vragen over de vorige opgaven.

Waar denk je aan bij zelfvertrouwen? Schrijf minimaal 3 woorden op die bij je opkomen.

Ken je mensen van wie je denkt dat ze veel zelfvertrouwen hebben? (Dit kan iedereen zijn, beroemde mensen en mensen die jij zelf kent)

Beschrijf minimaal een persoon.

Waarom denk je dat deze mensen veel zelfvertrouwen hebben? (denk dan aan iemand zijn/haar gedrag, eigenschappen en kenmerken).

Schrijf minimaal 3 dingen op.

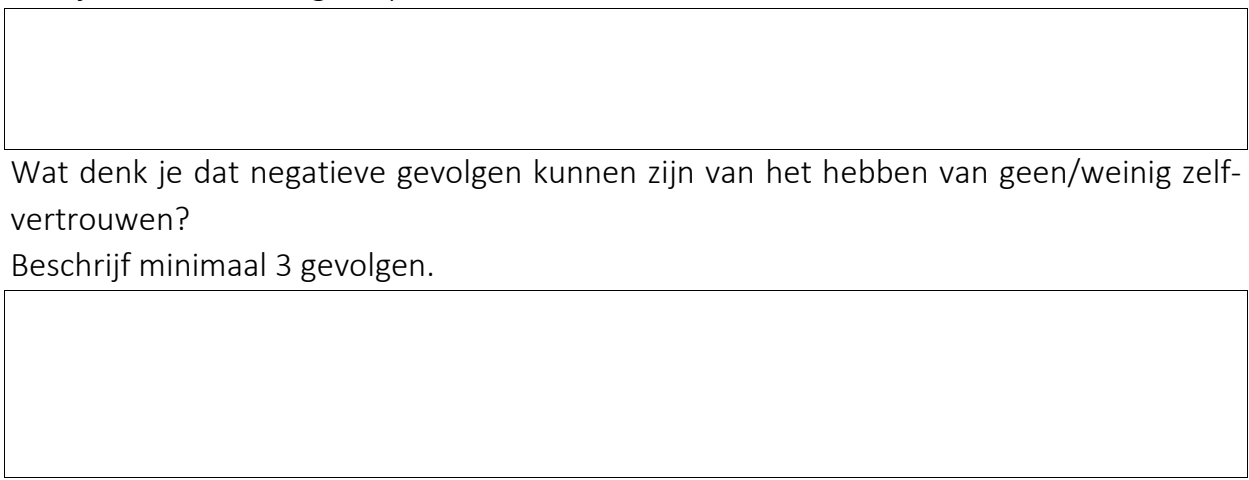


Wat denk je dat positieve gevolgen kunnen zijn van het hebben van zelfvertrouwen? Beschrijf minimaal 3 gevolgen.

Geef op de schaal 1-10 aan welk cijfer jij geeft aan je zelfvertrouwen.

$\begin{array}{llllllllll}1 & 2 & 3 & 4 & 5 & 6 & 7 & 8 & 9 & 10\end{array}$

Leg uit waarom je jezelf dit cijfer geeft voor je zelfvertrouwen.

Zou je je zelfvertrouwen verder willen ontwikkelen? Leg ook uit waarom.

Hoe denk je dat je je zelfvertrouwen verder kunt ontwikkelen? 


\section{Assignment 4:}

Opgave 4: Talentontwikkeling

Door je best te doen op school en een opleiding af te ronden heb je meer kans op een betaalde baan en is de kans op werkloosheid kleiner. Ook is de kans dat je in aanraking komt met criminaliteit in vergelijking met lager opgeleiden kleiner. Minder voor de hand liggend is misschien dat er ook een positieve relatie is tussen je opleidingsniveau en je gezondheid: als je een hogere opleiding hebt, weet je beter hoe je een goede gezondheid kunt houden, kun je ook meer gezondheidszorg betalen en wordt je ouder.

ledereen heeft zijn eigen talenten en vaardigheden ook als het gaat om schoolprestaties. Om het beste uit jezelf te halen is het verstandig om de dingen waar je goed in bent en die je leuk vindt om te doen verder te ontwikkelen. Dingen doen die je niet leuk vindt, houd je niet lang vol, maar toch kan het soms handig zijn ze even te doen. Misschien heb je soms geen zin om te leren voor een toets of om je huiswerk te maken maar kijk je liever naar een spannende film. Op het moment dat je deze keuze maakt is het verstandig om rekening te houden met je prioriteiten, de dingen die het belangrijkst voor je zijn, niet alleen voor vandaag maar ook voor je toekomst.

In deze opdracht ga je kijken naar welke talenten en vaardigheden voor jou belangrijk zijn om je doel te verwezenlijken.

Klik dadelijk op verder en beantwoordt dan de vragen over talentontwikkeling.

Als laatste krijg je nog een paar vragen over de omgeving waarin je deze opgave maakt en nog een paar vragen over de vorige opgaven.

Hieronder staat een lijst met vaardigheden. Lees deze vaardigheden door en ga dan verder met de volgende vraag.

\section{Lijst met vaardigheden:}

Goed met getallen

Goed met woorden

Creatief

Atletisch

Dingen voor elkaar krijgen

Behoeftes aanvoelen

Technisch

Artistiek

Luisteren

Discussiëren

Zelfstandig werken

Dansen

Beslissingen nemen 


\section{Chapter 6}

Dingen bouwen

Muziek

Anderen accepteren

Goed in weetjes

Voorspellen wat er zal gebeuren

Humor

Spreken

Dingen onthouden

Schrijven

Zingen

Samenwerken

Wat zijn de belangrijkste talenten/vaardigheden die jij denkt nodig te hebben in een succesvolle carrière? Leg ook uit waarom.

Beschrijf minimaal 3 talenten/vaardigheden.

Je mag natuurlijk ook talenten/vaardigheden opschrijven die hierboven niet staan vermeld.

In welke van deze talenten/vaardigheden ben jij goed? Leg ook uit waarom.

Beschrijf minimaal een talent/vaardigheid.

Je mag ook talenten/vaardigheden opschrijven die hierboven niet staan vermeld.

Welke talenten/vaardigheden bewonder je in andere mensen? Leg ook uit waarom. Beschrijf minimaal een talent/vaardigheid. 
Welke talenten/vaardigheden wil je graag verder ontwikkelen? Leg ook uit waarom. Beschrijf minimaal een talent/vaardigheid.

In de vorige vraag heb je beschreven welke talenten/vaardigheden je graag verder wilt ontwikkelen. Hoe denk je dat je deze talenten/vaardigheden verder kunt ontwikkelen? (Denk hierbij aan hoe je dit kan oefenen of hoe andere mensen goed zijn geworden in deze talenten/vaardigheden) 


\section{Chapter 6}

\section{Assignment 5:}

\section{Opgave 5: Samenwerken}

Je zult waarschijnlijk al in veel situaties met andere mensen hebben samengewerkt. Met andere leerlingen op school om een project te maken, met mensen van je sportclub om samen een wedstrijd te spelen maar ook met je ouders en vrienden. In de toekomst zal je nog vaak te maken krijgen met situaties waarin je met andere mensen moet samenwerken. Als je effectief met mensen kan samenwerken ben je in staat om samen naar een betere oplossing te komen, elkaar te waarderen en van elkaar te leren.

In deze opdracht ga je kijken naar het belang van samenwerken en hoe jij je hierin nog zou kunnen ontwikkelen.

Klik dadelijk op verder en beantwoordt dan de vragen over samenwerken.

Als laatste krijg je nog een paar vragen over de omgeving waarin je deze opgave maakt en nog een paar vragen over de vorige opgaven.

Kan je redenen bedenken waarom samenwerken belangrijk is? Beschrijf minimaal drie redenen.

Wat moet je doen om goed met anderen te kunnen samenwerken? Beschrijf minimaal drie dingen.

Welke dingen kunnen ervoor zorgen dat mensen niet goed samenwerken? Beschrijf minimaal drie dingen. 
Hoe denk je dat je deze dingen die een goede samenwerking moeilijk maken kunt oplossen of voorkomen? Beschrijf minimaal een manier waarop je dit kunt doen.

In welke dingen die een positieve invloed hebben op samenwerken ben je goed? Beschrijf minimaal een ding waar jij goed in bent.

In welk(e) ding(en) die een positieve invloed hebben op samenwerken zou je graag beter willen worden?

Kan je een situatie bedenken waar samenwerken met anderen tot een goed resultaat heeft geleid? Wat was jouw aandeel daarin?

Wat zou je de volgende keer anders doen?

Kan je een situatie bedenken waar er geen goede samenwerking was? Wat was het gevolg daarvan? 
Chapter 6

Hoe zou je dit aanpakken als je het opnieuw mocht doen? 


\section{Assignment 6:}

Opgave 6: Beslissingen maken en verantwoordelijkheid

Om je doelen te kunnen bereiken en om te kunnen doen wat jij belangrijk vindt moet je verantwoordelijkheid nemen voor jezelf en in staat zijn om zelf beslissingen te kunnen maken.

Om je doelen te kunnen bereiken moet je goed nadenken over hoe je dit het beste kan doen en welke acties hiervoor nodig zijn.

Je staat nu op een punt in je leven waarin je belangrijke beslissingen gaat maken die invloed hebben op je toekomst. Wat is voor jou het belangrijkst?

In deze opdracht ga je nadenken over dingen die echt belangrijk voor jou zijn en welke beslissingen jij zult moeten maken en welke verantwoordelijkheid je zelf zal moeten nemen om je doelen te bereiken.

Klik dadelijk op verder en beantwoordt dan de vragen over beslissingen maken en verantwoordelijkheid. Als laatste krijg je nog een paar vragen over de omgeving waarin je deze opgave maakt en nog een paar vragen over de vorige opgaven.

Zoals gezegd zijn er op dit punt in je leven veel beslissingen die je moet maken. Kan je een aantal positieve en negatieve beslissingen noemen die mensen van jouw leeftijd maken? Beschrijf minimaal drie beslissingen.

Welke factoren denk je dat jouw beslissingen en de beslissingen van anderen beïnvloeden? Kijk hierbij vooral naar je omgeving. Beschrijf minimaal drie factoren.

Welke van deze factoren hebben volgens jou een positieve invloed en welke factoren hebben een negatieve invloed? 


\section{Chapter 6}

Niet iedere beslissing is voor iedereen hetzelfde. De beslissing die je uiteindelijk maakt hangt af van je eigen doelen en waarden. Om je te helpen is er een stappenplan voor het maken van een goede beslissing:

1. Stel vast welke beslissing je moet maken

2. Denk na over mogelijke opties

3. Denk na over de gevolgen van deze opties voor jezelf en anderen

4. Kies de optie die leidt naar het beste resultaat

5. Zet je beslissing door

6. Evalueer het resultaat zodat je weet wat je de volgende keer het beste kan doen

Bedenk een situatie waarin je een beslissing moet maken en neem de zes voorgestelde stappen door. Beschrijf iedere stap.

Als je geen situatie kunt bedenken neem dan de volgende situatie: je hebt de mogelijkheid om na school wat extra geld te verdienen door een baantje aan te nemen maar de tijden van het baantje komen overeen met de tijden van je sportles bij je sportclub. Je teamgenoten van je sportclub gaan ervanuit dat je in hun team meespeelt dit seizoen. Wat moet je doen?

Beschrijf iedere stap.

Waarom denk je dat mensen soms beslissingen maken die schadelijk zijn voor henzelf en misschien ook voor anderen? Beschrijf minimaal een ding.

Welke dingen kunnen de uitvoering van een goede beslissing verhinderen? Beschrijf minimaal een ding. 
Wat denk je dat het maken van beslissingen te maken heeft met verantwoordelijkheid?

Kan je iets bedenken op dit moment in je leven waar je verantwoordelijkheid voor kunt nemen (iets waarover je meer controle kunt krijgen). Beschrijf minimaal een situatie.

Wat zou je kunnen doen om meer controle te krijgen in deze situatie? Beschrijf minimaal een ding. 


\section{Chapter 6}

\section{Assignment 7:}

\section{Opgave 7: Verwachtingspatronen}

Mensen om je heen kunnen invloed hebben op de beslissingen die je maakt en hoe je omgaat met bepaalde situaties. Sommige mensen zijn vatbaarder voor de mening van iemand anders dan anderen. Deze invloed van anderen kan positief zijn, als ze je advies geven en je helpen om de juiste beslissing te maken maar kan ook negatief zijn, als ze je hun mening opdringen en je verhinderen om de juiste beslissing te maken.

In deze opdracht draait het om de invloed die andere mensen hebben op jouw leven. Wie is het belangrijkst voor je en waarom? Wat zijn de eigenschappen van mensen die een positieve invloed hebben op jou?

Klik dadelijk op verder en beantwoordt dan de vragen over verwachtingspatronen.

Als laatste krijg je nog een paar vragen over de omgeving waarin je deze opgave maakt en nog een paar vragen over de vorige opgaven.

Kan je een voorbeeld bedenken van een situatie waarin iemand anders een grote invloed heeft gehad op een beslissing die je genomen hebt? Beschrijf minimaal een situatie.

Voel je wel eens druk van anderen om bepaalde beslissingen te maken? Zo ja, hoe ga je daarmee om? Beschrijf minimaal een manier om om te gaan met druk van anderen.

Kan je negatieve effecten van deze druk van anderen bedenken? Beschrijf minimaal een effect. 
Welke mensen hebben de meeste invloed op jouw leven? Leg ook uit waarom zij invloed hebben in jouw leven. Beschrijf minimaal 3 personen.

Vind je dat deze mensen die je net hebt beschreven een positieve of een negatieve invloed hebben op jouw leven? Geef dit aan voor iedere persoon die je genoemd hebt in de vorige vraag. Leg ook uit waarom.

Rolmodellen zijn mensen die bewonderenswaardige kwaliteiten en eigenschappen bezitten en deze laten zien door de keuzes die zij maken, hun gedrag en hun acties.

Wie of wat voor type mensen beschouw jij als rolmodel? Leg ook uit waarom. Beschrijf minimaal een persoon.

Geef commentaar op de volgende stelling: "ledereen heeft zijn eigen toekomst in handen". 
Final questionnaire:

Beste leerling,

De komende tijd werk je mee aan de ontwikkeling van een onderzoek waaraan jouw school meewerkt. Zoals je wellicht hebt gehoord is er momenteel veel te doen rondom het middelbaar onderwijs in de politiek. De huidige discussie rondom het onderwijs is deels gericht op de prestatieverhoging van leerlingen. Om meer duidelijkheid te scheppen in de discussie over hoe prestaties van leerlingen verhoogd kunnen worden, worden er door verschillende instanties onderzoeken op dit gebied uitgevoerd. De Universiteit Maastricht is een van deze instanties die onderzoek uitvoert naar de prestaties van leerlingen. Naast deze vragenlijst doe je later ook mee aan een aantal opdrachten, zodat we kunnen achterhalen of de prestaties van leerlingen in het middelbaar onderwijs kunnen worden verhoogd door leerlingen te laten deelnemen aan specifieke opdrachten. Daarmee kunnen we je school belangrijke informatie geven hoe ze het doen in vergelijking met andere scholen en hoe ze dingen anders kunnen doen.

In deze vragenlijst kom je een heleboel verschillende soorten vragen tegen. Denk niet te lang, maar geef het antwoord dat bij je opkomt. Als je ergens geen antwoord op wil geven, of iets niet weet, dan sla je het gewoon over.

Dank je wel voor je medewerking

\section{Wie ben je?}

Voornaam

Achternaam

E-mailadres

Geboortedatum

Geslacht

Postcode \& Plaats

School

Klas

Studie

Profiel/sector

Vakken 


\section{Huiswerk}

Hoeveel uur (hele of halve) besteed je ongeveer aan het maken van huiswerk, zowel door de week als in het weekend?

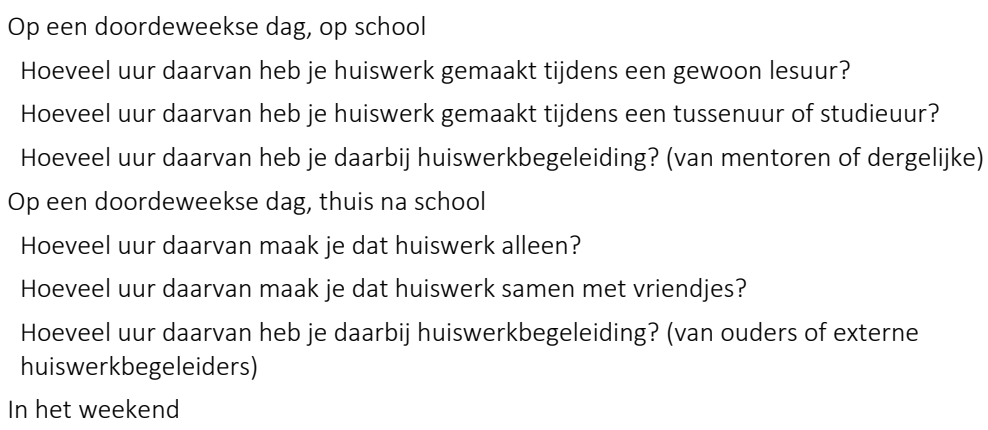

\section{Lesindeling op school}

Denk eens terug aan de afgelopen week, hoeveel lesuren had je?

Gewone volledige lesuren (van 50 minuten)

Ingeroosterde tussenuren of studie uren

Uitgevallen lessen

\section{Spijbelen}

Hoe vaak heb je dit schooljaar gespijbeld?
Nooit
O Een enkele keer
O Elke maand wel een keer
O Elke week wel een keer
O Elke week wel meerdere keren

Hoe soepel zijn ze bij jou op school als je spijbelt?
O Heel soepel
○ Vrij soepel
O Weet ik niet
O Vrij streng
O Heel streng 
Alleen voor degenen die ja hebben geantwoord op de eerste vraag onder het kopje spijbelen:

Als je spijbelt, hoe lang is dit dan meestal?

Ik spijbel nooit

Een lesuur

Een halve dag

O Een hele dag

Hoe reageren je ouders als ze (zouden) weten dat je spijbelt?
O Heel soepel
V Vrij soepel
O Weet ik niet
V Vrij streng
O Heel streng

\section{Motivatie om te leren}

Wat denk je dat er de komende jaren met je zal gebeuren?

\begin{tabular}{lccccc}
\hline & $\begin{array}{c}\text { Gebeurt } \\
\text { zeker niet } \\
--\end{array}$ & - & $\begin{array}{c}\text { Neutraal } \\
0\end{array}$ & + & $\begin{array}{c}\text { Gebeurt } \\
\text { zeker } \\
++\end{array}$ \\
\hline Ik stop met deze school zonder hem af te maken & 0 & 0 & 0 & 0 & 0 \\
Ik ga nog heel gemotiveerd doorleren & 0 & 0 & 0 & 0 & 0 \\
Zodra het kan, stop ik met leren & 0 & 0 & 0 & 0 & 0 \\
Ik ga interessante dingen leren & 0 & 0 & 0 & 0 & 0 \\
Ik ga een vak leren, maar buiten school & 0 & 0 & 0 & 0 & 0 \\
Ik ga nog doorleren omdat ik het leuk vind & 0 & 0 & 0 & 0 & 0 \\
Zodra ik een baan kan krijgen, stop ik met school & 0 & 0 & 0 & 0 & 0 \\
Ik ga nog heel lang doorleren & 0 & 0 & 0 & 0 & 0 \\
\hline
\end{tabular}

\section{Zelfbeoordeling}

Hoe goed ben jij in onderstaande activiteiten? Geef jezelf een rapportcijfer ( 2 = dikke onvoldoende, 4 = onvoldoende, 6 = voldoende, 8 = goed, 10 = uitmuntend)

\begin{tabular}{ll}
\hline & Cijfer \\
\hline Eigen mening geven & $\ldots$ \\
Winnen bij een ruzie & $\ldots$ \\
Mijn zin doordrijven & $\ldots$ \\
De baas spelen over anderen & $\ldots$ \\
Discussiëren & $\ldots$ \\
lemand troosten & $\ldots$ \\
Luisteren naar iemand die het moeilijk heeft & $\ldots$ \\
Leuke kleren uitzoeken en er leuk uitzien & $\ldots$ \\
Omgaan met andere leerlingen & $\ldots$ \\
Tekenen, schilderen of muziek maken & $\ldots$ \\
\hline
\end{tabular}


lets op de computer opzoeken

Hoofdrekenen

Schrijven zonder fouten

Het nieuws volgen

Je concentreren

Chatten / Msn-en op de computer

What's appen / pingen / chatten op de mobiele telefoon

Het programma Word

Het programma Excel

Internetten voor school

Internetten voor de lol

Computerspelletjes

Voorkomen dat ik ruzie krijg met anderen

Er goed tegen kunnen als ik geplaagd wordt

Goed overweg kunnen met mijn klasgenoten

Zorgen dat het leuk blijft op school

Zorgen dat het leuk is thuis

\section{Schoolwelbevinden}

Ben je het met de volgende stellingen eens?

\begin{tabular}{lccccc}
\hline & $\begin{array}{c}\text { Helemaal } \\
\text { niet mee } \\
\text { eens }\end{array}$ & - & $\begin{array}{c}\text { Neutraal } \\
\text {-- }\end{array}$ & + & $\begin{array}{c}\text { Helemaal } \\
\text { mee eens } \\
++\end{array}$ \\
\hline Ik vind het leuk op deze school & 0 & 0 & 0 & 0 & 0 \\
Als ik hulp van de leraar wil, krijg ik die ook & 0 & 0 & 0 & 0 & 0 \\
Sommige kinderen pesten mij & 0 & 0 & 0 & 0 & 0 \\
In de klas voel ik mij soms alleen & 0 & 0 & 0 & 0 & 0 \\
De leraren doen erg hun best voor mij & 0 & 0 & 0 & 0 & 0 \\
Ik ga graag naar deze school & 0 & 0 & 0 & 0 & 0 \\
Ik heb hier veel vriend(inn)en & 0 & 0 & 0 & 0 & 0 \\
De leraren vinden mij aardig & 0 & 0 & 0 & 0 & 0 \\
De leraren vinden mij slim & 0 & 0 & 0 & 0 & 0 \\
Ik heb een hekel aan deze school & 0 & 0 & 0 & 0 & 0 \\
Ik verveel me op deze school & 0 & 0 & 0 & 0 & 0 \\
De kinderen hier vinden mij aardig & 0 & 0 & 0 & 0 & 0 \\
In de klas voel ik dat ik erbij hoor & 0 & 0 & 0 & 0 & 0 \\
\hline
\end{tabular}




\section{Vertrouwen in de toekomst}

Hoe groot denk je dat de kans is dat je een diploma haalt op de volgende opleidingen?

\begin{tabular}{lccccc}
\hline & Heel klein & Klein & Redelijk & Groot & Heel groot \\
\hline Huidige opleiding & $O$ & $O$ & 0 & 0 & 0 \\
MBO - tweejarig (basiskwalificatie) & 0 & 0 & 0 & 0 & 0 \\
MBO - volledig & 0 & 0 & 0 & 0 & 0 \\
HBO / Hogeschool & 0 & 0 & 0 & 0 & 0 \\
WO / Universiteit & 0 & 0 & 0 & 0 & 0 \\
\hline
\end{tabular}

\section{Karakter - Big 5}

[Stellingen moeten nog door elkaar worden gehusseld]

Ben je het eens met de volgende stellingen?

\begin{tabular}{|c|c|c|c|c|c|}
\hline & $\begin{array}{c}\text { Helemaal niet } \\
\text { mee eens } \\
--\end{array}$ & - & $\begin{array}{c}\text { Neutraal } \\
0\end{array}$ & + & $\begin{array}{c}\text { Helemaal } \\
\text { mee eens } \\
++\end{array}$ \\
\hline Ik gebruik vaak moeilijke woorden & $\mathrm{O}$ & O & O & $\mathrm{O}$ & O \\
\hline Ik barst van de ideeën & O & O & O & $\mathrm{O}$ & O \\
\hline Ik pik snel nieuwe dingen op & O & O & O & O & O \\
\hline Ik heb weinig fantasie & O & O & O & O & O \\
\hline Ik heb een grote woordenschat & O & O & O & O & O \\
\hline Ik doe klusjes meteen & O & O & O & $\mathrm{O}$ & O \\
\hline Ik laat mijn spullen vaak slingeren & O & O & O & $\mathrm{O}$ & O \\
\hline Ik hou me altijd aan mijn afspraken & O & O & O & O & O \\
\hline Ik vergeet soms dat ik iets moet doen & O & O & O & O & O \\
\hline Ik ben nauwkeurig in mijn werk & O & O & O & $\mathrm{O}$ & O \\
\hline Ik praat veel & O & O & O & $\mathrm{O}$ & O \\
\hline Ik ben stil in een groep met vreemden & O & O & O & $\mathrm{O}$ & O \\
\hline Ik ben de gangmaker op feestjes & O & O & O & O & O \\
\hline Ik vind het leuk om met veel mensen te zijn & O & O & O & O & O \\
\hline Ik probeer mensen te helpen & O & O & O & O & O \\
\hline Ik ben geïnteresseerd in anderen & O & O & O & $\mathrm{O}$ & O \\
\hline Ik leef mee met anderen & O & O & O & $\mathrm{O}$ & O \\
\hline Ik ben vriendelijk & O & O & O & $\mathrm{O}$ & O \\
\hline Ik raak makkelijk van streek & O & O & O & O & O \\
\hline Ik ben snel gestresst & O & O & O & O & O \\
\hline Ik heb vaak een wisselend humeur & O & O & O & O & O \\
\hline Ik heb regelmatig een somber humeur & O & O & O & O & O \\
\hline
\end{tabular}


Karakter - doorzettingsvermogen en prestatiegerichtheid

[Stellingen moeten nog door elkaar worden gehusseld]

Ben je het eens met de volgende stellingen?

\begin{tabular}{|c|c|c|c|c|c|}
\hline & $\begin{array}{c}\text { Helemaal } \\
\text { niet mee } \\
\text { eens } \\
--\end{array}$ & - & $\begin{array}{c}\text { Neutraal } \\
0\end{array}$ & + & $\begin{array}{c}\text { Helemaal } \\
\text { mee eens } \\
++\end{array}$ \\
\hline Ik wil graag hoge punten halen & O & O & O & O & O \\
\hline Ik wil later goed zijn in mijn beroep & O & O & O & O & O \\
\hline Je best doen is belangrijk voor mij & O & O & O & O & O \\
\hline Succes wordt veel te belangrijk gemaakt & O & O & O & O & O \\
\hline Als ik aan iets begin, maak ik het ook af & O & O & O & O & O \\
\hline Ik stop als iets te moeilijk wordt & O & O & O & O & O \\
\hline Als iets tegenvalt, verlies ik snel de moed & O & O & O & O & O \\
\hline Ik ga door tot het gelukt is & 0 & O & O & O & 0 \\
\hline
\end{tabular}

\section{Tijd besteed aan naschoolse activiteiten}

Hoeveel uur besteed je gemiddeld per week aan de volgende activiteiten buiten school en huiswerk?

\begin{tabular}{lcccccc}
\hline & $\begin{array}{c}\text { Minder } \\
\text { dan een } \\
\text { half uur }\end{array}$ & $\begin{array}{c}\text { Half uur - } \\
\text { uur }\end{array}$ & $1-2$ uur & $2-4$ uur & 4-6 uur & $\begin{array}{c}\text { Meer dan } \\
6 \text { uur }\end{array}$ \\
\hline Sporten & 0 & 0 & 0 & 0 & 0 & 0 \\
Muziek maken & 0 & 0 & 0 & 0 & 0 & 0 \\
Andere vereniging/club & 0 & 0 & 0 & 0 & 0 & 0 \\
Tijd met vrienden doorbrengen & 0 & 0 & 0 & 0 & 0 & 0 \\
Lezen (geen schoolboeken) & 0 & 0 & 0 & 0 & 0 & 0 \\
Sociale media & 0 & 0 & 0 & 0 & 0 & 0 \\
Gamen & 0 & 0 & 0 & 0 & 0 & 0 \\
Bezoek museum / tentoonstelling & 0 & 0 & 0 & 0 & 0 & 0 \\
\hline
\end{tabular}




\section{E. Pilot study}

\section{Pilot study}

We conducted a pilot study before the start of the actual experiment. The pilot is intended to test various aspects of the intervention such as the child selection method, the appropriateness of the tasks and the feasibility of the intervention in schools. In addition, the pilot reduces the possibility of unforeseen events during the actual experiment. The pilot study was held at two schools that both offer the two tracks that this study aims at. For randomization of treatment in the pilot phase we use a cross-over design, where both schools are allocated a treatment as well as a control group. One school offers the treatment group in the lower track and control group in the higher track and vice versa. On the one hand, the advantage of the cross-over design is that schools always have a group of children that participates as a treatment group which enhances the participation probability of the school. On the other hand, there might be a concern that due to the cross-over design there might be spill-over effects from the treatment to the control group. We believe that this latter effect is unlikely to happen in our case as the schools have separate locations for the two tracks and the children have different teachers.

To determine the group of children that is flagged as underachieving and is eligible for treatment we use the two-step approach mentioned earlier: (1) a comparison of the test scores in $6^{\text {th }}$ grade and in $9^{\text {th }}$ grade, and (2) evaluation of this group by mentors and teachers. In deviation of the $9^{\text {th }}$ grade test described earlier, for the pilot we use an alternative test that is provided to us by the institute 'Cohort Onderzoek Onderwijs Loopbanen' (COOL) as the test we use in the actual experiment is not available in the pilot year. The alternative test we use for the pilot is very similar to the test we use for the actual intervention, it partly includes the same questions. In general, the teachers agreed with the children that were selected based on their diverging test scores between $6^{\text {th }}$ and $9^{\text {th }}$ grade and they only added additional information as to why some children had temporary lower school performance. For example, children might have been sick or there might have been some difficult home situations (e.g. parents got divorced). In a few instances teachers added a child of whom they thought the child should be able to perform better in school. This gives us confidence that our measure for the selection of underachieving children is valid.

At the end of the pilot phase two feedback rounds were organized. One feedback round focused on the discussion with the children that participated in the pilot and the other feedback round focused on the discussion with the mentors and teachers involved in the pilot. Overall, the pilot proved to be very useful for the actual experiment. First, we learned that designing an experiment in cooperation with schools results in a better understanding of the experimental design by schools and creates more willingness for schools and teachers to participate in the experiment. In addition, when schools and teachers understand the benefit of an experiment they are better able to 
translate this to their children. Second, intensive communication with schools is crucial for the proper execution of the experiment. This has an effect both on the logistic feasibility of the experiment but also on the accuracy of the effect measurement. Third, we established that our method for child selection was very similar to the teacher evaluation. Finally, the pilot contributed to the creation of the tasks that are used in the experiment. Parts of the content as well as the language used in the tasks was adjusted based on the feedback we received. To ensure that the tasks were suitable for the target group they were adjusted by a child in secondary school as part of a school assignment. This child was in $11^{\text {th }}$ grade in the pre-university track. 

Nederlandse samenvatting (Dutch summary) 



\section{Motivatie}

In elk stadium van zijn onderwijsloopbaan ontwikkelt een leerling zijn talenten en competenties, ontdekt hij waar zijn interesses liggen, en leert hij kennis en vaardigheden die nodig zijn voor de volgende stap in die loopbaan, zoals een vervolgopleiding. Leerlingen, en de samenleving in het algemeen, profiteren het meest als hun potentieel ten volste wordt benut en ze soepel door het onderwijssysteem bewegen. Investeringen in hun menselijk kapitaal zijn dan meest optimaal. Een soepele overgang tussen de verschillende onderwijssectoren is daarbij van groot belang. Een soepele overgang betekent dat verwachtingen over het potentieel van de leerling helder moeten zijn zodat een goede keuze voor onderwijsniveau of studierichting gemaakt kan worden. Dit vermindert risico's als zittenblijven, afstroom, wisselen van studie, of voortijdig schoolverlaten. Ook draagt het bij aan goed opgeleide beroepsbevolking waardoor het verdienvermogen van de Nederlandse economie toeneemt en sociale problemen afnemen. Studievertragingen, -wisselingen en uitval zijn inefficiënt en kostbaar.

Eén van de vroege overgangen in de onderwijsloopbaan is de overgang van het primair naar het voortgezet onderwijs. Deze overgang heeft een belangrijke invloed op latere uitkomsten (zoals welk type baan) omdat er belangrijke keuzes gemaakt worden. In het voortgezet onderwijs worden leerlingen in Nederland ingedeeld op verschillende onderwijsniveaus. In een internationale vergelijking wordt het Nederlandse onderwijssysteem hiermee gekenmerkt door een vroege selectie van leerlingen naar verschillende onderwijsniveaus. De keuze voor het onderwijsniveau, die op twaalfjarige leeftijd wordt gemaakt, heeft belangrijke consequenties voor de toekomstige schoolcarrière (Hanushek en Woessmann, 2006; Onderwijsinspectie, 2014; Timmermans et al., 2013). Er moet een keuze worden gemaakt voor schooltype (meer praktisch of meer theoretisch onderwijs) en het niveau van dat onderwijs (voorbereidend middelbaar beroepsonderwijs, hoger algemeen voortgezet onderwijs of voorbereidend wetenschappelijk onderwijs). Deze keuze is daarmee een belangrijke determinant voor de verdere schoolcarrière in het voortgezet onderwijs, maar ook voor het vervolgonderwijs en de arbeidsmarktpositie na het voortgezet onderwijs. De overgang van primair naar voortgezet onderwijs verloopt niet altijd soepel. Het komt regelmatig voor dat leerlingen in het voortgezet onderwijs de verwachtingen vanuit het advies van de basisschool niet inlossen. Soms is dat terug te voeren op een gebrek aan hun vermogen om zich aan te passen aan de nieuwe omgeving, soms zijn de verwachtingen vanuit het advies van de basisschool niet terecht.

Om een goede keuze voor het voortgezet onderwijs te maken, zijn instrumenten voor het meten van de capaciteiten van leerlingen nodig. In het Nederlandse onderwijssysteem worden hiervoor twee instrumenten gebruikt: het schooladvies van de basisschool en de score op een gestandaardiseerde toets aan het einde van de basisschool - meestal de Citotoets. Beide instrumenten schatten de capaciteiten van leerlingen op basis van deels gelijke, maar ook deels verschillende informatiebronnen. Een leerkracht 
baseert zijn oordeel over de capaciteiten van een leerling bijvoorbeeld op meer algemene en eerdere prestaties van de leerling, het gedrag in de klas, achtergrondkenmerken zoals een thuissituatie, persoonskenmerken en overige eigenschappen die hij observeert. De score op de toets meet hoe de leerling presteert op een cognitieve test die specifieke vaardigheden op het terrein van bijvoorbeeld wiskunde of taal in beeld brengt. Beide instrumenten kunnen tot andere voorspellingen komen en het is niet duidelijk welk instrument een betere voorspeller is voor de latere leerprestaties van de leerling.

Recent is er een belangrijke beleidswijziging in Nederland geweest die betrekking heeft op het gebruik van deze instrumenten bij de overgang van primair naar voortgezet onderwijs. Met deze wijziging, die in schooljaar 2014-2015 is doorgevoerd, krijgt het schooladvies dat de leerkracht geeft aan het einde van de basisschool een meer prominente rol toebedeeld als instrument in de bepaling van een passend schooltype en onderwijsniveau van leerlingen. Hiermee krijgt de score op de gestandaardiseerde toets wat minder nadruk. Deze ontwikkelingen zijn aanleiding voor wetenschappelijke onderzoeksvragen die ook beleidsmatig belangrijke informatie opleveren over de effecten van deze beleidsmaatregel en de inrichting van de overgang van het primair naar het voortgezet onderwijs.

Wanneer gekeken wordt naar de resultaten van Nederlandse leerlingen en volwassenen op internationale toetsen, zoals het Program of International Student Assessment (PISA) en de Survey of Adult Skills (PIAAC), wordt ons onderwijssysteem dikwijls beschouwd als een van de best presterende onderwijssystemen in de landen die behoren tot de OESO. De resultaten van PISA 2012 laten bijvoorbeeld zien dat van de 65 participerende landen, Nederland op nummer 10 staat bij wiskunde, op nummer 15 bij leesvaardigheid en op nummer 14 bij wetenschappelijke vaardigheden (OESO, 2016). Ondanks deze relatief hoge plek in termen van gemiddelde uitkomsten, is er een groeiende bezorgdheid onder beleidsmakers en toezichthouders over ongelijke kansen in het onderwijs en een toenemende rigiditeit in de plaatsing van leerlingen in een onderwijssysteem dat wordt gekenmerkt door vroege selectie (OESO, 2012; OESO, 2016; Onderwijsinspectie, 2016).

De Onderwijsinspectie stelt in de jaarlijkse evaluatie van het Nederlandse onderwijssysteem dat de verschillen in onderwijskansen tussen leerlingen van ouders met verschillende opleidingsniveaus toenemen. Het opleidingsniveau van ouders blijkt vooral een belangrijke voorspeller van schooladvies, toetsscore en plaatsing in het eerste jaar van het voortgezet onderwijs. Daarnaast is er volgens de OESO (2016, p.40) "een spanning tussen het centrale principe van vroege selectie, waarbij leerlingen met bepaalde cognitieve vaardigheden het beste passen bij een bepaald schooltype en de vrijheid van de school waarbij plaatsing afhangt van het schooladvies en scores op cognitieve toetsen die op een variabele basis geïnterpreteerd worden." Er zijn geen formele richtlijnen voor het tot stand komen van het schooladvies of plaatsing. Het is gebaseerd op variabele criteria, zoals een verschillend gebruik van toetsscores tussen 
scholen om het schooladvies vast te stellen. Daarnaast mogen scholen in Nederland leerlingen selecteren en staat het ze vrij om additionele vormen van selectie toe te passen (OESO, 2016; Korpershoek et al., 2016; Onderwijsinspectie, 2013). De Onderwijsraad (2010 en 2014) en de OESO (2012) hebben gesteld dat onderwijssystemen die gebruik maken van vroege selectie flexibiliteit moeten garanderen zodat leerlingen additionele mogelijkheden hebben als er zich veranderingen in hun prestaties voordoen. Toch bestaat de indruk dat deze mogelijkheden afnemen, omdat de ruimte voor brede brugklassen en het stapelen van diploma's steeds kleiner wordt.

Een andere uitdaging voor het Nederlandse onderwijssysteem is onderpresteren van leerlingen en een gebrek aan motivatie enkele jaren nadat ze de overgang naar de middelbare school hebben gemaakt. Volgens de OESO (2016) en de Onderwijsraad (2007) is de motivatie van Nederlandse leerlingen in het voortgezet onderwijs laag en zijn er, gegeven de over het algemeen hoge standaarden, weinig toppresteerders. Daarnaast is uit gesprekken met leraren op middelbare scholen naar voren gekomen dat veel leerlingen vanaf ongeveer de derde klas in het voortgezet onderwijs nog maar moeizaam tot presteren aan te zetten zijn, met name op het vmbo en havo. De leraren ervaren een gebrek aan motivatie en schoolhouding bij de leerlingen en geven aan dat de leerlingen niet naar hun kunnen presteren. Wanneer leerlingen onderpresteren is de accumulatie van menselijk kapitaal niet optimaal. Deze leerlingen zouden meer kunnen leren, misschien zelfs een diploma kunnen behalen op een hoger niveau en betere vooruitzichten op de arbeidsmarkt kunnen hebben als ze op het verwachte niveau zouden presteren.

In een onderwijssysteem dat gebruik maakt van vroege selectie is het belangrijk om te begrijpen wat de determinanten van plaatsing zijn en wat de relatie is met de verdere schoolcarrière van leerlingen. Het Nederlandse onderwijssysteem biedt de mogelijkheid om te onderzoeken wat de relatie is tussen het schooladvies, de toetsscore, plaatsing, het wisselen van onderwijsniveau op de middelbare school en andere maten van prestaties, zoals cijfers en motivatie. De relaties die in deze dissertatie worden onderzocht zijn gebaseerd op Nederlandse data, maar de resultaten van het onderzoek zijn van universeel belang om te begrijpen hoe het samenspel tussen het schooladvies van de leerkracht, de toetsscore en de prestaties van leerlingen in het voortgezet onderwijs kunnen worden geïnterpreteerd.

\section{Doel}

De vier studies in dit proefschrift geven inzicht in het belang van instrumenten voor het meten van de capaciteiten van leerlingen bij de overgang van het primair naar het voortgezet onderwijs. Vier onderwerpen vertegenwoordigen de kern van dit proefschrift: toetsen, het schooladvies van de leraar, plaatsing op verschillende onderwijsni- 
veaus en motivatie. Met een viertal studies beantwoordt dit proefschrift de volgende vragen:

1. Hoe zijn toetsscores en schooladvies van de leerkracht aan het einde van de basisschool gerelateerd aan plaatsing en opstroom of afstroom in de eerste drie jaar van het voortgezet onderwijs?

2. Hoe passen leerkrachten hun oorspronkelijke beoordeling van de capaciteiten van leerlingen aan na het ontvangen van informatie over toetsscores?

3. Wat gebeurt er met meetinstrumenten van het vermogen van leerlingen wanneer een beleidswijziging het belang van toetsscores vermindert?

4. Wat is het effect op de motivatie en schoolprestaties van onderpresterende leerlingen van een interventie gericht op hun niet-cognitieve vaardigheden?

\section{Samenvatting van de resultaten}

In het eerste inhoudelijke hoofdstuk van dit proefschrift (hoofdstuk 3) wordt onderzocht in hoeverre het schooladvies aanvullende informatie bevat bovenop de informatie uit de toetsscore aan het einde van de basisschool en hoe dit gerelateerd is aan opstroom en afstroom in de eerste jaren van de middelbare school. De toetsscore wordt gebruikt voor het bepalen van de capaciteiten van leerlingen in groep 8 en $3 \mathrm{VO}$. Eerst wordt onderzocht of er niet-willekeurige verschillen zijn tussen toetsscore en schooladvies op leerlingniveau. Vervolgens wordt onderzocht in hoeverre de toetsscore of het schooladvies van de leraar de plaatsing van leerlingen in $1 \mathrm{VO}$ en positie in $3 \mathrm{VO}$ voorspelt. Tot slot wordt onderzocht of leerlingen die wisselen van niveau (tussen $1 \mathrm{VO}$ en $3 \mathrm{VO}$ ) zijn geplaatst volgens de toetsscore of volgens het schooladvies van de leraar. De belangrijkste bevindingen kunnen als volgt worden samengevat. Ten eerste, voor 19 procent van de leerlingen bestaat er een substantieel verschil tussen de verschillende beoordelingsinstrumenten in groep 8 . Het is waarschijnlijker dat meisjes een schooladvies ontvangen dat hoger is dan hun toetsscore dan jongens en het is minder waarschijnlijk dat leerlingen met een lagere sociaal-economische achtergrond een schooladvies ontvangen dat hoger is dan de toetsscore in vergelijking met leerlingen met een hogere sociaal-economische achtergrond. Ten tweede, blijkt het schooladvies twee keer zo goed in het verklaren van het verschil tussen de laagste en de hoogste plaatsing in vergelijking met de toetsscore. Dit is het geval in zowel $1 \mathrm{VO}$ als 3VO. Ten derde blijken leerlingen die geplaatst zijn op basis van het schooladvies minder vaak van schoolniveau te wisselen dan leerlingen die geplaatst zijn op basis van de toetsscore. Ten slotte blijkt het schooladvies positief gecorreleerd met de toetsscore in 3VO, terwijl de toetsscore in groep 8 niet gecorreleerd is met deze toets. Het wisselen van schoolniveaus tussen $1 \mathrm{VO}$ en $3 \mathrm{VO}$ lijkt een negatief effect te hebben op de toetsscore in $3 \mathrm{VO}$ wat een indicatie is van het bestaan van kosten van wisselen. 
Hoofdstuk 4 bouwt voort op de analyses in hoofdstuk 3 door te laten zien hoe leerkrachten gebruik maken van de informatie die toetsscores geven om daarmee hun eerdere oordeel over de capaciteiten van leerlingen aan te passen. Dit onderzoek maakt gebruik van informatie over het oorspronkelijke schooladvies, toetsscores en het uiteindelijke schooladvies, in deze volgorde. Eerst wordt bepaald welke factoren van invloed zijn op het uiteindelijke schooladvies. In een volgende stap wordt onderzocht wat de effectgrootte is van het hebben van een andere toetsscore in vergelijking met het oorspronkelijke schooladvies op het uiteindelijke schooladvies. Tot slot wordt onderzocht of de aanpassing van de leraar verschilt met het geslacht of sociaaleconomische achtergrond van leerlingen. Twee belangrijke bevindingen komen uit de analyses naar voren. Ten eerste laten de schattingen zien dat leraren hun oorspronkelijke schooladvies gemiddeld met 19 procent van een standaarddeviatie aanpassen na het observeren van de toetsscore. Ten tweede, verschilt deze aanpassing naar geslacht en sociaal-economische achtergrond van de leerlingen. De aanpassingen zijn minder gunstig voor meisjes en leerlingen met een lagere sociaal-economische achtergrond. Zelfs wanneer leraren een rijke set aan achtergrondvariabelen meenemen in hun beoordeling is er een significant effect van de toetsscore in groep 8 als het gaat om het bepalen van de capaciteiten van leerlingen.

In hoofdstuk 5 wordt onderzocht of een verandering in prikkels de manier verandert waarop leerkrachten de beschikbare informatie meenemen in hun schooladvies. Vanaf het schooljaar 2014-2015 maken leerlingen de toets nadat de leerkracht zijn schooladvies heeft gegeven (in plaats van ervoor) en is het schooladvies de relevante maat voor de plaatsing van leerlingen in het voortgezet onderwijs. Het effect van deze wijziging is in drie stappen onderzocht. Ten eerste zijn het oorspronkelijke schooladvies, de toetsscore en het uiteindelijke schooladvies voor en na de beleidswijziging geobserveerd en wordt onderzocht of er veranderingen optreden. Ten tweede zijn de resultaten opgesplitst naar geslacht en het opleidingsniveau van de moeder en de vader en wordt er geobserveerd of er verschillen bestaan tussen het geslacht en het opleidingsniveau van de ouders. Ten derde is onderzocht of leraren gebruik gaan maken van eerdere toetsscores als input voor hun schooladvies nu ze de toetsscore in groep 8 niet tot hun beschikking hebben op het moment van advisering. $\mathrm{Er}$ is onderzocht of er een stijging in de voorspellende waarde van de toetsscore in groep 7 is voor het schooladvies. De resultaten wijzen er op dat er gemiddeld genomen geen verschil lijkt te zijn in de toetsscore. Echter, het oorspronkelijke en het uiteindelijke schooladvies zijn meer op elkaar gaan lijken na de beleidswijziging en het uiteindelijke schooladvies lijkt gemiddeld significant lager uit te komen. Het tweede resultaat van deze analyse is dat na de beleidswijziging meisjes significant hoger lijken te scoren op de toets, terwijl jongens significant lager lijken te scoren. Leerlingen van wie de ouders een hoger onderwijsniveau hebben afgerond lijken een hoger oorspronkelijk en daadwerkelijk schooladvies te ontvangen in vergelijking met leerlingen van wie de ouders alleen een 
lager onderwijsniveau hebben afgerond. Ten slotte lijken leraren meer nadruk te leggen op de toetsscores in groep 7 als input voor hun schooladvies na de beleidswijziging.

In hoofdstuk 6 wordt het effect van een interventie gericht op de niet-cognitieve vaardigheden en op de motivatie en schoolprestaties van onderpresterende leerlingen onderzocht. Onderpresteren staat in veel landen in de belangstelling, omdat onderpresteren leidt tot suboptimale investeringen in menselijk kapitaal. Er is een gerandomiseerd veldexperiment opgezet en uitgevoerd, waarbij onderpresterende leerlingen maandelijks opdrachten kregen die gericht waren op (a) hun studievaardigheden door bewustwording op het gebied van zelfdiscipline, kritisch denken, besluitvorming en probleemoplossing; en (b) schoolmotivatie en toekomstgerichtheid door het verhogen van het bewustzijn van het nut van de prestaties op school en het behalen van een diploma. Het programma confronteert leerlingen met hun studiegedrag en hun schoolhouding. Uitkomstmaten van dit onderzoek zijn voortzetting van deelname aan de interventie en de gemiddelde rapportcijfers van leerlingen. Aangezien de leerlingen in de doelgroep zijn geselecteerd omdat ze lager presteren dan verwacht, valt te verwachten dat deze leerlingen een grotere kans hebben om uit te vallen omdat hun motivatie om te starten met de interventie en deze af te ronden waarschijnlijk lager is in vergelijking met andere leerlingen. De schattingen laten zien dat leerlingen met lagere gemiddelde rapportcijfers en leerlingen met een hogere (zelf gerapporteerde) motivatie vaker doorgaan met de interventie. Uit het onderzoek komt niet naar voren dat er een effect van de interventie bestaat op de motivatie of het gemiddelde rapportcijfer van leerlingen.

\section{Implicaties}

De bevindingen in dit proefschrift hebben implicaties voor verschillende partijen. Bij de keuze voor een schooltype en onderwijsniveau in het voortgezet onderwijs, zijn leerlingen en ouders bijvoorbeeld gebaat bij een realistische inschatting in de capaciteiten van de leerling. De toetsscore geldt als een objectief instrument hiervoor, maar de resultaten laten zien dat de inschatting van de leraar een betere voorspeller is voor de capaciteiten van de leerling. Dit komt omdat ook andere vaardigheden, zoals persoonseigenschappen, nodig zijn om goed te presteren op de middelbare school. Tegelijkertijd laten de studies zien dat de leraar een neiging kan hebben om enkele achtergrondkenmerken sterker mee te wegen in zijn schooladvies, zoals sociaal-econonomische achtergrond. Hoewel het alloceren van leerlingen in onderwijsniveaus op basis van het schooladvies efficiënter lijkt te zijn omdat dit kan lijden tot meer investeringen in menselijk kapitaal, is er tegelijkertijd een afruil met betrekking tot de gelijke kansen die het onderwijs biedt.

De onderzoeksresultaten geven ook inzicht in het beoordelingsproces door leraren. De leerkracht neemt bij de beoordeling van de leerling andere informatie (bijvoorbeeld geobserveerd gedrag van de leerling) mee, maar ook dezelfde informatie (bijvoorbeeld 
cognitieve prestaties leerling) die hij op een andere manier weegt in zijn oordeel in vergelijking met de toets. Het gegeven dat de leerkracht bij het verkrijgen van nieuwe informatie uit een toets, een aanpassing doet aan het schooladvies dat ongelijk is voor verschillende groepen is een belangrijke input voor bewustwording bij leraren. De verschillen kunnen het gevolg zijn van een realistische inschatting op basis van de nieuwe gegevens of door stereotypering.

De studies geven ook inzicht in het selectie- en toewijzingsproces in schooltype en onderwijsniveau bij de overgang van primair naar voortgezet onderwijs. Scholen krijgen inzicht in de mogelijke consequenties van hun eigen beleid en keuzes die worden gemaakt aan het begin van de educatieve carrière van leerlingen. Basisscholen krijgen informatie over hoe goed ze in staat zijn hun leerlingen te determineren en middelbare scholen krijgen inzicht in of hun leerlingen van onderwijsniveau wisselen gedurende hun middelbare schoolcarrière ten opzichte van het advies en de plaatsing in de eerste klas. De maatschappij krijgt inzicht in de determinanten die kunnen resulteren in een optimalere investering in menselijk kapitaal en de gevolgen die dit mogelijk heeft voor gelijke onderwijskansen.

Tot slot laat het veldexperiment zien hoe moeilijk het kan zijn om onderpresterende leerlingen te benaderen met een schoolinterventie. Juist deze leerlingen zouden kunnen profiteren van interventies gericht op het verbeteren van hun motivatie en leerprestaties. Omdat ze echter niet gemotiveerd zijn om goed te presteren op school, zijn ze ook minder geneigd om met succes deel te nemen aan dit soort beleidsinterventies. De studie toont ook het belang aan van schoolondersteuning voor dit soort programma's. De ondersteuning door de mentor in de klas is cruciaal voor gecontinueerde deelname van de leerlingen aan de interventie. Interessant is ook dat deze interventie in samenwerking met scholen tot stand is gekomen, toch is zelfs dan participatie van leerkrachten niet gegarandeerd. 

Valorisation 



\section{The transition from primary to secondary education}

A good transition between the different stages of education contributes to an optimal development of children's human capital. Children as well as society in general benefit when investments in education are optimized and when all children use their potential to the fullest and smoothly move through the education system. This is likely to reduce retention rates, mismatches in study choices and on the labour market, and early school dropout rates. Switches and early dropout in children's educational career are inefficient and expensive. Therefore, in general, the decisions made regarding children's transition from primary to secondary education are high stakes for all parties involved.

In many countries, such as in the Netherlands, the transition from primary to secondary education is an important educational decision because children are placed into tracks based on their performance and expected ability. School tracks include both the type (more practical vs. more theoretical) and the level of education (vocational, general or academic). The educational track to which children are allocated to has important consequences for their future schooling career (Hanushek and Woessmann, 2006; Inspectorate of Education, 2014; Timmermans et al., 2013). The educational track in secondary education is a determinant for future school education as well as for labour market possibilities.

In addition, in the Netherlands, the decision is made at a rather early age, i.e. the age of 12 . In an education system that uses early tracking it is essential to understand the determinants of track placement and their relation to children's further school career. The Dutch education system, offers an opportunity to investigate the relation between the teacher's assessment, the test score, track placement, track switching, and other measures of performance such as grades and motivation. These topics are at the core of this dissertation.

\section{Relation between research, schools and policy ${ }^{77}$}

The data that is used in this dissertation is collected as part of a project called Educatieve Agenda Limburg. This project is a collaboration between Maastricht University, school boards (primary, secondary and tertiary) and government bodies in Limburg (a province in the South of the Netherlands). The goal of this project is to improve education by means of increased networks for dialogue, innovative studies, monitoring and research. An important instrument for this is extensive data collection in the OnderwijsMonitor Limburg (OML). The OML aims to gain insight into the educational devel-

\footnotetext{
77 The OnderwijsMonitor Limburg, 2018, De educatieve agenda Limburg. http://educatieveagendalimburg.nl/ onderwijsmonitor-p/english
} 
opment of children in order to pursue the further improvement of education and to acquire knowledge about the dynamics of educational processes in general.

The starting point of the OML is information which is already collected within schools. Additional testing and surveying is done where needed, in close collaboration with the schools. Data are collected at different ages, e.g. age of 6 ( $1^{\text {st }}$ grade), 12 ( $6^{\text {th }}$ grade) and 15 ( $9^{\text {th }}$ grade). The data include administrative data from the school information systems, surveys among children and their parents, test results and teachers' assessments. In this way information is acquired about students' test scores, socioeconomic background, personality, social-emotional wellbeing, social and academic skills and school attitude. The data covers children from all tracks with the exception of those who are in special needs education. This combination of data collection at different ages provides a unique dataset about the educational development of children in Limburg. Almost all schools in the region have participated in the data collection process. Approximately 95 percent of all primary schools and 90 percent of all secondary schools have participated in the data collection process. The unique feature of the data used in this dissertation is that these children are followed over time as they progress from $6^{\text {th }}$ to $9^{\text {th }}$ grade.

The data in the OML is collected in ongoing dialogue with teachers, school leaders and policy makers about school performance and development. As a part of the data collection effort, the researchers working with the data identified important educational challenges among which track switching, the influence of the test score and the teacher's assessment on children's outcomes and children's motivation in relation to underperformance. They have expressed a need to know more about these topics in the context of their schools and the children attending their schools. These challenges are addressed in this dissertation from a scientific point of view, but clearly arise from the school practice.

The OML is used at different levels:

- feedback for school on their educational performance, in relation to other schools in the regions and schools with a similar student population

- regional analyses on education and the identification of important challenges, such as language problems or early school dropout.

- research (both academic and applied) on educational questions and dissemination of insights into the domains of academia, policy and educational practice.

With the studies in this dissertation, a contribution is made on all three of these domains. Not only did the topics in this dissertation arise from school practice, the analyses are, where possible, used in the school feedback. This school feedback allows school boards and schools to adjust their policies and to measure and evaluate the effects of educational policies and practices. For example, the predictive value of test scores and the teacher's advice, and the switching rates in secondary education are also calculated at the school-levels and included in the digital reports that the schools re- 
ceive. As a result of this feedback, some schools identified the reduction in the switching between educational tracks as an important strategic goal for the upcoming years. Teachers with a research component in their job were appointed to analyse this in more detail. In a professional learning community these teachers joined forces with researchers of Maastricht University to analyse the data and interpret the findings. The results from this dissertation were an important input in this process.

Second, the results of the dissertation are used to present some regional analyses on the transition from primary to secondary education. Figures are presented on the website $^{78}$ and were presented at various occasions in the region. Children are free to choose their school in the Netherlands and secondary schools might use different rules and procedures with respect to the placement in the first year of secondary education. Each school has its own policy on accepting students based on the test score and the teacher's recommendation, and possible additional instruments (e.g. iq test or personality test). Some schools have a reputation of being strict, while others are perceived to be lenient towards students with lower scores and willing to 'offer chances to all'. Regional agreements can also be in place. It is therefore important to look at regional differences, also to understand regional mismatches in tertiary education or differences in unused potential of students.

Third, the dissertation clearly contributions to the scientific research on important educational questions. It adds to the literature and understanding about how to measure the educational development of children. The different papers in this dissertation all contain information that is valuable for schools to know in their ongoing effort to improve children's educational outcomes such as allocating children to the most appropriate track, switching between tracks and children's motivation to perform well in school. Results are translated into scientific papers and presented at both academic and policyoriented conferences.

Apart from the direct valorisation to school practice and policy arising from the data used, another important valorisation aspect stems from the field experiment. The mere topic of motivation and underperformance was the result of continued dialogue with teachers in secondary schools. Already at the set-up of the intervention, the cooperation between teachers, school leaders and researchers was intensive. First, a pilotintervention was developed with two schools. This pilot proved to be very useful for the actual experiment. First, we learned that designing an experiment in cooperation with schools results in a better understanding of the experimental design by schools and creates more willingness for schools and teachers to participate in the experiment. In addition, when schools and teachers understand the benefit of an experiment they are better able to translate this to their students. Second, intensive communication with schools is crucial for the proper execution of the experiment. This has an effect both on

78 http://educatieveagendalimburg.nl/limburg-cijfers/cijferpagina/schooladvies-en-positie-de-derde-van-demiddelbare-school 
the logistic feasibility of the experiment but also on the accuracy of the effect measurement. Finally, the pilot contributed to the creation of the tasks that are used in the experiment. Parts of the content as well as the language used in the tasks was adjusted based on the feedback we received. To ensure that the tasks were suitable for the target group they were adjusted by a secondary school student as part of a school assignment. This student was in 11th grade in the pre-university track.

18 schools participated in the actual intervention study. The intervention showed that it is not enough to have the support of the school boards if the teachers supporting the intervention on a daily basis do not have the time to execute it properly. This is important information for school leaders who strive to work in an evidence-based manner. Reliance on intervention studies is important, but for successful interventions teachers need to be included in the process.

After the intervention study, the assignments used in the interventions, were made freely available to all schools who participated in the intervention study (also control schools). Schools were free to use these assignments to try to improve motivation of children in their school. A number of schools have told us that they would like to use the materials as they believed the children in their school could benefit.

\section{Results of this dissertation}

These findings have implications for different parties. Concerning the choice of a secondary school both children and parents will benefit from a realistic assessment of children's ability. Children (and parents) benefit from the test as an assessment measure as it gives an objective assessment of their ability level independent from their other characteristics. The results show that the teacher's assessment is a better predictor of children's ability. This is because other skills such as personality traits are also needed to perform well in secondary school. At the same time the results show that the teacher seems to weigh in children's background characteristics when giving an assessment, such as children's social-economic background. Even though the allocation of children to tracks based on the teacher's assessment seems to be more efficient as it leads to a higher investment in human capital, there is also a trade-off with equal opportunities.

These studies also give an insight into the assessment process as done by teachers. The teacher uses different information compared to the test (e.g. children's classroom behaviour) but teachers also use similar information (e.g. children's cognitive performances) but the information is weighted in a different way in the teacher's assessment, compared to the test. The finding that the teacher uses the information obtained from a test to adjust children's assessment heterogeneously across different groups is important for teachers to be aware of. The differences in adjustments can be the consequence of a realistic assessment based on new information or stereotyping. 
The studies also provide information about the selection and allocation process during the transition from primary to secondary education. Schools gain insight into the potential consequences of their own policies and choices made at the beginning of children's educational career. Schools for primary education gain insight into their adequacy of assessing children's ability level and schools for secondary education gain insight into how their children switch between tracks during their school career compared to the teacher's assessment and the initial track allocation. Society gains insight into the determinants that can result in a higher investment in human capital and the potential consequences for equal opportunities.

The field experiment shows how difficult it is to target underperforming children with a school intervention. This study focused on children who in $9^{\text {th }}$ grade perform at a lower level compared to their expected performance in $6^{\text {th }}$ grade. These children could, arguably, benefit from interventions aimed at improving their motivation and performance. However, as they are not motivated to perform well in school they are also less likely to successfully participate in these kind of policy interventions. This study shows the importance of school support for this type of research. Without specifically targeting these children and without support from teachers and school staff it is difficult for outside researchers to successfully perform interventions. 



\section{Curriculum Vitae}

Eva Simone Michèlle Laure Feron was born on the $21^{\text {st }}$ of February 1986 in Groningen, the Netherlands. She graduated from Stella Maris College in Meerssen in 2004. Afterwards she obtained a bachelor's and a master's degree in International Business, with a specialisation in Finance, and a master's degree in Behavioural Economics from Maastricht University, the Netherlands. During her studies she was an exchange student at the University of Newcastle, Australia. She started her dissertation research at the Economics department of the School of Business and Economics at Maastricht University in 2011. During her dissertation research she attended a summer school on micro econometrics in Barcelona, Spain and she was a visiting scholar at the University of Pennsylvania in the United States. In 2015 she joined the Dutch Education Council as a policy advisor. During her stay at the Council she has worked on a number of different projects, ranging from early childhood education and care to lifelong learning. Currently, she works as a policy analyst for the OECD on the Education2030 project about curriculum re-design. 